



\section{FROM THE RIDICULOUS TO THE SUBLIME}

Examining the relationship between perception and reality in the context of a historical view of the virtual.
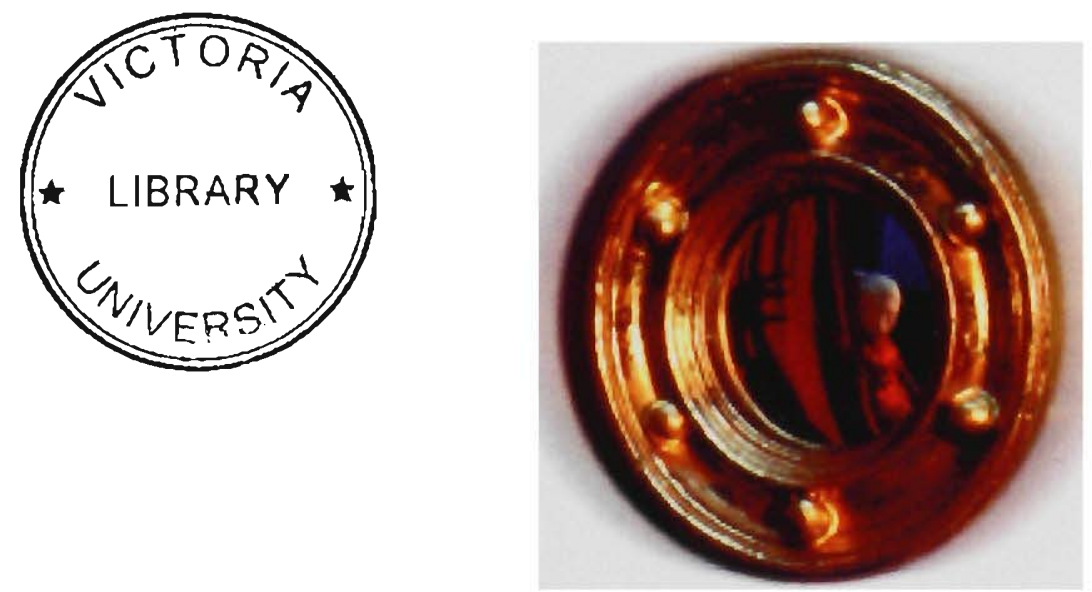

Megan Evans

We knowers are unknown to ourselves, and for a good reason: how can we ever hope to find what we have never looked for?

Neitzsche (Rasche 1982 Frontispiece)

Submitted in fulfilment of the requirements for the Doctorate of Philosophy by Exhibition and Exegesis at Victoria University

May 202003 
FTS THESIS

702.81 EVA

30001007973037

Evans, Megan

From the ridiculous to the sublime : examining the

relationship between 


\section{TABLE OF CONTENTS}

List of illustrations

Declaration of authorship

Acknowledgements

The Audience

p. 1

Prologue

0.1 The Unmapped p. 2

0.2 Writing an Artwork p. 3

0.3 Exhibiting the Text p. 4

0.4 The Sublime Sleep p. 5

$\begin{array}{ll}\text { Introduction } & \text { p. } 7\end{array}$

Chapter One: The Sublime

$\begin{array}{ll}1.1 & \text { Contemporary Sublime } \\ 12\end{array}$

1.2 Being Present p. 12

1.3 Historical Sublime p. 14

1.4 Longinus p. 14

$\begin{array}{lll}1.5 \text { Kant } & \text { p. } 15\end{array}$

1.6 Mathematical Sublime p. 16

$\begin{array}{ll}1.7 \text { Dynamic Sublime } & \text { p. } 18\end{array}$

$\begin{array}{lll}1.8 \text { Burke } & \text { p. } 19\end{array}$

1.9 Lyotard p. 21

1.10 Newman's Zip p. 23

1.11 Flat Depth p. 24

$\begin{array}{ll}1.12 & \text { The Immaterial p. } 24\end{array}$

$\begin{array}{lll}1.13 \text { Representing Sublime P.26 } & \text { P.24 }\end{array}$

$\begin{array}{ll}1.14 & \text { Virtual Sublime } \\ & \text { p. } 29\end{array}$ 
Chapter Two: The Painting of Form
2.1 Sleepskater
p. 32
2.2 Moebius strip
p. 32
2.3 Digital Brush
p. 34
2.4 Dialogue
p. 36
2.5 The Set
p. 38

Chapter Three: The Reality of Illusion

$\begin{array}{llr}3.1 & \text { The Truth of Illusion } & \text { p. } 43 \\ 3.2 & \text { Perspective } & \text { p. } 44 \\ 3.3 & \text { World View } & \text { p. } 47 \\ 3.4 & \text { Moving Illusions } & \text { p. } 51 \\ 3.5 & \text { Boxed perspective } & \text { p. } 53 \\ 3.6 & \text { Painted Eye's View } & \text { p. } 57 \\ 3.7 & \text { Van Eyck's Gaze } & \text { p. } 60 \\ 3.8 & \text { Plato's Cave } & \text { p. } 63 \\ 3.9 & \text { Vital Reality } & \text { p. } 65\end{array}$

Chapter Four: The Space of Paintings
4.1 Painted From
p. 67
4.2 Double Vision
p. 69
4.3 Sleepwalker
p. 70

Chapter Five: Dissecting the Eye

5.1 Past Vision

p. 74

5.2 Stereo

p. 77

5.3 Optical Wonders

p. 79

5.4 Time and Motion

p. 83

5.5 Moving Illusions

p. 87

5.6 Anamorphosis

p. 89

5.7 Animated Anamorphosis

p. 91 
Chapter Six: Stepping out of the Frame
6.1 Animated Illusions
p. 92
6.2 Empty Illusions
p. 94

Chapter Seven: Space as Virtual
7.1 Interspace
p. 96
7.2 Perceptual Space
p. 97
7.3 Virtual Space
p. 100

Chapter Eight: Installation Space
8.1 Activation of Space
p. 103
$8.2 \quad$ Sleep Space
p. 104
8.3 Internal Space
p. 104
8.4 Movement in Time
p. 105
8.5 Spatial Painting
p. 105

Conclusion

p. 108

Epilogue

p. 113

References

p. 114

Appendices

p. 118

Assorted Pages from Sketch books

Selection of pages from SLEEPWALKER (2001) comments book

Selection of pages from THE SUBLIME SLEEP (2003) comments book 


\section{LIST OF ILLUSTRATIONS}

P. 11. Form in my house 2001 by Megan Evans, from VirtuallyPAINTED series,

P. 28 Hold Vessel \# 2003 Detail by Lynette Wallworth, projections, digital imagery, collection Australian Centre for the Moving Image.

P. 32 Form rows Free, 2003 by Megan Evans, from VirtuallyPAINTED series,

P. 32 Form seeks the answer, 2003 by Megan Evans, from VirtuallyPAINTED series,

P. 34 Cenami Cellini and Arnol Fini, 2000 by Megan Evans

P. 36 Digital MANDALLA 2000 by Megan Evans

P. 38 The Altar Piece of St Cecilia 1304 by Master of the Altar Piece of St Cecilia, Before, Uffizi, Florence.

P. 39 The Birth of the Virgin 1342 by Pietro Lorenzetti, , Museo dell'Opera del Duomo, Siena.

P. 40 The Voyage, from Bill Viola: Going Forth by Day by Bill Viola, 2002

P. 41 Detail of Giovanni Arnolfini and Jeanne Cenami 1434, by Jan Van Eyck, London National Gallery.

P. 41 Form Skates out of the frame, 2003by Megan Evans, from VirtuallyPAINTED series,

P. 45 Diagmatic reconstruction of Brunelleschi's perspective demonstration of the Palazzo de' Signori, Florence.

P. 46 Brunelleschi's peep-hole and mirror system for viewing his perspective demonstration of the Florentine Baptisery.

P. 49 Perspective Box 1756 Samuel Van Hoogstraten, , ,London National Gallery.

P. 50 Perspective Box 1756 Samuel Van Hoogstraten, , ,London National Gallery, detail.

P. 50 Perspective Box 1756, Samuel Van Hoogstraten, ,London National Gallery, detail.

P. 53 Inexternal, outside view, 1992 by Megan Evans oil on wood,

P. 54 Inexternal, inside view, 1992 by Megan Evans oil on wood, 
P. 54 Context, Internal installation, 1992. by Megan Evans, oil on wood and found objects,

P. 55 Detail from the Ghent Altar Piece, God the Father, 1432 by Jan Van Eyck.

P. 58 Detail, The Paele Madonna, 1436 by Jan Van Eyck, , Brugges.

P. 59 Luca Madonna, (no date) by Jan Van Eyck, Frankfurt.

P. 61 Giovanni Arnolfini and Jeanne Cenami 1434 by Jan Van Eyck, , London National Gallery.

P. 66 Invitation 1992 by Megan Evans, oil on canvas, $8 \mathrm{ft} \times 5 \mathrm{ft}$,

P. 68 Form plays to the illusion, by Megan Evans, from VirtuallyPAINTED, 2003

P. 69 Arcus 1989 by James Turrell,

P. 71 Sleepwalker installation, 2001 Centre for Contemporary Photography,

P. 72 Sleepwalker 2001 detail

P. 73 Still from Video of SleepWALKER, by Megan Evans 2003

P. 75 The Camera Obscura, from Athanasius Kircher's Ars magna Lucis et umbrae, 1649.Rome

P. 76 Book Camera Obscura, Theatre de l'univers, 1750.France,

P. 77 Camera Lucida with eye piece, lenses and equipment box, London Science Museum.

P. 77 Upper portion of camera Lucida from Cornelius Varley's A Treatise on Optical Drawing Instruments, 1845.London

P. 78 Wheatstones reflecting stereoscope viewer, 1850 London Science Museum,

P. 79 The original Kaiserpanorama, 1880s Berlin,.

P. 80 The original Kaiserpanorama, 1880s Berlin,.

P. 81 Stereoscope display at the London Science Museum.

P. 82 Emile Reynaud, Praxinoscope Theatre, 1879.

P. 82 Emile Reynaud, Praxinoscope, 1879.

P. 84 Triple Magic Lantern

P. 85 Magic Lantern Slides, London Science Museum.

P. 86 La lanterne magique,by Jean Ouvrier,(French, 1725 - 84) after Johann Eleazar Schenau (German, 1737 - 1806) etching and engraving Los Angeles, Getty Research Institute, Werner Nekes Collection. 
P. 88 Le Décapité récalcitrant.Le squelette s'enfriut avec la tête du décapité. Jules David dit Marius à gauche, Harmington à droite

P. 89 The Ambassadors, by Hans Holbein, 1533, National Gallery London

P. 90 Anamorphic Portrait of Charles 1, with Viewing Mirror, France about 1.780.

P. 92 Still of anamorphic video, Virtually vanishing, 2002by Megan Evans

P. 94 The pepper's ghost illusion,http://www.acmi.net.au/AIC/PEPPER_BIO.html

P. 101 Real-time frame captures of Ectasis by Metraform

P. 112 Form asks the question, by Megan Evans from VirtuallyPAINTED series 2001 


\section{Declaration of authorship}

This thesis contains no material which has been submitted for examination in any other course or accepted for the award of any other Degree or Diploma in any University. To the best of my knowledge and belief, it contains no material previously published or written by another person, except where due reference is made in the text.

Megan Evans 


\section{ACKNLOWLEDGEMENTS}

The Sublime Sleep is a project that has unfolded over a five year period.

There are many people I want to thank for their support, encouragement and inspiration throughout that period.

Professor Maureen Ryan for her undauntable support and endless hours of work as my supervisor.

Loy Lichtman who encouraged me to take on a project that I would perhaps never have considered and for his co supervision in the early stages.

Jill McCallmun who was forever encouraging me when I was lost in the wilderness and who contributed by making the dress for the life size model of Form.

Enza Gandolfo who read my exegsis and encouraged me to keep going.

Helen Lucas who spent long hours doing the final edit of the exegesis.

Zanna who was the life size model of Form.

Sal Cooper who was the voice of Emptiness and Form

Barbara Brook who also gave me advice on the exegesis.

Claire Brunner who encouraged me in moments of despair.

Mark Pitman who helped with technical problems in Sleepwalker.

The following people helped with the installation of Sleepwalker in 2001 and The

Sublime Sleep 2003: Lisa Young Jan Parker, Lee and Merindah Griggs, Kathy Griggs, Jessie Mitchell, Jill McCallmun, Shanra Austin and Harry Williamson.

Braham Cidor for his advice on lighting.

Last but not least I want to thank Harry Williamson who has worked tirelessly with me to develop the lighting, animatronics and audio visual equipment. He built the set and stereoscope boxes and most importantly composed and played the music and sound effects for the sound tracks. 


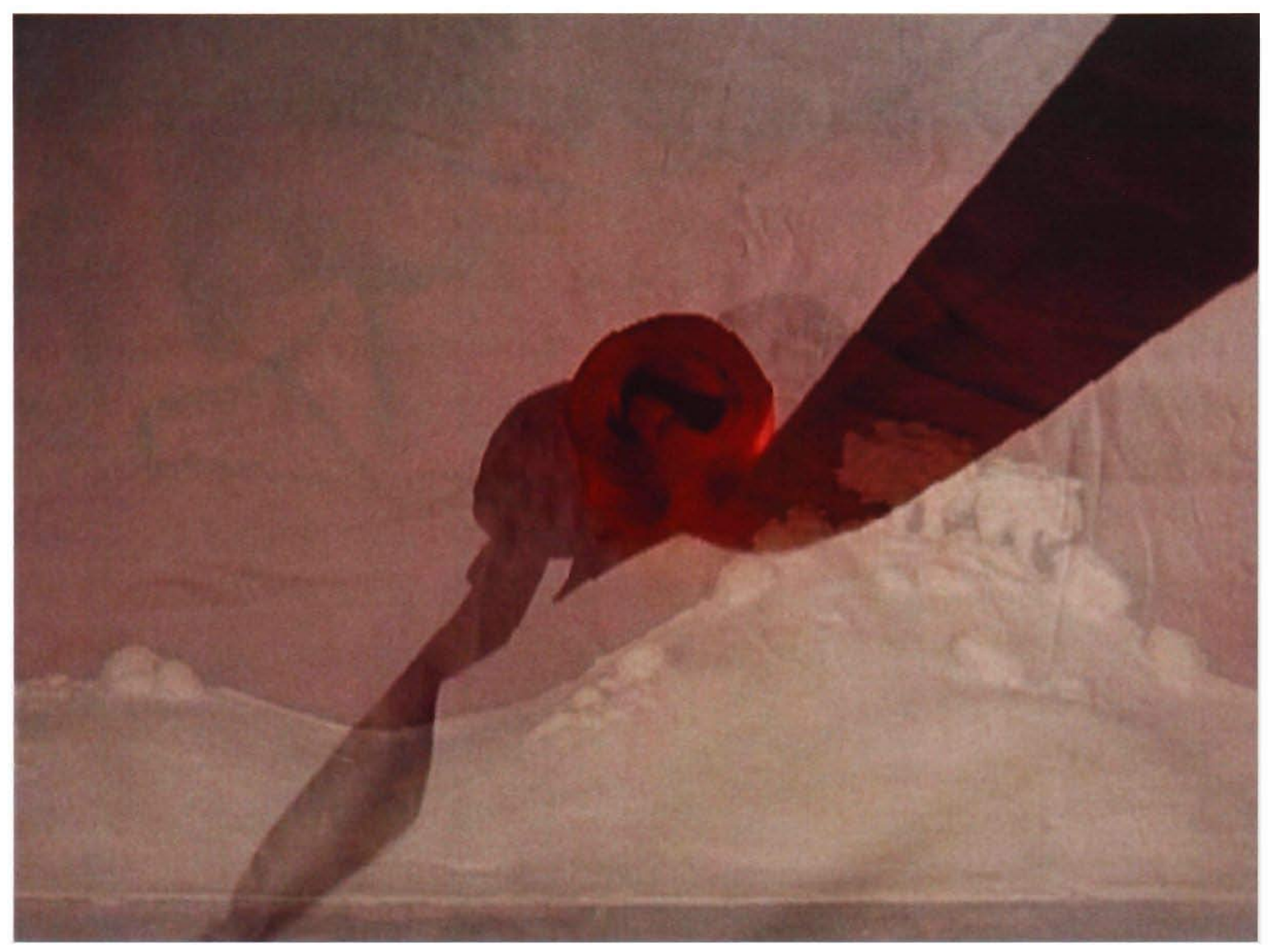

I dedicate The Sublime Sleep to Flick Evans and Nan Evans, my mother and father who have always supported my career as an artist and established at an early stage an enquiring mind, which is the basis of this work.

Megan Evans 2003 


\section{THE AUDIENCE}

'The relation of language to painting is an infinite relation. It is not that words are imperfect or that, when confronted by the visible, they prove insuperably inadequate. Neither can be reduced to the other's terms: it is in vain that we say what we see; what we see never resides in what we say. And it is in vain that we attempt to show, by the use of images, metaphors, or similes, what we are saying; the space where they achieve their splendour is not that deployed by our eyes but that defined by the sequential elements of syntax. And the proper name, in this context, is merely an artifice: it gives us a finger to point with, in other words, to pass surreptitiously from the space where one looks; in other words, to fold one over the other as if they were equivalents' (Foucault 1970, p.9).

\section{VIEWING - READING PROCESS}

My preference is for the artwork to be viewed before the reading of the text.

I want the project to be viewed as a complete work and the danger with reading the exegesis first is that it may evoke a preconceived idea of what the artwork will entail. Part of the text is included as a sound-scape in the exhibition and the text itself will be available as an artist's book. Ideally the text should be read as a part of the total work, however copies of the exegesis will be available to be read separately. 


\section{PROLOGUE}

\section{The Unmapped}

An art project that extends over a three year period has a specific nature. Many ideas have come and gone over my lifetime as an artist, some realised and some shelved, however in order to create a project that would last over the period of a doctorate, I found myself paring down my ideas to some very essential questions that were at the heart of all of my work. These ideas are about perception, illusion and reality. In the process of exploring them my research expanded to encompass the realms of space, the sublime and virtual reality. I have engaged with a wide range of theoretical disciplines in the research for this project and I am aware that I have not begun to represent them all in their entirety. I have dipped into them to take what I need. In this project I do not intend to present a case or argue a position. Instead I am exploring, discovering and making connections between diverse elements, allowing for the unfolding and creation of something.

The final outcome of my work as an artist comes from a unique web of intersecting thoughts and experiences. Mapping this web is the role of the exegesis. My ideas have formed, often quite independently from each other and were placed on the page like an isolated mark in a dot to dot drawing. The numbers that linked them were placed afterwards and the exegesis drew the lines from number to number, bringing an image to life from an apparently chaotic grouping of points. The process of art making is not linear for me. Consequently the rational connections I make seem obvious in retrospect, however the intersecting pathways have almost always been stumbled across by accident or intuition. Suddenly the reasoning for a particular image, a colour or use of an object makes sense, and the logic of the next point becomes clear .

Anton Ehrenzweig in his book The Hidden Order of Art makes the point that the undifferentiated unconscious is coordinated with the differentiated conscious in a work of art. He calls 'unconscious scanning' (Ehrenzweig 2000,p.5) the process by which I have compiled my research; a seemingly chaotic and non-linear search for clues to an unknown answer. While it is traditional to think that the unconscious or primary process 
in the research is undifferentiated and chaotic and must be structured by a conscious secondary and more logical process Ehrenzweig argues that the intuition is precise.

'On the contrary, the primary process is a precision instrument for creative scanning that is far superior to discursive reason and logic' (Ehrenzweig 2000, p.5).

Intuition has played a large part in the development of this project. The exegesis attempts to reveal the intuitive journey through my thinking processes and the relationship between the artwork and the ideas.

\section{Writing an Artwork}

The structure of the exegesis separates the ideas from the artwork, with each chapter of theory being followed by a chapter on an aspect of the exhibition. This mimics the distinction made in the process of the work between days spent working in the studio and hours spent with my head in a book. Alternating the chapters allows the reader to follow the development of the relationship between the artwork and the ideas.

The artwork developed almost independently of the theory, however synchronistic leaps made in the studio often led the enquiry on an intellectual level. I call this process writing an artwork, which I consider to be quite different to writing on or about an artwork. Writing an artwork is a method drawn from my research process. The role of the text is not to describe the artwork nor is the artwork an illustration of the text. Instead I see the text as a thread of ideas that is woven throughout the work, indistinguishable now from the art. The exegesis is the final articulation of the research for the work and because of the symbiotic relationship between them, the experience is of having two languages with which to explore ideas; one textual and one visual.

Both expressions interweave aspects of art and art history, philosophy and technological ideas from the past until the present. The ideas are principally philosophic in nature and yet this project is not based in the discipline of philosophy. Many artists before me have engaged in philosophical ideas through their work, René Magritte being a notable one. Magritte is said to have rejected the name 'artist', describing himself as 'a man who thought, and who communicated his thought by means of painting' (Gablik 
1985). My work is a similar engagement with ideas. Questioning the nature of reality is a task generally relegated to philosophy, however the philosopher is constrained by the rational. What they say has to be argued logically. Art on the other hand has no such restrictions and can explore and lay claim to extraordinary leaps in the irrational and inarguable, allowing me to stretch the boundaries of reason further than would be accepted by philosophy. The exegesis must be distinguished therefore from a traditional theoretical philosophic debate; instead it illuminates the creation of an artwork that aims to explore some philosophical understanding.

\section{Exhibiting the Text}

The text also includes a dialogue that is interspersed through the theory as a creative lull in the storm of rhetoric. The device of dialogue refers to the philosophic tradition of Socratic dialogue. The two characters whose voices we read are the main characters in the artwork. While each voice has an individual identity they are manifestations of two parts of the one character: material and immaterial. The material identity is called Form and the immaterial identity is called Emptiness. Form and Emptiness discuss the nature of themselves and each other in the context of a debate about reality. The written style of these discussions is distinct from the more theoretical text, which makes up the body of the exegesis. The theoretical text examines the ideas in a more traditional academic manner. The dialogue is a textual artwork that uses prose to allude to or highlight the concepts discussed in the theoretical text. It is the artwork of the text and will be heard as a soundscape in the exhibition, intending to provide a glimpse or glance in the audience's peripheral vision, of ideas that when looked at squarely, may vanish. This part of the text enfolds the written exegesis in the exhibited work. The dialogue acknowledges Foucault's point on the inadequacy of words to describe what we see and the inability of images to illustrate what we say. It acts as a poetic response to the intellectual concepts while at the same time directly connecting the written word to the visual experience. In the exegesis the dialogue is separated from the main text physically by being printed on a transparent overlay. 


\section{The Sublime Sleep}

The Sublime Sleep is the title of the exhibition and refers to a state of wakefulness in which one is fully present. It plays with the idea that while we presume we are awake, we are in fact asleep and our experience of reality is a dream. The sublime sleep names a mythical state of consciousness that is akin to our experience of dreaming when reality is not fixed. In this state our experience of reality is fluid and we are dynamically connected to our environment.

The exhibition is an installation that involves three spaces. The main space is entered through a curtain and is darkened. It has three works in a long, narrow room. The first work is an architectural structure reminiscent of a renaissance church that has a video work installed inside it. The viewer can see through the walls and doors of the symmetrical church to look at an animated cylinder anamorphosis that sits in the centre of the church. This work is called VirtuallyVANISHED and shows the character Form lost in a void. The second work sits on the long walls on either side of the room. It consists of two boxes approximately six metres long and fifteen centimetres high that each house eight pairs of stereoscopic lenses. The lenses emit a light and encourage the viewer to look into their virtual spaces and see the three-dimensional environment inside. This series of work is called VirtuallyPAINTED. The third work is a video projection. The video work is called SLEEPWALKER and involves video footage taken in an installation of the same name that was produced in July 2001 as work in progress and exhibited at the Centre for Contemporary Photography. This footage combines live video and animation of Form done since the 2001 exhibition.

Outside this room is a space that contains a large painting hanging on the wall called MANDALA. A third room opens off this space, which is blacked out and contains a three-dimensional set with the character Form sitting inside. This work employs the technique known as 'pepper's ghost' to create the illusion of an animated character, in this case, Emptiness who moves about the set, dialoguing with Form. Objects move independently and randomly inside the set, encouraging the viewer to stay and watch. This work is called VirtuallyREAL.

The soundtracks in each room involve the voice of Emptiness and Form. Form's voice sounds as though it is in the real space of a room and Emptiness sounds hollow 
and disembodied. The music and sound effects are designed to enhance the surreal nature of the work.

The artwork uses three elements: the illusion of movement in a three dimensional space, using techniques from the early $19^{\text {th }}$ century; stereoscopic images which create the illusion of a non-linear narrative in three-dimensional stills, frozen in time; and the transformation of reality using anamorphosis. The characters in the artwork demonstrate the media explored in the thesis to develop the relationship between painting, the moving image and virtual space.

From the Ridiculous to the Sublime is the name of the entire project, which encompasses the journey from day one until the last word is written and the exhibition installed. The Sublime Sleep is the major part of this project and the exegesis is the articulation of the ideas that were developed throughout the process of investigation. 


\section{INTRODUCTION}

From the Ridiculous to the Sublime is a project that examines the relationship between perception and reality. The ridiculous alludes to the proposal made by the work that our perception of reality is an illusion. The sublime is a recognition of this expressed as a state of being in which our experience of reality, is as though we are interconnected with all things. In this state reality occurs as spaceless and our individual self is dynamically related to everything that surrounds it. (my definition)

These corresponding ideas are explored in the context of representational painting and its relationship to virtual reality. Two things are reinterpreted in this process: the intention of representational painting and the nature of the sublime. Within these new interpretations a connection is made between painting of the $15^{\text {th }}$ century and virtual reality of the $21^{\text {st }}$ century. The history of representation in painting is viewed from a contemporary perspective as a precedent to virtuality and from this perspective I propose a way of viewing virtual reality as a tool to question our relationship to reality. This body of work explores the degree to which the viewer makes the view. We tend to stand back from a work of art, presuming that we are a witness to something that is independent of us. The tradition of painting has encouraged this perspective by its material existence, clearly separating it from the viewer. This work proposes that viewing is a creative act; that the viewer makes their experience in the act of perception. This position is explored conceptually through a dialogue, as well as through the artwork that unseats the viewer's usual perception via illusion. By using simple and old fashioned techniques such as stereoscope, anamorphosis and Peppers Ghost the viewer is confronted with a trickery that is often unseen in a contemporary setting where the illusion is hidden behind much more sophisticated frameworks. In developing the work, what became apparent was the connection between illusions created by the technologies of the past and technologies of the present. It also revealed a previously hidden relationship between my interest in illusion in representational painting, and the phenomena of virtual reality. This led to an examination of the tradition of painting viewed from the perspective of illusion and a connection to other techniques that are seen as precursors to the contemporary 
phenomena of the virtual. This placed painting in a context that relates more readily to the digital age and immersive environments.

It is my proposition that understanding the materiality of painting in the age of the virtual is crucial to the ability of the tradition of the object to survive in the future as an art form as new and unprecedented ways of viewing and experiencing art become available. In developing this work I was always questioning what did my 20 years' practice as a painter have to do with my new ability to create work in the non-physical world of the virtual. Why was I drawn to the computer and why did I bring with me an aesthetic from my painting days? In the early days of the project I could see no relationship between the two, however as I continued I began to discover what fascinated me was the phenomenon of illusion. Illusion in the painted surface was what drew me to $15^{\text {th }}$ century painters like Van Eyck. The illusion of the image created by numerical calculation was what first fascinated me about digital imagery. My early painting was a physical reproduction of a virtual image, 'MANDALA'. I discovered an obtuse connection between my paintbrush, palette and studio and the mouse, screen and digital image

This discovery was key to my thinking that there was an alternative view of the virtual (meaning that illusion was not an attempt to duplicate reality but instead an attempt to display the falseness of that reality. If you could trick the eye so easily then how do you know that the eye is not being tricked every moment in its perception.) that would shed some light on the relationship between perception and reality in the contemporary virtualised world. The idea of the sublime came as a way to describe that relationship: a state of being present to the moment such that you experience being connected the world.

In Chapter One the sublime is explored philosophically, examining the historical interpretations of Longinus, Kant, Burke and more recently Lyotard. This chapter establishes the philosophical nature of the work and creates a context for the rest of the project. I discuss the work of Barnett Newman and Mark Rothko in reference to the sublime and draw from these influences to create my definition of the sublime, which encapsulates a state of being. 
In Chapter Two, I discuss the development of the characters, which are central to the exhibition, and the dialogue, which is where the philosophical issues are played out poetically in the exegesis. I discuss my struggle encountering the digital world and the issues that instigated the philosophical inquiry, the physical and sensory experience of art making pre-digital and the apparent void between an analogue practice and a digital one.

The tradition of realism in painting was established with the invention of perspective. In Chapter Three I look at the ways we have learnt to relate to representational painting as an illusion of reality and question the presumed disjuncture between a $15^{\text {th }}$ century painting and a VR helmet. The development of perspective and optical illusion in art is understood as a precursor to contemporary issues of virtuality. The difference between the illusion of reality and the reality of illusions is made, and by highlighting a particular era of painting, I examine the project of representation from a particular view. I argue that with the development of the history of illusion artists were questioning the nature of reality rather than attempting to represent it. If we consider representational painting as an engagement with the illusion of reality, the context of art becomes philosophical.

Chapter Four introduces the character Form as a vehicle for this inquiry. The relationship between painting and space is examined through the stereoscopic images used in The Sublime Sleep called VirtuallyPAINTED. These works simulate a painting that is viewed in three dimensions. The audience's experience of this is likened to stepping into space that is virtual. This technique was used in the exhibition Sleepwalker (a work in progress done half way through the doctorate), and this exhibition is used to discuss the experience of virtual space and how that interacts with the space of installation. The work in progress is discussed to show the development of these ideas through the artwork.

The eye is crucial to the disembodied experience of virtual space and Chapter Five reviews the privileging of vision since the Enlightenment as a tool for empirical knowledge. The peephole is a device that disconnects the viewer from their surroundings. The history of the stereoscope is explored along with other pre-modern tools that paved the way for the moving image as animation and then film, all of which have utilised the representation of illusion. 
Chapter Six examines the illusion of the three-dimensional in the artwork VirtuallyVANISHED and VirtuallyREAL. Both these pieces require the viewer to witness the illusion from a distance as distinct from the immersive experience of the stereoscope. These works create a link between the era of two-dimensional painting and the world of virtual reality through the $17^{\text {th }}$ and $18^{\text {th }}$ century techniques used to explore illusion.

Although these techniques are outdated by the sophisticated technology now available, the same issues arise. If our experience of reality is subjective, then what consequences arise from that? In Chapter Seven a new context for space is proposed as a pathway to an experience of the sublime. In Chapter One the sublime was defined as a state of being in which one experiences being entirely connected to all aspects of the universe, as indistinguishable as one drop in an ocean. Chapter Seven explores the role of virtual reality in providing an experience of a reality where the individual is dynamically connected to their perceived world. In virtual space you cannot act independently of your reality, and Chapter Seven proposes this as a metaphor for the real world. Virtual reality accesses this experience of being part of a connected whole. This is the sublime as defined in my project.

In Chapter Eight the space of the virtual is discussed in relation to the gallery space of the installation. The devices used to create a sense of interaction with the viewer are discussed, while explaining the use of old techniques rather than contemporary technology. The artwork is described as a tool to confound the viewer's perception and although it does not propose to create an experience of the sublime, it does endeavour to provide a conceptual understanding of the potential of the virtual to reawaken a debate on the sublime.

In conclusion, with the development of technology, our experience of reality has been called into question by cyberspace, digital image manipulation and virtual reality. The more technology interacts with imagery the more our conception of what is visually real becomes uncertain. Painters from the $15^{\text {th }}$ century were the originators of a tradition that trained us to see painting as representation, a depiction of some reality that is fixed. The technology of digital imaging calls for a reinterpretation of this reading of the history of representational painting. The history of illusion provides a precedent to the 
contemporary phenomenon of virtual reality and puts the issues we face in integrating this powerful new medium into our art, in a historical context.

My contemporary interest in the nature of reality in art is situated in relation to hundreds of years of a similar inquiry, which makes sense of the historical leaps in the influences on my work. It also creates a context for the somewhat radical claims of virtual reality as a way to transform our relationship to reality from one in which we are shaped and influenced by it, to one in which we are the generators of it. If there is an acceptance that there has been an exploration of the illusion of reality for hundreds of years, we could claim to have developed our understanding of it to a degree that this leap is possible. Being the generator of personal reality is relating to the world as though it is virtual. The experience of being an individual drop in a collective ocean of drops is one where your movements, expansions and contractions interact with the ocean. This is relating to space as virtual and is what I call the sublime. In the Sublime Sleep the dream is the reality and that reality is the sublime space. The space of the virtual.

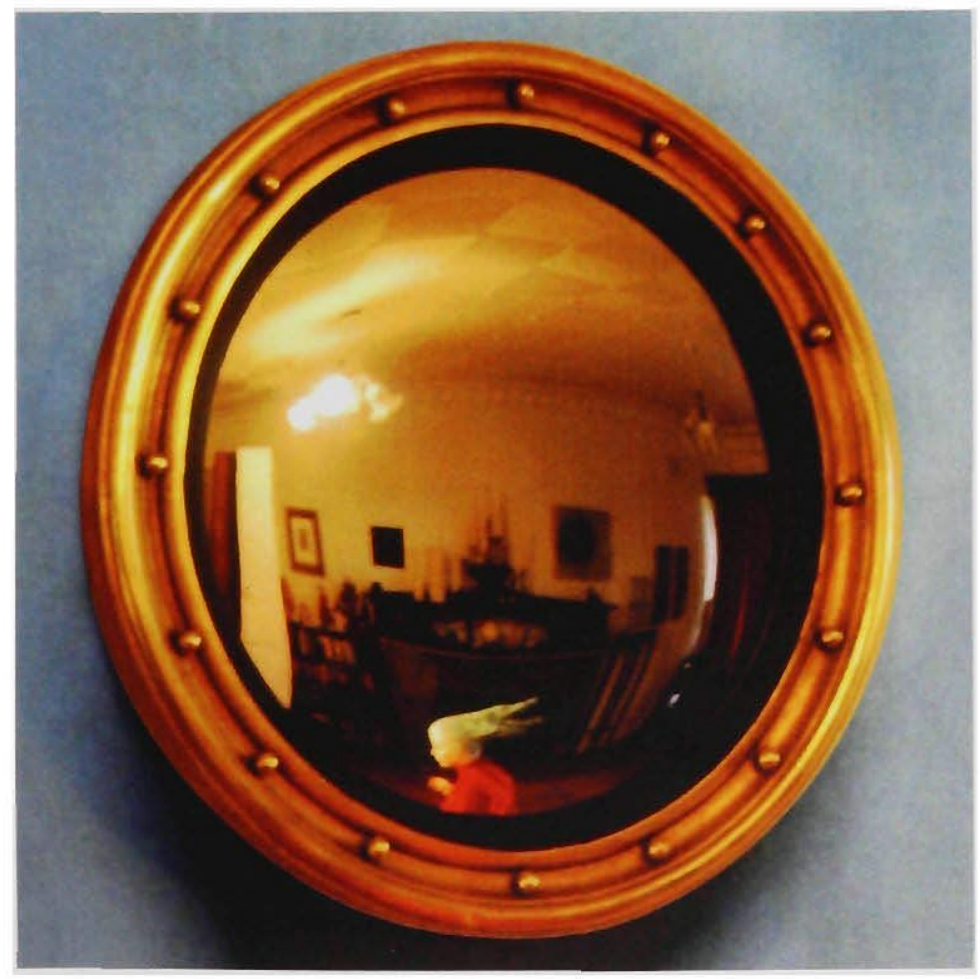

Form in my house from VirtuallyPAINTED series by Megan Evans 2001 


\section{CHAPTER ONE: THE SUBLIME}

\section{Contemporary Sublime}

The concept of the sublime remains overshadowed by modernist interpretations. The subject has been explored over a long period of time, beginning with Longinus in the first century $\mathrm{AD}$ and then more definitively by Immanuel Kant in the late $18^{\text {th }}$ century in his Critique of the Power of Judgment. Many other philosophers have responded to the debate and expanded on the ideas of Kant, yet in researching this area Kant's definition remains the most influential. Cornelia Klinger (1997) provides a feminist interpretation of Kant, arguing that Kant's modernist definition of the sublime subjugates women because he interprets the sublime as anything that allows man to transcend nature. Woman as aligned with nature becomes the other in a dualist paradigm that provides a limited modernist view. Inside this paradigm women become the barrier to the sublime. As a woman artist at the beginning of the $21^{\text {st }}$ century $\mathrm{I}$ am interested in a reinterpretation of the sublime. This project aims to create a definition that is relevant to my experience as an artist in the digital age and to place the sublime in a context that takes it out of the modernist project and makes it relevant to a postmodernist reading. My interpretation of the sublime comes from experiences I have had of being present in the moment such that I felt no separation or space between myself, and my environment. In those moments I was aware of the dynamic relationship between myself and all other elements in the universe. My self expanded and the experience of boundaries or edges to my being disappeared. The description I gave to these moments after they had occurred was 'sublime'. This led me to investigate my definition of these experiences. I began by looking at the history of the philosophy of the sublime.

\section{Being Present}

It is generally agreed that the sublime is a heightened state in which the individual is transcended. My definition is created for the purpose of looking at the experience of bodily transcendence that occurs with virtual reality, and describes the state of being where the world as separate and distinct from the individual disappears. I propose that 
when individuals transcend their self-conscious state, they experience a connection to everything, and when there is no space between them and everything else they are aware of the intimate relationship between things. This relationship to the world is one where individuals experience creating their environment and circumstances rather than being contingent of circumstances and environments. They are not isolated and separate, an object in the world of objects.

This proposition comes from my personal experience of such a state. A trip to India led me to investigate the art of meditation. My attempts were never particularly fruitful until found a teacher who could translate the practice into a discipline I could understand. He taught me to be present to everything; my breath, my body, the sounds, the smells, the touch of my clothes, the air on my skin. When practising this one day in my studio I had an experience of my awareness expanding. Although I knew at all times that my physical body remained sitting on the studio floor, the sensation was of my awareness expanding outward, slowly at first, like a cloud. I felt that I became the surrounding environment as I expanded. There was a limit to this awareness but it grew until I was experiencing being a portion of the factory that housed my studio, and the air between my building and the building next door, even the portion of the railway line that went through my cloud of awareness. At a certain point a train went by and I was the train as it moved through my cloud. Shortly after that I felt concerned that I would lose my sense of my self and so I opened my eyes. In a micro second I felt myself shrink back into my body and I had the most extraordinary experience of seeing my reality as though through peepholes. My sense was that the reality I knew and took for granted, existed as only one reality and my eyes were my access to it. They were what took me into a reality that I live in as though it is the reality. While I have been able to repeat this experience twice more but the more I tried to recreate it the less able I was to achieve it. However, I have been left with a definition of what I now call an experience of sublime space.

For the purpose of this project I define the sublime as 'being present in the moment such that the experience of the world as a multitude of objects in space disappear'. Defining the sublime in this way allows me to place it in the context of the virtual. The virtual is a reality constructed by the viewing participant. Without the act of perception there is no reality. In examining the illusion of reality inherent in the virtual, 
the sublime points to the idea of being the creators of our reality rather than the illustrators of a reality that exists independently of us.

\section{Historical Sublime}

What follows is an examination of the sublime from the point of view of Longinus, Kant and Burke and how their distinctive definitions inform my own. Longinus locates the sublime in the object and says this object causes transcendence; Kant argues for the immaterial nature of the sublime, regarding it as existing as a function of reason, distinguishing two categories; the mathematical and the dynamic sublime in order to argue this; and Burke who critiques the conceptualisation of the sublime altogether. I then look at Lyotard's more contemporary interpretation of Kant's definition and how it relates to the depiction of space by particular $20^{\text {th }}$ century abstract painters. I argue against Lyotard's position that the sublime can only be represented by the nonrepresentational, and state that the space of the sublime is re-emerging in the new era of virtuality, unrestricted by the constraints of the non-representational.

\section{Longinus}

Longinus wrote the earliest recognised treatise on the sublime. His work attempts to define the sublime in order to answer the question, of whether sublimity can be taught through the arts. In the time of Longinus it was generally held that the sublime was born in a man not learnt by instruction. Longinus believed otherwise and set out to define it. According to Longinus, the sublime is to be found in the arts and when it is present the experience of the sublime is transferred to the viewer, lifting one up to noble thoughts and aspirations, to 'fine madness and divine inspiration' (Longinus 1953, reprinted) p.281).

Longinus saw the sublime as an indication that man can transcend the human condition and in order to understand this ephemeral state, he distinguished between the human, which he saw as the physical or material design of the human being, and the soul or spirit which could only to be alluded to and defied empirical knowledge. He said that the soul is the site at which an experience of the sublime may occur. Longinus used 
analogies of motion to describe the sublime; motion that involved some sort of shift from one's usual site within the material body to an uplifted state, transcended, transported as in flight. He defined the sublime as an intrinsic aspect of the object, rather than the object being the source of the sublime, which occurs in the viewer as an experience.

I agree with Longinus's position that the material self is transcended; however I disagree that the sublime exists externally to that experience. My definition aligns more closely to Kant who in the Critique of the Power of Judgement argues the dangers of locating the sublime in the object. He avoided such unquantifiable measures and looked at the sublime from the position of the rational. He related to the sublime as absolute and as such saw it as having no limitations and therefore no form.

\title{
Kant
}

Kant describes nature as a site for the sublime. However he was not seeking the sublime in the awesome landscape. He asserts that sublime virtues are not natural virtues, instead they arise from reason, often prompted by nature as we are pressed up against our own insignificance in the face of the force of the natural elements.

\begin{abstract}
'Sublimity....does not reside in any of the things of nature, but only in our own mind, in so far as we become conscious of our superiority over nature within, and thus also over nature without us (as exerting influence upon us). Everything that provokes this feeling in us, including the might of nature which challenges our strength, is then, though improperly, called sublime, and it is only under presupposition of this idea within us, and in relation to it, that we are capable of attaining to the idea of the sublimity of that Being which inspires deep respect in us, not by the mere display of its might in nature, but more by the faculty which is planted in us of estimating that might without fear, and of regarding our estate as exalted above it' (Kant 1928, p.114).
\end{abstract}

He believed that the sublime could not be contained in any form because of its limitless nature and therefore could only be encountered through reason. He believed that the sublime was a product of the mind, of 'that which is absolutely great' (Kant 2000, p.131). 


\section{Mathematical Sublime}

Kant creates a distinction between two aspects of the sublime; the mathematical sublime and the dynamical sublime. He claims that the characteristic of the sublime is, a 'movement of the mind connected with the judging of the object' (Kant 2000, p.131). While the beautiful releases feelings of calmness on the mind, the sublime according to Kant does not. This movement is connected to either the ability to perceive or the tendency to want or hope. He sees the perceptive ability as a mathematical disposition and desire as a dynamic disposition, and claims that the sublime is evident in both these ways.

In his investigation of the mathematical sublime he notes that an object, or something identifiable is not the site of the sublime because it may be formless, however its magnitude even in a formless state is what we can measure. To determine rationally that something is great it needs to be able to be measured. However if we ask the question of 'how great?' we always require a comparison. It is therefore always comparative and incapable of affording an absolute. If there is no comparison and it is absolutely great then nothing is sought outside itself and the magnitude is equal only to itself. Kant deduces therefore that the sublime cannot be sought in nature or objects, but only in ideas of the mind; nothing that is an object of the senses can be considered to be sublime. In fact he saw as one of its purposes the enlargement of the imagination.

'That is sublime which even to be able to think of demonstrates a faculty of the mind that surpasses every measure of the senses' (Kant 2000, p.134)

In the attempt to grasp the magnitude of the absolute, Kant distinguished between the estimation of magnitude by means of numerical concepts and the estimation of magnitude by intuitive means, which is what he calls aesthetic. In this, he saw that all logical estimation of magnitude was mathematical. However, whatever is used as the measure must also be measured. To mathematically measure an expansive landscape, metres can be used, however one must understand the measure of a metre. One can only ever understand the measure of the measure intuitively, as otherwise another measure must be used to establish the measure. In this case the magnitude of the measure must be 
intuitively understood, an apriori understanding of the measure, for the measurement of magnitude is then used to conceive of numerical concepts, which means we can never have a categorical concept of a given magnitude. This led Kant to the conclude that:

'...in the end all estimation of the magnitude of objects of nature is aesthetic'(Kant 2000, p.135).

So the mathematical categorisation of magnitude provides no 'greatest' because numbers go on to infinity, however in the aesthetic estimation of magnitude there is a 'greatest' because subjectively something can be the greatest. I can conceive of the greatest tree, because it is the greatest tree I have seen in my particular experience. Kant believes that the subjective estimation of the sublime brings with it an idea of the sublime, which cannot be reached through mathematical concepts. Intuition can grasp magnitude absolutely as far as the imagination can reach.

In order to grasp the intuitive measure of magnitude and use it as a numerical measure, two faculties must be employed - apprehension and comprehension. Comprehension is to take hold of something in your understanding of it, whereas apprehension is to perceive with the senses, having a sense of it. Apprehension can be infinite but comprehension meets its limits. Kant uses an experience of viewing the pyramids to explain this. When you stand far back you can comprehend the entirety of the pyramids but as you advance toward them and begin to see them stone by stone, at a certain point you can no longer comprehend their totality. In Kant's mathematical sublime the experience of arriving at the unimaginableness of the magnitude is thinking beyond every limit, and the doing of this is sublime.

'Now the proper unalterable basic measure of nature is its absolute whole, which, in the case of nature as appearance, is infinity comprehended. But since this basic measure is a self-contradictory concept (on account of the impossibility of the absolute totality of an endless progression), that magnitude of a natural object on which the imagination fruitlessly expends its entire capacity for comprehension must lead the concept of nature to a supersensible substratum (which grounds both 
it and at the same time our faculty for thinking), which is great beyond any standard of sense and hence allows not so much the object as rather the disposition of mind in estimating it to be judged sublime' (Kant 2000, p.139).

Comprehension is useful in determining the measure, but apprehension is the faculty for the intuitive measure of magnitude. Apprehension, according to Kant, takes you beyond your reason and in this state I would argue that you are present. Kant claims that this state is a function of reason whereas I would say that it is a function of being. In the moment of being stretched beyond your capacity to understand you are not conscious of the self as an individual and once the rational is transcended all there is, is being. My definition of the sublime is located here, perhaps arrived at through the same route but explained in a different way. However I argue that the sublime is experienced in the moment and it is only after the fact that the experience can be explained. In the moment there is no 'mind' or 'moving' because you are not present to language or description.

\section{Dynamic Sublime}

Kant's dynamic sublime, on the other hand, is an experience of one's power over nature. Not the power of force, but the power involved in the strength of being unattached or unmoved by the force or terror of nature. Kant cites objects in nature such as threatening cliffs, hurricanes or volcanoes, as forces that allow us to discover in ourselves, a 'strength of soul above its usual level' (Kant 2000, p.144). In these moments we transcend our fears for our own survival and become better than we are. These moments, according to Kant, are sublime. When you are able to transcend your survival in the face of a threat to it, you know yourself as not constrained by your material body; you are brought to a point where you are present in the moment rather than beset with imagining what might happen. What comes to mind are the stories of mothers defying the forces of nature in order to save their children or finding the strength to lift up a car that has fallen on a loved one. However these stories are not usually related to the sublime but rather to the force of natural instinct.

This same experience can occur without threat by being overwhelmed by the enormousness of nature and one's own insignificance in relation to it. We define 
ourselves by what identifies us as individuals. Klinger claims that Kant's theory was designed to help define man's identity as a rational being. By Kant's definition the sublime is an experience denied to women because as Klinger puts it, 'Every person socialized in our culture infallibly classifics reason and rationality as male and emotions and sentimentality as female; (Klinger 1997, p. 192). If the access to the sublime is through reason then it is a male prerogatuve

I locate my definition of the suhtinas in the contest of Kant's dynamic sublime. (Being present in the moment such that thet eyporumue of the world as a multitude of objects in space disappear.). In his explanatuan ad un dyamus sublime, however, this definition has as its purpose to deconstruct the facknay af the individual. I argue that in the moment of experiencing the sublime as Kant descrntes it the world does not appear as separate and distinct. We are able to be better than we are kocasuse we for that moment do not see ourselves as individuals. There is no separative betwees us, and the world, we are not gendered, we are merely present.

Emptiness: Being present. Odd name for my reality. Its more like not being. or filling up so much with everything that I am no longer space, form or time. I am eternal. I am nothing. The heaviness of rain full clouds, the definition of a flat horizon. I meet the sky and sea and drench the underground with light. I am the swell in the ocean; moments ripple through me, and the individual drop that identifies me is indistinguishable from all the restless waters of the world. All things are like that for me. Oceans of space and everything a drop, indistinguishable from the dense rolling emptiness of nothing. Just 'being' and the experience of no separation.

\section{Burke}

Edmund Burke wrote on the sublime in the mid- $18^{\text {th }}$ century. He speaks of being 'in' the experience of the sublime and in that place one cannot objectively view its object because 
ourselves by what identifies us as individuals. Klinger claims that Kant's theory was designed to help define man's identity as a rational being. By Kant's definition the sublime is an experience denied to women because as Klinger puts it, 'Every person socialized in our culture infallibly classifies reason and rationality as male and emotions and sentimentality as female;'(Klinger 1997, p.192). If the access to the sublime is through reason then it is a male prerogative.

I locate my definition of the sublime in the context of Kant's dynamic sublime. (Being present in the moment such that the experience of the world as a multitude of objects in space disappear.). In his explanation of the dynamic sublime, however, this definition has as its purpose to deconstruct the identity of the individual. $I$ argue that in the moment of experiencing the sublime as Kant describes it the world does not appear as separate and distinct. We are able to be better than we are because we for that moment do not see ourselves as individuals. There is no separation between us, and the world, we are not gendered, we are merely present.

\section{Burke}

Edmund Burke wrote on the sublime in the mid- $18^{\text {th }}$ century. He speaks of being 'in' the experience of the sublime and in that place one cannot objectively view its object because 
'the mind is so entirely filled with its object, that it cannot entertain any other' (Burke 1990, p. xiv).

Like Kant he categorises the sublime in an attempt to define it. According to Burke, bulls are sublime and oxen are not, wolves are sublime and dogs are not, kings and God are sublime and ordinary people are not. Through these categories he is alluding to, rather than defining something because he also refers to the sublime as unknowable. He sees the sublime as 'that which ruptured the continuity of experience and tradition' (Burke 1990, p.xv). In this he privileges ignorance, claiming that understanding an idea merely indicates the simplicity of the idea: 'a clear idea is another name ...for a little idea' (Burke 1990, p.xv). He sees the sublime as an unmanageable concept, citing the source of our admiration of things in our ignorance of them. For Burke the sublime is present with the experience of pain and terror and it is these violent experiences that conjure up the strongest emotion necessary to know the sublime.

Form : What is the I? When did it occur to me? When did I occur to me? I don't remember. How could I because if I remembered then there would have been an I to remember and it would have been after, not before, the I came into being. BI and AI. Before I and After I. I cannot even imagine 'not I'. Sometimes when I am almost awake but not quite, when the bat wings of darkness flap into my consciousness, I feel myself spread. It's like a cool melting. From form to no form. 
'the mind is so entirely filled with its object, that it cannot entertain any other' (Burke 1990, p. xiv).

Like Kant he categorises the sublime in an attempt to define it. According to Burke, bulls are sublime and oxen are not, wolves are sublime and dogs are not, kings and God are sublime and ordinary people are not. Through these categories he is alluding to, rather than defining something because he also refers to the sublime as unknowable. He sees the sublime as 'that which ruptured the continuity of experience and tradition' (Burke 1990, p.xv). In this he privileges ignorance, claiming that understanding an idea merely indicates the simplicity of the idea: 'a clear idea is another name ...for a little idea' (Burke 1990 , p.xv). He sees the sublime as an unmanageable concept, citing the source of our admiration of things in our ignorance of them. For Burke the sublime is present with the experience of pain and terror and it is these violent experiences that conjure up the strongest emotion necessary to know the sublime. 
Emptiness: For you it is that way. For me there is no I. I am not separate, I am not, not anything. I am you, I am the cupboard, I am the wall and the floor. I am present. I am awake.

Form: But you have form, I can hear your voice and it must come from somewhere.

Emptiness: There is the paradigm that you exist in. For you the only way to exist is to have form, to be a 'thing', an object, a tangible presence. I am like the air around you. You swallow me with each inhale. I permeate your pores, swim in your blood stream. I am the sound in your ears. I pass through the stale matter of your material self with the breath of a bird. I am so real that molecules move aside when I enter objects in the way that you only know when you walk through a mist. Your form is stopped by all kinds of physical obstacles. Can you walk through this wall?

\section{Lyotard}

Jean Francois Lyotard (1993) in The Post Modern Condinion discusses Kant's definition of the sublime as the conflict between the inability to present the unpresentabie and our ability to conceive of the infinite. The absolute can be imagined however any attempt to represent it is limited frustratingly because whatever represents it, is not absolute This combination of pleasure and pain is, according to Lyotard, how Kant defined the wuhlinat

'...the pleasure that reason should exceed all presentation, the pain that imaginatias and or sensibility should not be equal to the concept.' (Lyofard 1993, p.81). 


\section{Lyotard}

Jean Francois Lyotard (1993) in The Post Modern Condition discusses Kant's definition of the sublime as the conflict between the inability to present the unpresentable and our ability to conceive of the infinite. The absolute can be imagined however any attempt to represent it is limited frustratingly because whatever represents it, is not absolute. This combination of pleasure and pain is, according to Lyotard, how Kant defined the sublime:

'...the pleasure that reason should exceed all presentation, the pain that imagination and or sensibility should not be equal to the concept.' (Lyotard 1993, p.81). 
Lyotard takes a distinct approach to Kant's theories in examining the sublime. Whereas Kant referred to the power of nature to elicit the experience of the sublime, Lyotard refers to art and literature. While Kant used his search for the sublime to argue for a transcendent or superior state that man could reach through reason, Lyotard does not see the sublime as representing a higher realm. Instead he sees it as representing the unrepresentable.

"The sublime is a thought that is felt on the occasion of an absence of the objects form.' (Lyotard 1994, p.231)

Klinger (1997) states that Lyotard, having rejected Kant's search for a superior moral order, thinks of the sublime in postmetaphysical and postmodern terms in which the significance of the sublime lies in what is beyond any possible order.

According to Klinger (1997) Lyotard views the sublime as "the heroic gesture of breaking free from the bonds of a surrounding reality' (Klinger 1997, p.205), claiming that art is the site for an 'ontological dislocation' (Lyotard 1989, p.206). With this agenda Lyotard is criticised by Klinger as taking a masculine and modernist approach to transcending the human condition, articulating a painful and violent wrenching from the consensual reality. Lyotard sees the experience of transcendence as causing unification with all things and he relates this experience to society rather than nature, as did Kant. Naturally this echoes the ideology of the totalitarian state and consequently brings with it a fear of the loss of the individual right. Klinger sees a paradox in Lyotard's theory here. The sublime as the unrepresentable is beyond any possible order. Unless this state remains a fantasy that is only imagined, individuals must transcend their identities to achieve it. To transcend your identity you experience becoming a part of the whole. In my definition I argue that a more personal and private dislocation from the experience of the world is available that results in an experience of fusion, a unification, which is not the totalitarianism that Lyotard claims we all fear. In this state the individual experiences being totally responsible for their reality, quite the opposite of a totalitarian reality. This experience is difficult to represent and the work of abstract artists from the early $20^{\text {th }}$ century bare witness to this fact. Representation of an experience is always a 
representation and never the experience. While the representation may induce an experience in the viewer it is not reliably the experience that was represented.

\section{Newman's Zip}

In art, the whole project of representation became flawed in the desire to represent the unrepresentable and the presentation of the infinite was described by pointing to what was not there, by representing the negative. In the 1940s Barnett Newman attempted to create artwork that gave one the experience of just being. By taking away the influences of memory, association and representation, the viewers stand before the work blank, with no clues. They are encouraged to be 'in the moment', which for Newman represents the sublime. My definition of the sublime is most closely related to Newman's project. In 1949 Newman visited an Indian tumuli, a simple architectural building made of mud and he subsequently wrote a text called Ohio, 1949, in which he described a seminal experience, which could be called an experience of the sublime. He described it as a work of art that cannot be seen but must be experienced, an experience of an apparition, an experience of the physical sensation of time. It was a subjective experience of space, which rejects the fascination over space in an objectified sense that has been at the source of Western art history since the discovery of perspective at the time of the Renaissance.

What Newman (1949) describes is an example of the famous aura critiqued by Walter Benjamin in his essay $A$ Work of Art in the Age of Mechanical Reproduction Newman had already been exploring this phenomena in his 1948 painting Onement $I$. This painting became a key artwork of that period and was named as a result of the experience that it produced in the viewer, a peaceful state of being in the moment. A neutral ground with a vertical line, called by Newman a 'zip', which lies in the centre of the painting. Newman considered that the line or zip did not divide the two sides of the painting but instead created the effect of unity and indivisibility. According to Georges Didi-Huberman (1996) in the catalogue for the exhibition Negotiating Rapture this work developed without a plan and is the result of what Benjamin called a 'unique apparition'. The painting cannot be seen figuratively and yet has an experience of distance. It is a 
depth that has nothing to do with the illusion of perspective. It has what is described as flat depth, a term used by Jean Clay to refer to the work of Pollock and Mondrian.

\section{Flat Depth}

It is this flat depth that appears again as a phenomenon in virtual reality, however it is in the viewing process that the flat depth of Newman's work relates to the realism of virtual reality. The illusion exists in the moment and at no other time. It doesn't exist on the wall in the painting as we walk away. On the other hand, the illusion of perspective doesn't disappear as the viewer moves away. The depth in Newman's abstraction and in virtual space requires something of the viewer. They must be in the moment, they must be outside of their thoughts and inside the experience of looking. I argue that the sublime is the space, the flat depth, the virtual space, and when you enter it, so to speak, you are in the space of the sublime.

In a recent trip to the Tate Modern in London I was struck by the ability of painting to produce an experience of interior depth in the work of Mark Rothko. The Rothko room at the Tate Modern is dimly lit with only the paintings illuminated. The walls are painted a soft grey and Rothko's large maroon and black paintings fill every wall. In the centre of the room is a bench where you can sit surrounded by the work. The experience was much the same as being in a video installation. The intensity of the paint demanded as much of the viewer as a moving image. Similarly to the Newman work there was nothing recognisable to refer to, so the experience was one of being with the work and letting it work on you. The depth was not perspectival but as a viewer I felt drawn into the paintings, into a space of contemplation.

\section{The Immaterial}

In 1985 Lyotard curated an exhibition called Les Immateriaux (The Immaterial) at the Georges Pompidou Centre. Lyotard aimed at deciphering the sensibility of postmodernism in this labyrinthine-type exhibition involving the work of many artists in over sixty sites in thirty-one zones. The installation was encountered by wandering through the spaces wearing headphones, which were prompted to play music as well as 
readings of literature, philosophy and poetry set off electronically by each exhibition piece. Lyotard wished the entire project to be viewed as an artwork in itself. The work explored the uncertainty created by the rapid displacement of all things familiar as we venture further into the electronic unknown. According to Paul Crowther (1992) in his essay Les Immateriaux and the Postmodern Sublime, Lyotard's project was based on the notion that Postmodernism has confounded our ability to perceive reality as substantive self contained material surfaces' (Crowther I992, p.193). The exhibition is described by Crowther as examining the various ways that we receive and understand reality through meaning, and promotes the view that the structures of meaning we have created are trembling and are in the process of undergoing a transformation. The reality that we know and take for granted is supported by a complex matrix of subliminal forces in the form of past experiences, memories, culture, class and location that shape our present experience. Our awareness of this, along with the speed of technoscientific advances is transforming our relationship to reality (Crowther 1992). The human body or form, sexuality, industrial material and new technologies were investigated in an attempt to represent that:

'Every familiar aspect of reality - even that of the embodied self, now proves to be infinitely analysable and transformable into a web of microscopic and macroscopic processes and relations (i.e. 'immaterials')' (Crowther 1992, p.194).

Lyotard saw modernism as beginning with the Enlightenment and as being characterised by the aesthetic of the sublime (Crowther 1992). In Les Immateriaux the work of prominent postmodern figurative painters such as Schnabel or Clemente are missing and Lyotard's neglect of these painters is based on a criticism of their return to concerns of pictorial reality. He sees the role of the painter as being endlessly engaged in the task of attempting to represent the unrepresentable, which is how he defines the sublime. He claims that the project of representing the unrepresentable, capturing the sublime, as singularly the most important one in the coming century. He sees his definition as only being able to be attempted through abstract work that does not provide anything that can be recognisable as finite. He believes that the painter's fascination should be with the question, 'What is painting?' and it is in this enquiry that the tension 
between pleasure and pain ensues; the fundamentally impossible task of presenting what is invisible.

\section{Representing Sublime}

The parallels between Lyotard's definition of the sublime, and my own, lie in the conviction that the sublime cannot be represented. Lyotard on the other hand tends toward the hopeful project of negative representation. He argues that by engaging with what is not there in a painting one encounters the area of the sublime. For example, the paintings in the Rothko room were abstract fields of colour that appeared to float on one another. They were maroon and black and the areas of colour had no defined edges, which left me unable to see them as constructed or designed objects. The paintings vibrated as I attempted to fix my gaze on one area. They denied a visual definition that would relate to them as recognisable and would therefore fulfil Lyotard's project of negative representation, however I believe that the paintings referred to something unrepresentable rather actually than representing it.

A definition of the sublime that relates to absence still locates the sublime in an object. It is my position that a new definition of the sublime is available through the contemporary fascination with virtuality. Lyotard argues for the convincing influence that perspective had on the design of our social order, creating a rationalist ordering principle that has lasted through the ages and that can still be seen in the way we lay out our cities. Most houses even today are placed with the front of the house parallel to the road. The illusion of space began with perspective and has been developed since that time with more and more clever tricks of the eye constituted by the artist. Rather than the space of the illusion being examined however, the content was at the forefront and the devices that allowed for the creation of reality were seen mostly as clever parlour games. With the opportunity of lightening fast computers that can create a simulated environment that keeps pace with and interacts with the viewer's movements, comes another look at the space of illusion. When the viewer can step into the illusion of space I contend that rather than viewing the sublime, in the medium of the virtual the sublime space is entered. The attempt made by painters for centuries to provide the viewer with a transcendent 
experience is, I would argue, beyond the reach of a two dimensional surface. Simply put, the viewer is distracted from a pure contemplation of the artwork in front of them by the sights and sounds of their peripheral awareness.

In the virtual space the viewer is immersed in a created reality. They become the participant and experience themselves as interacting with a reality that they know is not there. This knowledge is absorbed at a level of experience and the overall sensation is one of being at the source of their reality, causing their environment to react as they react. I claim that this is a transcendent experience. I agree with Lyotard's assessment of the worth of an engagement with the sublime, however I see the opportunity of a new postmodern sublime coming from an engagement with the technology of the future and there is no reason why the output of that technology should be limited to work that is non representational. A simple but beautiful example of this was provided by Lynette Wallworth's work, Hold Vessel \# 1 shown in the exhibition Deep Space at the Australian Centre for the Moving Image in 2003. Wallworth required the viewer to carry a glass bowl into the exhibition space and catch the images as they were projected onto the floor. As the white frosted glass moved under the light, images of fish, night skies and microscopic cells appeared to leap into the bowl. 

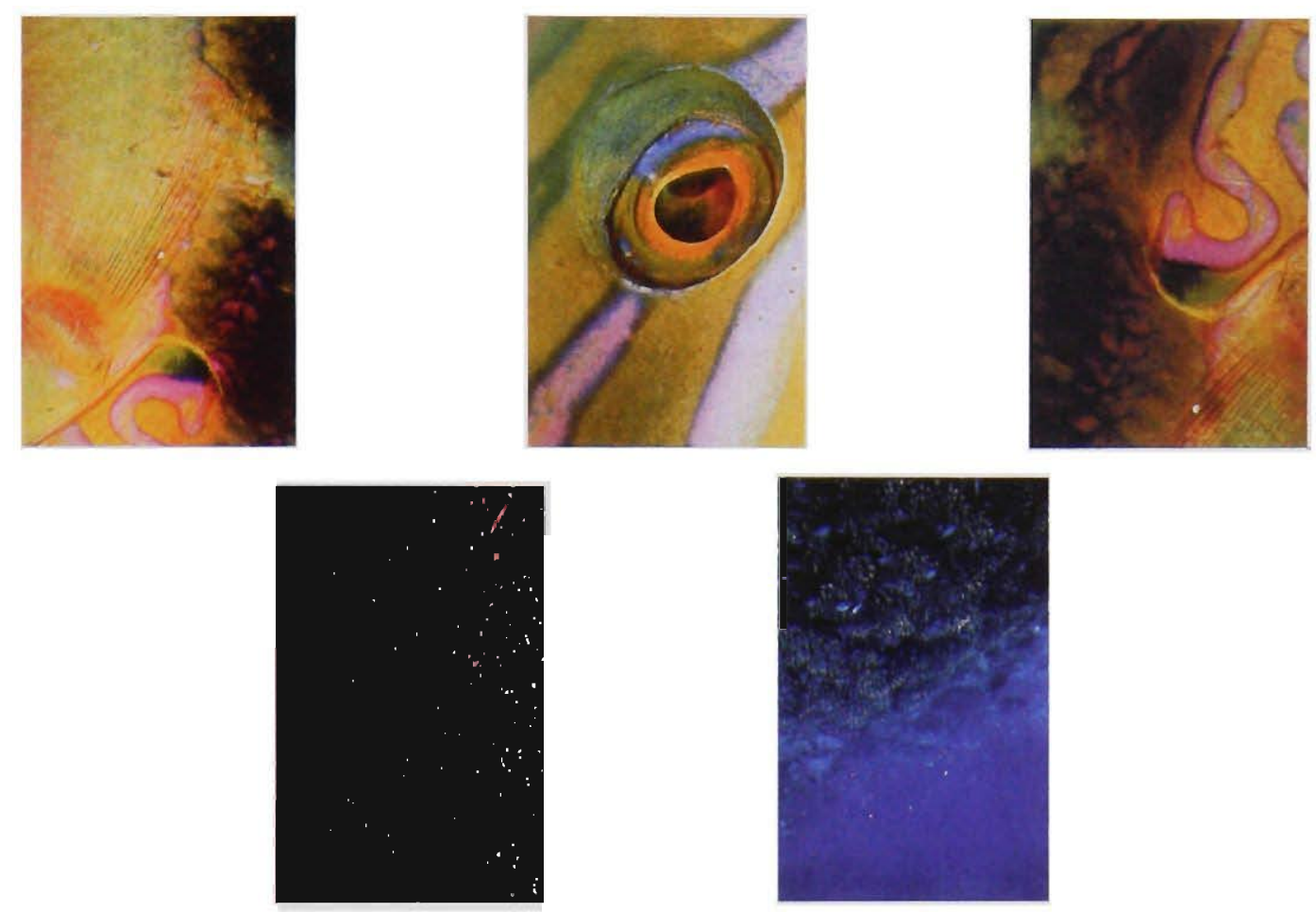

Hold Vessel \# 1 Detail by Lynette Wallworth, projections, digital imagery, collection Australian Centre for the Moving Image. Reproduced from Deep Space Sensation and Immersion, Art Gallery of New South Wales, 2001.

The viewer became the participant in the artwork and the work moved interactively with their movements. Victoria Lynn claims in the catalogue essay,

'Wallworth invites us to 'hold' them in our hands, to reconnect, in a sense, with their wonder. If, as Paul Virilio maintains, the object now has the sensorial function of the subject', then Wallworth reinstates the optical sensations of the human eye in order to recapture the digital image into the realm of meditation and contemplation`(Lynn 2001, p.16).

Deep Space explored the experience of sensation and immersion that I connect to the sublime, and the work was predominately representational. 


\section{Virtual Sublime}

Frances Dyson (1998) in his essay "Space," "Being," and Other, Fictions in the Domain of the Virtual, notes that cyber theorists refer to cyberspace as a 'mode of being' and that in an investigation of the ontology of cyberspace there is a wish to define the new technologies as providers of access to being.

‘...many proponents of virtuality recognize nonetheless that authentic being, "being there," generates what is possibly the last bastion of hope against the fear and cynicism that pervades late-twentieth-century culture, transforming the gloss of technological progress into another form of toxic overlay' (Dyson 1998, p.28).

Dyson acknowledges that virtual space has historical precedents and that these precedents have created viewers that are screen-based. We have been prepared for a relationship to the screen that allows us to experience a space that is not there in reality. We watch television and interact with the computer and rarcly do we witness the actual surface of

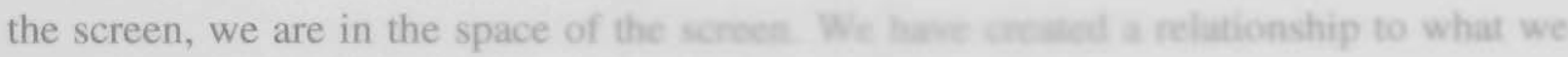
see that takes us there. Seeing is replacad by fack and the space required for 'being in' is the space of the watan

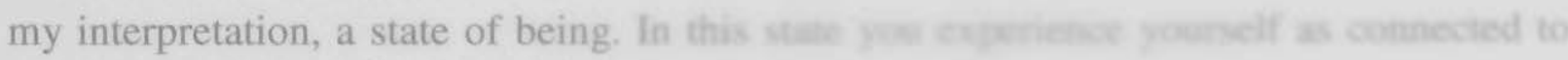
your reality, rather than being overwhelmed by a rastiry that unaposes itself on you, existing outside of yourself as interpreted by Kant. Yae know yourself as a part of a whole that is connected to every part of your being and your expresuion within that whole impacts the entirety. What Kant describes as the limit of reason is, I believe, the transcendence from a rational state, to a state of being present, where understanding. reason and thoughts are quietened by the experience of heing in the moment. That moment is a timeless moment and is described after the fact as sublime.

Form: How do I know that my hand is before me?

Emptiness: I have no voice. I am the knowingness of things. I am the formless form of objectness. Objects 'being' 


\section{Virtual Sublime}

Frances Dyson (1998) in his essay "Space," "Being," and Other, Fictions in the Domain of the Virtual, notes that cyber theorists refer to cyberspace as a 'mode of being' and that in an investigation of the ontology of cyberspace there is a wish to define the new technologies as providers of access to being.

"...many proponents of virtuality recognize nonetheless that authentic being, "being there," generates what is possibly the last bastion of hope against the fear and cynicism that pervades late-twentieth-century culture, transforming the gloss of technological progress into another form of toxic overlay' (Dyson 1998, p.28).

Dyson acknowledges that virtual space has historical precedents and that these precedents have created viewers that are screen-based. We have been prepared for a relationship to the screen that allows us to experience a space that is not there in reality. We watch television and interact with the computer and rarely do we witness the actual surface of the screen, we are in the space of the screen. We have created a relationship to what we see that takes us there. Seeing is replaced by being, according to Dyson, and the space required for 'being in' is the space of the virtual. The sublime is an ontological state in my interpretation, a state of being. In this state you experience yourself as connected to your reality, rather than being overwhelmed by a reality that imposes itself on you, existing outside of yourself as interpreted by Kant. You know yourself as a part of a whole that is connected to every part of your being and your expression within that whole impacts the entirety. What Kant describes as the limit of reason is, I believe, the transcendence from a rational state, to a state of being present, where understanding, reason and thoughts are quietened by the experience of being in the moment. That moment is a timeless moment and is described after the fact as sublime. 
Form: I know my hand is before me because I do hand-like things with it. I wave, I pick up the gun, I sew and sew and sew. Sewing the seams of my universe. I must not slip through the fabric of my reality. Keep sewing up the holes. It is a large task, sewing all the red velvet in the world. Sometimes it stretches, that seductive material. It stretches over the bones of what I know so that they almost poke through. It reminds me of my mother's hand when she grips tight and her knuckles go white. Sometimes it bunches, goes slack, and then is truly beautiful. The folds are like the creases in my mother's face, or like the fabric of a Van Eyck Madonna, rich and dripping with the corporeal. When my world crumples and goes soft I can sink into the material. Madonna's face is fabric and I lie cheek to cheek in the lap of the world, so comfortable I weep.

In the installation The Sublime Sleep, the characters Form and Emptiness represent the arguments for and against the desire for transcendence. 
In the installation The Sublime Sleep, the characters Form and Emptiness represent the arguments for and against the desire for transcendence. 


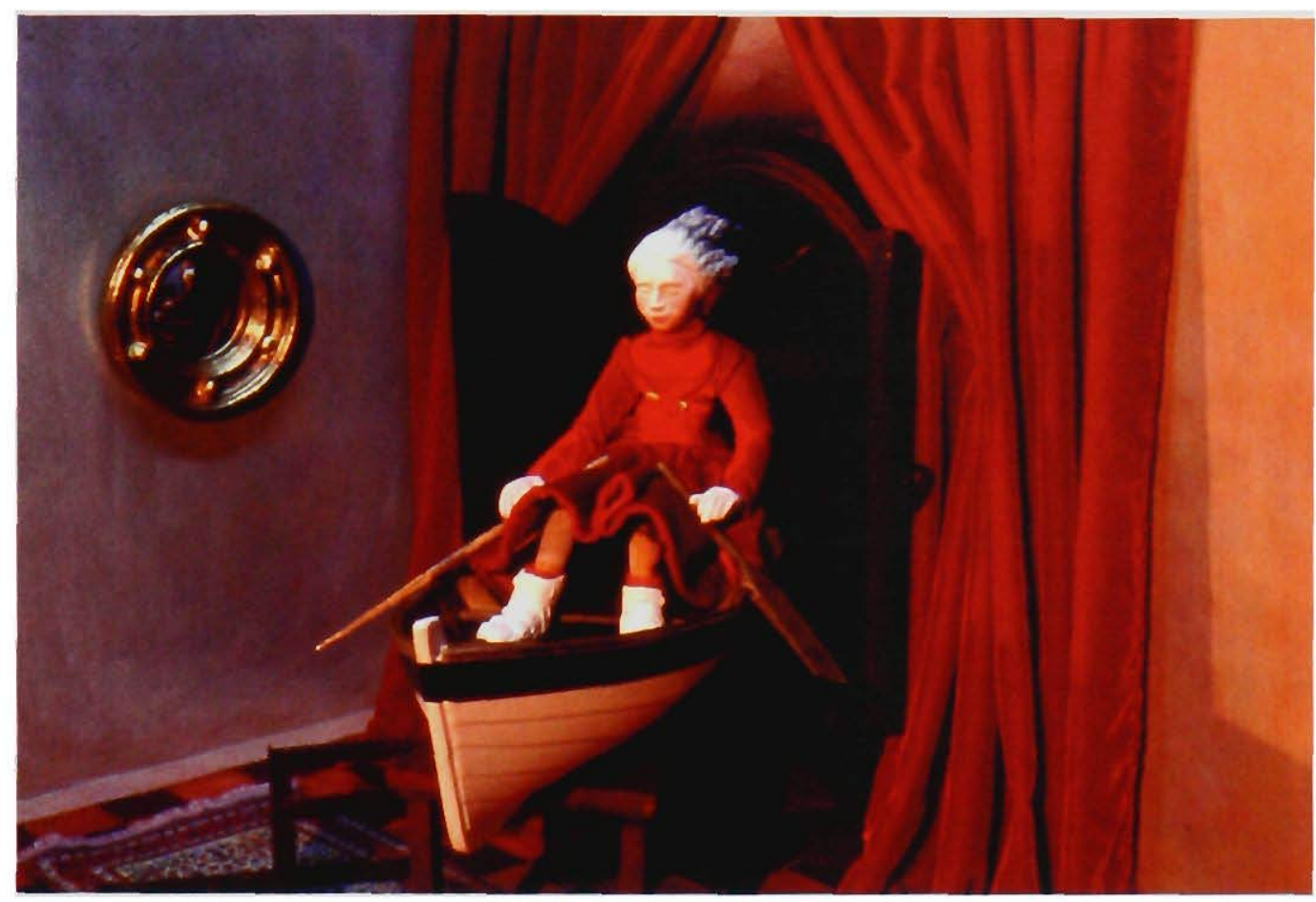

Form rows free by Megan Evans from VirtuallyPAINTED series 2001

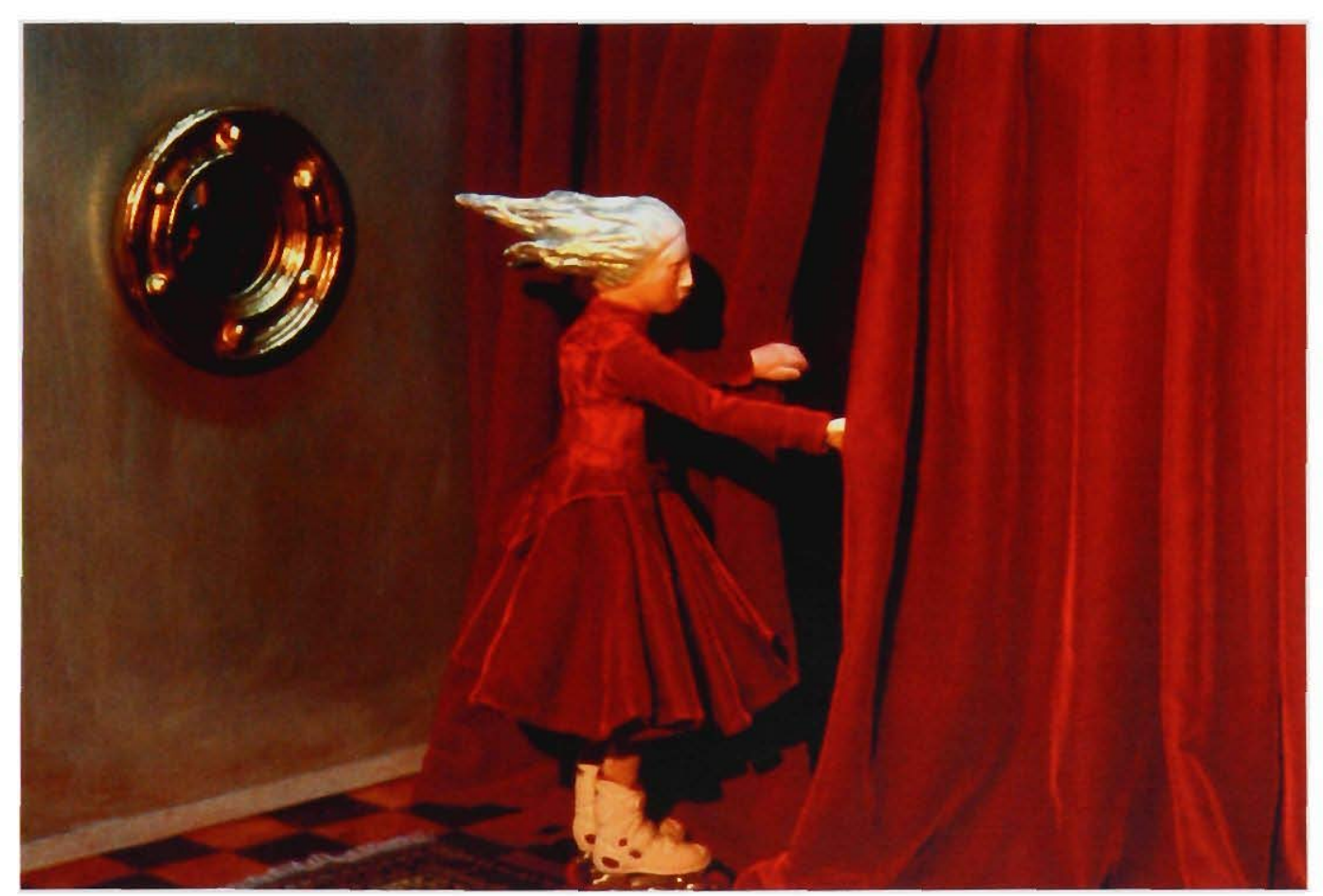

Form seeks the answer by Megan Evans from VirtuallyPAINTED series 2001 


\section{CHAPTER TWO: THE PAINTING OF FORM}

\section{Sleepskater}

The character Form has her eyes shut and is a sleepwalker. She experiences her state of sleep as natural and fears the nightmare of waking up which would correspond to our state of dream. She is falling awake and dreaming up from her state of wake. Falling awake refers to falling asleep, dreaming up refers to waking up and state of wake refers to a dream state. Form dialogues with Emptiness who is a part of herself. Emptiness is what we could call her being, or her immaterial self, a virtual copy of Form that appears to magically materialise and dematerialise and move about the real space. Emptiness is attempting to wake up the sleeping Form through a debate about the nature of her reality. Emptiness is based in reality and Form is in a world of illusion, however, Form's illusion is recognisable to us, but the reality that Emptiness experiences may not be the reality that we know.

Form struggles with her reality. She is constantly questioning: is she as Emptiness says, in a painting? This struggle is played out in the work VirtuallyREAL through the dialogue, which occurs between the material Form. It is heard as a soundscape throughout the exhibition. This project explores the concept that all reality is an illusion and our very existence is virtual. The virtual realm is utilised to explore the realm of the virtual.

\section{Moebius Strip}

The 'moebius strip' is a topological anomaly that best describes the journey of the creation of this artwork. Like the moebius strip I started out on a pathway and after taking a one hundred and eighty degree twist, I found myself travelling down the same path I began. The creation of the artwork emerged from an investigation into the nature of reality. I began as an analogue artist, exploring the virtual domain of the digital and ended investigating the virtual domain of the analogue. My expectation was that the virtual existed entirely in the realm of the digital. In this sense I went backwards arriving at a 
place I had begun from, but with a better understanding as an artist, of the impending influence of virtual reality.

The implications of digital technology on the tradition of oil painting are profound for me as an artist. The speed with which images can be created in the digital realm shook the confidence of the fastest oil painter. The ability to be able to create an image and then change the colour, tone, shape and orientation of that image in the blink of an eye is breathtaking and was part of the reason for my ambivalence about digital technology. I was intimidated by what it all meant for me as an analogue painter trained in the $20^{\text {th }}$ century. The technique of painting has always been very physical. You begin with stretching a canvas, which involves bodily moving around the wooden stretcher and pulling the canvas into shape over the stretcher. The next step is to wash down the canvas to shrink it to a taut surface which drums when you flick it with your finger. This is then left to dry in the studio in a place that will receive even temperature so that the canvas doesn't warp. When it is dry the rabbit skin glue is prepared on a double boiler over the studio element. The glue is then applied to the canvas in even strokes and absorbed into the weft of the canvas to seal it from the properties of the oil paint. Once the glue is dry the canvas is even more stable and tight like a drum. Then the gesso is painted on to create a smooth white surface on which to paint. Gesso is applied several times with the intervening layers being sanded down to take the 'tooth' or rough points off the canvas. This process can take days, even weeks if an oil based gesso is used. The preparation of the surface of the painting is crucial to the quality of the finished painting as the colours, textures and surface of the painting are all affected by the base that they are applied to. Once the painting begins the tools used to apply the paint become important. Poor quality brushes and cheap paint produce a raw and unpolished result. The material and temporal experiences are very present in the creation of a painting

The process of painting was connected through time to the beginning of the technique. Despite the changes in the source of supply for all these requirements the application of them has remained basically the same since the $15^{\text {th }}$ century. One couldn't help but ponder when boiling up the rabbit skin glue, about the early masters of these techniques who would have had apprentices to prepare their canvases and grind their pigments and would probably have boiled up the rabbit skin on a fire instead of an 
element, however there was a connection over time through the physicality of the process. Knowing that I shared the movements of my forbears in the making of an artwork gave continuity to my experience of being an artist.

\section{Digital Brush}

Suddenly I was creating marks that took a slight movement of the wrist, yet they stretched across metres of a virtual canvas. Would I now create work that was wildly different from my previous work? Would I fall prey to the influence of a digital aesthetic? How did this new medium relate to my ideas and technique? I began by experimenting. and in the tradition of postmodernism, I created a digital simulacrum of a detail (Cenami Cellini's face) from the famous Van Eyck painting, The Marriage of the Arnol Fini.
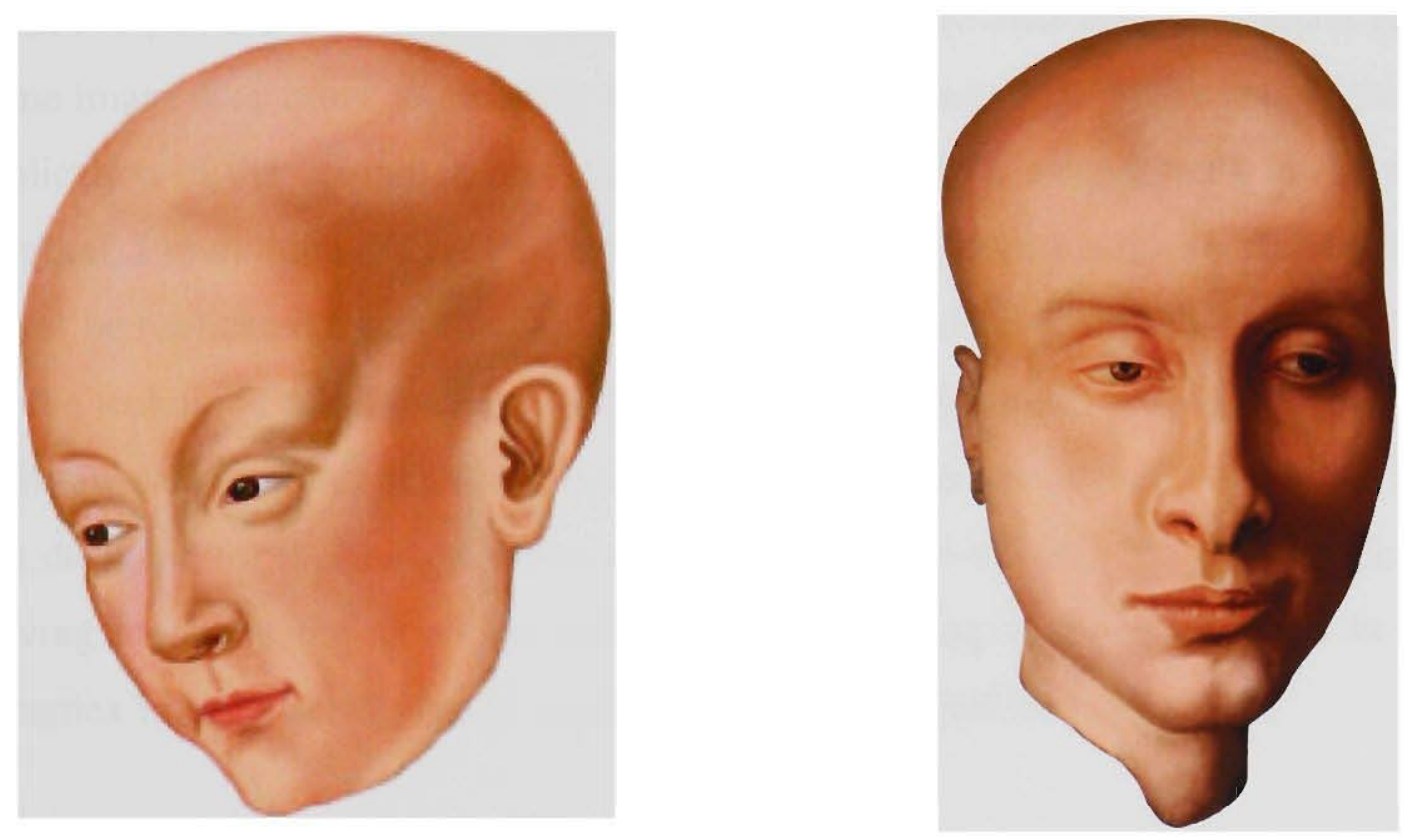

Cenami Cellini and Amol Fini, 2000 by Megan Evans

Painted in Adobe PhotoShop using the airbrush tool. I was able to create a mimic of the original that used the method of layering in the place of glazes. I could zoom in to such a degree to be able to paint pixel by pixel, giving me the ability to produce very fine detail. This experience had me examine again the writing of Walter Benjamin and his discussion of the aura. Benjamin (1931) blamed the camera and mechanical reproduction for the loss 
of the aura that he claimed emanated from the mark of the original. I had made a replica of a part of an original painting that undeniably had the significance and the mark of the originator, yet my copy could be replicated ten thousand times without any loss of quality. The aura was decidedly absent in the digital image and made the analogue photograph look as significant as once only the original oil painting did. My work also did not exist in any physical form once I turned off the computer and even with the computer on it was dependent on the program that turned my marks and movements into a numerical computation. Zeros and ones were at the root of my work as opposed to canvas, oil and pigment. My fascination was tinged with repulsion.

While questioning the tradition of painting in the dawning era of the digital, I was still sufficiently connected to the analogue process to want to begin my $\mathrm{PhD}$ project with a brush in my hand. So I scanned some red velvet into the computer and by a series of kaleidoscopic manipulations produced a mandala-like image, which I broke into four identical quarters. I projected each quarter onto a square canvas and set about painting the same image four times to examine what happened when the painter's brush attempted the replication of the computer, and the relationship of the analogue mark to the aura of the original. I found that the painted mark was capable of producing something, which could never be replicated by a print. The depth of colour and quality of light that was produced by the technique of oil on canvas was never going to be replaced by a digital print, which will always be one-dimensional by comparison. I also discovered that human beings are not designed for replication. I was slowed down and eventually stopped by the tedium of having to repeat the slow and laborious mark making that was required to create the complex image I was trying to reproduce from the digital into an original. 


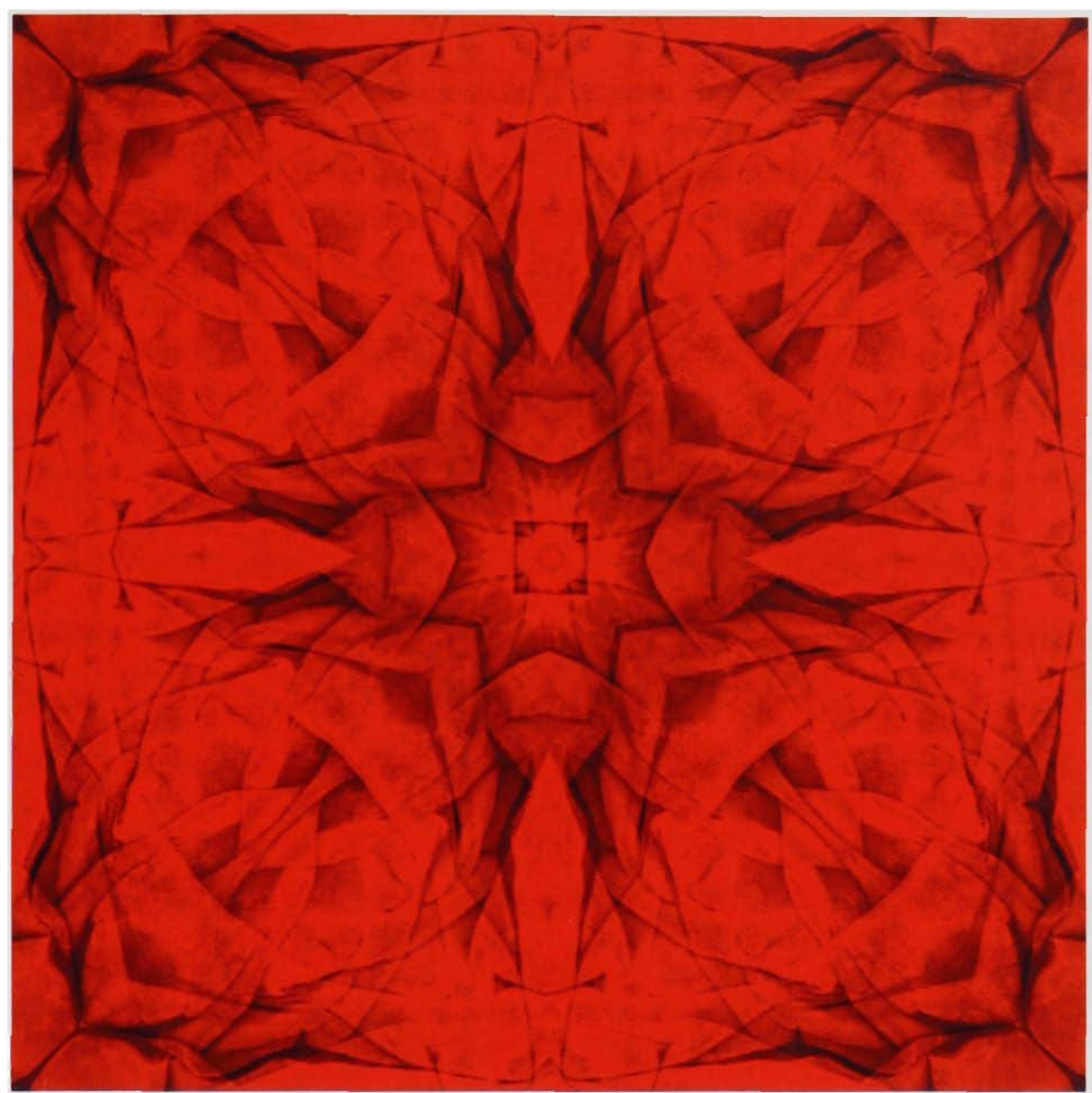

Digital Image of MANDALA by Megan Evans 2000

Painting from life, even though the source was a digital image in two dimensions requires extreme discipline in observation and ability to be present to the task. The tendency is to be distracted either by physically wandering away from the canvas or by drifting intellectually and avoiding the focus required over a long period of time. After painting two thirds of the first canvas I put the analogue paintings aside and left them for three and a half years, coming back to them only at the end of my process.

\section{Dialogue}

A chance listening of a radio play provided a surprising turn in my endeavour: the use of dialogue. I had previously read the Three Dialogues between Hylas and Philonous in opposition to sceptics and atheists by Berkley (1963) and enjoyed the use of discourse to unfold a philosophical argument, however the radio play provided an opportunity of using discussion in a creative rather than a rational linear way. I was also looking for a 
way to investigate my concerns in both art and text and weave them together so that the entire project was holistic and integrated, rather than the stereotype of the head (the text) being severed from the body (the art).

A dialogue required more than one voice, which proposed characters. Characters need a shape or identity. Enter Form, a miniature figure that represented myself. She was created from a wooden artist's model that is traditionally used to teach students to draw the human form in the right proportions. I built her intuitively without much of a preconceived idea of what I was doing. Consequently an archetypal figure emerged with flowing green hair that stood stiffly out behind her and an innocent and almost serene face with her eyes closed. She wears a red velvet dress with an extra full skirt that hangs like a lush curtain in folds, halfway down her calves. She echoes Alice in Wonderland and yet is less conscious than Alice. She is not in an unreal world and doesn't react the way Alice did to her upset reality.

Form wears roller-skates and appears to be slightly removed from the rigour of daily activities, withdrawn into a philosophic reverie, questioning everything yet convinced she knows everything. Form talks to herself, conducting an internal dialogue that replicates the mind arguing with itself. Her 'self' has a name and an identity that is separate to Form, the 'being' of Form; an immaterial ghostly figure that has a vastly different point of view to the physical Form. This other voice is called Emptiness and she debates with Form about the nature of reality.

Emptiness proposes that Form is actually asleep, believing her dream of reality to be the truth, unconscious to actual reality. However Form's reality is common with our own and as the debate ensues it becomes clear that Emptiness is talking about a reality that is immaterial, akin to Plato's philosophy of pure Forms. Emptiness is determined to wake up the sleeping Form from her illusion via philosophical discussion and the question becomes which reality would she wake up into, would she as Baudrillard (2000) says, cease to exist as form if she were present to herself and absolute reality?

'If same were identical to same, we would be faced with an absolute reality, with the unconditional truth of things. But absolute truth is another name for death' (Baudrillard 2000, p,72). 
Alternatively, would she wake into a state of the sublime where she is integrated with her environment?

\section{The Set}

Form's environment was created as a response to the development of her identity. The set was influenced by the perspective of Italian Trecento painters of the $14^{\text {th }}$ century. particularly the work of Pietro Lorenzetti. The Birth of the Virgin (1342) and The Altarpiece of St Cecilia done by the Master of St Cecilia Altarpiece (Before 1304). In the Birth of the Virgin two rooms are indicated from a 'one point perspective' and behind the virgin, who is the central figure in the scene, a curtain lines the wall suggestive of a space behind it. In The Altarpiece of St Cecilia, the virgin is surrounded by small architectural spaces with similar curtains and all viewed frontally. Each architectural space is inhabited by miniature figures that enhance the illusion of space by their realistic proportions relative to the architectural elements.

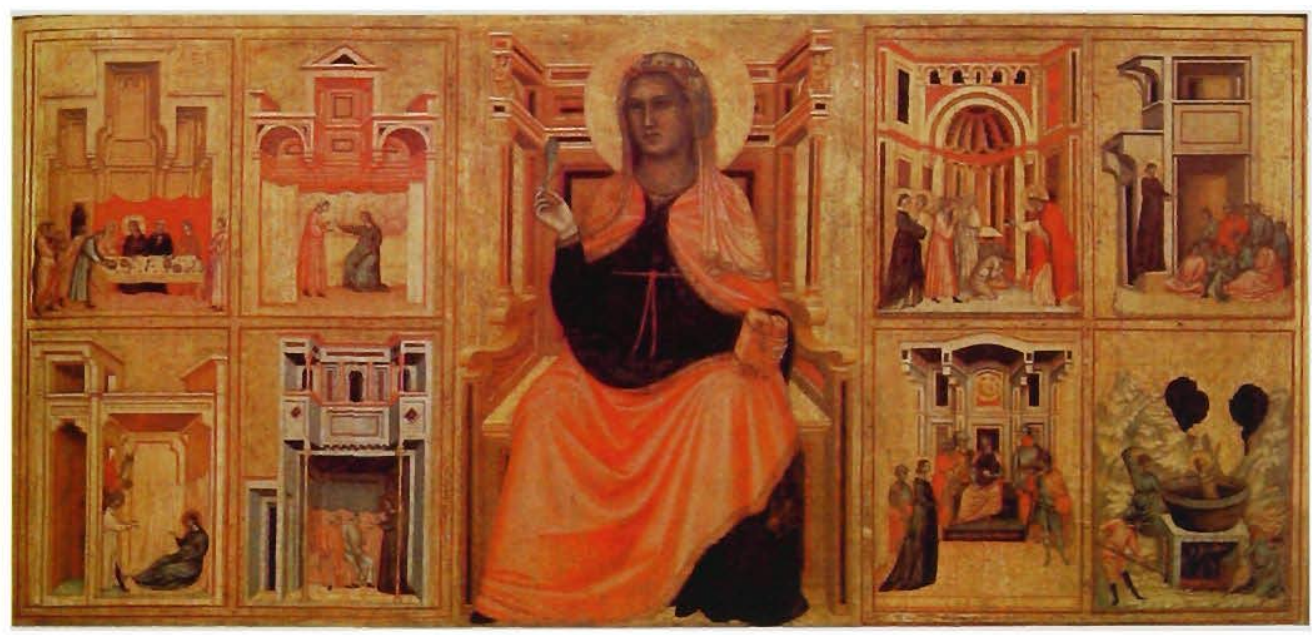

The Altarpiece of St Cecilia by Master of the St Cecilia Altarpiece

Before 1304, Uffizi. Florence, Tempera on Wood, 85 x $181 \mathrm{~cm}$, reproduced from Great Masters of the Trecento by Maria Prokopp 1986

According to Maria Prokopp (1986) in Great Masters of the Trecento the figures are the 'subjects of a lyrical narrative, enclosed in a decorative setting'. This singular view is replicated in the artwork in The Sublime Sleep by the set. 


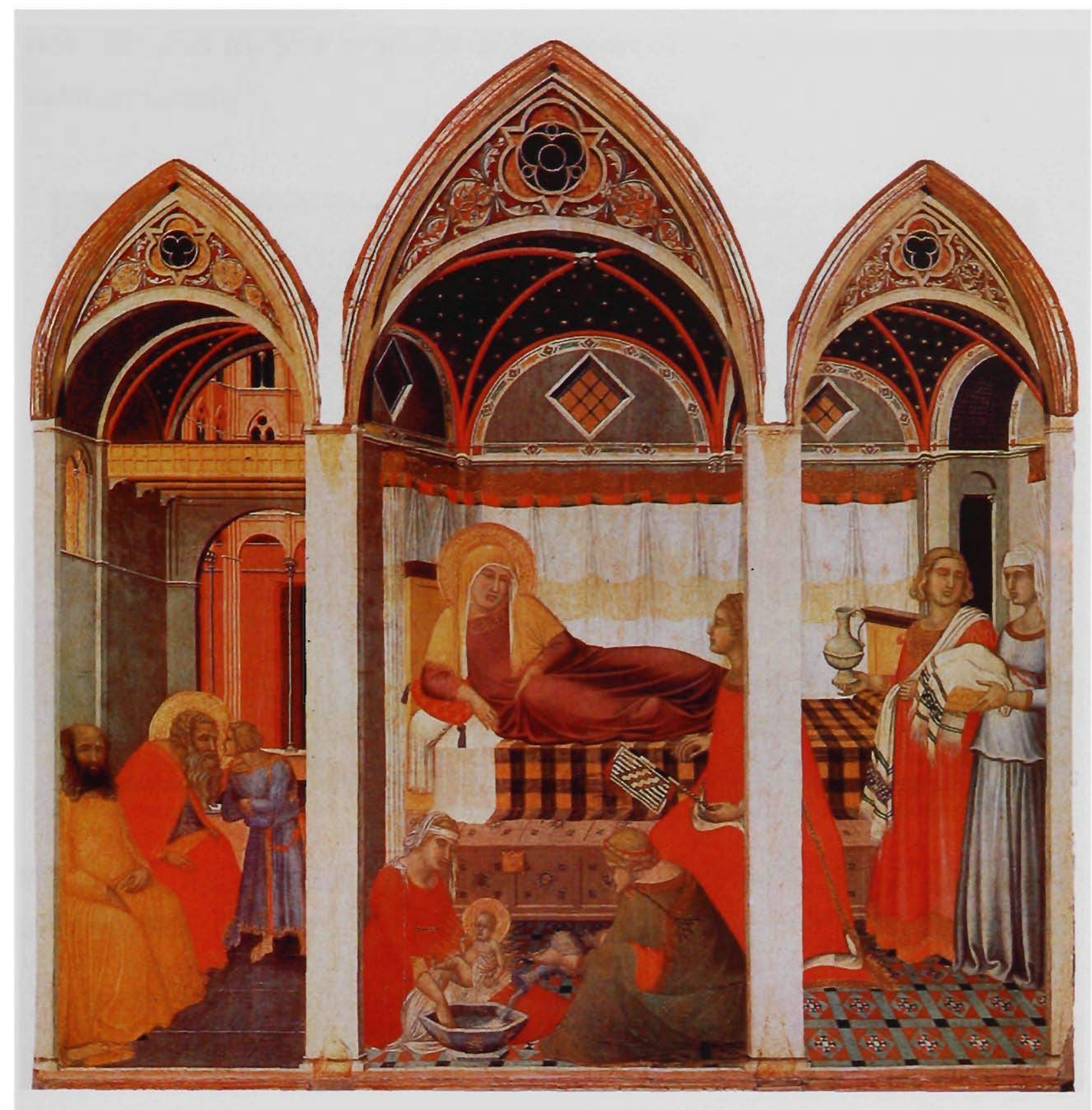

The Birth of the Virgin by Pietro Lorenzetti,

1342. Museo dell'Opera del Duomo, Siena,Tempera on Wood, $188 \times 183 \mathrm{~cm}$, reproduced from Great Masters of the Trecento by Maria Prokopp 1986

Bill Viola also refers to the work of the Italian masters in a similar way in his video installation Going Forth by Day with the piece The Path, which shows a cutaway view of a room in which a man lies dying, waiting for the journey after death. The influence of the tradition of painting on Viola's work is well documented. He creates spatial 
representations of a traditionally two-dimensional media and brings them to life using video. His work has been influential on my interest in a contemporary reworking of the tradition of painting.

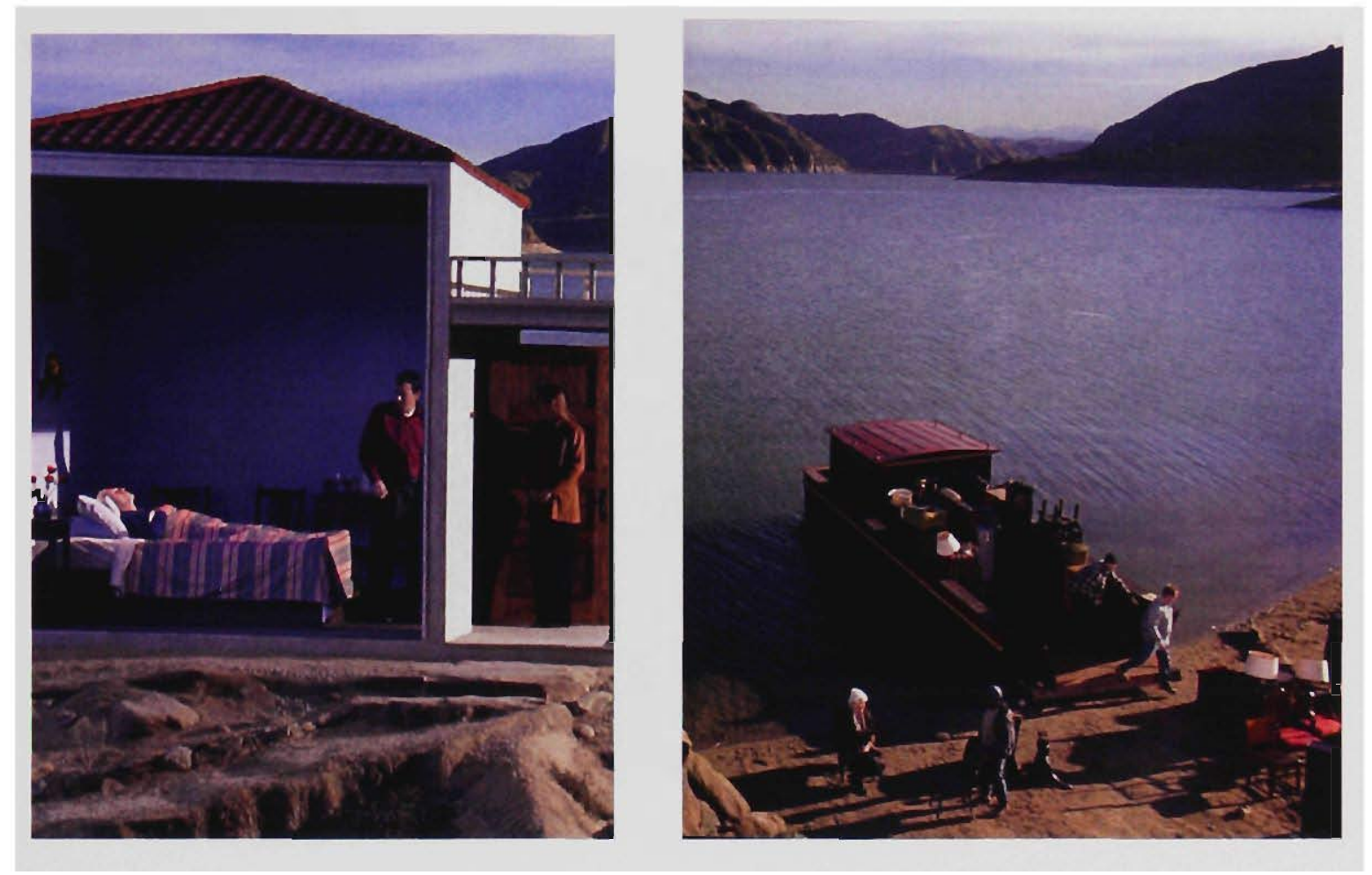

The Voyage, from Bill Viola: Going Forth by Dal by Bill Viola, 2002, reproduced from catalogue, Going Forth by Day,. 
The set was designed to frame a space that related to painting yet was in the third dimension. The interior was dealt with in a painterly manner that created an atmosphere suited to being viewed through a lens. The potential for animation of the character and creating the effect of a moving painting was the reason for this. The reference to Van Eyck also became apparent at this stage with the inclusion of a convex mirror.

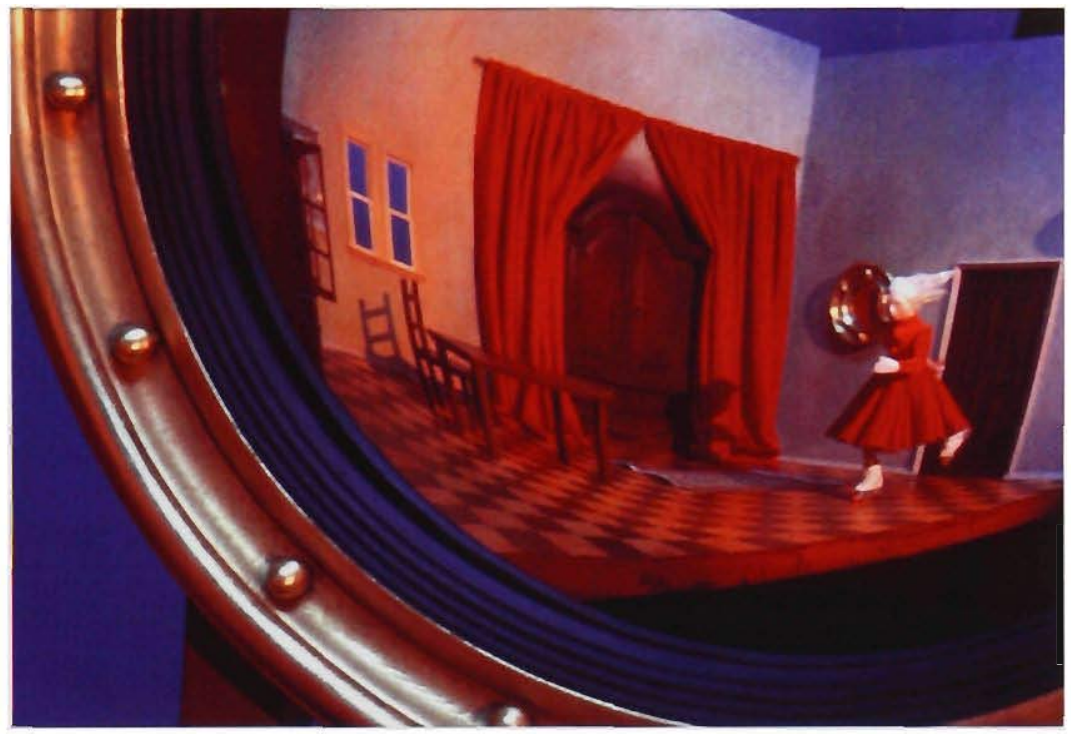

Form skates out of the frame by Megan Evans from VirtuallyPAINTED series, 2001

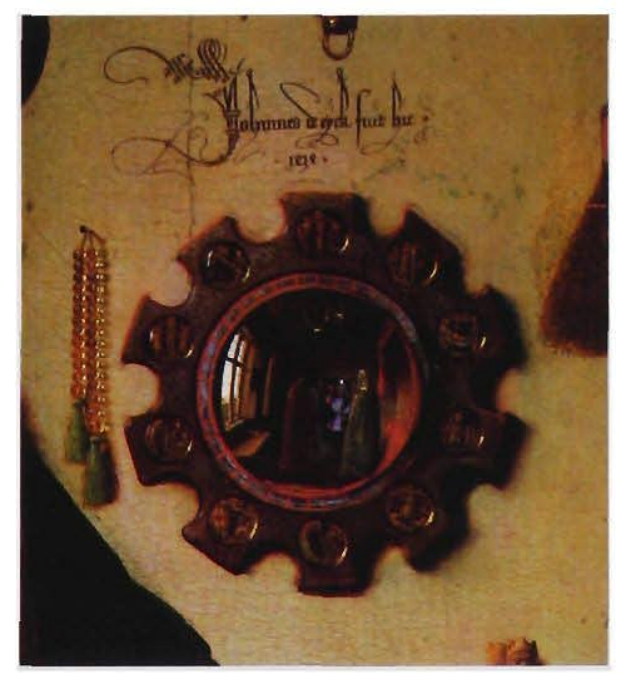

Detail of Giovanni Amolfini and Jeanne Cenami

by Jan van Eyck 1434. London. National Gallery, reproduced from Van Eycti and the Founders of Early Netherlandish Painting. 1994 
The quality of colour and light achieved in the three-dimensional space alluded to the painted surface of Van Eyck's work. The back wall of the set has a red velvet curtain, which covers a cupboard that contains objects of material desire. The chequered floor relates to a perspective device used in countless Renaissance paintings. The mirror reflects the space of the set rather than as in Van Eyck's famous use of a mirror reflecting the reality of the viewer. This provides a sense of the space being a contained world. The set also replicates much of my own world. In VirtuallyREAL the set contains a standard lamp from my childhood, and the red curtains and convex mirror are in my lounge room. The book on Descartes is a reference to my research and the chequered floor is mimicked in plaster on the ceiling in my house. It was through the creation of the set that I understood my connection to the painted image in the context of this investigation and the influence of early Renaissance painting on my work. The work in The Sublime Sleep allows me to discover a context for painting that accounts for my fascination with the art of early Renaissance Netherlandish artists, and how they belong in a postmodern era, more than five hundred years after they practised.

Margaret Wertheim (1999), a noted science writer, claims that the Renaissance and the discovery of perspective were influential in the psychological understanding necessary for the discovery of modern physical space. My investigation of the space of the virtual necessarily needs to account for this influence. Form's environment is a metaphor for the security of the illusion of reality. All the trimmings of materialism appeared in her space, echoing my own desire for comfort found in the corporeal. However as her reality took shape, the voice of Emptiness resounded in the back of my mind. The material Form and her environment appear dialectically opposed to their digital reproductions and Emptiness was the voice that reminded me of this. They were physical and the representation of them was not. This dialectic developed in the dialogue that ensued between Form and Emptiness, which drew on and extended my interpretation of the virtual and the sublime. The philosophical interpretations of the sublime were played out in this arena and my definition started to take shape as the work progressed. 


\section{CHAPTER THREE: THE REALITY OF ILLUSION}

\section{The Truth of the Illusion}

Interpretations of the sublime have flaws to the extent that they rely on a universal sensation or site for the sublime. They are confounded by the deconstruction of the truth brought about by postmodern debates. Postmodernism is a loose term these days to describe something in which we are embedded. It has many different interpretations all of which rely on a context. In the context of the visual arts, postmodernism has challenged the notion of the history of art being singularly devoted to a white male hierarchy. In common with other disciplines it also questions the idea of truth, and the values of high and low art have been challenged within this debale. In short, art has become freed from the weight of tradition and the modemist presumptions about what is and is not art.

The aspect of this debate that is relevant to this project is the question of truth and I have chosen to look at this from the perspective of illusion as a way to examine the nature of our experience of reality. Baudrillard $(2000)$ writes of the murder of reality in his book The Vital Illusion and claims that we carnot even pose the question of what is real anymore because of the nature of the virtual. The virtual has always existed in some way in the form of illusion in art and I claim that while Gombrich, in his book, Ant and Illusion (2000), traces the history of illusion in art, this history can he vicwad also as the illusion of 'a reality'. One could ask; which reality? If the history of the development of the illusion of reality is viewed from the perspective that artists were not attempting to describe a fixed reality that was out there, instead they were creating the illusion of reality in order to question our perception of the truth, then the history of representation can be viewed as moving from depictions of illusions of the truth to representations of an abstract reality; an undifferentiated reality in which the viewer can create

Form: I am looking, I keep telling you I am looking, but I can't see what you mean.

Emptiness: You look in the cupboard outside yourself instead of the cupboard inside. 


\section{CHAPTER THREE: THE REALITY OF ILLUSION The Truth of the Illusion}

Interpretations of the sublime have flaws to the extent that they rely on a universal sensation or site for the sublime. They are confounded by the deconstruction of the truth brought about by postmodern debates. Postmodernism is a loose term these days to describe something in which we are embedded. It has many different interpretations all of which rely on a context. In the context of the visual arts, postmodernism has challenged the notion of the history of art being singularly devoted to a white male hierarchy. In common with other disciplines it also questions the idea of truth, and the values of high and low art have been challenged within this debate. In short, art has become freed from the weight of tradition and the modernist presumptions about what is and is not art.

The aspect of this debate that is relevant to this project is the question of truth and I have chosen to look at this from the perspective of illusion as a way to examine the nature of our experience of reality. Baudrillard (2000) writes of the murder of reality in his book The Vital Illusion and claims that we cannot even pose the question of what is real anymore because of the nature of the virtual. The virtual has always existed in some way in the form of illusion in art and I claim that while Gombrich, in his book, Art and Illusion (2000), traces the history of illusion in art, this history can be viewed also as the illusion of 'a reality'. One could ask; which reality? If the history of the development of the illusion of reality is viewed from the perspective that artists were not attempting to describe a fixed reality that was out there, instead they were creating the illusion of reality in order to question our perception of the truth, then the history of representation can be viewed as moving from depictions of illusions of the truth to representations of an abstract reality; an undifferentiated reality in which the viewer can create. 
Form: Oh cliché, cliché !!!!!! The cupboard within holds nothing, its empty, it's a cupboard of dreams, a void in which nothing is solid. If I open that door I could drown in the vastness of emptiness. I need to hold on to my substance. I need hard evidence, real life, reality.

Emptiness: You open, and open, and open. Trying to find a world other than the one that lies behind the door. Behind the door is the darkness of depth. The falling world. The world of hurtling objects, pointed and prismed to reflect you back at yourself. The cupboard is a jungle of dangerous implements, dancing like shadow puppets, an ogre of hollowness. And as you reach in to touch the thingness your whole arm disappears into deep and howling loss. You can't see, can you? That you are falling into all your doubt.

Falling, a phenomenon of objects. Unknown to being.

Form: I cradle my most precious object. It aches in my chest.

\section{Perspective}

Ironically, the more strikingly real an image is the mene uncken of la

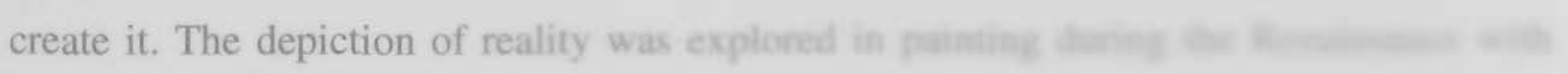
the invention of perspective. The ability to create accursuc persecto key to the mastery of illusion on a two dimensional surfaxe The knp be

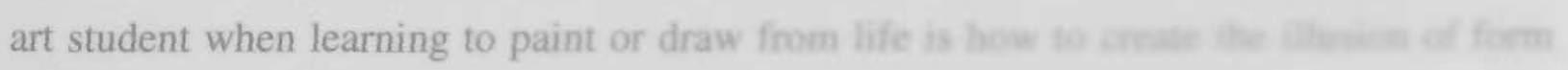

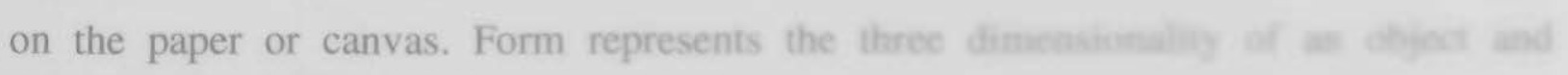

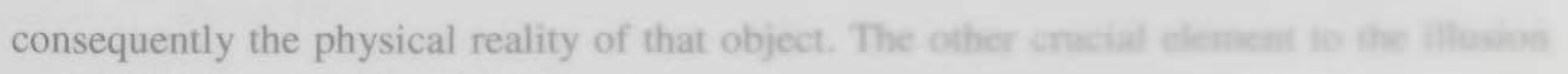
of reality is space. The three-dimensional object must exist in squece. Antanepte at itse accurate depiction of space were made in fourtecnth century lialy, however, if was nat until the $15^{\text {th }}$ century that Brunelleschi developed a consistent system that demonstrated all the spatial elements in a picture based on repeatable foundations. Amtonio Manetti (1413), Brunelleschi's biographer, believed that the discovery of perspective was made in the early phase of Brunelleschi's career (Kemp 1990). Manetti recorded descriptions of two paintings by Brunelleschi that demonstrated his mastery of perspective, The 


\section{Perspective}

Ironically, the more strikingly real an image is the more tricks of illusion are employed to create it. The depiction of reality was explored in painting during the Renaissance with the invention of perspective. The ability to create accurate perspective in a painting was key to the mastery of illusion on a two dimensional surface. The first lesson learnt by the art student when learning to paint or draw from life is how to create the illusion of form on the paper or canvas. Form represents the three dimensionality of an object and consequently the physical reality of that object. The other crucial element to the illusion of reality is space. The three-dimensional object must exist in space. Attempts at the accurate depiction of space were made in fourteenth century Italy, however, it was not until the $15^{\text {th }}$ century that Brunelleschi developed a consistent system that demonstrated all the spatial elements in a picture based on repeatable foundations. Antonio Manetti (1413), Brunelleschi's biographer, believed that the discovery of perspective was made in the early phase of Brunelleschi's career (Kemp 1990). Manetti recorded descriptions of two paintings by Brunelleschi that demonstrated his mastery of perspective, The 
Baptistery of St John and The Palazzo de Signori. The Baptistery is an octagonal building and Brunelleschi is said to have reconstructed it with scientific accuracy.

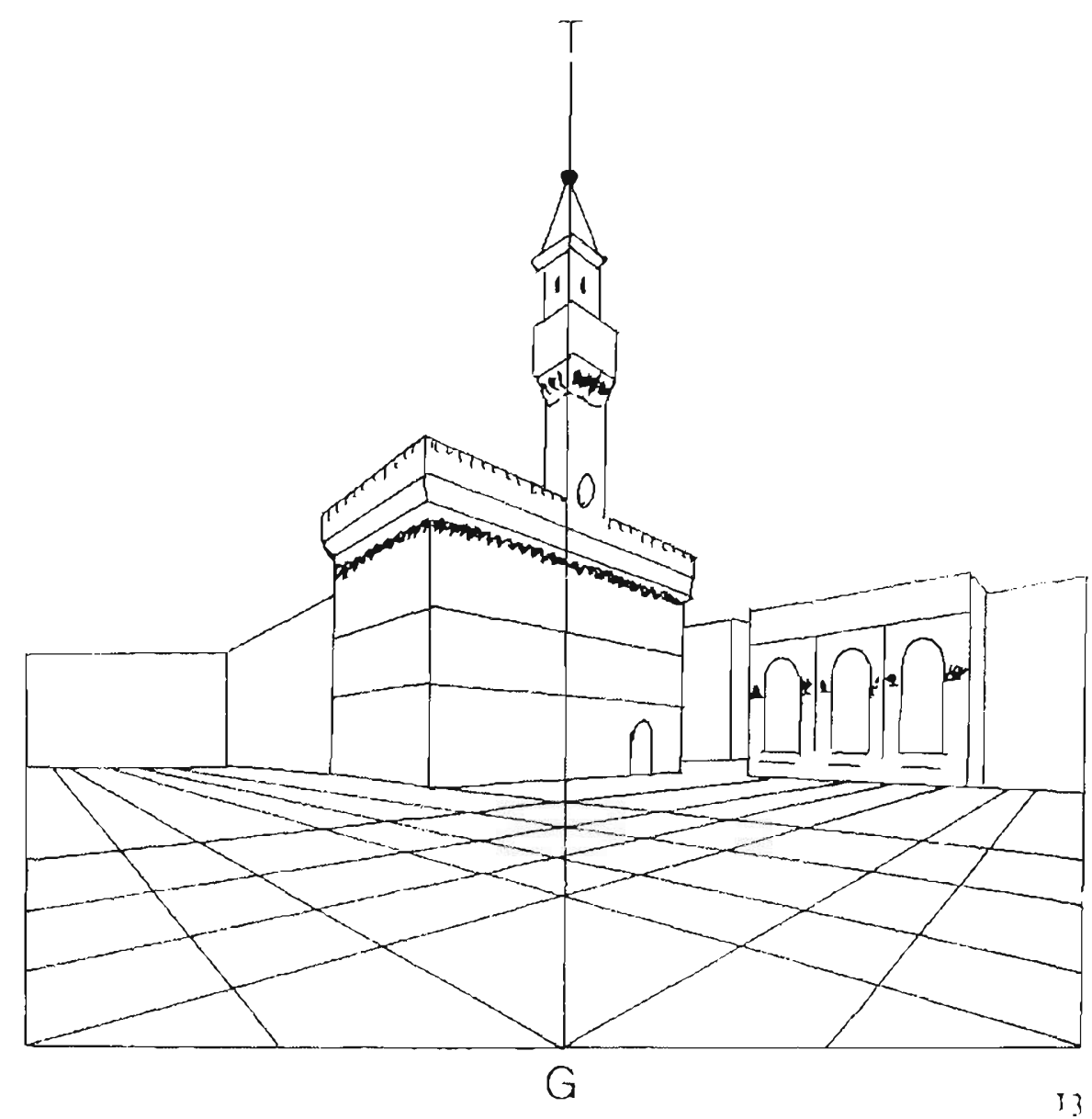

Diagramatic reconstruction of Brunelleschi's perspective

demonstration of the Palazzo de' Signori, Florence (Kemp1990, p.13).

reproduced in The Science of Art, Optical themes in western art from Brunelleschi to Seurat, by Kemp M,1990 


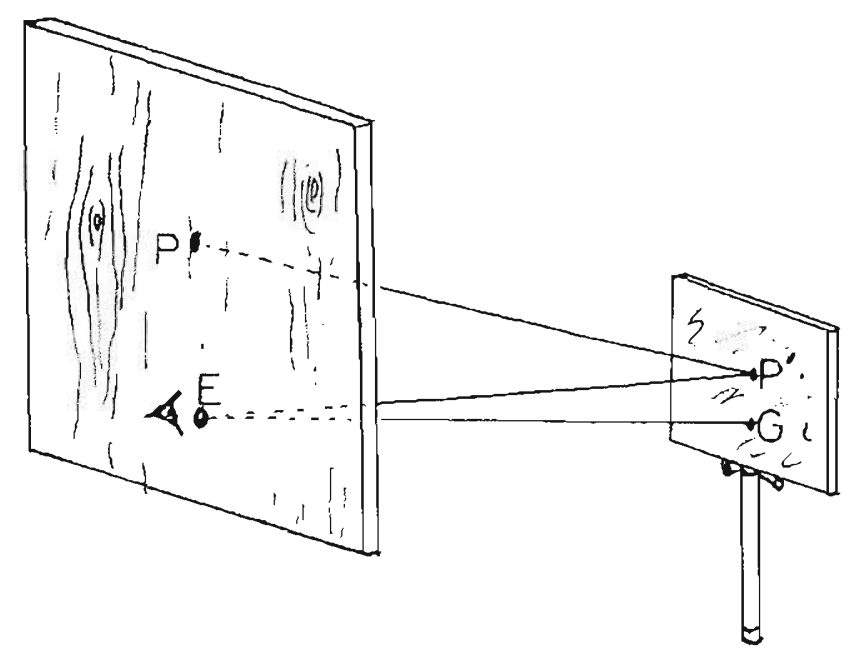

Brunelleschi's peep-hole and mirror system for viewing his perspective demonstration of the Florentine Baptistery (Kemp 1990, p.13) reproduced in The Science of Art, Optical themes in western art from Brunelleschi to Seurat, by Kemp M,1990

To add to the illusion he used a peephole device that which determined the exact position of the viewer. The Baptistery of St John was painted on a panel of wood approximately thirty centimetres square. He drilled a small hole in the back of the panel at the point where his line of sight met with the Baptistery. He placed a mirror half the dimension of the painting at an angle in front of the panel in such a way as to reflect the surface of the painting. To add to the illusion he covered the painted area of the sky with a reflective surface so as to reflect the real sky. The viewer was to peer through the back of the painting to see its image in the mirror.

In the second demonstration painting, The Palazzo de' Signori, Brunelleschi cut away the skyline to be able to verify the accuracy of the perspective. He was able to match the outline of his painting with the lines of the actual building. Although there is a record of Brunelleschi's achievement, there is no record of how he made this breakthrough. He applied his principles to existing buildings. Most artists of the time were not recording reality but attempting to paint imagined scenes. Therefore, Brunelleschi's principles were not widely adopted for some time. Kemp (1990) claims that it was not until Masaccio's Trinity (1426) that true linear perspective is evidenced and he believes that Brunelleschi played a part in this young painter mastering the 
technique. From an analysis of Masaccio's fresco, Kemp has reconstructed this imagined space using plan and elevation drawings. While this was possible in such a painting it was not possible in others as the inadequacies of one-point perspective became apparent.

Kemp discusses Leonardo's distinction between natural perspective and artificial perspective. Natural perspective is the measurement of the relative size of the actual objects in nature and artificial perspective concerns the artist's projected forms onto a surface, which is subject to its own foreshortening (Kemp,1990). Leonardo drew attention to the impossibility of creating an absolute perspective which can be viewed from any position and claimed that the only accurate perspective has to be viewed from one point, preferably 'through a hole' (Kemp1990,p49).

\section{World View}

Perspective established a way to view the world. The laws of perspective became widely used throughout the Renaissance and the picture plane became the invisible frame before our eyes, from which all perspective lines were drawn. Countless interiors were painted during the early Renaissance that resembled a view into a box with the front wall removed. The technique of perspective was developed to a very complex level throughout the $16^{\text {th }}$ and $17^{\text {th }}$ centuries and many technical devices were developed to aid the artist in producing accurate perspective renderings of reality. Ironically, the technique that gave us visible depth on a two-dimensional plane kept us out of that depth. The image projected onto the picture plane limited our view and kept us separate from the space within the picture. It was a clear breakthrough in the representation of the world on a twodimensional surface, yet the illusion was never really complete in the painting hanging on the wall unless the viewer was directed to a specific position to perceive the work.

The tradition of one-point perspective that developed encouraged the use of peep show devices where the viewers had to put their eyes up to a hole to gain an accurate view. These images were often painted inside a box. Alberti (1435), the well known author of the earliest treatise about painting On Painting, created an early example of an image in a box. Kemp cites a description of a closed box by Alberti's anonymous biographer, which, on peeping through a hole at one end, showed a vast landscape. Dutch perspective boxes were also popular and the master of these was Samuel Van 
Hoogstraten. Born early in the $17^{\text {th }}$ century Van Hoogstraten, described painting as being about illusion and the ability of the artist to fool the observer. In Van Hoogstraten's fourhundred page treatise on painting, Inleyding tot de Hooge Schoole der Schilderkonst (1678), he enthusiastically claimed that the perspective box could create the impression that a figure the size of a finger was, in fact, life-sized (Brusati 1995). Celeste Brusati's in-depth study of Van Hoogstraten's Artifice and Illusion (1995) has highlighted this artist's importance in a twentieth century context. According to Brusati (1995) Van Hoogstraten said of the perspective box that it,

'makes things that do not exist appear to exist and thus deceives in a permissible, pleasurable and praiseworthy manner' (Van Hoogstraten, (p.25) in Brusati 1995, p. 170).

Brusati notes that these boxes were seen as experimental works of art at the time and were marvelled at for their clever illusions. The most accomplished of Van Hoogstraten's boxes is thought to be the Perspective Box with Views of a Dutch Interior, which currently resides in the National Gallery of London. 


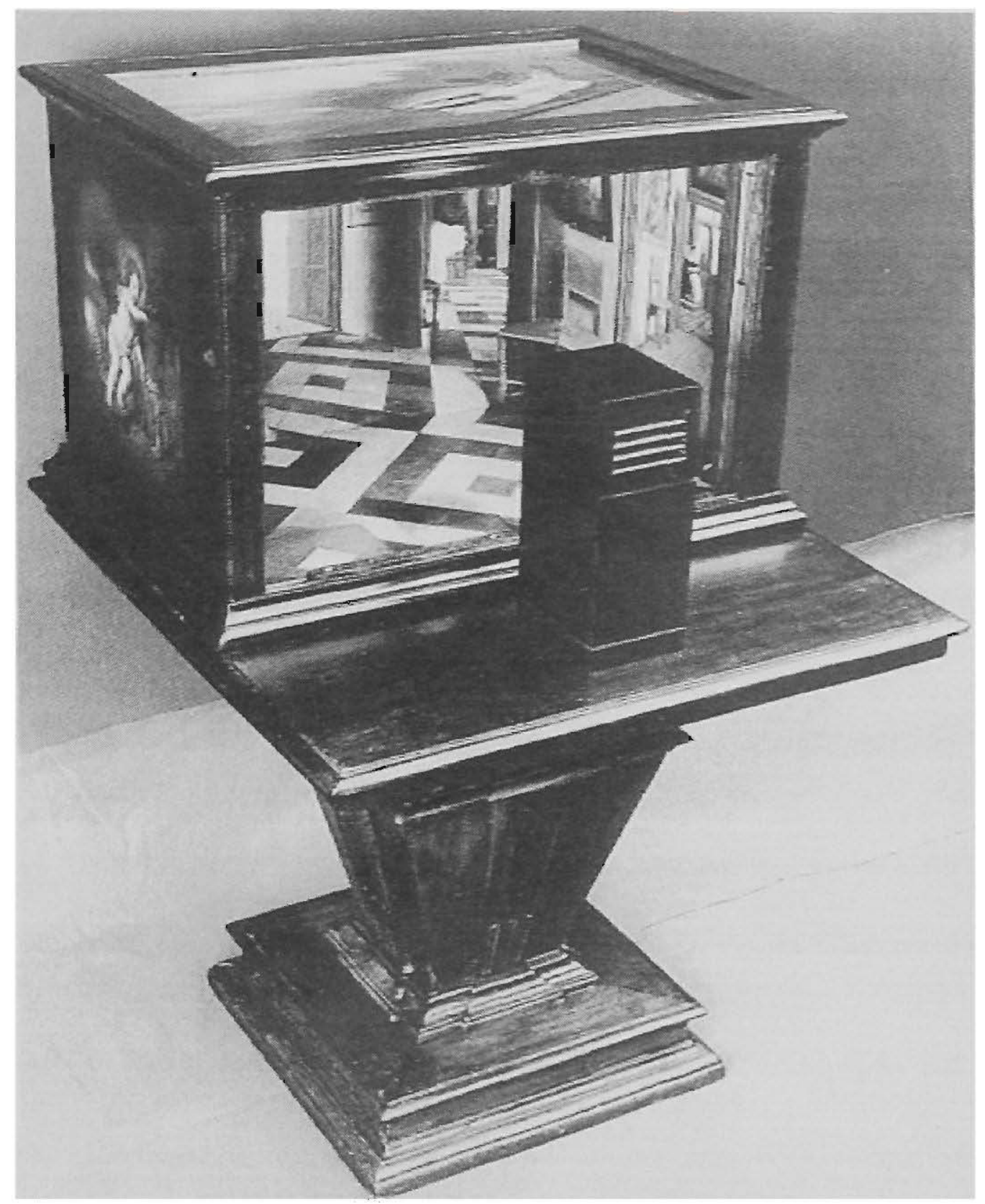

Samuel Van Hoogstraten, Perspective Box, 1756, National Gallery London, reproduced in Artifice and Illusion: The art and writing of Samuel Van Hoogstraten, 1995 

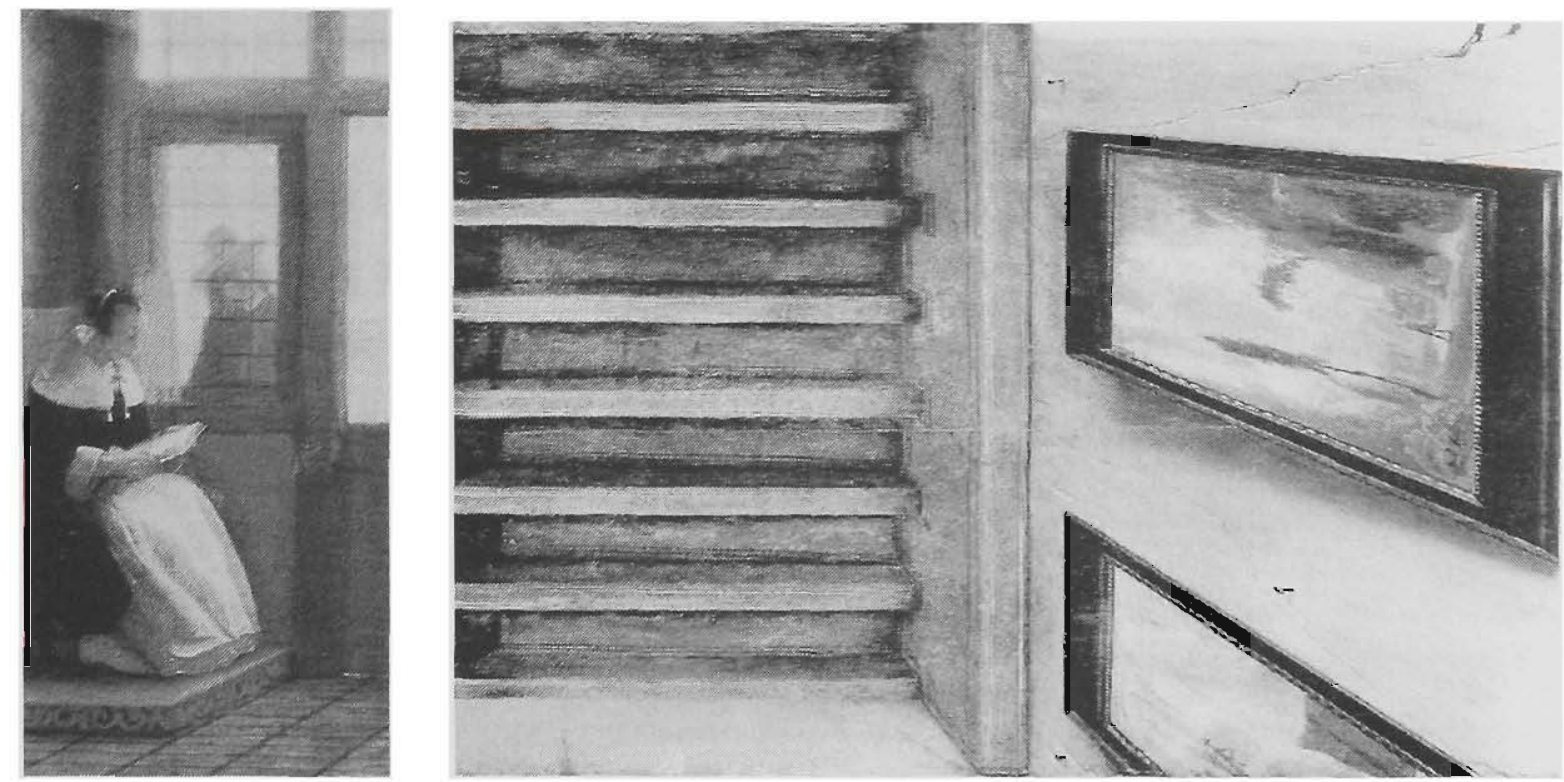

Samuel Van Hoogstraten, Perspective Box, 1756, National Gallery London, Details reproduced in Artifice and Yllusion: The art and writing of Samuel Van Hoogstraten, 1995

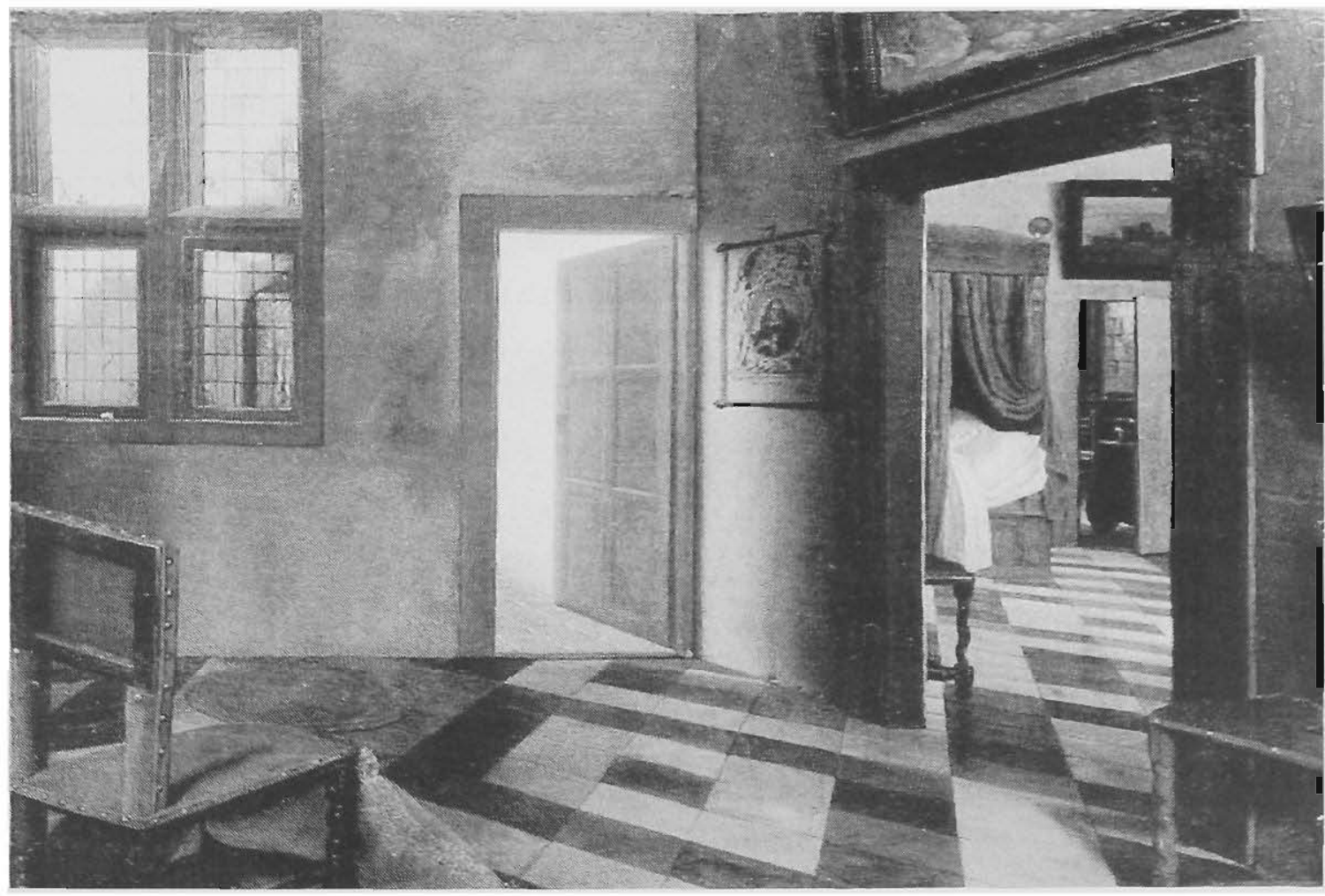

Samuel Van Hoogstraten, Perspective Box, 1756, National Gallery London, Detail reproduced in Artifice and Illusion: The art and writing of Samuel Van Hoogstraten, 1995 
This box is approximately two feet high, three feet wide and two feet deep. It has an open front and two peepholes at either end allowing a view inside from either direction. The inside of the box is painted so that when viewed from the two peepholes it gives the illusion of $3 \mathrm{D}$ space that extends beyond the walls of the box. Through open doors and windows you can see into nine different spaces. Looking into the box from the left side the viewer sees through a doorway that leads into an outdoor garden area seen through several windows. The apparent adjoining wall has a doorway through which two rooms are visible, the furthest has a woman seated by a window reading a book. A man is visible, peering through the window unnoticed by the woman. Each room is adorned with paintings and furniture of a relatively middle class Dutch family. A mirror on the wall between these rooms adds another perspective. When viewed from the right side the viewer is brought into the space as the invisible subject of a dog's gaze. The dog appears to sit in the middle of the room. The viewer is a virtual inhabitant of the house and can see through another two rooms to the outside of the house.

The illusion is also scattered with metaphors and symbols that seduce the viewer as a ghostly inhabitant, to a disembodied state. Brusati calls the deception of the eye an aesthetic conquest and points to 'art's power to seduce and gratify the desirous eye'. (Brusati, 1995 p.181).

'The fantasy of ocular ubiquity offered by the perspective box not only gratifies but also disarms and disembodies the viewer, for the box's seductions and possessions are not available to an embodied beholder but only to the eye placed at the peephole' (Brusati, 1995, p.182).

Van Hoogstraten clearly aims to create distrust in the viewer of their perception of reality as the front of the box is left open to expose the illusion.

\section{Moving Illusions}

According to Brusati (1995) Van Hoogstraten's fascination with the illusion of reality extended to the camera obscura. Like Descartes, he saw the camera obscura as modelling the phenomenon of vision. Rather than seeing the eye as a recorder of reality, an 
intersection of the transparent pyramid, as Alberti and the Italian Renaissance masters of perspective did, Van Hoogstraten conceived of images as a counterfeit of vision; the eye as the location of the image which was produced in and by its seeing.

'I have seen this very thing done quite marvellously in Vienna at the residence of the Jesuits, in London by the river and in other places as well. In Vienna I saw countless people walking and turning about on a piece of paper in a small room; and in London I saw hundreds of little barges with passengers and the whole river, landscape and sky on a wall, and everything that was capable of motion was moving' (Van Hoogstraten, p.263, in Brusati, 1995, p.71).

This could be seen as a presentiment of moving images in the cinema and eventually virtual reality. Brusati claims that Van Hoogstraten distinguished between visible nature and nature; visible nature being the appearance of nature before the eye. He analyses nature, what he calls our everywhere present masterpiece in terms of its visible elements; colour, shape and form. In Van Hoogstraten's terms, visible nature changes depending on where and when it meets the eye. He describes perspectives that are not constrained by the physical limitations of the body. He places the eye at the centre of a circular field of vision.

'The picture here is treated as a replica of a piece of the world being seen and pictured by an eye in the world' (Brusati, 1995, p.185).

Brusati notes that this approach to perspective allows for countless vanishing points created along a single horizon line. This enables the stationary viewer to move their sight along that line, to look about so to speak, and to create a panorama in the mind by adding multiple images together, in much the same way that the movie camera did later. Brusati claims that this demonstrates that the eye actively creates images and at the same time is deceived by them. 


\section{Boxed Perspective}

In 1993 I produced a series of boxes for an exhibition called Inexternal. The boxes presented the idea that the internal experience of the world is in every way connected to the external experience; that perception of the world is an act of creation and there is no unmediated external world to be objectively viewed. I used the metaphor of a shell to depict the complex enfolding of the internal and the external. The boxes were the containers for real objects as well as illusions of objects that implied the transient nature of life.

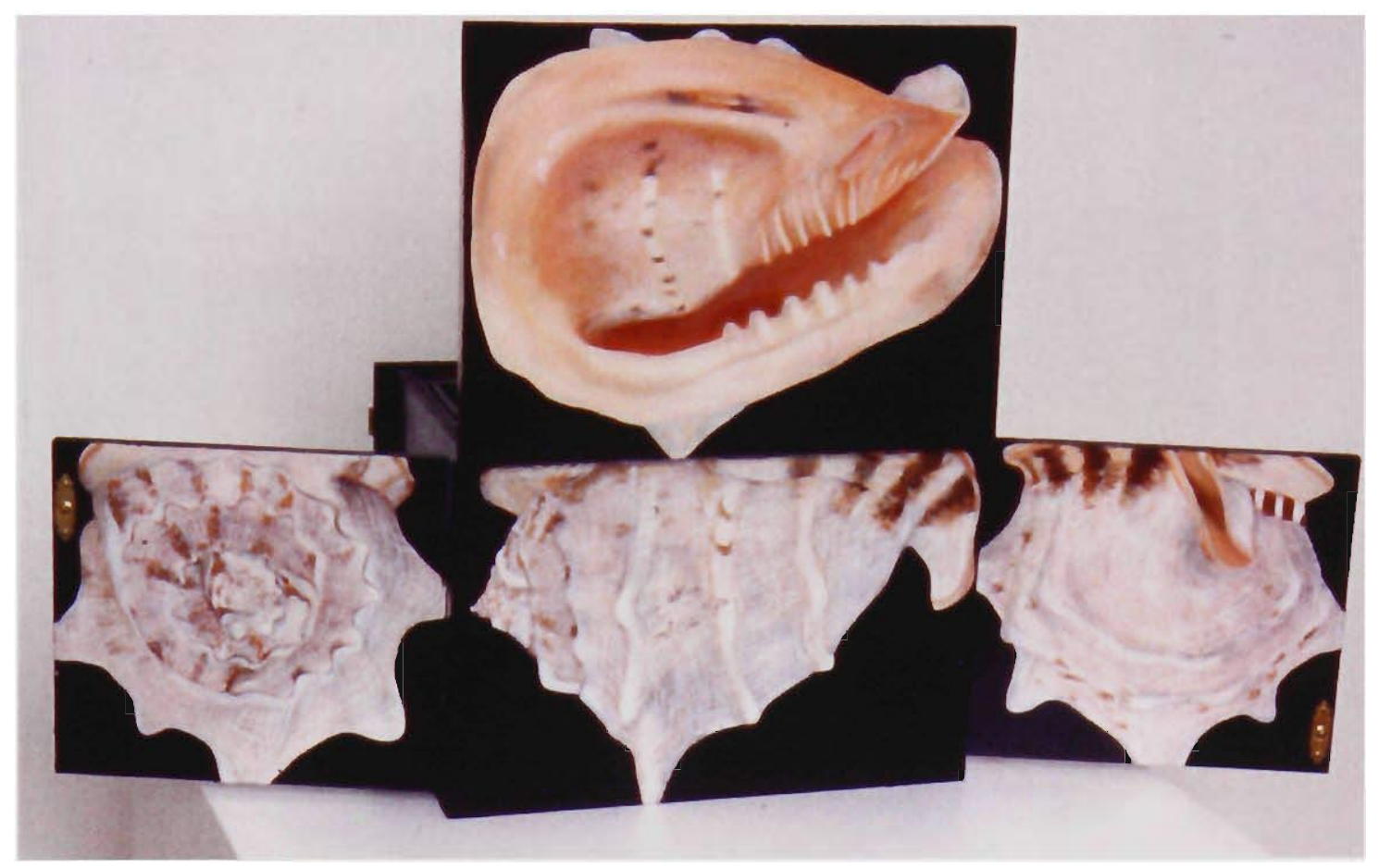

Inexternal, outside view, by Megan Evans, Oil on wood, 1992

Photographed by Flick Evans 


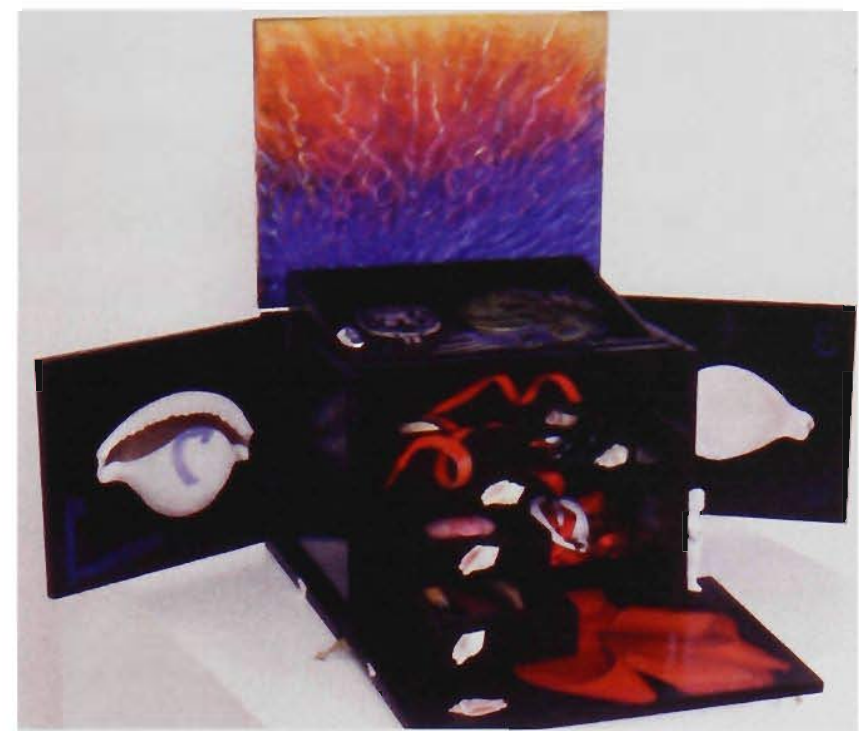

Inexternal, inside view by Megan Evans,

Oil on wood, found objects, 1992

Photographed by Flick Evans

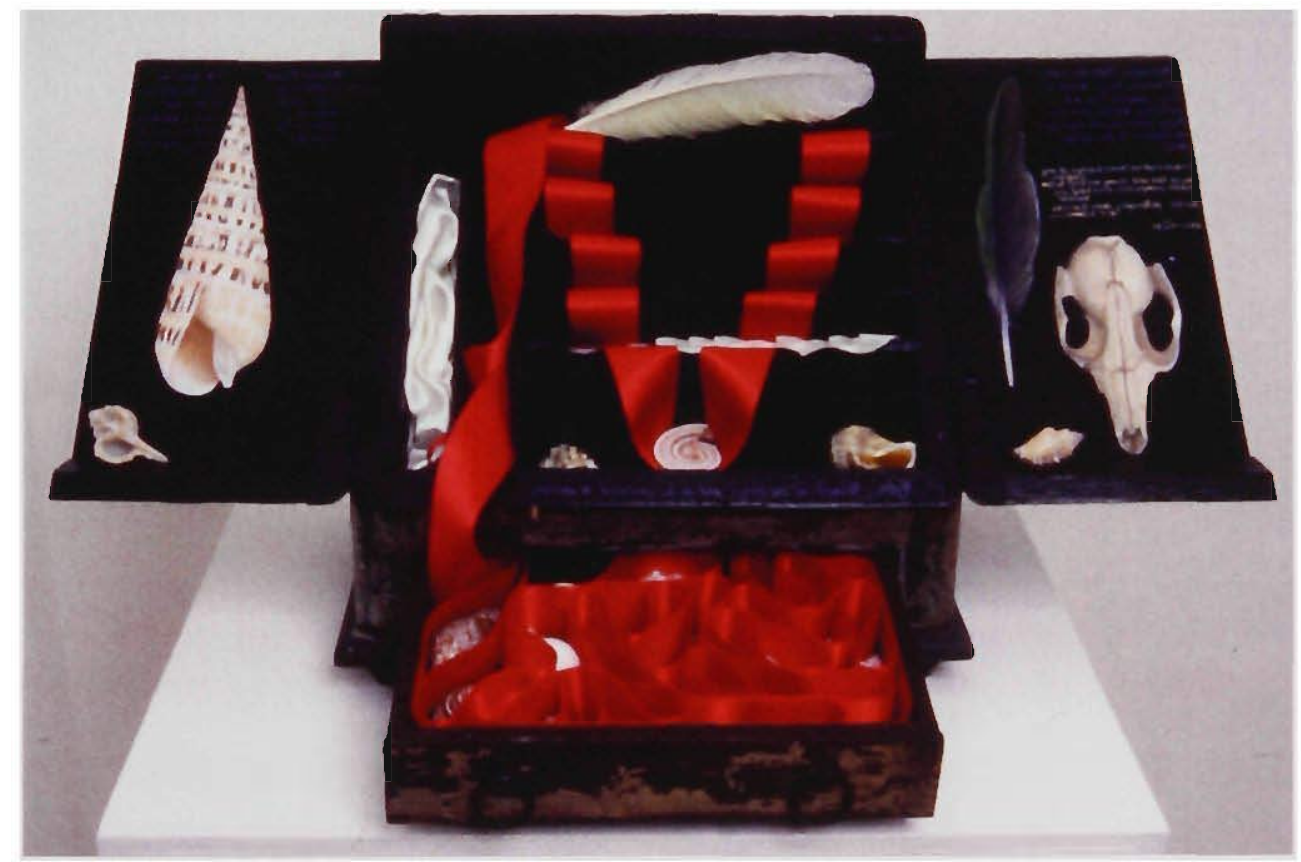

'Context, Internal installation' by Megan Evans, oil on Wood and found objects, 1992.

Photographed by Flick Erans

Inexternal was a contemporary still life in a box that deceived the viewer by mixing the material or physical with the illusive. The perspective box is a bodily experience of this 
concept attained by dislocating the eye from the body of the viewer. The scale of the view is not apparent to the viewer because their body bears no relation to what they are seeing. Their body is locked behind, and invisible to, the viewing eye. The viewer is both excluded physically from the box and included virtually into the space. The scale is only related to the measurement of the eye. This is in opposition to the Renaissance concept of the perspective picture that separated the viewer and the viewed.

'Instead of looking through a window onto a world, the viewer of the perspective box is offered a replica of the picture making activity of the seeing-eye. Rather than being posited at a certain distance from a transparent intersection, the beholder's eye looking through the peephole is situated, like the seeing-eye in the world, at the juncture of the visible world and its representation on the retina. The relation between the seeing subject and the world seen emphasized here is thus one of liminality and self-reflexivity rather than straightforward binary opposition' (Brusati,1995, p.198).

This description is similar to my experience of viewing my reality after the meditative experience of the sublime. The perspective box seduced the viewers into its space: they were invited to become participants in the illusion of reality rather than oursiders aware of the edges of the illusion; the frame of the painting. This mises the question, are we looking through peepholes into our everyday reality and is it actually virtual?

Emptiness: Waking into reality. What a strange place. My hand grasps the glass and flattens fingerprints into clear cold pads. It does not pass through. Does not dip into the surface of the object. The reflection is real, hard, immutable. It is not a reflection. There is substance in this wake. But no it is not a wake, I am adream, and I am waking. At every moment I pull away and try to open my eyes to dream but waking is on me like a heavy coat. In the world of waking I am fixed and afraid. It is a bad wake I want to dream up from it. I am walking down a path to the river, the path solid 
concept attained by dislocating the eye from the body of the viewer. The scale of the view is not apparent to the viewer because their body bears no relation to what they are seeing. Their body is locked behind, and invisible to, the viewing eye. The viewer is both excluded physically from the box and included virtually into the space. The scale is only related to the measurement of the eye. This is in opposition to the Renaissance concept of the perspective picture that separated the viewer and the viewed.

'Instead of looking through a window onto a world, the viewer of the perspective box is offered a replica of the picture making activity of the seeing-eye. Rather than being posited at a certain distance from a transparent intersection, the beholder's eye looking through the peephole is situated, like the seeing-eye in the world, at the juncture of the visible world and its representation on the retina. The relation between the seeing subject and the world seen emphasized here is thus one of liminality and self-reflexivity rather than straightforward binary opposition' (Brusati,1995, p.198).

This description is similar to my experience of viewing my reality after the meditative experience of the sublime. The perspective box seduced the viewers into its space; they were invited to become participants in the illusion of reality rather than outsiders aware of the edges of the illusion; the frame of the painting. This raises the question, are we looking through peepholes into our everyday reality and is it actually virtual? 
beneath my feet. My feet stuck to the bottom of my legs, my whole body clad by the outside. I am in a package. I am like the barbie doll on the shelf in the supermarket, with a plastic moulded see through packet shaped to fit her form. In this wake the river is at the end of the path and the corresponding sounds are undoubtable signs, no bleeding off into fountains of red jelly and melting bookcases. The river is polluted. Bags of rubbish flap in the current and let go of their snag to billow out, like discarded jellyfish. I walk down to its shore, sliding down the slope, fragile, careful not to slip into the water. Water. Water is like being adream. It is fluid my stick disappears as I put it against it. There is no against it. It swallows up the space around an object. This is more familiar. Reflections. Fluid, moving, swimming space. Rippling reality. Wandering waves of fixity. Notions that appear and disappear, revealed and concealed by shifting sands that drift across thought. The walls of my daytime are papered with text that drips in waxen spots onto the tablecloth. Tales told by the looseness of wondering in water. In water I am waking and seem to be adream. I step back from the river in my wake. It still ripples there, silver tree trunks shivering and dissolving in rythmic waves. Perhaps I nearly dreamed up and that is why it all seemed so real for a moment. Now the sensations of this unreal world press in on me, the earth underfoot and the sounds of the sky blowing by in wind that lifts my hair. It pulls gently on my scalp and then falls back on my shoulder like the tapping of a breath. My arm moves back and forth as I walk and the cloth of my shirt creases into my elbow, small ridges that roll into my skin at the inner bend of my arm. The cold of cotton wraps against the upper outside edge of my shoulder, a line in two dimension that makes me feel rubbery and pink. What is this reality. Perhaps I will dream up from this wake and find myself still pressing my flesh, my dreaming that I thought was waking, all an 
illusion and I will be forever trapped in the hard land where everything is fixed.

\section{Painted Eyes' View}

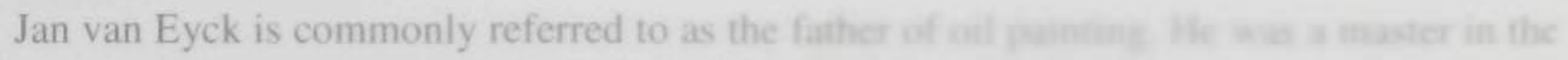
re-creation of reality through illusion. His major works ans warn luege in sale and extremely realistic, recording such detail as the light caught wa a fowif throwa and the reflection in a pearl bead.

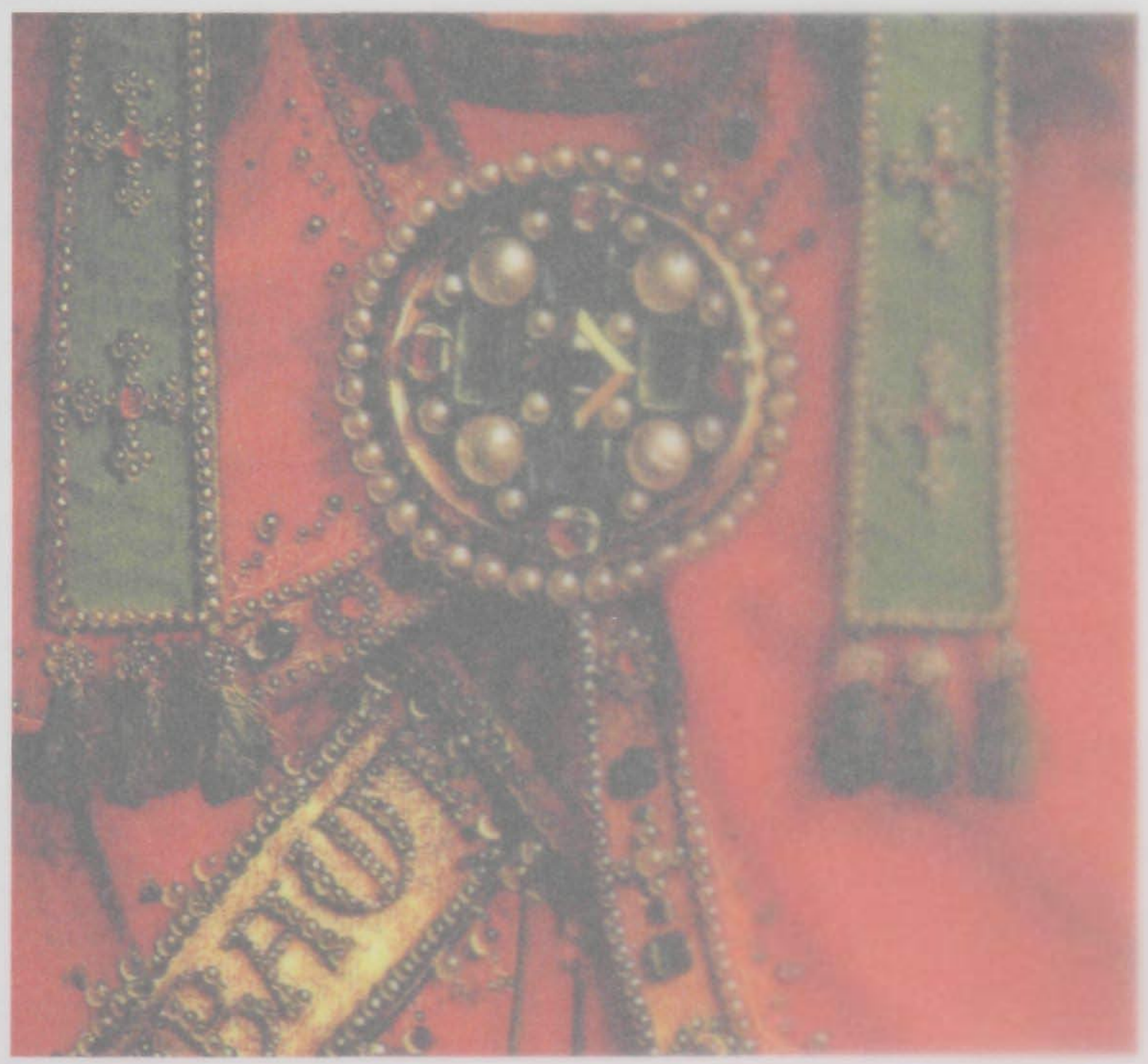

Detail from the Ghent Altar Piece, God the Father, by Jan Van Eyct. 1442 Reproduced from Van Eyck and the Founders of Early Netherlandish Paunuat iney 


\section{Painted Eyes' View}

Jan van Eyck is commonly referred to as the father of oil painting. He was a master in the re-creation of reality through illusion. His major works are very large in scale and extremely realistic, recording such detail as the light caught on a gold thread and the reflection in a pearl bead.

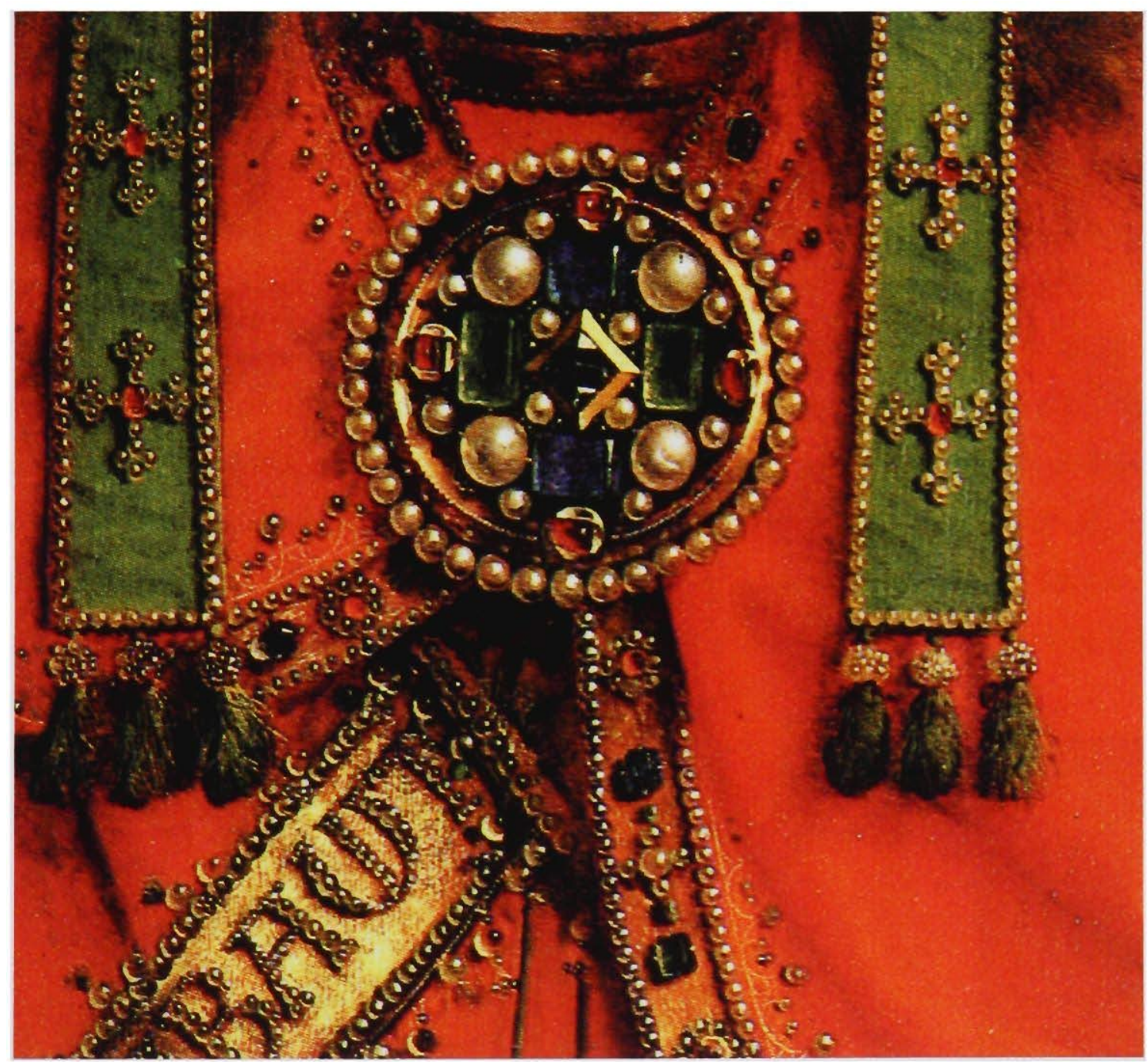

Detail from the Ghent Altar Piece, God the Father, by Jan Van Eyck, 1432

Reproduced from Van Fick and the Founders of Early Netherlandish Painting 1989 
There is also an almost artificial, plastic look that we would associate these days with a computer-generated 3D modelled work. Many of his paintings could be hung in a contemporary collection and would not look out of place because of their scale and slightly surreal quality, which is extraordinary given they were painted early in the $15^{\text {th }}$ century.

Van Eyck and his contemporaries became masterful in using colour to create light-filled paintings. Jan van Eyck used an unknown element in his paintings, which gave them the unusual effect of appearing to emit a light of their own. This was discovered after the Second World War when the Ghent Altar piece was in need of restoration, after examination with the latest equipment it was revealed that he used drying oil mixed with an unknown ingredient. Otto Pacht (1994) claims that it was this mix of ingredients that can account for 'the unique brilliance' (Pacht 1994, p.13) of the painted surface of a Van Eyck painting. Pacht believes that the technical breakthrough. which allowed the colours to glow was only a part of Van Eyck's success in creating paintings that vied with the brilliance of the stained glass windows of the time. The other element was the use of light and shade as a technique in creating credible space in a painting. Medieval painting is renowned for the lack of shadows. Light was represented as a metaphor for the divine rather than as a depiction of material reality. Cast shadows appeared in the paintings of Masaccio in Italy at around the same time as they appeared in the work of the early Netherlandish painters. Once shadows began to appear, the source of the shadows had to be accounted for and so the depiction of naturalistic light became a priority.

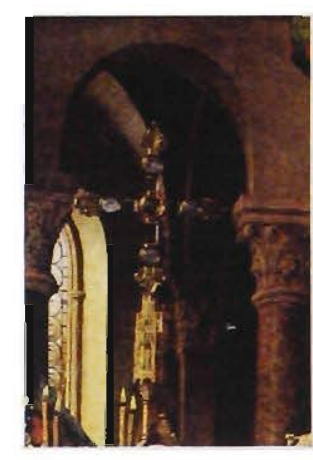

Detail, The Paele Madonna, by Jan Van Eyck, 1436, reproduced from Van Eyck and the Founders of Early Netherlandish Painting 1989 
Jan van Eyck was particularly interested in creating paintings that were a direct representation of what is seen. Painting was known in the Netherlands at the time as "the descriptive art' and Van Eyck, according to Pacht (1994) took this to an ontological extreme. His paintings were created from a single point of view, meaning that the perspective of the viewer was also the perspective of the artist. By concentrating the singular perspective Van Eyck forces the viewer to perceive the image from a certain point, allowing the whole image to be viewed at once as though looking at a photograph. His attempt to still the gaze of the viewer is particularly evident in Lucca Madonna a portrait of the Madonna and child in a small alcove.

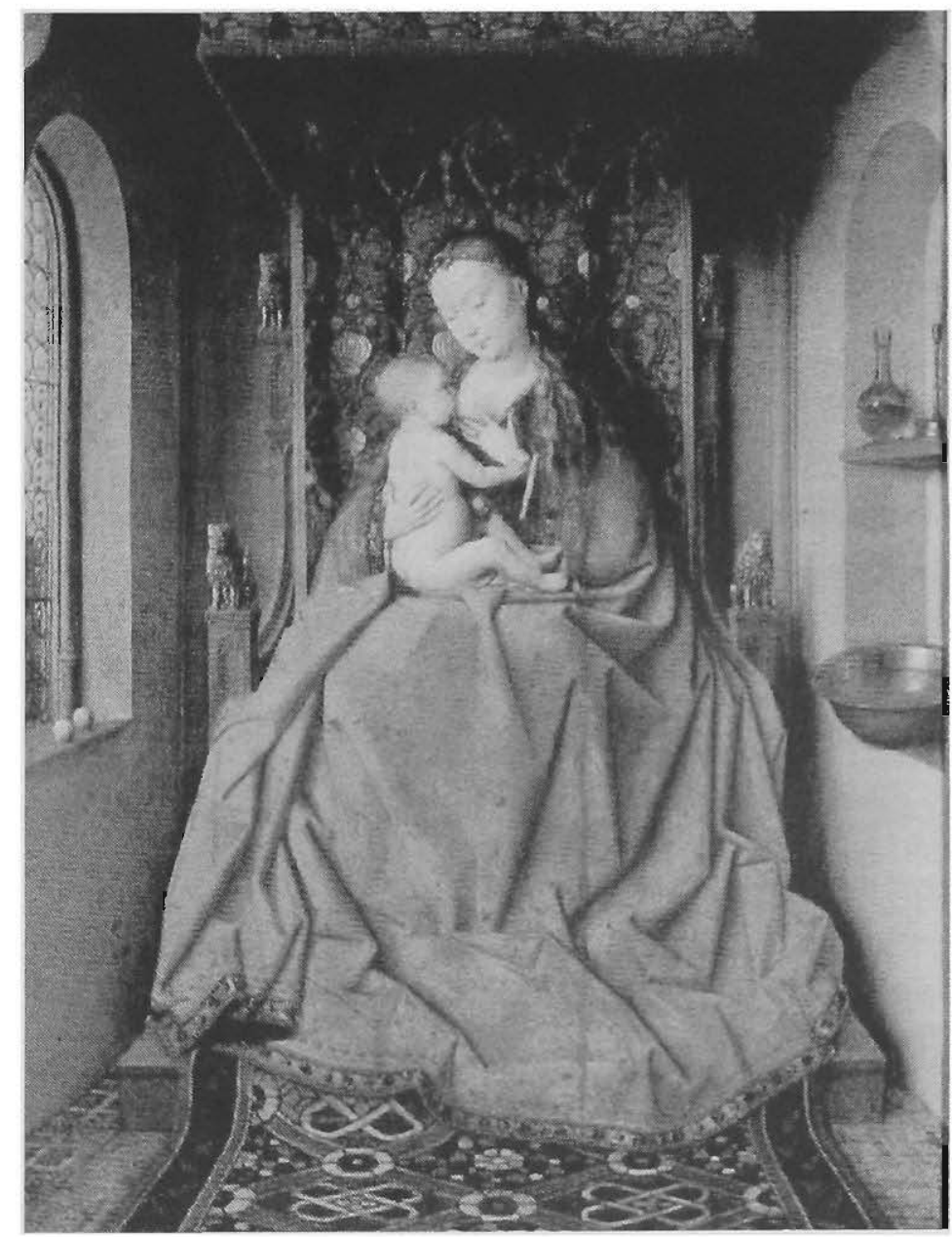

Lucca Madonna, by Jan van Eyck, Frankfurt am Main, Stadelsches Kunstinstitut

Reproduced from Van Eyck and the Founders of Early Netherlandish Painting 1989 
We look up at the Madonna and the viewpoint keeps us from seeing into her lap. The use of perspective foreshortening makes the torso seem unnaturally small. The viewer is encouraged to gaze at the painting rather than look around in it, transforming the picture plane into a screen onto which the reality behind is projected, rather than a window into an imagined reality. Pacht saw naturalism as "pure art, because it relies on the utopian fiction that, in the act of perception, a human being can become all eye' (Pacht, 1994, p.24).

I would call it pure seeing. It is the type of looking that an artist does in order to flatten a three-dimensional world onto a two-dimensional surface in order to give it the illusion of depth. Ironically it is a function of monocular vision that allows for the artist to visually flatten a $3 \mathrm{D}$ view. This function is contained in the stereotypical image we have of the artist holding up a pencil or paintbrush at arm's length and closing one eye. When trained most artists can see in this way without closing an eye. They defocus in a way that eliminates the experience of depth, while being able to see clearly enough to paint or draw what is in front of them.

\section{Van Eyck's Gaze}

Van Eyck draws the viewer into his virtual space by using the technique of one-point perspective. He did not know the rules of perspective as they were later defined, and his use of perspective was not mathematically-based. However he applied the principles based on his own perception of reality. His purpose, in Pacht's opinion, was to slow down the viewer to a meditative gaze. His most well known painting of Giovanni Arnolfini and Jeanne Cenami, has been widely debated regarding readings of its representation. Is it an image of a secular marriage with Van Eyck as the witness, evidenced by his signature 'Jan Van Eyck was here'? 


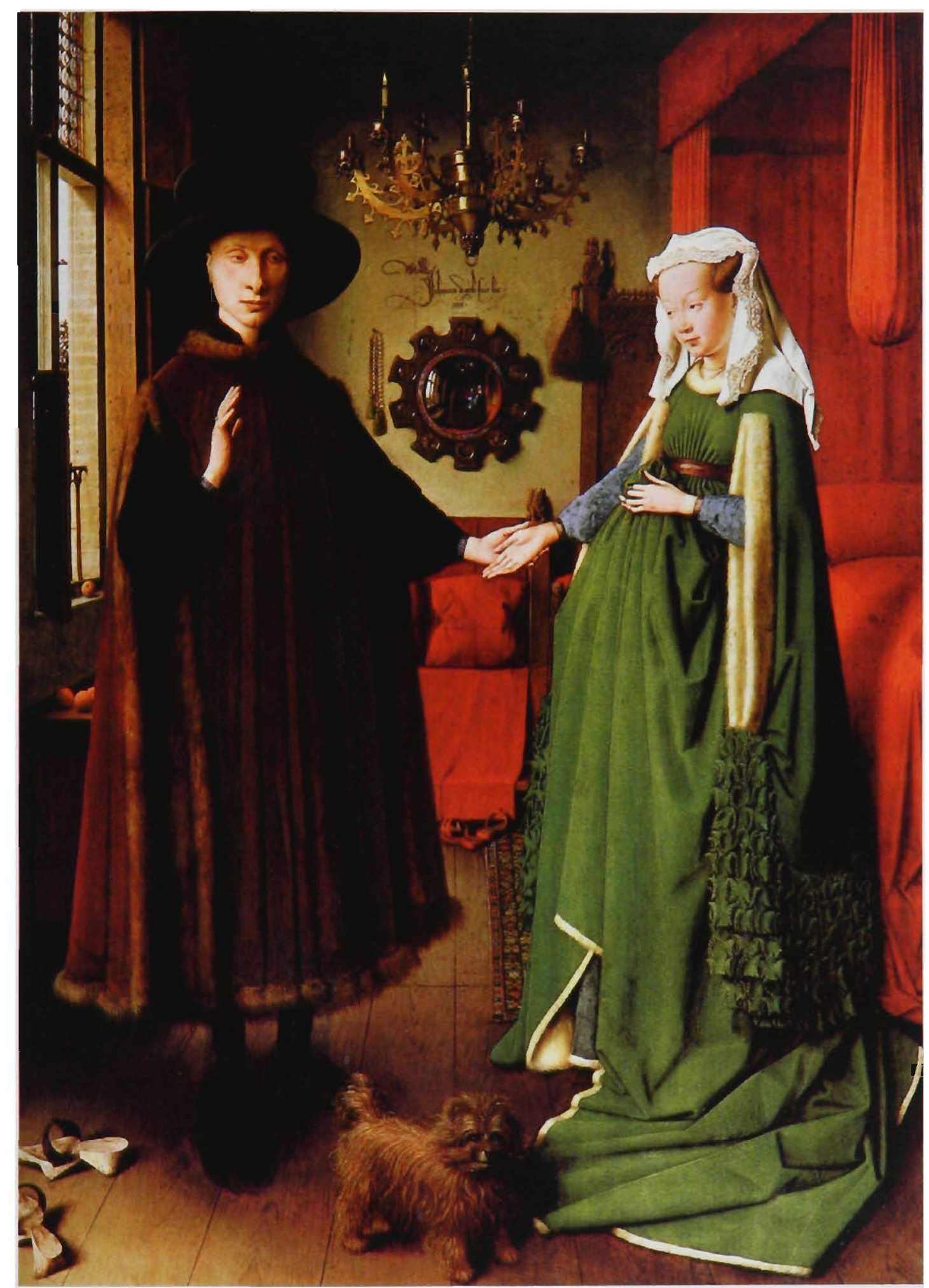

Giovanni Arnolfini and Geanne Cenami, by Jan Van Eyck, 1434, London National Gallery.

Reproduced from Van Eyck and the Founders of Early Netherlandish Painting 1989 
Is he making comment on the existence of the audience by his reflection in the mirror? Hubert Damish claims that this was a common practice in early Flemish painting and served to present different perspectives (Iles 2001). Pacht believes that the artist's interest lay in the creation of a state of being in the audience, a silent state of witness to the present. He likens the painting to the still life genre with the humans being the stil] life.

'For Jan Van Eyck, the stilling of the viewer's, and the painter's eye go hand in hand with the total stillness of the subject painted. Momentariness, in the sense of the capturing of a momentary event, has no place in this painting: this is a secular image of timelessness' (Pacht, 1994, p.30).

Interestingly, although Van Eyck is known as a master in his astounding ability to represent the physical world there are three elements that Pacht identifies as constant in Van Eyck's work which defy this seemingly materialistic bent. The first is images of the Madonna, the second are images of silent spiritual meetings between more than one figure as in the Ghent Altar piece, and the third, portraits of people in particularly peaceful states. All of these are images of stillness. Pacht calls it 'uncompromising uneventfulness' (Pacht,1994, p.31). He says,

'All convey a state of being. Jan's paintings transport us to a still life world in which nothing ever happens' (Pacht, 1994, p.31).

Van Eyck's work commonly refers to a state of being, whether it be stillness, uneventfulness or as a silent witness to the present. While he is creating images of unprecedented richness and beauty that seem to represent the material, they are actually closer in tradition to still life and this questions the materiality and permanence of life. In June 2002 I travelled to Brugge in Belgium to see a major exhibition called The Age of Van Eyck 1430 - 1530. Van Eyck's paintings were almost impossible to see because of the continual crowds pressed up against them. The masterful technique could not explain to me the fascination his work creates nearly five-hundred years after his death. It is my 
belief that Van Eyck's intention in creating illusionistic work was to muse on the illusion of reality.

\section{Plato's Cave}

Plato (427-347BC) described the human condition by using the metaphor of prisoners trapped in a cave. They are watching shadows projected onto the cave wall, a silhouette of unseen objects manipulated by unknown entities, and they believe this to be reality. The illusion is complete in that the prisoners do not know that they are prisoners. They believe this is life and so seamless is the illusion that the gaoler waving a bunch of keys before them, come to set them free does not occur as an opportunity for liberation. This idea is played out creatively in the film The Matrix where humans are grown in pods to create energy for the world of machines. In the film the everyday reality that we recognise, life at the end of the $20^{\text {th }}$ century, is in fact a neural interactive simulation or complex computer program, which creates a world, which hides the human population from the truth that they are slaves.

In Plato's cave the people are prisoners of everyday life. They love the shadowy illusions cast by the flickering of the fire of the physical (Heim, 1993). For them the senses are the ultimate reality, the divining rod to the truth, the highest reality. Plato claims that we, as the prisoners, are only free of the corporeal when we realise that what attracts us in the sensory world is a mere projection of the concepts we hold. We only see a vision of reality when we are liberated from the illusion and this vision is from the mind's eye, which Plato distinguishes from the physical eye. This liberation according to my definition is enabled when one is being present. In this state of being, the space of the sublime is available and the 'mind's eye' is opened. In this space Form and Emptiness are indistinguishable. Similarly, Plato distinguishes the material from the immaterial; two worlds; one the ordinary world of materiality and the other, made up of pure forms, which are eternal and immaterial. The world of forms according to Plato, is the true reality. Form was Plato's manifestation of Pythagoras' mathematical construction of reality. He believed that ultimate reality could not consist of ordinary experience, ultimate reality must be changeless. In the material world life is transient; matter dies and decays. Plato calls this the world of 'becoming' and sees this world as less real than the 
world of 'being' which is the world of pure form. In the world of pure form, Form recognises herself as a part of a whole, a piece in an exhibition.

Emptiness : I see how strange your reality is now that I have been awaking (dreaming) in it. There is no space. Everything is so fixed and solid. In my reality there is all the room in the world to move, there are no boundaries or limits.

Form: If there are no boundaries how do you move. There must be an edge of something or you cannot move through it. There is no it.

Form thinks - Imagine floating, moving through the shining mercury air, and stopping ...... mid movement........ to breathe in .... and out..... yourself. With one long sigh you're inside out and can only right yourself with a sharp gasp, sucking back all that you are, into the skin bag. Imagine pressing your face into the trunk of that tree trunk, too big to put your arms around, and going inside and then out the other side, being tree for a moment, passing through rather than going around, slicing the world of objects like butter, and, like mercury, it will suck its parts back into shape. Emptiness: Think of it like this, maybe you're a painting.

Form: What do you mean?

Emptiness: Well, you know in a painting there is no depth, it is just a flat surface with the illusion of space. What if your reality was the same? How do you know that when you look out at the world, your not seeing many millions of scenes painted to fool you into thinking that there is depth, that there is something out there. Or perhaps it is a painted world that you move about in and at each moment you are a new painting. You think that your reality extends out seamlessly into infinity. How do you reconcile all the other realities that people have, do they bump up against one another, where do they fit? 
world of 'being' which is the world of pure form. In the world of pure form, Form recognises herself as a part of a whole, a piece in an exhibition. 
Form: So your saying I live in a world inside a world. Absurd! I know what's real!

\section{Vital Reality}

Baudrillard (2000) calls the world of Plato's cave the 'vital illusion' (Baudrillard 2000). Reality is being challenged by the concept of virtuality. He sees the technology of the virtual as bringing about the extermination of the real or the destruction of the illusion of the real. Painters throughout history have been fascinated with the illusion of reality but they have never mistaken a painting for reality. No-one believes they can step into the landscape of a Constable. Virtual space challenges viewers to re-evaluate their experience, of the painted surface and contemplate the world from the position, as Baudrillard says, that reality is a concept: 'Illusion is the general rule of the universe; reality is but an exception' (Baudrillard, 2000, p.72). He describes '...the absence at the heart of the world that constitutes the illusion' (Baudrillard 2000, p.71), by using the example of a star and the gap in time between the perceived light of the star and the actual star which is often destroyed long before we perceive its light. His use of the term 'absence' relates to my proposition of a lack of presence. When the world is experienced through concepts there is no ability to be present to one's experience, as that experience is once removed by the accompanying concept of the experience. One is absent from oneself, and direct sensation. Absence or lack of being present, creates the illusion of being an object in a world of objects. In the artwork Form is absent or not present and therefore is characterised as being asleep.

We believe that there is a real world out there and the task of illusion in art is to replicate it. Questions raised by postmodernist critique of the certainty of empirical investigation, and the consequent shaking of the foundations of truth, allows for another reading of illusion in art. Perhaps there has been an underlying agenda, previously unexamined, in the historical fascination with the task of illusion. Representing reality presumes the unquestioned existence of that reality. The clever replication of that reality was generally seen as the primary aim of representation in art in the Renaissance and that assumption remained until the $20^{\text {th }}$ century when the surrealists and the super realists among others, used realism to for other purposes. While representation has been 


\section{Vital Reality}

Baudrillard (2000) calls the world of Plato's cave the 'vital illusion' (Baudrillard 2000). Reality is being challenged by the concept of virtuality. He sees the technology of the virtual as bringing about the extermination of the real or the destruction of the illusion of the real. Painters throughout history have been fascinated with the illusion of reality but they have never mistaken a painting for reality. No-one believes they can step into the landscape of a Constable. Virtual space challenges viewers to re-evaluate their experience, of the painted surface and contemplate the world from the position, as Baudrillard says, that reality is a concept: 'Illusion is the general rule of the universe; reality is but an exception' (Baudrillard, 2000, p.72). He describes '... the absence at the heart of the world that constitutes the illusion' (Baudrillard 2000, p.71), by using the example of a star and the gap in time between the perceived light of the star and the actual star which is often destroyed long before we perceive its light. His use of the term 'absence' relates to my proposition of a lack of presence. When the world is experienced through concepts there is no ability to be present to one's experience, as that experience is once removed by the accompanying concept of the experience. One is absent from oneself, and direct sensation. Absence or lack of being present, creates the illusion of being an object in a world of objects. In the artwork Form is absent or not present and therefore is characterised as being asleep.

We believe that there is a real world out there and the task of illusion in art is to replicate it. Questions raised by postmodernist critique of the certainty of empirical investigation, and the consequent shaking of the foundations of truth, allows for another reading of illusion in art. Perhaps there has been an underlying agenda, previously unexamined, in the historical fascination with the task of illusion. Representing reality presumes the unquestioned existence of that reality. The clever replication of that reality was generally seen as the primary aim of representation in art in the Renaissance and that assumption remained until the $20^{\text {th }}$ century when the surrealists and the super realists among others, used realism to for other purposes. While representation has been 
commonly seen as the task of skilfully describing a world that is out there and examining the content of that world, I propose an alternative interpretation of the intention of representation, creating the illusion of reality to highlight its insubstantial and constructed nature. If we can so vividly create the appearance of distance and form on a flat surface where there is none, then what does that mean about the appearance of distance and form in what we call the real world? Both are a product of our perception.

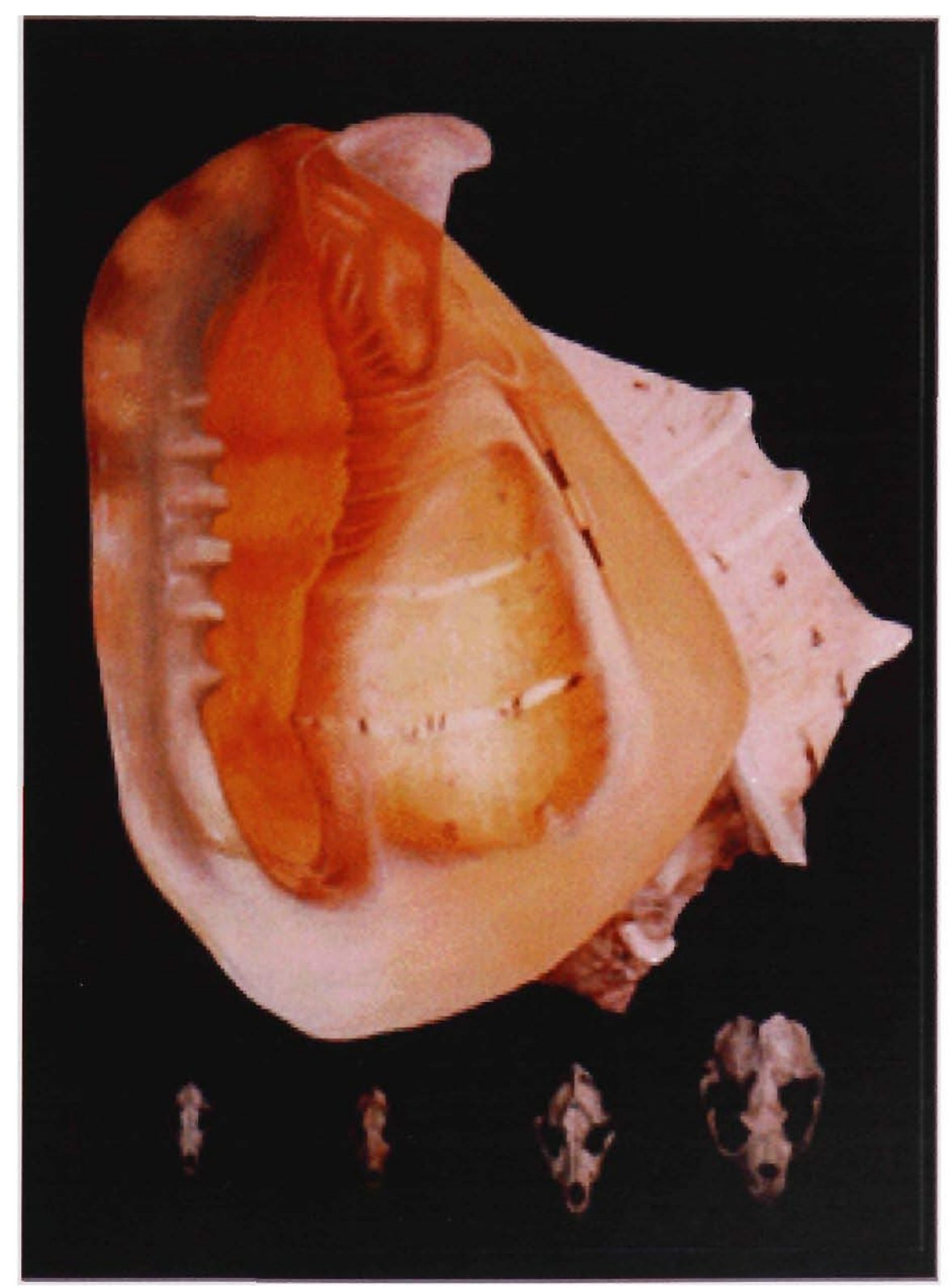

Invitation. by Megan Evans, Oil on Canvas, $8 \mathrm{ft}$ x $5 \mathrm{ft}, 1992$ photographed by Flick Evans 


\section{CHAPTER FOUR: THE SPACE OF PAINTINGS}

\section{Painted From.....}

The character Form was named after the tradition in painting of learning to create threedimensional images on a two-dimensional surface and struggling to capture the illusion of form. Form represents the physical and struggles with the seduction of the material. Her red dress is made of velvet and is a metaphor for the seduction of the illusion of the physical/material. She sews red velvet, frantically sewing all the reci velvet in the world in an attempt to consume her own desire for consumption. However the material is the illusion and her fascination with it keeps her absent from herself and subverts the possibility of being present. She is the potential of Plato's idea of pure form, the ideal or 'being' of an object, however she is unrealised. Her 'being' is the character of Emptiness whose role is to wake up the sleeping Form. Emptiness debates with Form, in an attempt to lead her out of Plato's cave of illusions, to wake her up to a state of wakefulness, being present: the state of the sublime. Emptiness represents both the space of the virtual and the sublime, in the artwork.

The virtual space apparent in the stereoscope images refer to the sublime space discussed in Chapter One. However Emptiness is the ideal of the sublime. Her voice is heard throughout the exhibition space and her lack of physical presence alludes to the space of the sublime. She debates with Form about the immaterial and where she manifests in VirtuallyREAL as a visual entity she is illusive and appears only as an apparition who dissolves frequently. In VirtuallyPAINTED the stereoscopic images are a narrative of stills, capturing moments in time, when Form and Emptiness are engaged in debate. In some images Form is occupied with exploring the consequences of the debate and in some she is engaged in an internal debate that is externalised in the soundtrack. Emptiness sometimes occurs visually in these works and is also represented by the illusion of $3 \mathrm{D}$. 


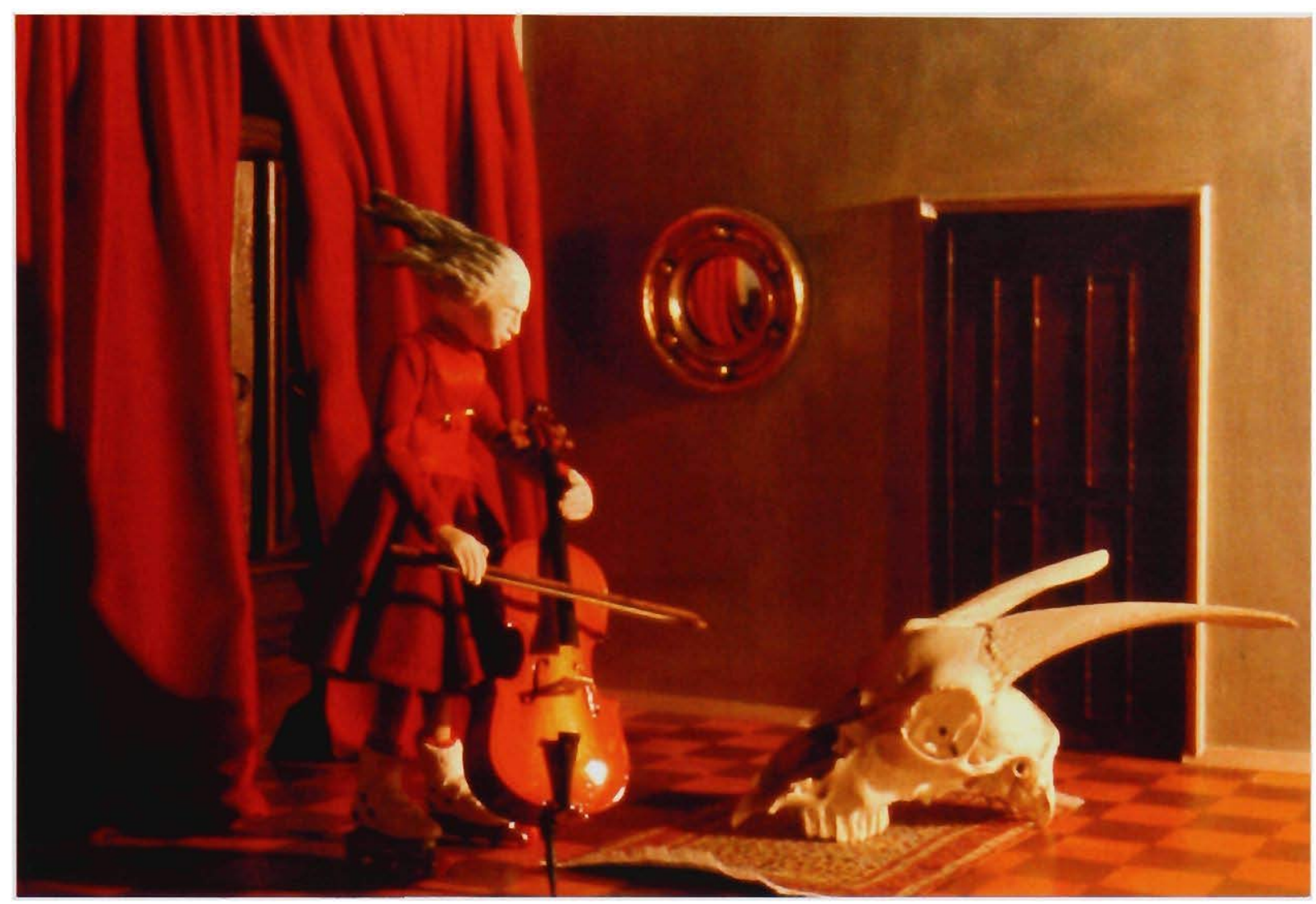

Form plans to the illusion, by Megan Evans, from VirtuallyPAINTED, 2003

When the viewer puts their eyes up to the eyepieces they slip into the space. Their peripheral view is excluded from their vision as they look around inside a virtual space, conceptually, the space of the sublime. These stereoscopic works do not claim to provide an experience of the sublime; they are not able to achieve the levels of immersion required to transcend physicality, however they are representing the sublime as a concept by providing an experience of virtual space, a space that appears to be there but is clearly not. The inverse of this experience is demonstrated by James Turrell's work Arcus, exhibited in Deep Space in 2003. The viewer enters a room and sees what appears to be a glowing blue rectangle on the opposite wall. My first impression was that of a flat wall, lit to create an abstract blue image. On further investigation I discovered that what appeared to be flat was actually a space that had no apparent limit to its depth. I experienced putting my arm into a depthless space. This work supported my view that the space of the sublime is the space in which your experience of reality is disrupted. 


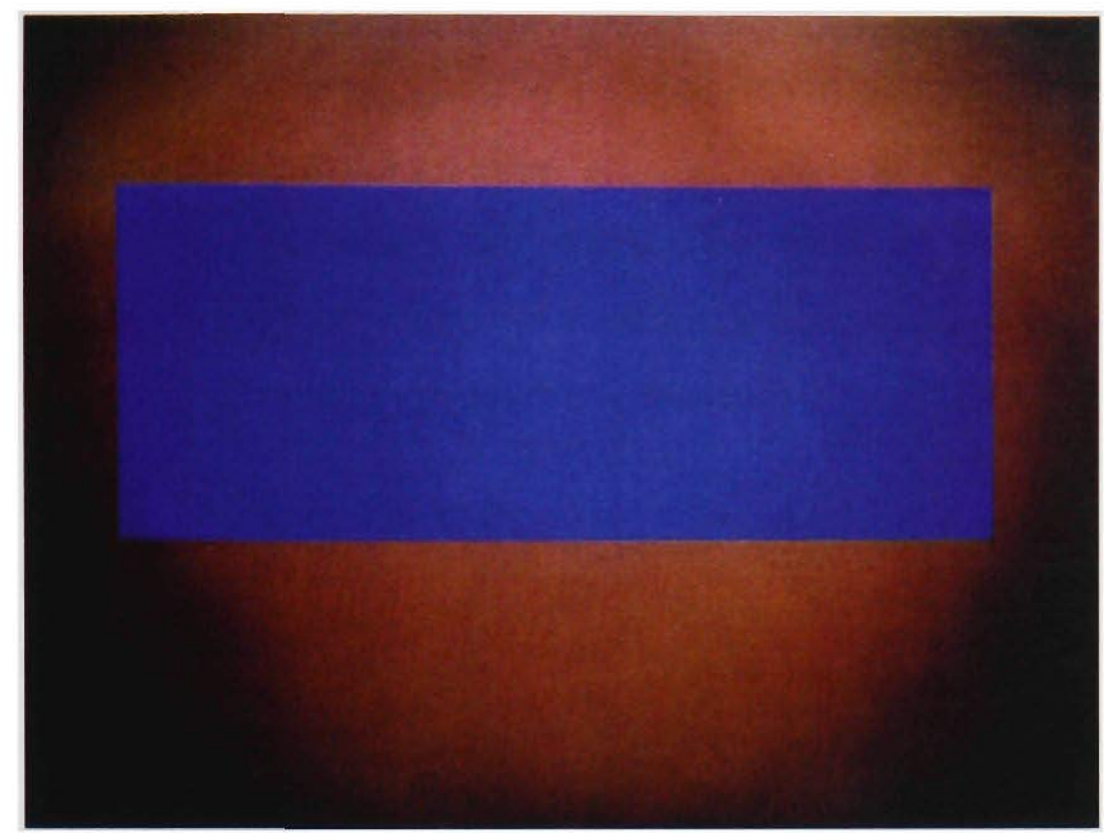

Arcus by James Turrell, 1989

Reproduced from Deep Space Sensation and Immersion,

Art Gallery of New South Wales, 2001.

\section{Double Vision}

When a painting is looked at, the viewer is separate from the world of the painting. It's just another object in the world of objects: peripheral vision of the surrounding environment precludes immersion, keeps the observer objective. When a viewer steps up to view something beyond the surface, something that perceptually allows them into the space, they become disconnected from their environment. In VirtuallyPAINTED, the viewer is enticed into Form's reality through the device of the peephole. Viewer's place their eyes up to the artwork and in that way enter her world rather than stand back and review the work from a distance. Reviewing is symptomatic of viewing a view, whereas Form invites the viewer into the view, somehow stripping them of their own bodily reality for the moment of looking. Their peripheral view of themselves disappears and their only perspective is the world of Form; a virtual space of indeterminate scale. The viewer's awareness goes with their vision into that space. Figuratively, the viewers put their faces into the canvas, stepping into the painting. Moving into the virtual domain gives one an experience of being in a reality, which conceptually we know does not exist. 
The device of stereoscope is used here to create a sense of depth. Using the technique of the earliest stereoscopic photographs, taken around 1841, a single lens $35 \mathrm{~mm}$ camera was used mounted on a slide bar. One shot was taken and the camera was then moved approximately two and a half inches along the slide where another shot was taken. When each eye's view is isolated to each image the binocular ability of the brain creates a three dimensional replica created from dual two-dimensional images.

\section{Sleepwalker}

The technique of stereoscope was employed in Sleepwalker, an exhibition of the work in progress presented half way through my research. It was held at the Centre for Contemporary Photography in Melbourne in July 2001 and involved an installation in the rear of the gallery. There was a large tent-like construction made from black fabric that surrounded a pillar in the centre of the gallery that housed a box with twelve stereoscopic viewing ports. The tent was lined with lush red velvet curtains and a red satin roof and provided enough room to navigate around the pillar and look into the viewers. A soundtrack of music, vocals and sound effects was played inside the tent.

The audience entered the artwork by stepping into the tabernacle-like space of the fabric tent; they were no longer detached. To view the work they had to put their eyes up against eyepieces inserted into a central pillar. These eyepieces revealed a stereoscopic view of painterly scenes of a room, with references to Van Eyck. While witnessing the $3 \mathrm{D}$ view the audience was drawn into the space; bodily reality was diminished for a moment. A total of twelve scenes were presented and as one moved around the lush space, lined with red velvet curtains, a narrative unfolded enhanced by a audio track of sound effects relating to the activities that appeared to be happening in the scenes. The narrative was open-ended and up to the audience to create, however one was left with the distinct impression that the character in the room was moving around and froze each time she was viewed. The work created a paradox of space 


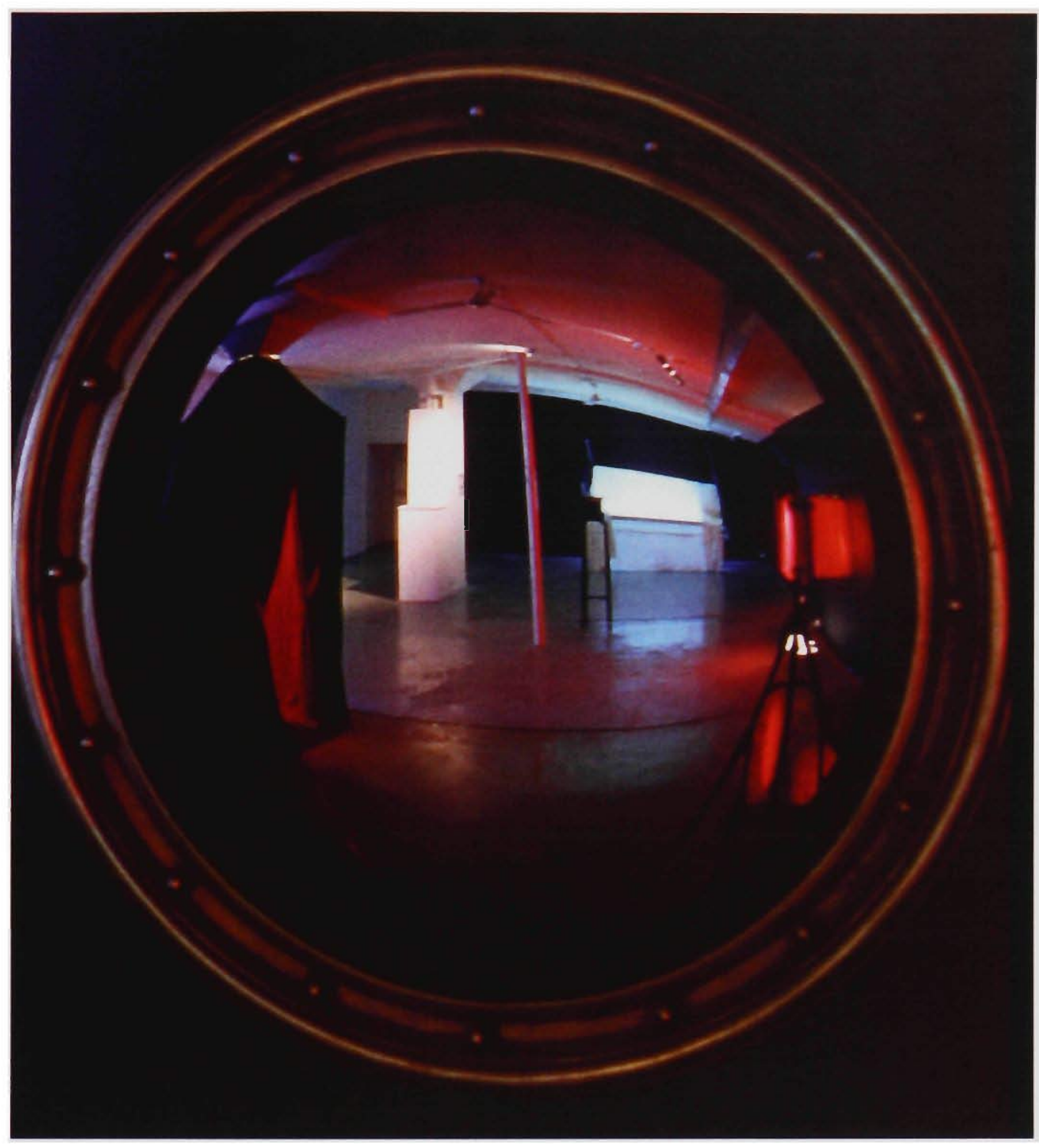

Sleepwalker installation, Centre for Contemporary Photography 2001 Photograph by Vicki Jones

The scene in the stereoscopic image was of a room with a checked floor, furniture, a concave mirror and a red curtain. In some scenes the character was a model made of wood and clay, doing everything from roller-skating to rowing a boat out of a cupboard, or having a glass of whisky while reading the Bible. The miniature scale of things did not really register, as everything looked slightly surreal. In other scenes, however, the model was a real person, a recreation of the character Form, with green hair streaming out behind her in a sculpted shape identical to the smaller version. This switching from real to inanimate, from large to small further confused the viewer. A trick of the eye was 
apparent in the three- dimensionality of the scenes as there was plainly no room for the room in the small enclosure and the viewing ports look in at a concrete pillar approximately $45 \mathrm{~cm}$ square. The space was clearly virtual.
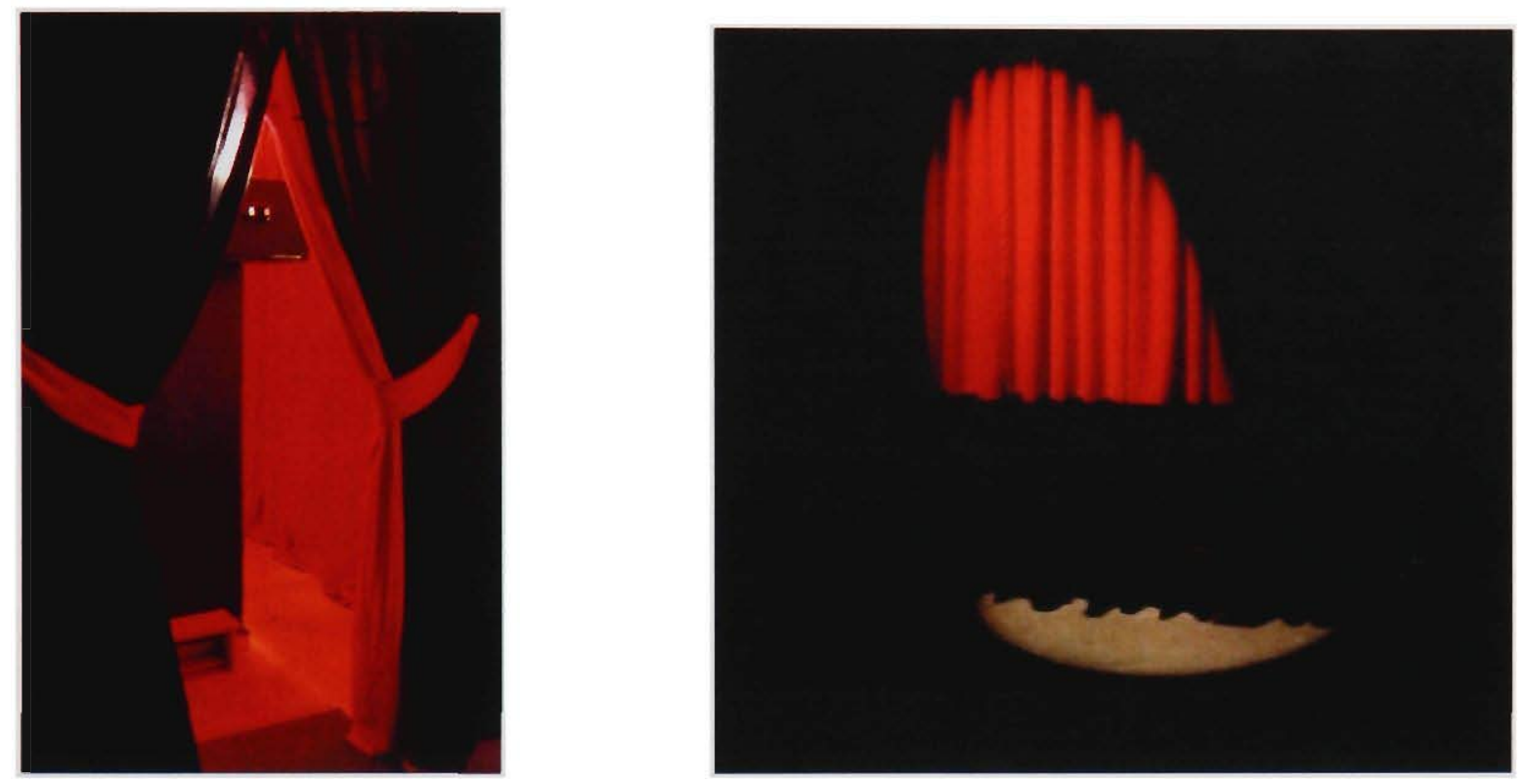

Sleepwalker, details, 2001

Photographs by Vicki Jones

The room outside the tent the room was painted black and, concealed behind a red curtain was a second set of viewing ports. The red curtain was suspended in space, lit with a spotlight in the fashion of a theatre curtain. The audience was unsure whether they were about to witness a performance or were expected to enter the space behind the curtain. The soundtrack drew them in and when in the space their legs were seen below the curtain. The area behind the curtain was black except for the holes of light; the viewing ports into the stereoscopic world of the set. In this work the space was neither entirely virtual nor real. One was expecting the space of a stage and yet the set, which could be the stage, could be entered, despite the illusion of the curtain and spotlight.

Included in the exhibition was a larger than life construction of a cast iron bed suspended from the roof. The surface of the bed was a rear-projection video screen showing the moving surface of a bed, animated by an invisible sleeper. The animation devolved from the moving dint of a person and into a more disturbing and psychological 
animation of ribbon and fabric. The whole piece could be seen in the large concave mirror that hung at the opposite end of the gallery.

The stereoscopic stills led to a desire to animate Form and to play with the scale of the character. I recreated the dress and headpiece of Form in a human scale and worked with a model to photograph and video the character in motion. The stereoscope images of the model were digitally imported into the slides of the space to create the illusion of a life size figure in the set. In The Sublime Sleep, the work SleepWALKER uses footage of the model filmed in the exhibition space. It also includes stop frame animation of the miniature character and depicts the reality of Form, switching from her view of herself as moving about apparently conscious and awake, to our view of her perception, clearly asleep and in a world of dreams.

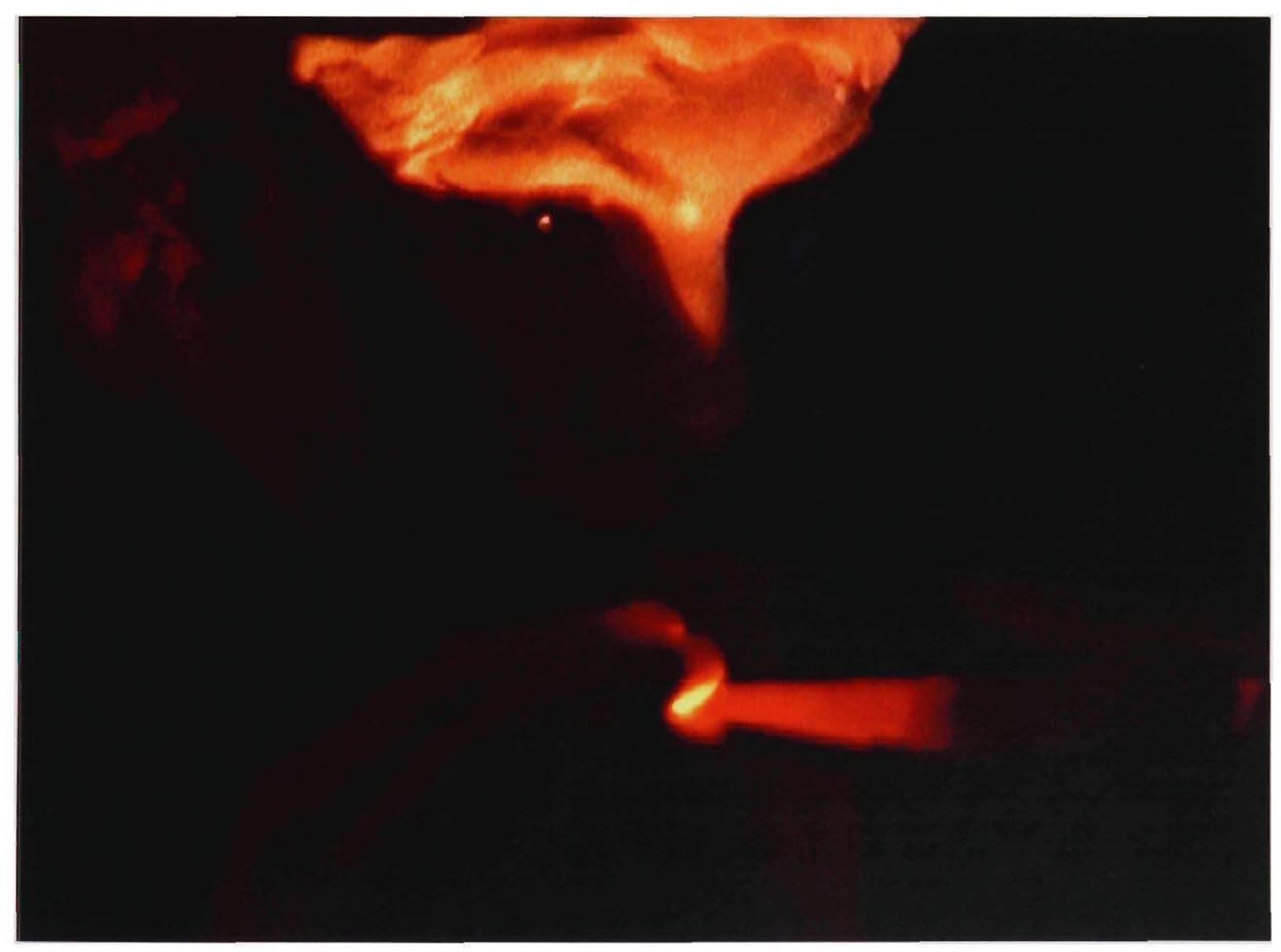

Still from Video of SleepWALKER, by Megan Evans 2003 


\section{CHAPTER FIVE: DISSECTING THE EYE}

\section{Past Vision}

The precedence of early optical tricks has been overlooked in the desire to see virtual reality as a new and revolutionary phenomenon. Batchen (1998) advises that before we leap into the imagined future it is circumspect to look to our past fascination with similar phenomena. To make "- an analytical gesture that would of course replicate the forward but inward stare of the fully equipped cybernaut' (p.274).

The privileging of vision as the key to judging reality was established during the Renaissance when the eye became a resource for the acquisition of empirical knowledge (Kemp 1990). Attempts to enhance the act of perception were made as artists and scientists experimented with technological means to augment vision. Theoreticians now claim that virtual space is not new and has many precedents in the past. Barbara Maria Stafford (Devices of Wonder 2000), says that virtual reality has its precursor in the optical devices that were prevalent in the eighteenth and nineteenth centuries. Margaret Wertheim (1999) calls the Arena Chapel at Padua and the Basilica at Assisi painted in the $14^{\text {th }}$ century early examples of a virtual reality, creating spaces that take people out of themselves. Batchen (1998) cites Allucquere Rosanne Stone, a virtual reality historian who claims to trace the phenomena of virtuality back to the invention of the stereoscope in 1838 with descriptions of 'a dream-like exaltation in which we seem to leave the body behind us and sail away into one strange scene after another, like disembodied spirits' (Batchen 1998, p.275). The phenomenon of virtual space is still reliant today on the technique of stereoscope. In an exhibition called Devices of Wonder held at the Paul Getty Museum in 2001-2002, Terpak and Stafford (2001) examined the visual devices that they claim have increased the act of human perception from the $15^{\text {th }}$ century until today. (Terpak, and Stafford, 2001)

Prominent philosopher of the $17^{\text {th }}$ century Rene Descartes, wrote extensively on the nature of vision and considered the eye to be a scientific instrument (Terpak 2001). Early scientists saw optical devices as extensions of the human eye. Descartes proposed an experiment to witness the working of the human eye, which could either be done with 
a recently deceased human or, more ethically, an ox. The back of the eyeball was dissected and, when an image was placed before the pupil, that image was consequently projected onto a white sheet of paper held behind the eye in place of the retina. Descartes attempted to reproduce the function of the human eye in the camera obscura. The camera obscura dates back to antiquity, its Latin name meaning 'dark chamber'. It consisted of small, darkened rooms with the only light source being a small hole, which acted like a lens, allowing an image of what was outside the hole to be projected onto the opposite wall of the room as an inverted image. Versions of these were built in all sizes from rooms to pocket models the size of a book The technique was originally used to witness solar eclipses and eventually became a tool for artists to trace or copy images from reality. It was a way to project an image of reality onto a surface, the predecessor to the camera and even of the movie projector.

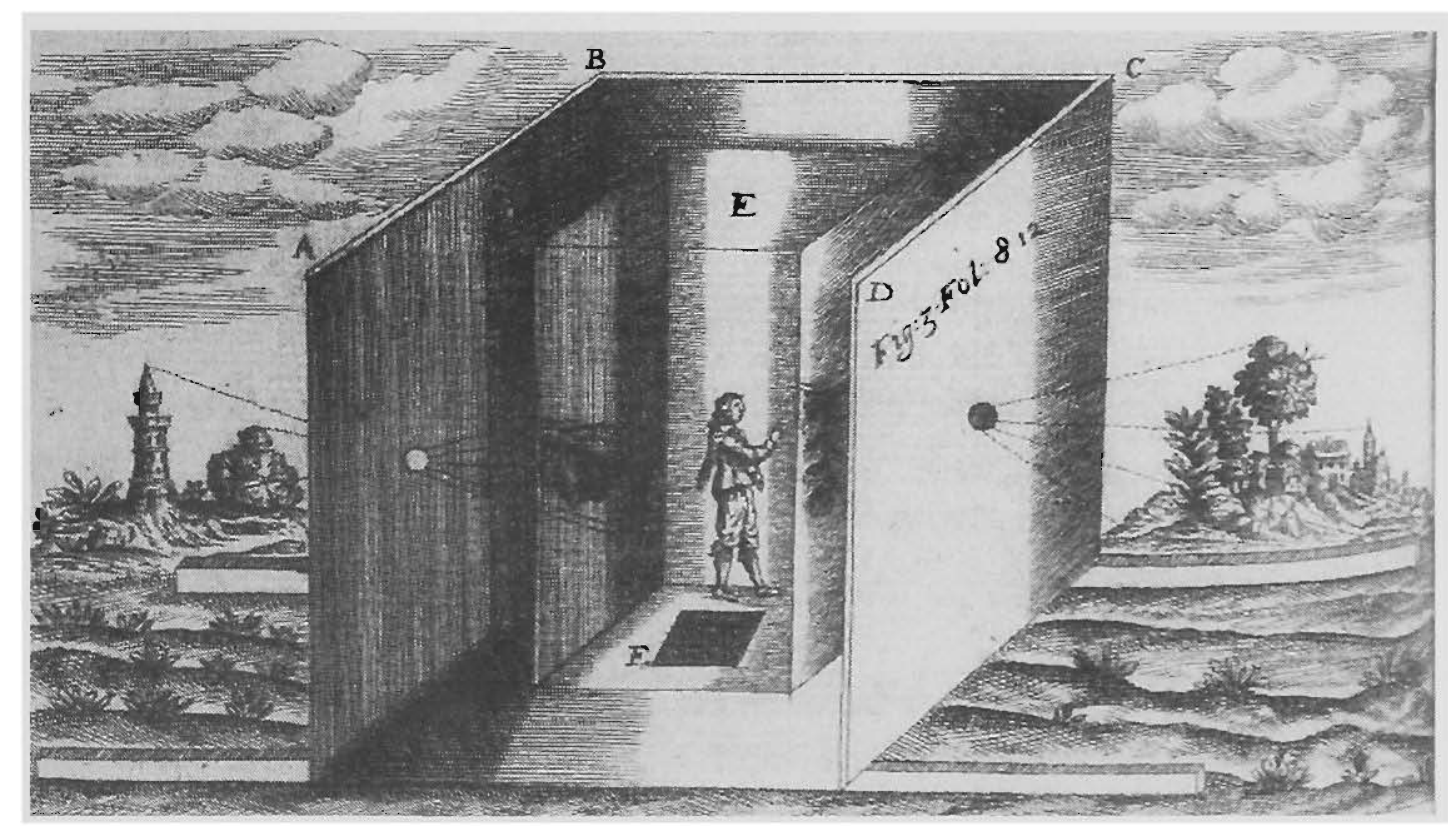

The Camera Obscura, from Athanasius Kicher's Ars magna Lucis et umbrae, Rome 1649 Reproduced from Devices of Wonder, From the World in a Box to Images on a Screen, by Terpak and Stafford 2001 


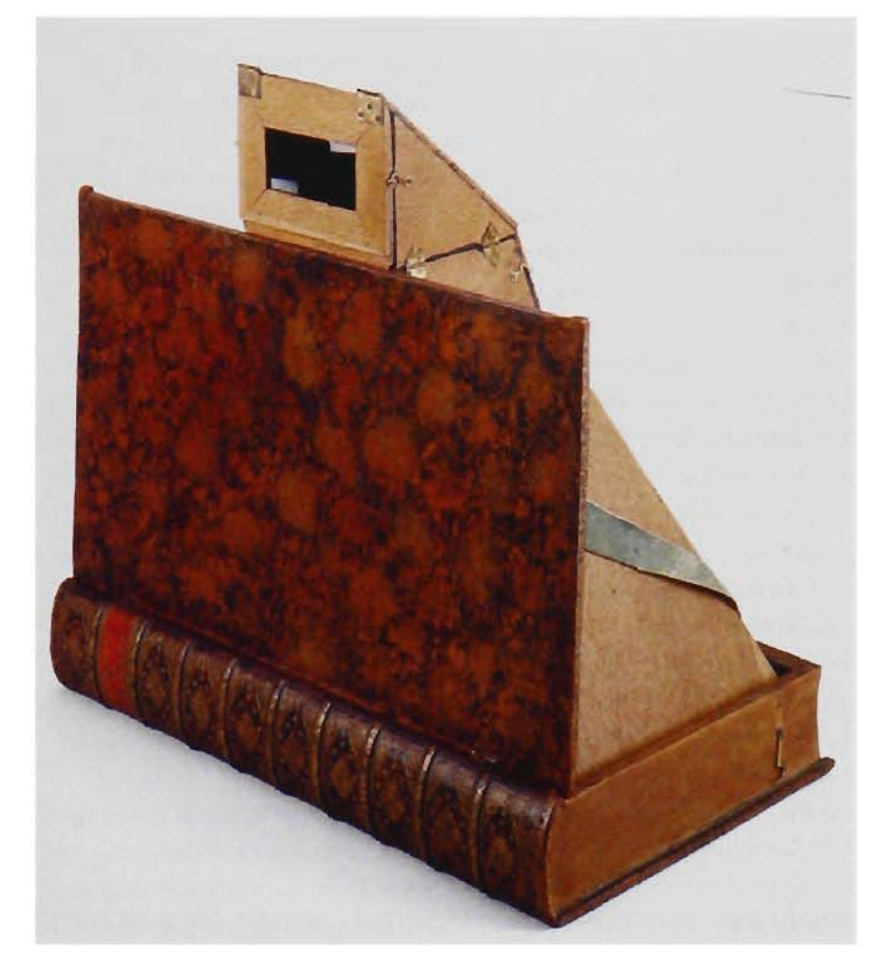

Book Camera Obscura, Theatre de l'univers, France, 1750.

Reproduced from Devices of Wonder. From the World in a Box to Images on a Screen. by Terpak and Stafford 2001

Other technical means were used by artists to assist in accurately representing reality such as the Camera Lucida, which captured the scene in a prism to be looked through and traced onto paper, and the Lorrain Glass, a lens that reduced colours into tonal areas. These techniques developed from a desire to capture the reality of a natural scene and eventually led to the process of photography. They all assisted artist's ability to create the illusion of three-dimensionality on a two-dimensional surface. While this was perfected to a high degree in the work of artists such as Van Eyck, the picture plane still kept the viewer separate from the image, trapped on the other side of a screen. 


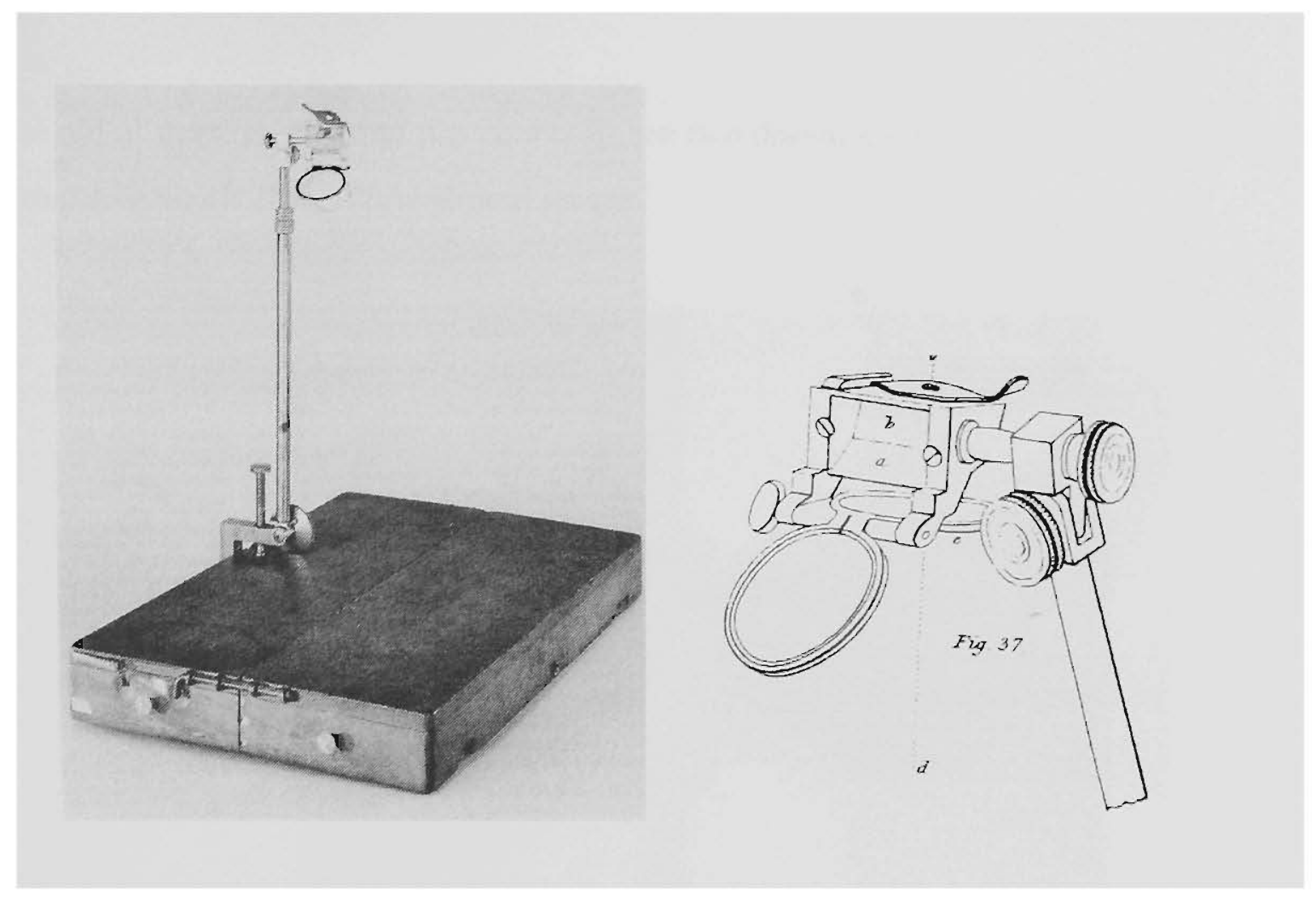

Camera Lucida with eye piece, lenses

London Science Museum
Upper portion of camera Lucida and equipment box, From Cornelius Varley's A Treatise on Optical Drawing Instruments, London, 1845

Reproduced from The Science of Art, Optical Themes in Western Art from Brunelleschi to Seurat, 1990

\section{Stereo}

Binocular vision is necessary to create the perception of depth or relief in an image. While the painted or photographed image of an object gives the impression of form and depth, the illusion of relief needs something else. Each eye needs to be isolated and given a slightly different perspective of the one scene for the condition of three-dimensionality. The virtual space of the stereoscope was discovered by English physicist Charles Wheatstone in 1838. He demonstrated that the eyes receive images from slightly different perspectives and combine them in the brain to perceive depth. Wheatstone's theory was that the distance of two to three inches between the eyes was what allowed humans to see the world in three-dimensions. He developed the first stereoscopic device, which, with 
the aid of mirrors, allowed the viewer to see two drawings placed parallel and facing each other as a single three-dimensional image.

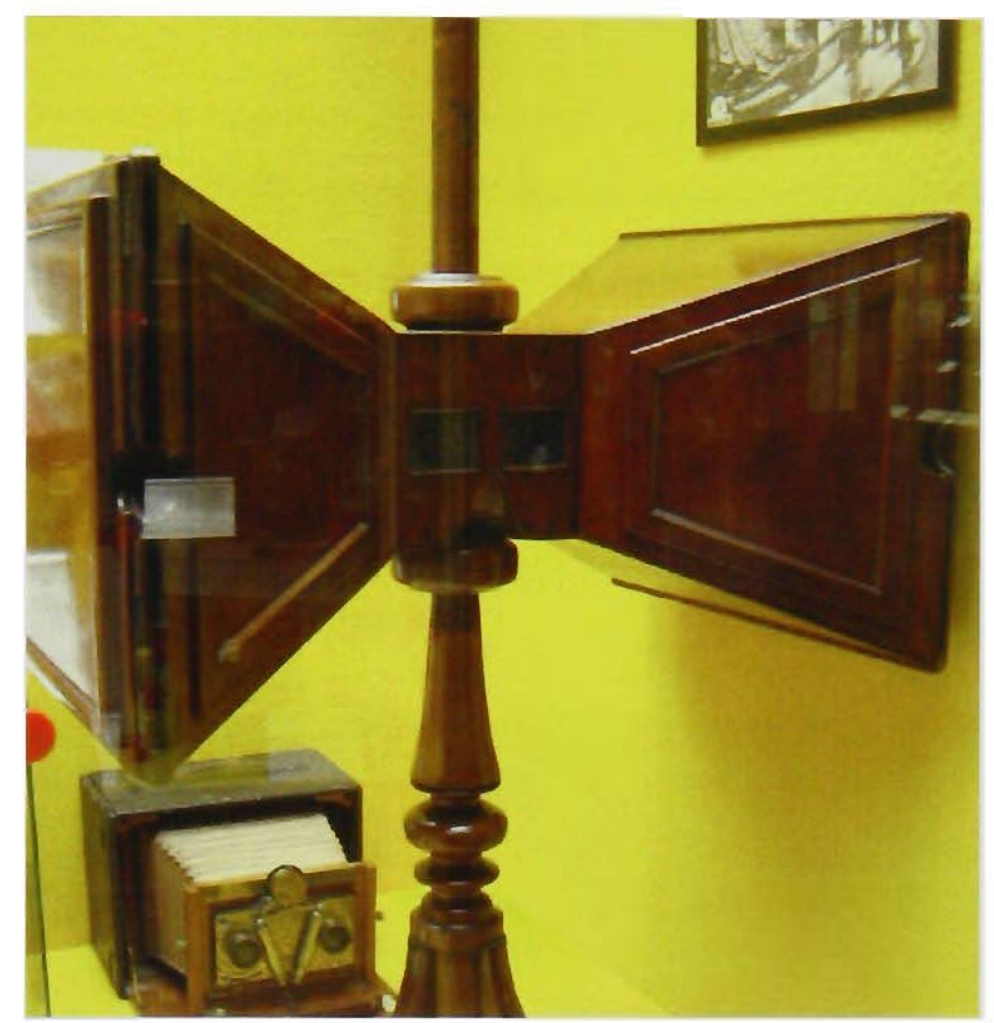

Wheatstone's reflecting stereoscope viewer, 1850 London Science Museum, photograph by Megan Evans.

Wheatstone demonstrated this phenomena to the Royal Society of London in 1838. A year later the invention of photography allowed Wheatstone to develop his theory photographically to create a three dimensional image that resembled virtual space. The theory of binocular vision was discussed even further back by Euclid and Galen in antiquity and then later by Leonardo in his Milan manuscript in 1484. The idea of applying it to photography was taken up by the inventor of the kaleidoscope, Sir David Brewster and after many false starts he finally interested an optician who was also a photographer, Jules Duboscq who manufactured Brewster's model in 1850. Queen Victoria was presented with a model the following year and by 1851 a quarter of a million stereoscopic images had been sold in France and England (Terpak 2001). 
Terpak claims that in the years between 1860 and 1920 the stereoscope was as popular in America and Britain as the contemporary television.

\section{Optical Wonders}

Stereoscopic peepshows were later developed for the mass audience. August Fuhrman, an 'optical entrepreneur' (Crary 2001) created the Kaiserpanorama which enabled 25 people to view a series of stereoscopic images in a rotating viewing device. A visual version of a carousel, the audience would sit at chairs around a large cylinder with sets of binocular viewing ports spaced around it. At regular intervals acknowledged by a bell, the glass slides inside would rotate providing a new view. The show went for fifty minutes, a long period of immersion in a virtual world (Crary 2001).

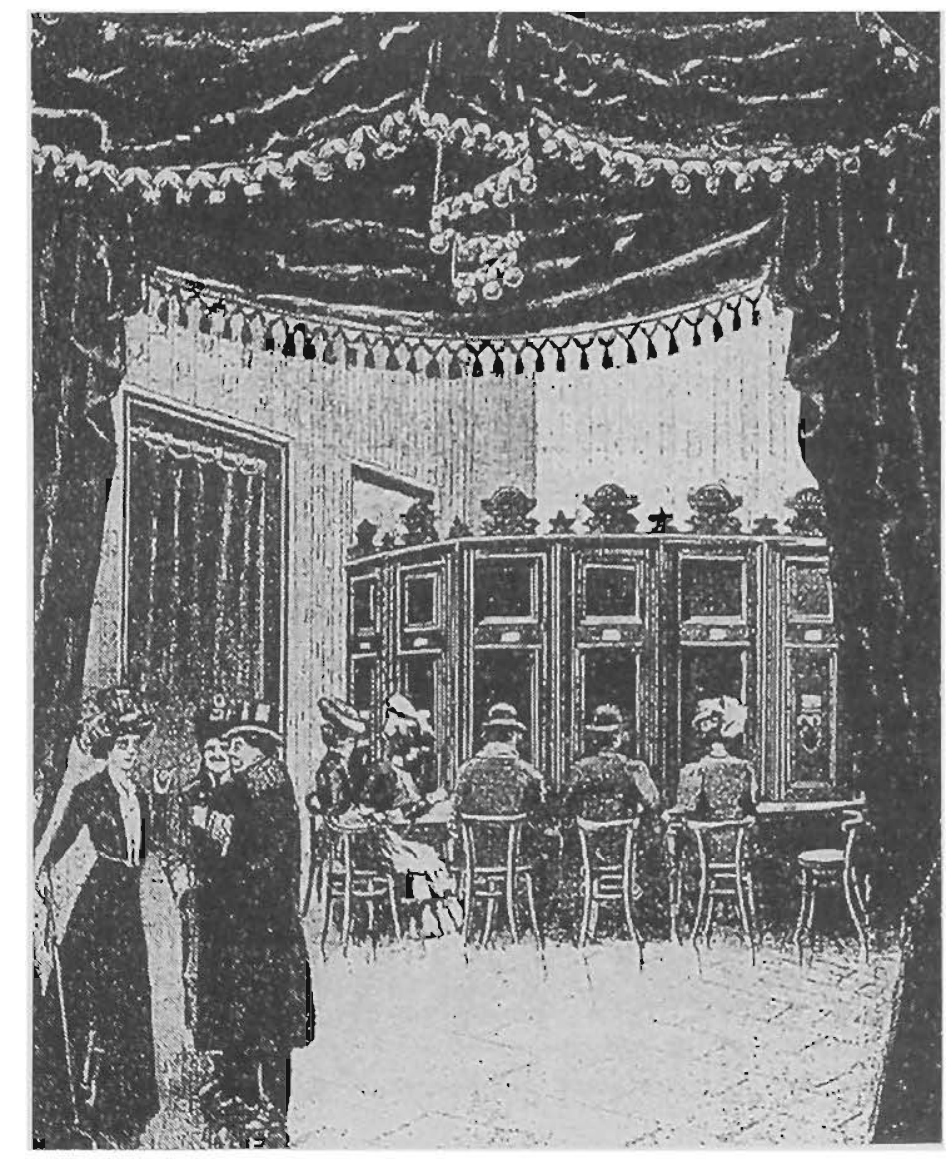

The original Kaiserpanorama, Berlin, 1880s,

reproduced from Suspensions of Perception, Attention, Spectacle and Modern Culture by Crary J, 2001. 


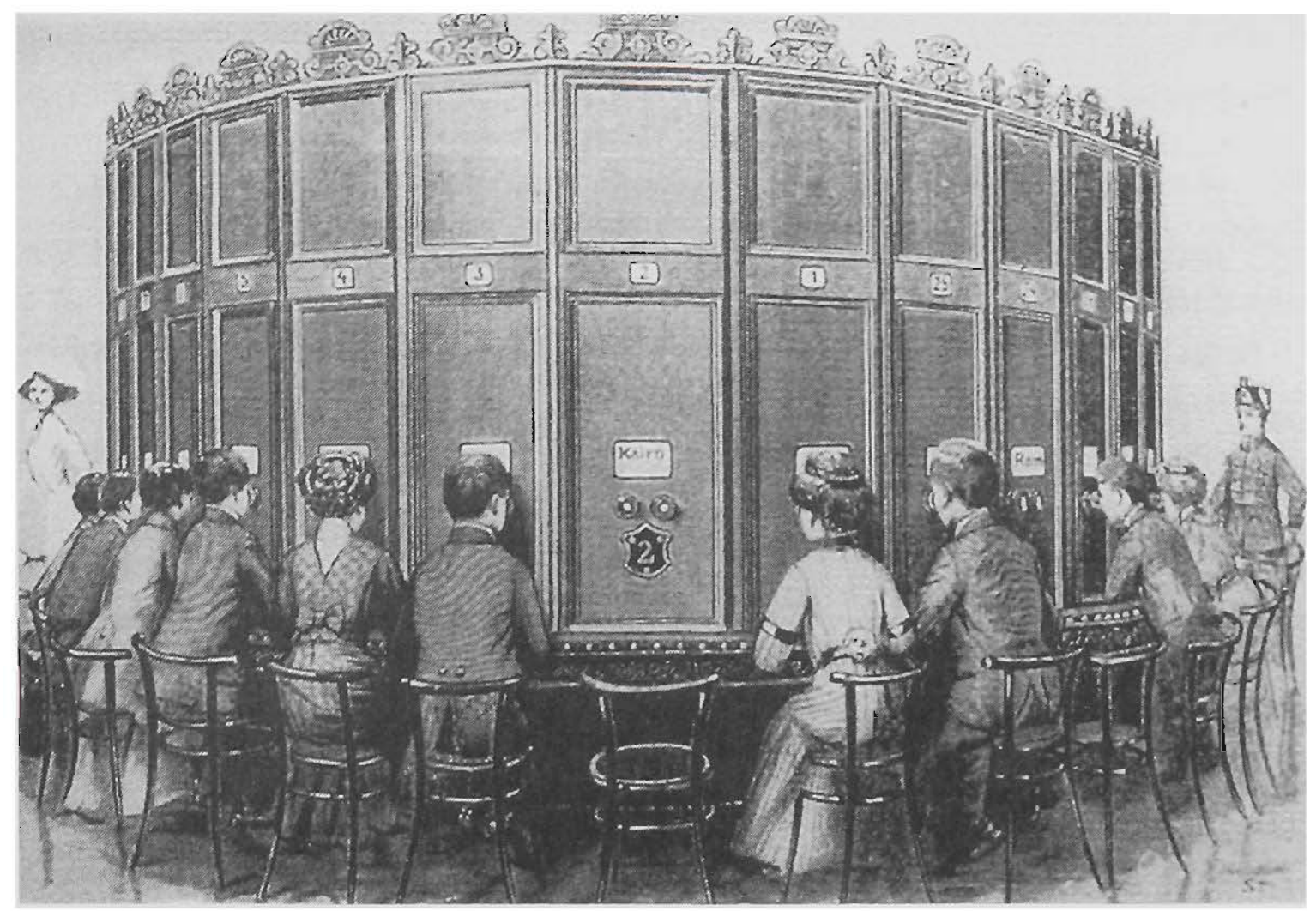

The original Kaiserpanorama, Berlin, 1880's,

reproduced from Suspensions of Perception, Attention, Spectacle and Modern Culture by Crary J, 2001.

In the $16^{\text {th }}$ century a natural scientist Jakob Scheuchzer, described the eye as 'a small world within another world' a 'dark chamber of infinite art' (Terpak 2001 p.145), an early description that relates the eye to the experience of peephole viewing. When one looks through into an image, rather than looking at the image from a distance, the eye's natural experience of vision is replicated.

Terpak (2001) calls the stereoscope 'a precursor to virtual reality machines' (p.358) and notes that their ability to immerse the viewer in the scene means that even relatively ordinary subjects are able to hold the attention of an audience. Fairly soon twin lens stereoscopic cameras were developed and the inevitable progression of the idea led to attempts to project large scale stereoscopic images to be viewed from a distance using a double magic lantern. 


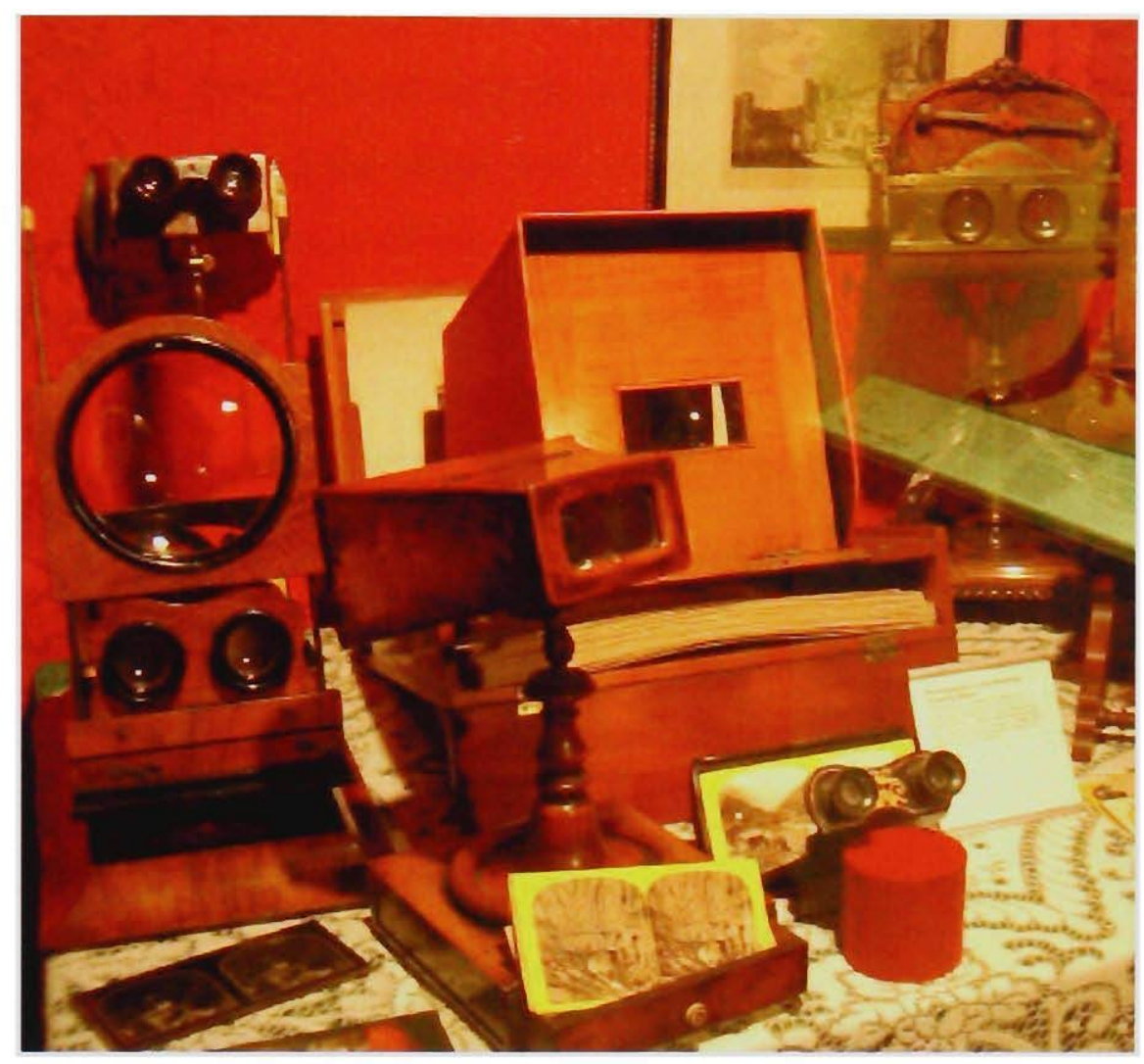

Stereoscope display at the London Science Museum, 2003, photographed by Megan Evans

To achieve the clarity needed for virtual depth, the physicist Joseph-Charles d'Almeida covered one lens with a red filter and one with a green filter, and then gave the audience correspondingly tinted glasses to great effect. Predictions followed of the possibility of moving images.

'The same year, Edoard Hospitalier made the prescient comment that if the sensational "perspective" of the stereoscopic projection were continued with the equally impressive movement of images achieved in the revolving ring of mirrors at the center of the praxinoscope, a quite marvellous effect would result' (Terpak 2001, p.359).

The Praxinoscope was one among many optical toys in fashion in the early 1800s. The interior of a cylinder was painted with a sequence of images in various stages of 
movement. These were reflected onto a set of mirrors in the middle of the cylinder facing out and the reflections were viewed through narrow vertical slits in the outer cylinder. When the cylinder was rotated the effect was of one image in animated movement. This effect relied on the 'phenomenon of persistence of vision' (Terpak 2001. p.354), which allows an image to be held in the brain for a moment after its replica is gone.

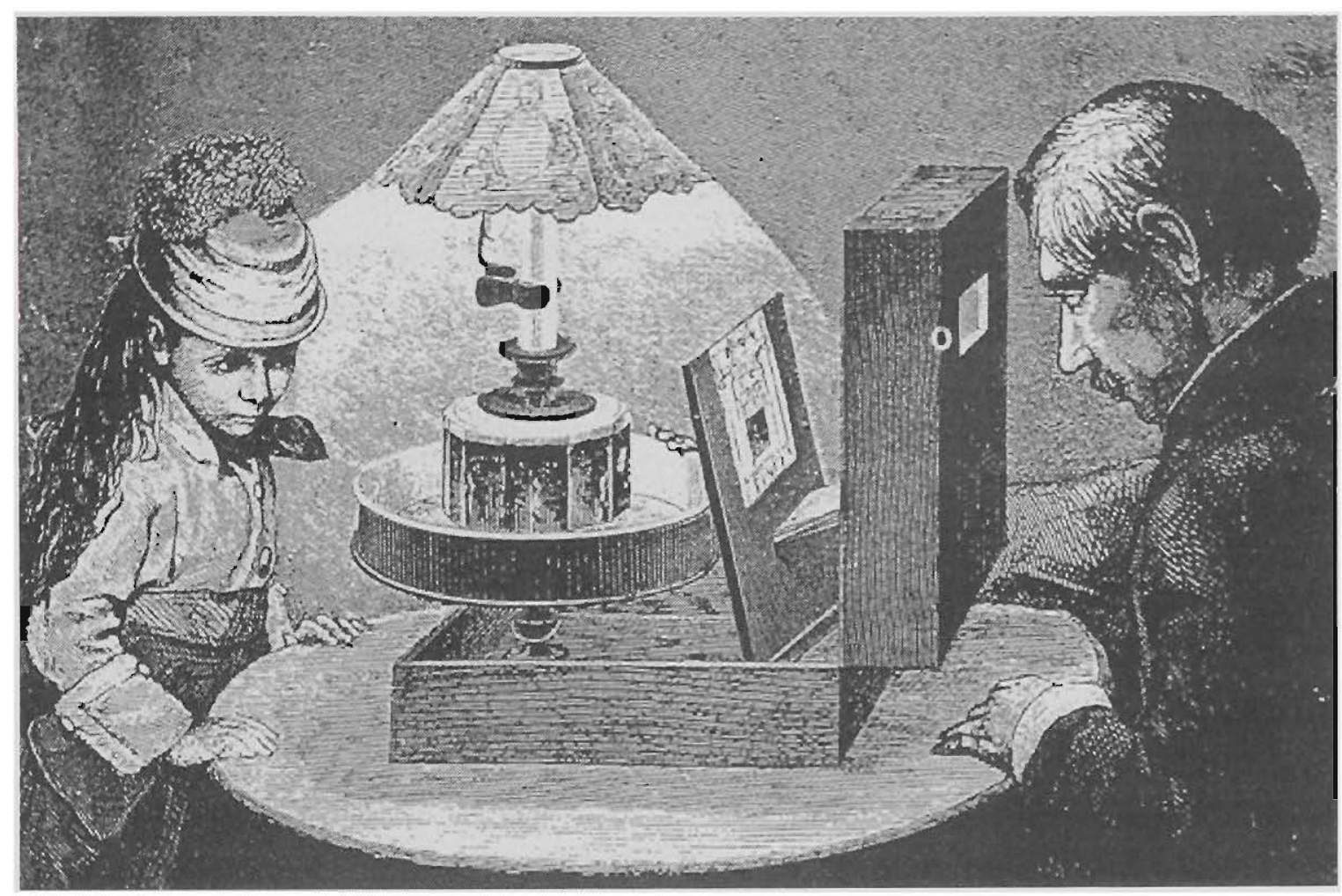

Emile Reynaud, Praxinoscope Theatre, 1879,

reproduced from Devices of Wonder, From the World in a Box to Images on a Screen, by Terpak and Stafford 2001

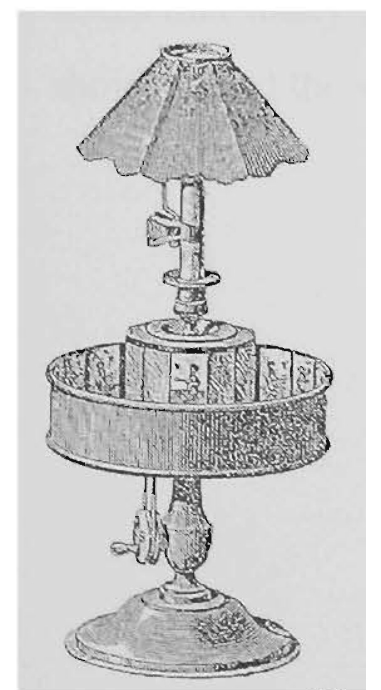

Emile Reynaud, Praxinoscope 1876, Reproduced from Devices of Wonder, From the World in a Box to Images on a Screen, by Terpak and Stafford 2001 


\section{Time and Motion}

Famous also for his large output of stereoscopic photographs, Eadweard Muybridge in the latter half of the $19^{\text {th }}$ century experimented with motion and time in a series of sequential photographs of animals and humans in motion. While there is often a connection made between Muybridge and the invention of cinema, Michel Frizot (1998) claims that there were others who were more interested in representing the moving image.. Muybridge's interest was more scientifically based, using photography to reveal truths that the human eye could not catch. His first successful depiction of movement was in 1878 at the request of Leyland Stanford, a prominent American and horseman who had a semi scientific interest in the positions of horses' legs at different stages in their trot. After several failed attempts due to the slow rate of exposure of available film, he achieved success by using a bank of twelve cameras with slit shutters exposing the film for one twenty-fifth of a second, activated electrically. Interestingly the same technique was used over a century later, on a famous scene in the film The Matrix that shows the main character suspended mid air from 360 degrees. This was done using more cameras, activating them all at the same time to achieve images which when compiled in a $3 \mathrm{D}$ computer program provides the unusual effect of being able to view the character in the third dimension.

Although Muybridge was not personally interested in the development of the moving image, it is hard to believe that his work did not further the progress of this development. Maureen Furniss (1998) in her book Art in Motion, Animation Aesthetics, states that many forms of optical toys and early moving projections from magic lantern shows paved the way for the first motion picture shown publicly in 1895 . 


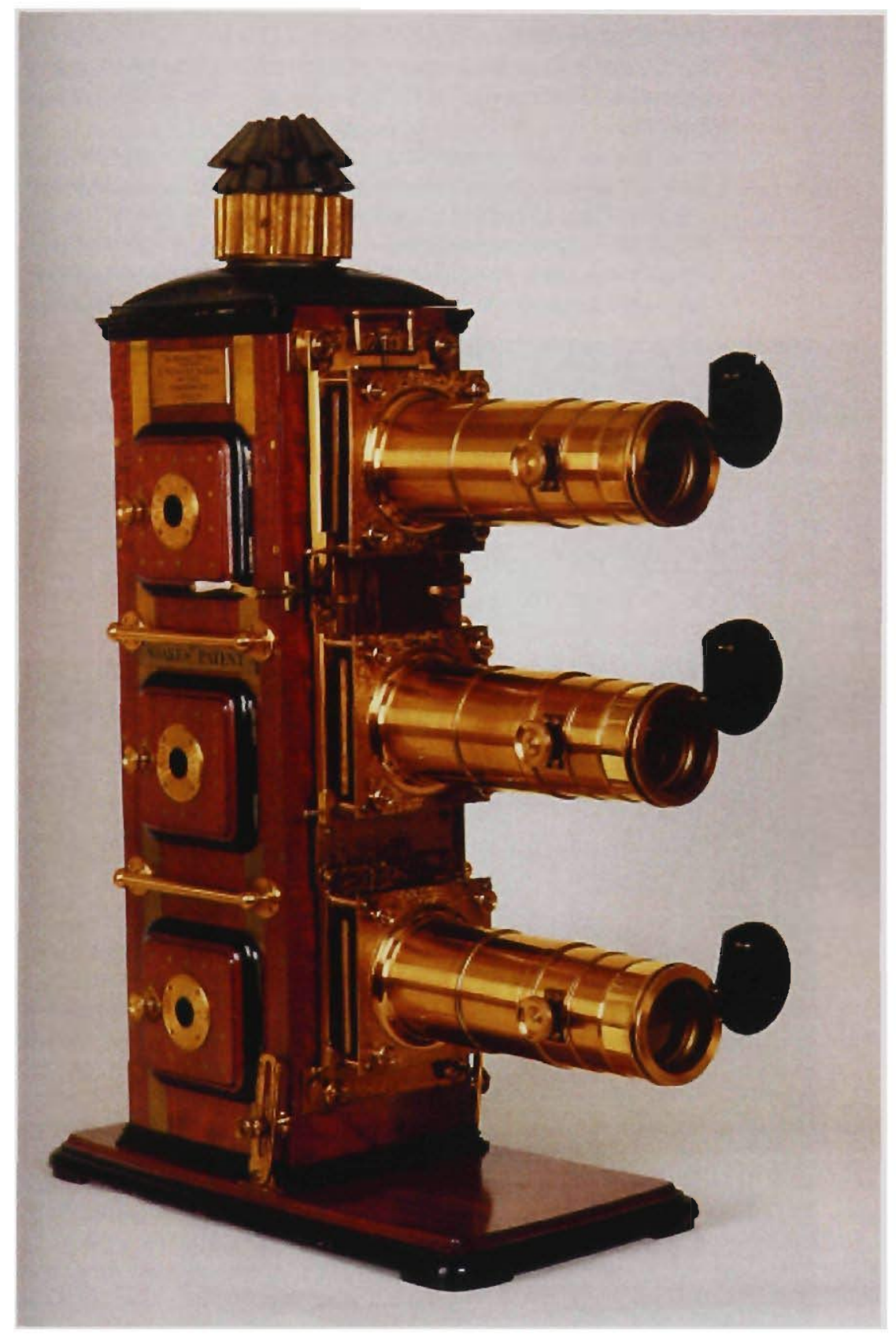

Triple Magic Lantern Reproduced from Méliès, magie et cinema 2002

The Magic Lantern, first used in the mid seventeenth century, involved painted or photographed glass slides that were moved across the lens to create what became known in film as panning. Some were moved by hand and some used a wheel device to mechanically move the slide, 

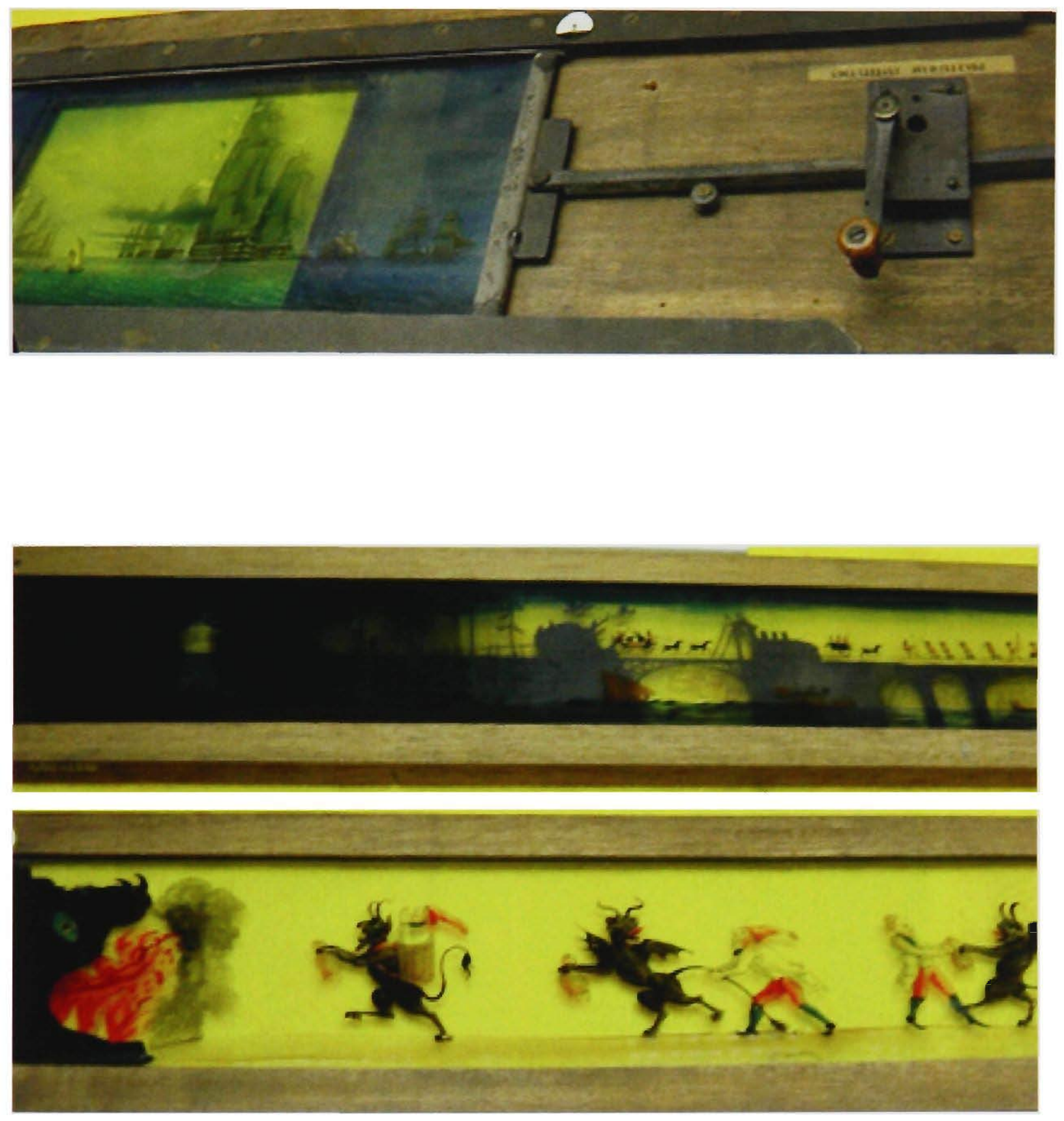

Magic Lantern Slides, London Science Museum photographed by Megan Evans

For many years they were popular as the first large scale projections in the public arena. Finally August and Louis Lumiérè developed the technology to record sequential images on film stock and the virtual life on a screen was born. 


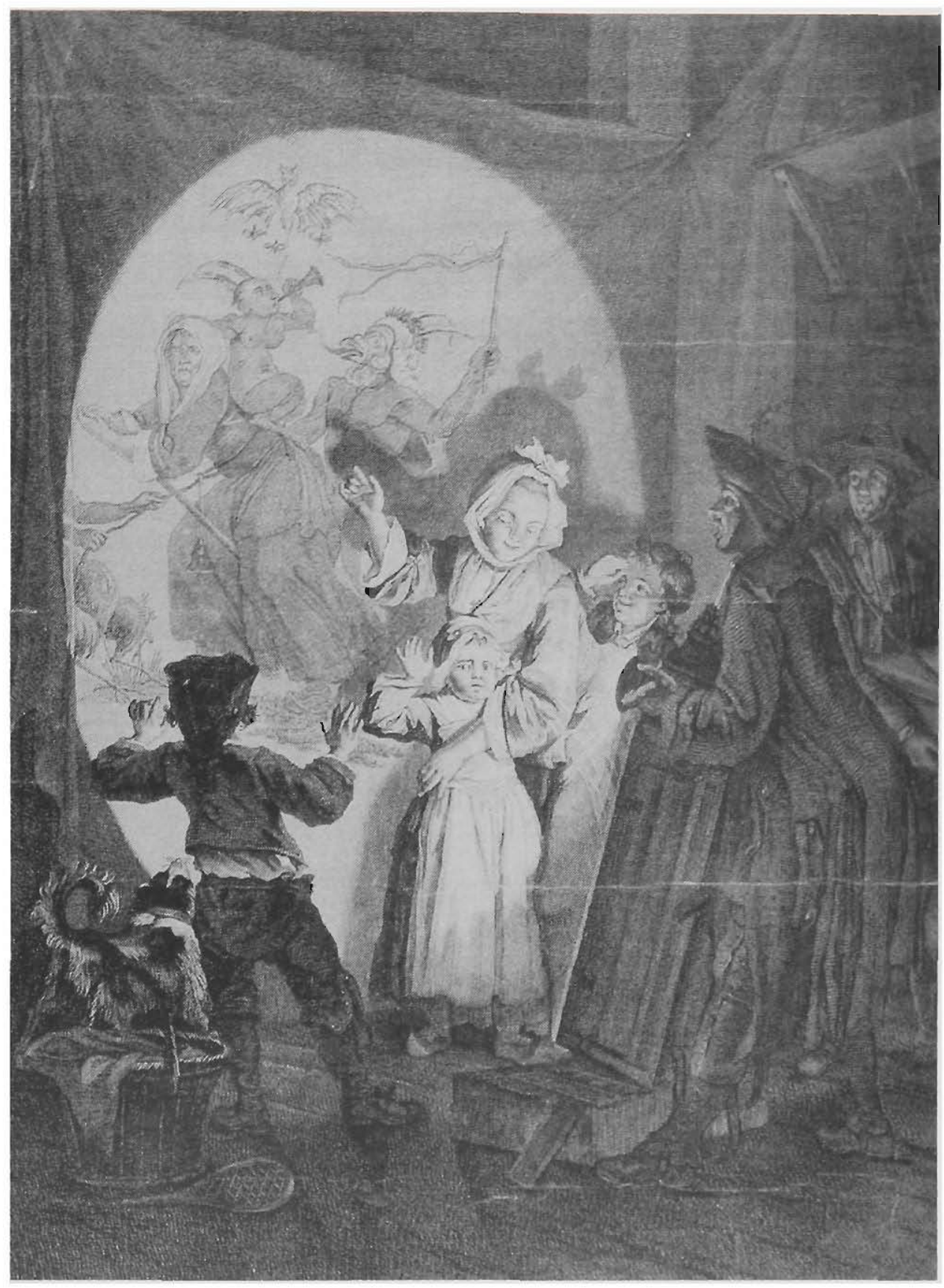

La lanterne magique,by Jean Ouvrier,(French, 1725 - 84) after Johann Eleazar Schenau (German, 1737 - 1806) etching and engraving Los Angeles, Getty Research Institute, Werner Nekes Collection,

Reproduced from Devices of Wonder, From the World in a Box to Images on a Screen, by Terpak and Stafford 2001 


\title{
Moving Illusions
}

The Lumiére brothers had a studio above a magician named Georges Méliès who owned and ran the Theatre Robert Houdini. Méliès was invited by the Lumiére brothers to the first public screening of their patented Cinématographe movie camera (Steigrad, 2003).

\begin{abstract}
"The other guests and I found ourselves in front of a small screen, similar to those we use for projections, and after a few minutes, a stationary photograph showing the Place Bellcour in Lyons was projected. A little surprised, I scarcely had time to say to my neighbour: "Have we been brought here to see projections? I've been doing these for ten years." No sooner had I stopped speaking when a horse pulling a cart started to walk towards us followed by other vehicles, then a passer by. In short, all the hustle and bustle of a street. We sat with our mouths open, without speaking, filled with amazement".
\end{abstract}

(Steigrad http://www.mshepley.btinternet.co.uk/melies.htm, 2003)

When cameras became available, Méliès purchased his own, and began making the films for which he is best known today; films of fantasy and illusion. He discovered stopmotion by accident and saw the potential of special effects, which together with his knowledge of magic provided ground-breaking outcomes that would influence the future of special effects in film.

"One trick leads to another. In the face of the success of this new style, I set myself to discover new processes, and in succession I conceived dissolves from scene to scene effected by a special arrangement in the camera; apparitions, disappearances, metamorphoses obtained by superimposition on black backgrounds, or portions of the screen reserved for décors; then superimpositions on white backgrounds already exposed which are obtained by a device which I am not going to reveal, since imitators have not penetrated the whole secret. Then came tricks of decapitation, of doubling the characters, of scenes played by a single actor... Finally, in employing the special knowledge of illusions which 25 years in the Théatre Robert-Houdini had given me, I introduced into the cinema the tricks of machinery, mechanics, optics, prestidigitation etc. With all these processes mixed one with another and 
used with competence, I do not hesitate to say that in cinematography it is today possible to realise the most impossible and the most improbable things".

(Steigrad http://www.mshepley.btinternet.co.uk/melies.htm, 2003)

Méliès used an established form of illusion in his film and theatre productions, known as 'Pepper's Ghost' where an image that was off-stage was reflected onto a sheet of half silvered glass that was lit from behind so the audience could see the image and not the glass. It was a popular method of creating the illusion of an apparition.

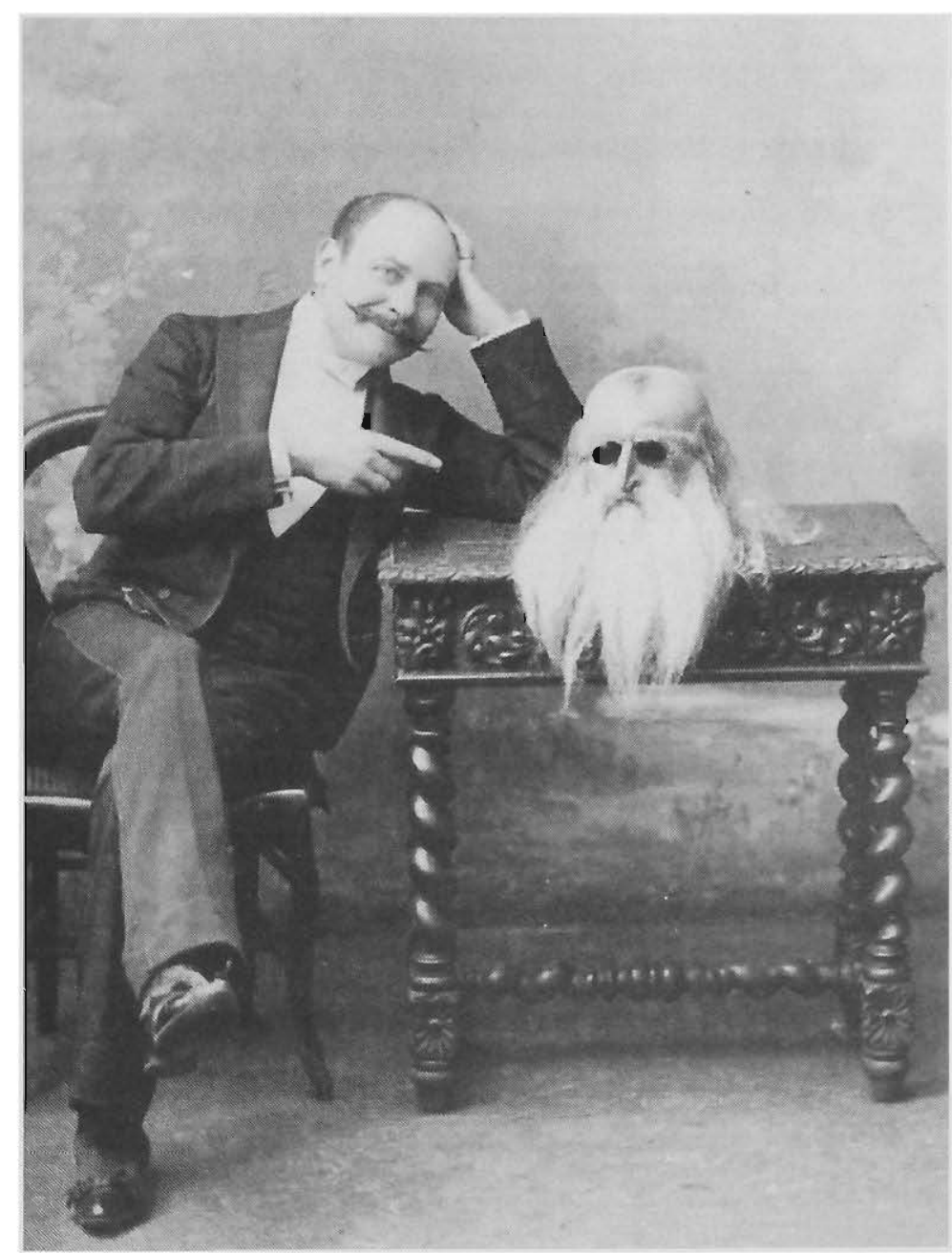

Le Décapité récalcitrant.Le squelette s'enfriut avec la tête du décapité. Jules David dit Marius à gauche, Harmington à droite reproduced from Méliès, magie et cinema 2002 


\section{Anamorphosis}

Issues of reality and illusion were explored in a two-dimensional way with the technique of anamorphosis. The word is derived from the Greek, 'to transform', and is the means by which an image is distorted so that it is only recognisable from one position where it pulls together into a unified reality. In the sixteenth and seventeenth centuries this technique was used both for entertainment with objects of trickery, and also as an example of the ephemeral spiritual powers that underpinned the illusion of reality (Kemp, 1990). The technique of distortion often was used to prompt the viewer to physically shift their point of view. Instead of admiring the richness of the painted image they were encouraged to consider an alternative perspective. By positioning their eyes at a specific point a hidden reality was revealed, which often related to the immateriality of life.

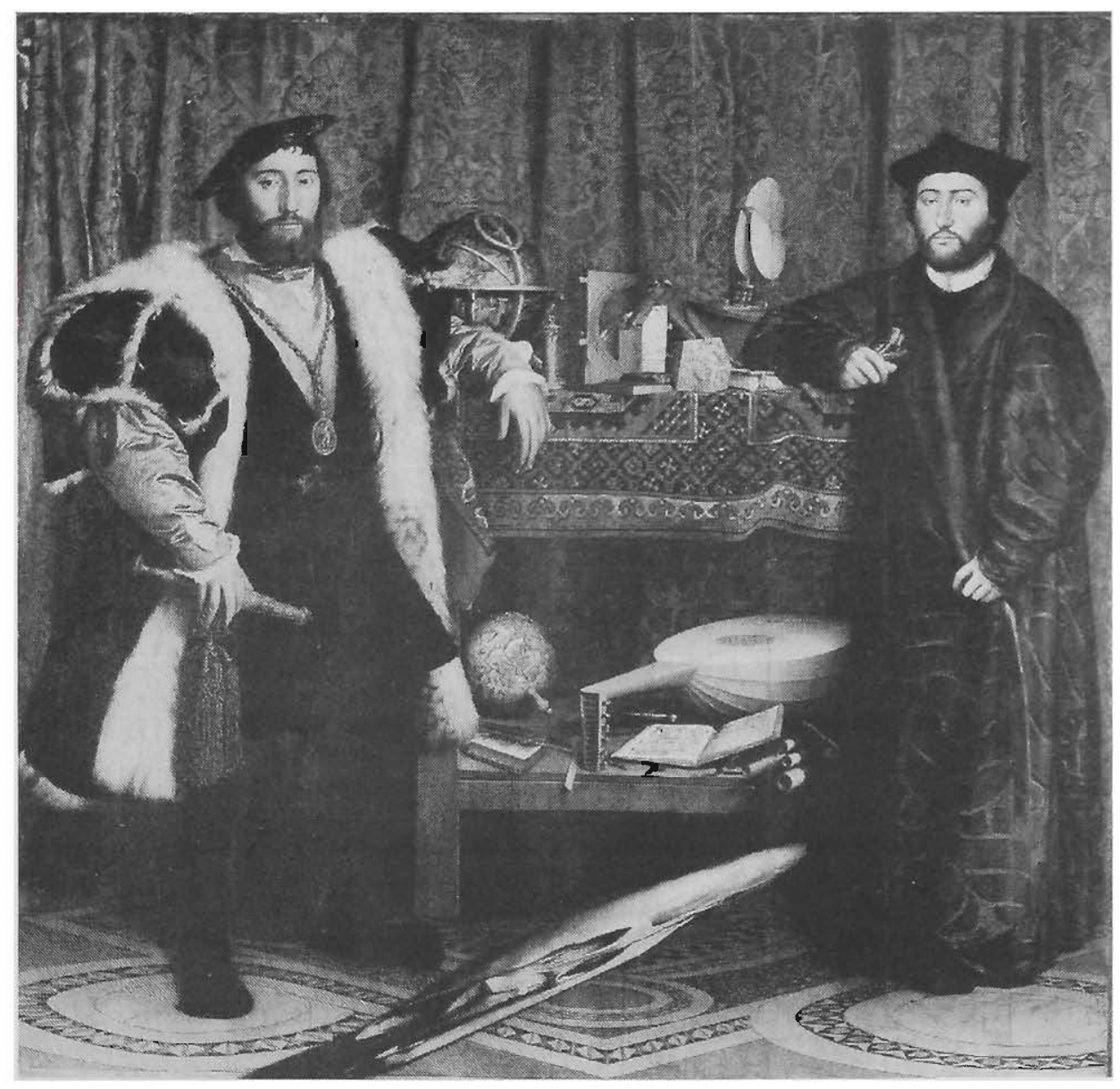

The Ambassadors, by Hans Holbein, 1533, London National Gallery.

Reproduced from The Science of Art, Optical themes in western art from Brunelleschi to Seurat, Kemp 1990 
In Hans Holbein's painting of The Ambassadors (1533) he represents two men lavishly attired. Between them is a collection of scientific and cultural objects, and a distorted image in the foreground. When the painting is viewed from the front this image is unrecognisable, however, if the viewer steps to the side and looks across the face of the painted surface, a human skull can be seen.

Anamorphic images were also constructed to be viewed in reflective cylindrical mirrors known as catoptric mirrors, which came into vogue in the mid $18^{\text {th }}$ century (Baltrusaitis, 1977). This method requires distorting the image around a cylindrical mirror and, "...by virtue of the laws of the angles of incidence of reflection, it is reconstituted on a convex surface which diminishes and corrects the curves' (Baltrusaitis, 1977, p.131).

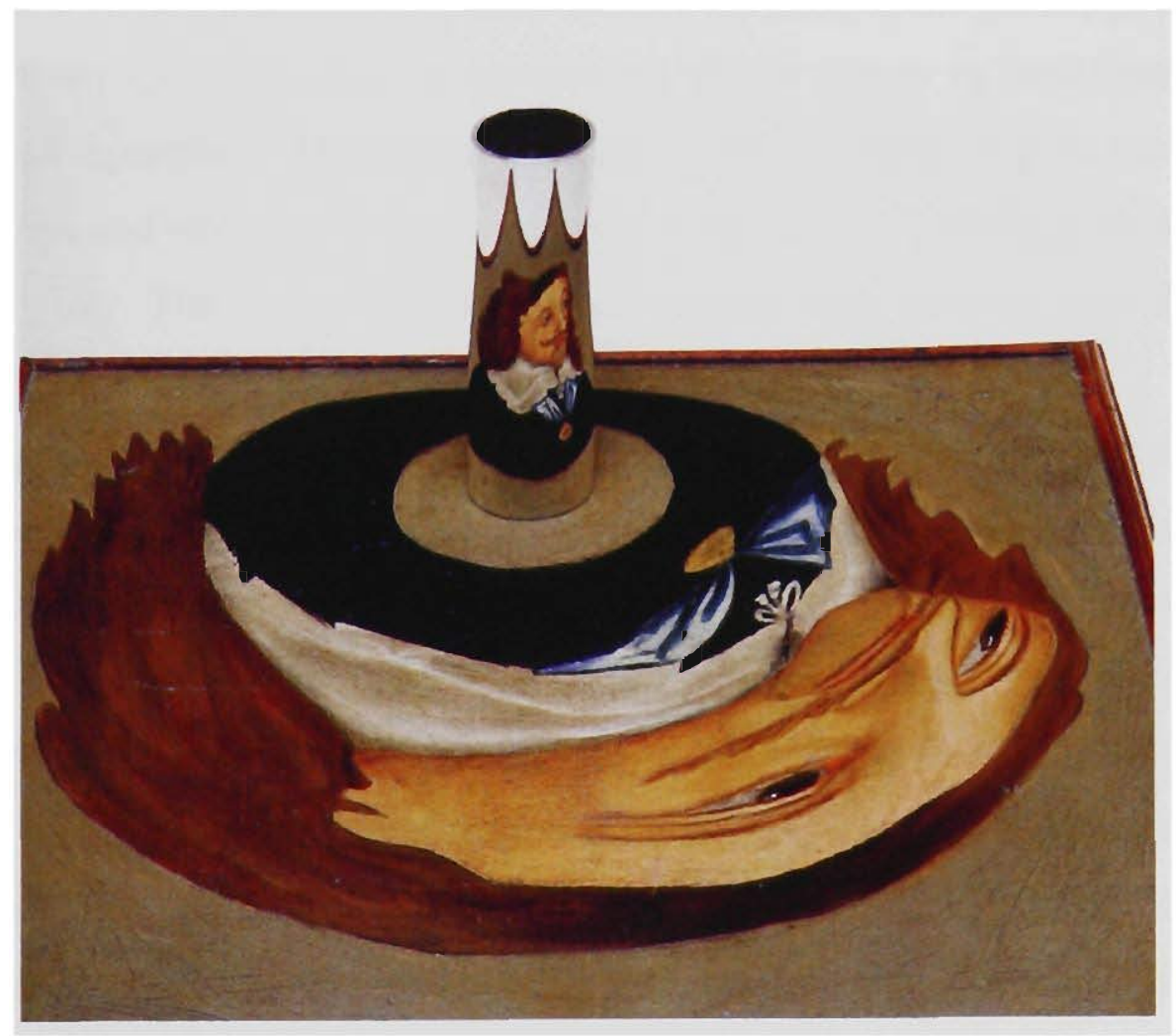

Anamorphic Portrait of Charles 1, with Viewing Mirror, France about 1780, oil on wood and cylindrical mirror, Watertown Massachusetts, Richard Balzer Collection.

Reproduced from Devices of Wonder. From the World in a Box to Images on a Screen, by Terpak and Stafford. 2001 
Cylindrical anamorphosis was often used to portray illicit images that could not be viewed openly. Baltrusaitis cites a Flemish anamorphosis done in the second half of the seventeenth century called The Erection of the Cross, referencing the painting of the same name by Rubens. However when viewed from a particular place the cylinder reveals a pair of lovers painted opposite the Crucifixion. By the 1840 s cylinder anamorphosis was rare and had according to Terpak 'fallen into oblivion' (Terpak 2001, p. 245).

\section{Animated Anamorphosis}

In De Artificiali Perspectiva or Anamorphosis by the Quay Brothers, stop-frame animation is used to explore this distinctive form of illusion. The animation documents several famous anamorphic paintings and frescos seen through the eyes of a character whose head is a picture frame with eyes set behind the glass of the picture plane. The film claims that anamorphosis forces the perspective of the viewer to look from one point, ideally through a peephole. The central character of the animation depicts the relationship between the eye and what it sees, representing the view of the world that frames reality as an objective view. The film claims that anamorphosis both conceals and discloses the truth that underlies appearances.

The prominence of vision in the art of illusion lends itself to the visual arts as a discipline for its examination. Fredric Jameson discusses the pornographic nature of the visible, in the introduction to his book Signature of the Visible, and claims that films and I would add art generally, 'ask us to stare at the world as though it were a naked body' (Jameson 1992, p.1). He argues for an ontology of the visible, making the eye the primary sense above all others and claims that the conflict between humans for power and desire will occur between 'the mastery of the gaze and the illimitable richness of the visual object' (Jameson 1992 p1). The relationship between painting and the moving image is the illusion of reality. Distorted perspective and special effects confront the mastery of the gaze and the stereoscope seduces the eye out of the body and into an illusory space. 


\section{CHAPTER SIX :STEPPING OUT OF THE FRAME}

\section{Animated Illusion}

The desire to animate Form came after the exhibition Sleepwalker and developed from an interest in the illusion of movement influenced by the stop-frame animation of the Quay Brothers. Form is animated in Virtually VANISHED and can be seen in two perspectives; the distorted perspective of cylinder anamorphosis on the screen and the accurate perspective in the reflective cylinder. She is trapped inside an architectural construction and the reality of her image is distorted and lies on the floor of the church like space. However she appears virtually as a reflection in the mirrored cylinder in the middle of the room.

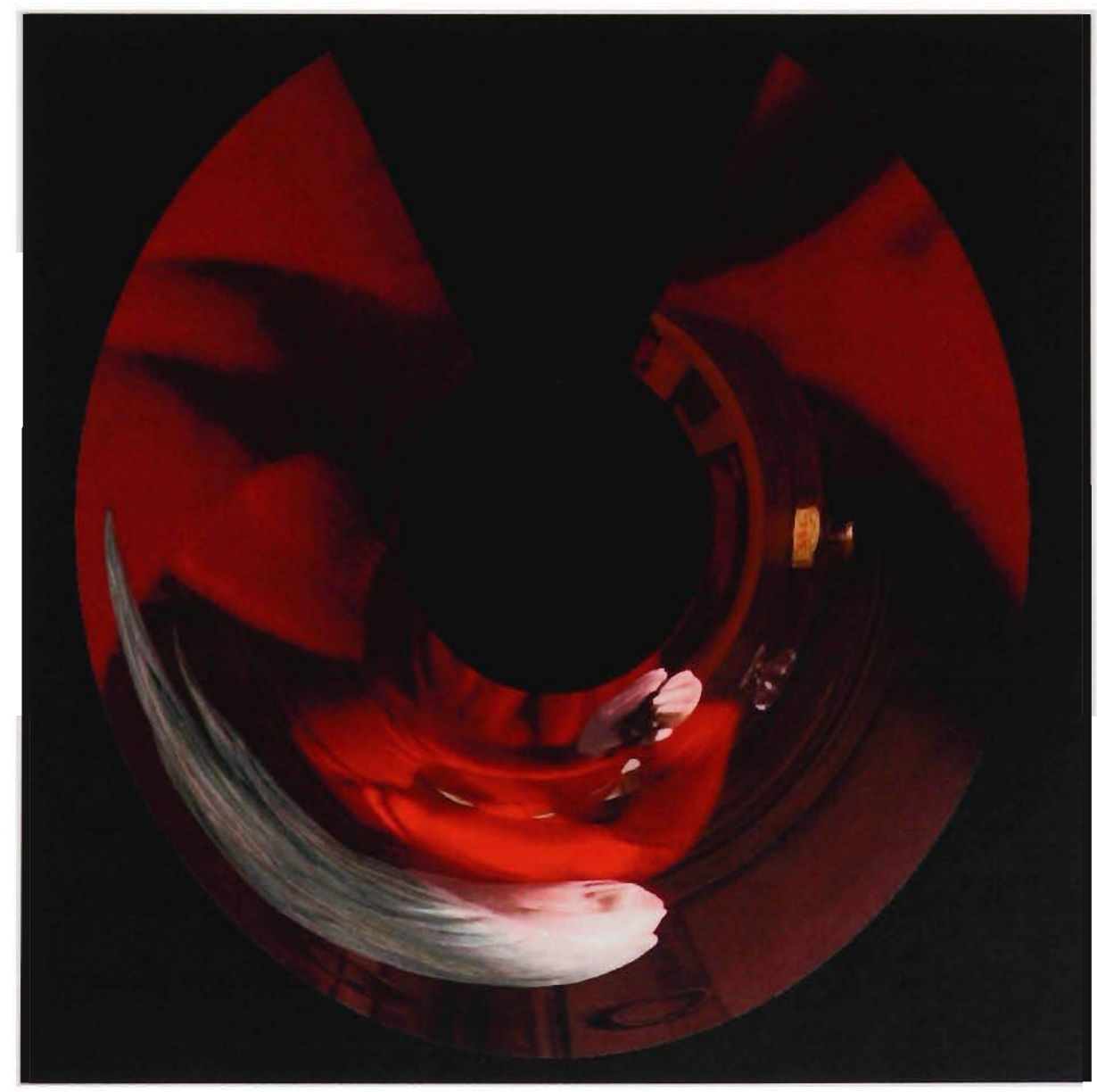

Still of anamorphic video, Virtually vanishing, by Megan Evans 2002 
Views into the room are possible from all sides. Form seems to be bereft of the material in the house of the spirit and is lost, attempting to find a way out. The technique of anamorphosis was used to disappear the reality of the image. The perspective that shows the true image exists only as a reflection in the mirror. In this work the illusion is the reality. Form is lost in the void and the void is Emptiness. The character was animated using stop-frame technique on digital video. Each frame was distorted to create the anamorphic images and then reanimated. This work was trialed in an exhibition called The Synthetic Image, Digital Technologies and the Image curated by Vince Dziekan at Monash University in July 2002.

In the work called Virtually Vanishing, Form is in the set and plays out her dreams, riding her pushbike into the cupboard of desire and rowing out again in her boat. A rhinoceros lumbers across the set, and Form finds a gun and shoots her reflection in the mirror. I made a decision to animate Form against a black background, for the work in The Sublime Sleep, instead of in the set. In Virtually Vanishing the illusion was constrained by the edge of the set being visible in the distorted image. This resulted in the idea of her as stumbling about in the Emptiness of Emptiness as is signified by the space of the illusion.

The built construction resembles the architecture of Renaissance church's and yet is symmetrical, it has no back or front. Views into the building are the same from each side. The digital ability to replicate is constructed in three dimensions to create a space that has no identification with location. One could imagine this house of air being built in the clouds. Nothing can be put in it as there are no walls to situate anything against: living in this space would be like living in a corridor full of doors. It is the house of Emptiness, a metaphor for a place of being. 


\section{Empty Illusions}

VirtuallyREAL is based on the idea of a three-dimensional moving painting. The illusion of three-dimensionality evident in the stereoscope images is created in a physical form; a $3 \mathrm{D}$ painting in the analogue sense. For a moment this painting appears to be a still life with Form sitting at the table unmoving, surrounded by the environment we have seen represented as a virtual space. However, all is not what it seems. As the viewer watches, Emptiness appears, a replica of Form only somewhat ghostly. This illusion is achieved by the technique known as 'Pepper's Ghost'. Pepper's ghost is an early version of virtual reality originally invented by Henry Dircks in 1858 to create an apparition. Dircks's invention only worked on a small scale and Professor Henry Pepper, a presenter of optical tricks, heard of it and worked collaboratively with Dirks to create the illusion for theatre (Davis 2001). The phenomena, later called 'pepper's ghost', used half-silvered glass to capture the image of an actor off stage, illuminated by a lantern. The glass is lit from behind which makes it invisible to the audience.

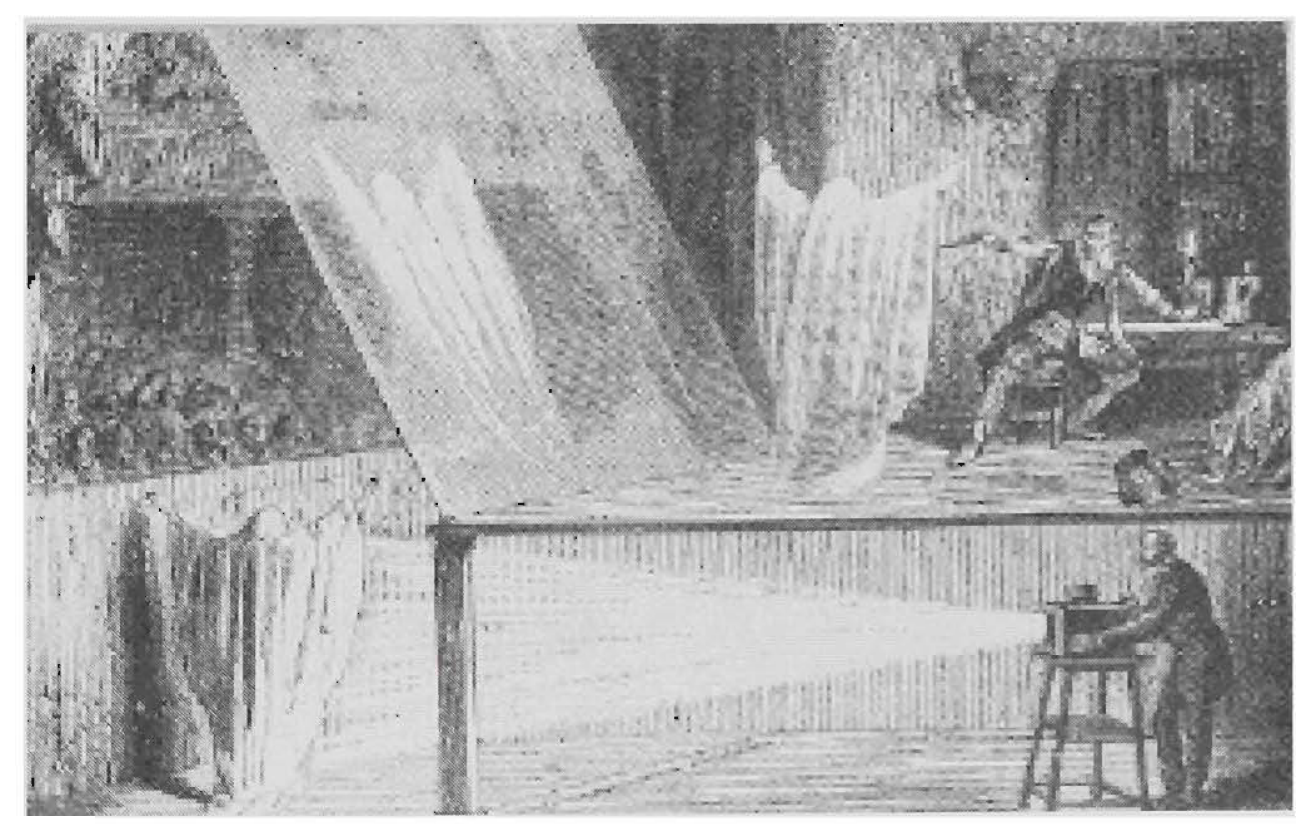

The Pepper's Ghost Illusion, reproduced from http://www.acmi.net.au/AIC/PEPPER_BIO.html 
This technique was used prolifically in theatre around the late nineteenth century as a way to play with the audience's perception. In this case it is used as an example of early virtual reality and signifies Emptiness who fades in and out of view as she moves around the set in her silent debate with Form.

The debate is heard by the audience but not seen as the characters do not open their mouths. It is a debate that happens inside their heads, a virtual argurnent like those we have with ourselves that no-one else is party to. This conversation goos on while Emptiness performs certain acts and Form is stationary. Form is immobutised by the conversation like Melancholia in Albretch Durer's etching of the same name. Emptiness, the being of Form, floats around free from the constraints of physicality and analysis, in the virtual space of the sublime.

Emptiness: What for? Your possessions? They don't hold anything. Like your twenty eight jugs, they are empty. They are all the form jug. They hold nothing and they are everything to you.

Form: But you miss the point of possession. Each Jug is not jugness. Each Jug is its own dance, its own unique curve, its own heart racing space perfection. Each jug pours an individual emptiness. It carves out its own area of not jug. It holds its own special space which can only ever be imagined by bigger than jug holding objects like you and me. A space that disappears as the jug breaks.

Emptiness: Don't include me in the bigger than jug holding objects. As I stand, where the jug is I am the jug, the jugs space, inside and out. I am its unique curve and its perfection. I am poured by each jug the same.

Form: If only you could see the sense of a symphony of pouring, a jug ballet, an opera of ovals. Sense is lost on you. 
This technique was used prolifically in theatre around the late nineteenth century as a way to play with the audience's perception. In this case it is used as an example of early virtual reality and signifies Emptiness who fades in and out of view as she moves around the set in her silent debate with Form.

The debate is heard by the audience but not seen as the characters do not open their mouths. It is a debate that happens inside their heads, a virtual argument like those we have with ourselves that no-one else is party to. This conversation goes on while Emptiness performs certain acts and Form is stationary. Form is immobilised by the conversation like Melancholia in Albretch Durer's etching of the same name. Emptiness, the being of Form, floats around free from the constraints of physicality and analysis, in the virtual space of the sublime. 


\section{CHAPTER SEVEN: SPACE AS VIRTUAL}

\section{Interspace}

A new context exists for space in the twenty first century as a result of virtual reality; a context that encompasses our imagined realities and vision, one that can provide a new possibility for the experience of being a human being. Frances Dyson (1998) examines the being of human being and the being of technology. She claims that cybertheorists who assign being to cyberspace are attempting to create an ontology of the virtual as a way to authenticate it. But is there a relationship to the world of virtual space that can reveal more than an illusion? While some have seen a relationship between virtual reality and meditation, Damien Keown (1998) claims that the virtual experience will never replace the virtue of meditation. Darren Tofts (1997) says that the hype surrounding the realm of the virtual and cyberspace is far ahead of the reality. According to Tofts we are in danger of 'hyperventilating' on the promise of a technology, which has yet to be fully realised. Dyson says that space is the central metaphor through which an examination of these issues can happen.

"The power of "space" lies in the possibilities it implies: immersion, habitation, "being-there", phenomenal plenitude, unmediated presence, all fall within its domain. Without "space" there can be no concept of presence within an environment, nor, more importantly, can there be the possibility for authenticity that "being-in-the -world" allows.' (Dyson 1998, p.28)

Char Davies (1998) is an artist who is engaged with the space of virtual reality. Her work attempts to challenge our traditional ways of seeing by using immersive environments that take us beyond our usual sensibilities. In 1995 she completed a work called OSMOSE, an artwork that involves 'a stereoscopic head mounted display, threedimensionally localised interactive sound, and an embodying interface driven by the user's breath and balance' (p.145). Davies claims that the effect of full immersion on the 
viewer is a shift in their experience of being. After watching more than five thousand participants experience OSMOSE she says:

'The experience of floating through things, along with the work's reliance on breath and balance as well as solitary immersion, causes many participants to relinquish desire for active "doing" in favour of contemplative "being" (Davies 1998, p.146).

People have described an experience of transcending time and space; being connected or merged with the world; undifferentiated, and a sense of being both in the body and out of the body at the same time. They also reported feelings of joy and euphoria that left them speechless. OSMOSE creates a world that is transparent and illusive rather than a replication of our traditional view of the world constituted by objects and subjects, divided between foreground, middle ground and background. An artform that steps through the illusion of the painted image, Davies aims to de-solidify the notion of the object in an attempt to dissolve spatial distinctions and interrupt the participants' relationship to reality. The participant experiences moving up and down in the world by breathing in and out, and side to side by leaning. Davies found this grounded the interactive experience in the body of the participant, as distinct from other interactive immersive environments that, by the use of the glove for example, encourages the user to relate to the illusion as object based. This project allows the user to embody the virtual space.

\section{Perceptual Space}

Pierre Levy (1998) says that the virtual often signifies the 'absence of', and the real the 'presence of. Levy cites Gilles Deluze's distinction between the virtual and the possible where the possible is like an apparition of the real; identical yet lacking embodiment, a latent reality, the realisation of which is a logical step from disembodied to embodied. Levy agrees that the potential of the virtual is part of the creation of the real, however, he sees the virtual as 'but a change of identity, a displacement of the centre of ontological gravity of the object considered' (Levy 1998, p.26). The being of an object no longer 
resides in the physical. He gives an example of the virtual company, which has no physical location, instead it exists in networks and relationships that function together via remote technology. Levy locates the being of the object in the virtual rather than the actual. I have explored this idea through the character Emptiness who is virtual but represents the being of Form. Levy argues that virtual space was created by language, which allowed us to travel via memory and imagination to other times and places through the visual, the musical and the spoken word. Emptiness exists as a virtual entity through her spoken voice and is always attempting to reconciled with Form.

Our bodies, according to Levy, are virtualised by the simplest technology. A tool is created as an extension of the human form to perform an action, this tool is then forever that virtual action; fire became virtual when flint was discovered and there was a means of creating fire at will.

'Virtualization is one of the principle vectors in the creation of reality' (Levy 1998, p.27)

If the virtual creates reality by the potential of it, then surely that reality is as flexible as its virtual beginnings. As Form and Emptiness integrate the reality that they inhabit it is not the reality that we know, the reality of reason and logic, it is a reality of the dream, where we are the creators of what we experience.

Max Velmans (1998) distinguishes between three types of realities in order to define the role of VR, physical, psychological and virtual. Physical reality exists in space independent of the observer. Psychological reality is immaterial and inhabits no space and does not exist independent of the observer. Virtual reality appears to exist in space but does not; it appears to exist independent of the observer but does not, and its existence is dependent on the interaction between the observer and the equipment. Velmans (1998) says that these assumptions are based on conventional thinking about the nature of perception, which is that an object in the world reflects light, reacts with the visual system of the subject to produce an image of that object in the brain, the product of which is a percept of the image in the mind. This is what Velmans describes as a Dualist Model of perception, similar to the Reductionist Model except that this model insists that 
the percept of the image exists in the brain rather than the mind. In looking for a model of perception to locate virtual reality, Velmans (1998) discards both of these and relates it to the Reflexive Model which claims that the experience of the image is merely the image as perceived in space. It does not exist in the brain or mind.

'Perceptual processing in the brain can result in experiences that have a subjective location and extension beyond the brain' (Velmans 1998, p.49).

Velmans calls this 'perceptual projection' (p 52) and gives as evidence of this in the case of an amputee who still feels sensation in the non-existent limb. Other examples are of the auditory sensation of music that appears to exist outside of the head, and tactile sensations that are projected to the area of the body that is receiving them.

Visually it seems clear that objects and images of objects appear very differently to us, however both are experienced and both rely on the perceptual processing of the brain. Velmans (1998) argues for,

'the evidence for cerebral involvement in the 'construction' of objects as-seen, including their seen location in three-dimensional space' (Velmans 1998, p52).

The illusion of stereoscope is an example of visual construction of a three-dimensional space. Compare this with looking at a painting of a three dimensional object or scene. The depth is flattened by the edge of the image, which reinforces the two-dimensional surface. When you looks at a stereoscopic image you experience looking through the image rather than looking at it. A way to demonstrate this is to look at a painting through a rolled up piece of paper to see how the three-dimensionality is enhanced.

Velmans (1998) suggests that virtual reality fits into the reflexive model of perception where the brain, reacting to a perceived image, constructs and projects that image into the world. 
'In so far as the information input from VR systems is similar to the $3 \mathrm{D}$ information supplied by the normal world, they will be experienced as facsimiles of the normal world located and extended in 3D space' (Velmans 1998, p 55).

He claims that there is no phenomenal distinction on between what we believe to be the world and the world that we perceive. 'With our eyes open the 'physical world' is what we experience' (Velmans 1998, p.56). My first experience of immersive interactive virtual reality was an artwork that gave me a sense of this.

\section{Virtual Space}

I participated in the trial of Metraforms * new artwork 'Ectasis, human presence in digital environments' which involved viewing a curved screen while wearing $3 \mathrm{D}$ stereoscope glasses with tracking devices on them. I sat down with three other strangers who were also involved in the trial and we put our glasses on without speaking. The first work was a spatial landscape, an endless space of moving and floating abstract shapes, some solid, some painterly, some semi-transparent. It was like being inside an abstract painting that was built in layers. What came to mind was the experience of being a particle that floats between the layers of paint pigment. The veils of colour floated towards me and I had the distinct impression of them brushing my face as they passed. In the second work there were several small objects that moved like fish and floated in the virtual landscape. We discovered independently that each icon or avatar was related to one of us and we could direct their movement with our heads. Only a slight movement would create quite a large sweep in the avatar. Fairly quickly we experimented with the fluid range of movements and were playfully swimming with one another in virtual space. The next discovery was that we could move together through the space turning left and right up, and down and discover the landscape and all the surprises of an uncharted world. In this world my experience was one of being fluid and free, much like a dreamworld where you are unencumbered by your physical form.

* Metraform team: Jonathon Duckworth, Lawrence Harvey, Mark Guglielmetti. 
The glasses appeared heavy and cumbersome when I first put them on and within minures the discomfort was gone. However it was not the sensation of settling into or getting used to them. It was more that the body that felt the discomfort was gone. My experience was that I was no longer sitting in the chair. I became the tapered icon that swam effortlessly in space. In other words, in the virtual environment, I was experiencing perceptual projection and my experience of my body being affected by my environment was gone. I was in a created reality and for that moment I was in the space of the sublime. beyond my experience of myself.
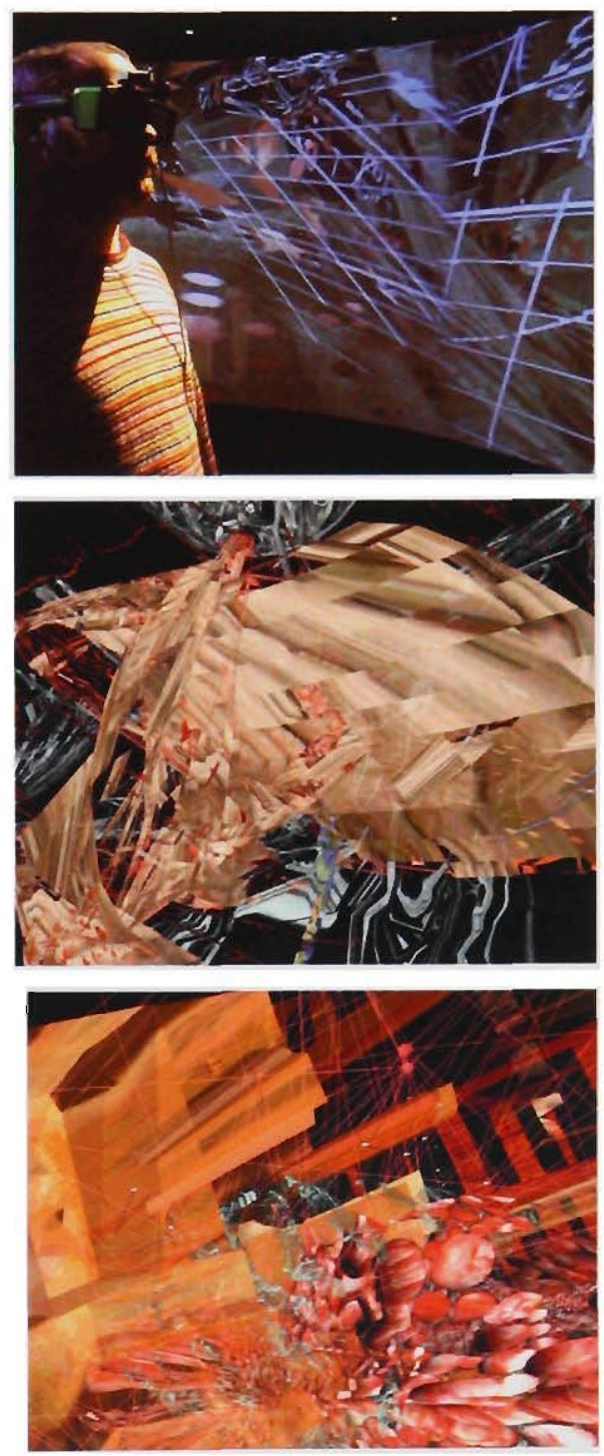

Real-time frame captures of Ectasis

Image courtesy of Metraform, single user interaction 
There is no material world out there to describe in virtual space. When we look at a $3 \mathrm{D}$ stereoscopic image or put on a Virtual Reality helmet, we perceive space but know that the space does not exist. Our perception resides in us, not in anything independent of us. When we take the VR helmet off there is no other world out there that we are physically stepping out of. If we move away from the stereoscopic image, it no longer appears to contain space. Both things require the physiology of our brains to create the very real effect of space. We are visually creating a world that does not exist independent of our perception. This experience gives us a sense of being the cause of our perception. 


\section{CHAPTER EIGHT: INSTALLATION SPACE}

\section{Activation of Space}

The Sublime Sleep is an installation in the sense meant by Adam Geczy and Benjamin Genocchio when they say that Installation Art is an activation of space "which takes into account the subjective, temporal specificity of the beholder'. (Geczy and Genocchio, 2001 p.3) Stepping into the space of the gallery is stepping into a context that is particular to this artwork, the space of the virtual. Seeing The Sublime Sleep from the context of virtual space places the viewer in a relationship to the work that is participatory rather than observational. You could view the exhibition from the curtained doorway and only see a darkened room with some lit peepholes and a small stage. However by stepping up to the work and engaging with it the virtuality of the space becomes apparent. My intention is to have the entire space experienced as a virtual realm as a result of the low light and the consequential focus on the realm of the artwork. When one is in the dark the world exists in monotone and areas of spotlight appear to be holes into another reality. In this case that reality is the artwork.

There are several spaces in the exhibition and the viewer is required to move between them. This is intended to create a shift in awareness of perception from the way we view the two-dimensional surface of a painting, the illusion of three-dimensionality in stereoscope, the three-dimensionality of the sculptural image and the moving images of video. The temporality of the different works also changes. The main room includes, a video projection on veils of fabric, which is SleepWALKER, stereoscopic boxes which are VirtualPAINTING, and the video installation of VirtuallyVANISHED.

The stereoscopic work in VirtualPAINTING can be viewed as one would view a diorama, with the knowledge that the image is motionless, however the viewer can look around inside the image in a way that you cannot do with a two-dimensional image. In VirtuallyVANISHED the work can be circumnavigated by the viewer with the architectural space of the art work containing the object of interest. In this work the viewer is outside of the space looking in, a subtle reminder of the fact that they are outside of the virtual space looking in. The combination of animation and anamorphosis 
in this work distorts the frame of the screen and the moving image escapes the confines of the ratio, $4 \times 3$, moving into the third-dimension in the reflection in the cylinder.

\section{Sleep Space}

SleepWALKER refers to the previous exhibition of the same name, which was a work in progress, done half way through the doctorate. This work operates like a dream of The Sublime Sleep by bringing a human scale to the familiar imagery. A life size version of Form floats doll-like around the space of an exhibition in which she is represented, as if the character has come to life and is haunting the artwork. A comment by an anonymous viewer in the visitor's book from the exhibition Sleepwalker provides a clue to a reading of The Sublime Sleep, 'Being like a Sleepwalker is like Being dead alive'. Form is dead alive, in a state of sleep, which is our waking state. Emptiness has developed as a result of the work in progress and is trying to wake up Form, bring her back to life and metaphorically drag her from a two-dimensional life where she is unable to step through the picture plane, into the world of being where nothing is fixed and the world is a created act. The world of pure form, absolute reality.

\section{Internal Space}

The internal space of meditation is what is referred to by MANDALA, a series of painted images that divide the two rooms of the exhibition. While I do not expect the viewer to be meditative in a gallery context, all the works allude conceptually to a proposition that time spent with a painting can provide something that cannot be achieved by a passing glance. This work requires an internal space similar to Newman's Onement I. It combines the duplication of the digital image with the aura of an original. 


\section{Movement in Time}

The fifth space of the exhibition is a small room that houses VirtuallyREAL. This piece tempts the viewer to linger. Initially the space looks sculptural, a small theatre or stage behind glass. Ideally when the viewer is about to leave, having taken in all there is to see, a figure appears and the dialogue begins. The figure entertains intermittently, with pauses long enough for the viewer to think that the show is over. Just as the viewer is about to leave the next move takes place, teasing them to stay. Objects move randomly in the set with no perceptible sequence and even the loop of the character is changed by the alternative mood created depending on which event is happening to coincide with it.

This device to prolong the audience's viewing time was influenced by a Bill Viola (2002) installation commissioned for the Deutsche Guggenheim Berlin called Bill Viola: Going Forth By Day. This large scale video installation involved five screens that surrounded the viewer. As I sat watching the various screens in the darkened space, the person sitting next to me commented that two of the screens had very dramatic and poetic climaxes. As a result of this comment I stayed for the entire thirty five minutes that the work took to complete. I realised that I had never brought to video art the attention or patience I had given to film, I would expect to grasp the effect of the work in the time it took to view a stationary image. The Viola work built over time to a crescendo that had a transcendent effect on me as a viewer. Viola sees time as critical to his work. The unfolding of time and awareness is, he believes, at the heart of the tradition of painting. Viola relates to the still image as a moment in time captured in such a way as to speak of an entire era. Influenced by Violas work, the random animation in VirtuallyREAL operates to capture the viewer in time, to stay with the work for long enough to enter the world.

\section{Spatial Painting}

Although the set is clearly three-dimensional it is also painterly in its aesthetic. The influence of the animation of the Brother Quay can be seen here. Their work is visually textured in a painterly way that is unusual for 3D animation. The world of Form is more richly coloured than the dark environments of The Street of Crocodiles and The Cabinet 
of Jan Svankmajer, however the fascination with old technologies and the history of painting can be seen in the Quay's work also. The experience of visually stepping into the space of the stereoscope via peephole viewing is attempted on a real three dimensional scale. The set is placed before the viewer amid black surrounds and the tricks of allusion give a sense of the world being inhabited. However, the scene is framed behind glass. which separates the viewer in a way reminiscent of the picture plane in a twodimensional image. The elements of time and space in this work make for a confusing reality that recalls the illusion of the stereoscope but with the narrative of stills ser to life. In the same way that Form struggles with her identity, arguing with Emptiness about whether she is a painting, living in a virtual world believing it to be reality, the viewer is also presented with the dilemma of what seems to be a painting pulled into the third dimension, activating a space just as the viewer does when they enter the exhibition.

Form: It seems so real and so independent of me. My reality. It never wavers or ripples to let me know that I am its author. However I have noticed some remarkable coincidences. The same patterns emerging in more than one place, like my existential footprint, marking all things that I touch, coding all my experiences even before I have them. Always....I spill the milk when thinking of that hateful cat. And somehow the shadow of that old tree is cast across my facer when the evening is lonely ........ but that old tree fell down twenty years ago. Can a ghost cast a shadow?

Emptiness: You are your own ghost. It's your shadow.

Form: You really mean me to believe that I make my world. I plaster and paint my daily experience?

I am framed, and not by some crooked law man. 
of Jan Svankmajer, however the fascination with old technologies and the history of painting can be seen in the Quay's work also. The experience of visually stepping into the space of the stereoscope via peephole viewing is attempted on a real three dimensional scale. The set is placed before the viewer amid black surrounds and the tricks of illusion give a sense of the world being inhabited. However, the scene is framed behind glass, which separates the viewer in a way reminiscent of the picture plane in a twodimensional image. The elements of time and space in this work make for a confusing reality that recalls the illusion of the stereoscope but with the narrative of stills set to life. In the same way that Form struggles with her identity, arguing with Emptiness about whether she is a painting, living in a virtual world believing it to be reality, the viewer is also presented with the dilemma of what seems to be a painting pulled into the third dimension, activating a space just as the viewer does when they enter the exhibition. 
Have I really pushed my face so far into the picture that it has become my world and I have forgotten the other side of the frame; slipped into that reality unaware.

Perhaps I can step back, extract myself form the mercury of my world and watch it take its own shape...... witness my view....... see the frame of my life. Maybe even walk around in the gallery, the white walls of creation. 


\section{CONCLUSION}

Virtual reality is still just potential. Darren Tofts argues that unlike the consensual opinion that technology is outpacing our ability to keep up with it, there is a vacuum in the wake of the concept of virtual reality and in that vacuum we have a "culture that has yet to materialise, a genuine "virtual reality"”." (Tofts 1997, p.19) However the vision of virtual reality is powerful and it is my belief that the realisation of that potential is inevitable. When it comes, the next revolution in the visual culture of our society will have arrived. In the same way that the printing press and the photographic camera changed art forever, so does the prospect of VR. The unrealised potential of immersive technology will offer new possibilities to art. The audience will no longer be observers and assessors of art, they will be participants, engaged like never before in the context of the gallery. Georges Didi-Huberman writes of Barnet Newman's Onement $l$ in a way that could be a description of Char Davies's OSMOSE.

\footnotetext{
'Why is that ambiguity of the place rhythmic, appearing and disappearing at the same time? Because something in it passes through - infiltrates, mixes with, permeates - and disintergrates any certainty about space. This something is again the aura, which we must now understand in terms of a third characteristic, which returns to the most archaic and "physical," the most material sense of the word aura. This meaning is that of breath, of the air that surrounds us as a subtle, moving absolute place, the air that permeates us and makes us breathe' (Didi-Huberman 1996, p.60)
}

The aura referred to here is aligned with space; the space of our breath and the air that we inhale. Newman's Onement $I$ created that experience in some observers but not in all. It requires a dedicated art lover to engage purposively with a two-dimensional artwork in order to be so moved. However participants in Char Davies's OSMOSE were frequently profoundly affected by the work. In the recent exhibition Deep Space - sensation and immersion, at the Centre for the Moving Image in Melbourne the 
artworks were entered, in many cases the viewer was necessary for the work to be seen. In Lynette Wallworth's work Hold Vessel\#l, the viewer took a glass bowl and held it under the stream of light that was the projection. Immediately the artwork came to life in the hands of the audience as the imagery was caught in the bowl. Luc Courchesne's work The Visitor: Living By Number is seen by the viewer putting their head inside the work, which is a Panascope 360, a reflective screen in the shape of a bowl. The experience is only available individually and while the viewers are immersed in the voice-activated artwork they become a part of the object.

The immersive experience is currently being explored by artists in many and diverse ways, however the tools of true immersion are not yet available to most people due to the prohibitive expense of the technology. Attempts to create the realm of the virtual can be seen in the history of illusion in painting beginning with the development of perspective at the time of the Enlightenment. By relating our contemporary understanding of virtual reality to a historical context we are better able to understand its place in our society and more particularly its potential influence on art in the $21^{\text {st }}$ century.

Along with an increasing interest in the virtual comes a questioning of the nature of reality. What we perceive to be the 'truth' about reality, carves one part of our universe from another, like the surgeon's knife. We are trapped in our own conceptions of the objects of our world. We pick up a cup with the certainty of how it will feel and how much it will weigh. What we know to be out there in front of our eyes, denies us any one of a thousand other possibilities. The device of stereoscope is like a drug free hallucination in the way it forces the viewer to acknowledge that what they know to be true, is denied by their experience of reality, what they can see before their eyes (ie there is no room behind the peepholes). It asks the question, if what we know doesn't match our experience how can we be so sure of what we know? In the act of viewing an illusion like the stereoscope or anamorphic image the certainty of the separation between our world and our perception of it is shaken and we are forced to question how separate are we from what we perceive.

In The Sublime Sleep, Form acts as a metaphor for this division between herself and her environment. She is as separate from her environment as we consider 
ourselves to be from ours, standing alone from the moment of birth, an object in a world of objects. From outside the set we see that she is all part of the one construct. She does not exist in isolation, she is one part of an artwork, sitting in a set in a room in a gallery. It is clear to us that she does not exist independently in the world as we do, however are we any different? Can we ever see the context that we live inside, the set and room and gallery that constitutes our lives?

Entering the space of the virtual is a way to step into an artwork, to experience being in the world as a part of an interactive whole. Being in the world in this way is being fully present, being in the space of the sublime. The virtual provides a clue to experiencing the sublime, a chance to be conscious of what we are usually unconscious of, that we are already in an immersive interactive environment that subtly moves, changes and shifts with each move change or shift we make.

The Sublime Sleep is a dialogue about this proposition, questioning what we take for granted, playing with our senses. It utilises the technologies of the past as a way to locate the virtual outside a contemporary technological construct. I argue that there has been an historical fascination with the virtual, which can be seen in our interest in illusion over the centuries. I claim that this fascination resides in an ongoing struggle to release ourselves from the constraints of our fixed perception of reality. The artwork in The Sublime Sleep was designed to give the viewer a moment of freedom from that constraint and allow them to consider that what they see is just what they see and not necessarily a construction that exists outside of their perception. The technologies used and the visual inferences create the context of a view of the virtual that stretches back to the Renaissance and recontextualises the agenda of the early history of painting from a representation of reality as a truth to a construction of an elaborate illusion

Throughout the development of the artwork I was continually challenged with this proposition myself in the discovery of the unnerving yet beguiling nature of illusion. My view of the world was constantly being witnessed as a painting and my experience of paintings were always challenged by the idea that I could step into them. The artwork is a process of discovery of this mystery for myself, and my relationship to the world. The exegesis is an attempt to understand that discovery. For a period of time I put away my palette and paints; I was unclear how to proceed as an artist confronted by the 
materialism of my practice and confused by the digital surge that $I$ could feel running through society as the twentieth century drew to a close. A tradition that had survived for centuries was being severed from its past. How was the canvas to survive? Would it become an archive of the pre-technological era?

What drew me back to the painted image was the illusion of space. In the work of Van Eyck I saw the stillness that slows time, a state of being in a painting that I wanted to explore as a viewer. The experience of looking into the illusion of that reality had me want to move about in it, to quietly sneak into the corner of the canvas and peer behind the frame. My eyes were widened by that looking and I felt a need to step through the picture plane into the space of painting. To look at the world newly, as a child, is the opportunity of new technology and particularly, virtual reality.

Virtual space is a chance to test our boundaries and explore the edges of who we know we are. To step into the virtual realm of painting requires a willingness to reassess our certainty about the walls we know that we can't walk through. It requires overcoming our fear of disappearing as we lose our boundaries. Being lost to ourselves may be the best thing that we could ever experience. It may mean discovering we have been asleep and the toils of our life are the dreams we have created. It may mean having to be responsible for the castles we have not built and the people we have not embraced. We may discover that while our eyes have seemed to be open perhaps like Form we are actually sleeping, in the long dream between birth and death, yet to see the light of reality.

The contemporary interest in the virtual is providing a new arena for examining our experience of reality. Form is offered as a template to map our own perception. As she discovers that in fact she is a painting in three dimensions moving about in virtual space, we are asked to consider the moving painting that is our life's experience. 


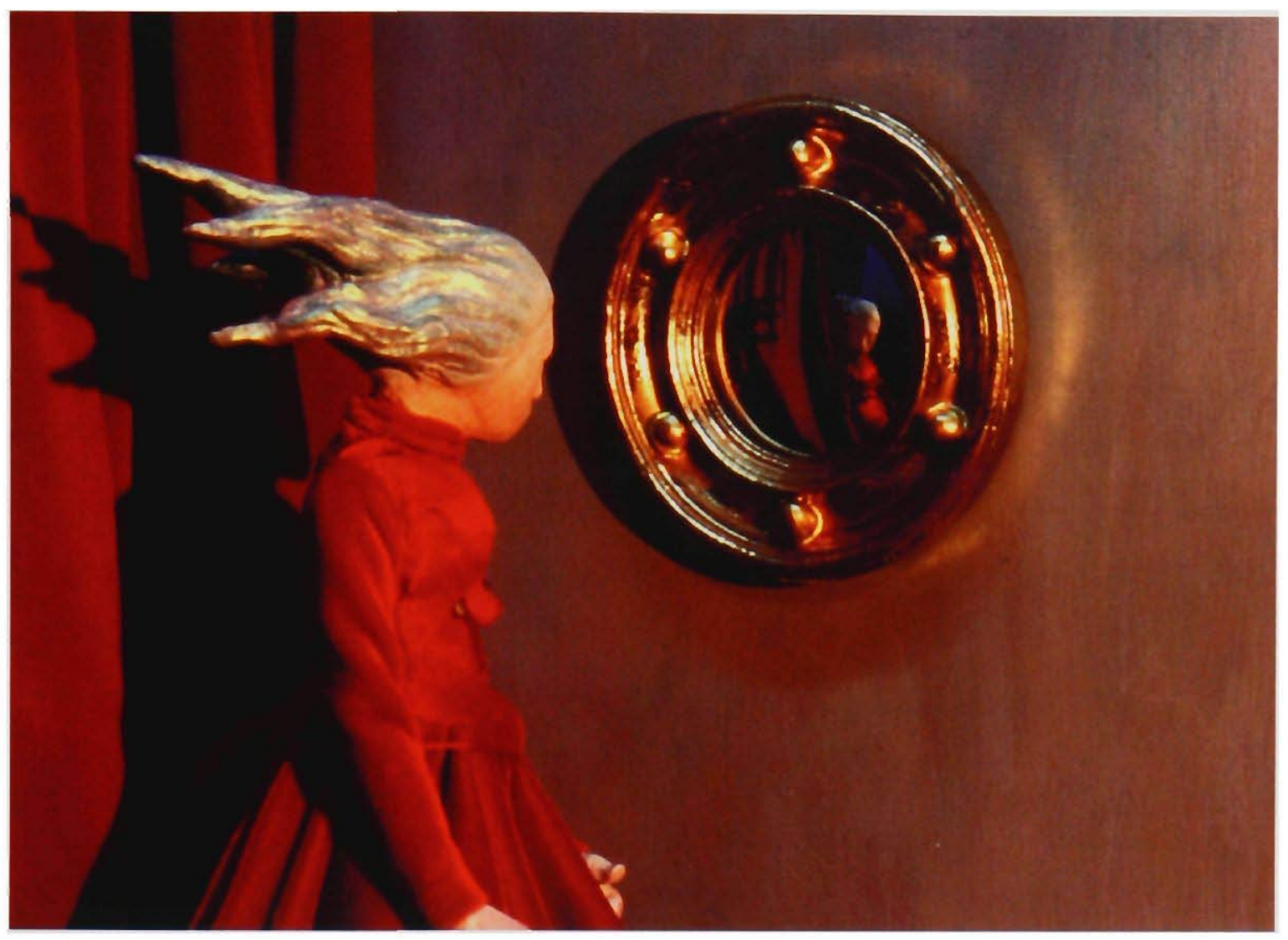

Form asks the question, by Megan Evans from VirtuallyPAINTED serics 2001 


\section{EPILOGUE}

Man.....probably the most mysterious species on our planet. A mystery of unanswered questions. Who are we? Where do we come from? Where are we going? How do we know what we think we know? Why do we believe anything at all? Countless questions in search of an answer, an answer that will give rise to a new question and the next question will give rise to the next question and so on..... But, in the end, isn't it always the same question? And always the same answer. The ball is round. The game lasts 90 minutes. That's a fact. Everything else is pure theory.' - The umpire.

From Film Run Lola Run, directed by Tom Tykwer - Film X Creative Pool. 


\section{REFERENCES}

BALTRUSAITIS J 1977 Anamorphic Art, Harry N. Abrams, Inc, New York,

BATCHEN G 1998 Spectres of Cyberspace in Visual Culture Reader, N. Routledge, London.

BAUDRILLARD J. 2000 The Vital Illusion, Ed by Julia Witwer - Colombia University Press, New York.

BERKELY G. 1963 A New Theory of Vision and other writings, Dents and Sons, London.

BRUSATI C. 1995 Artifice and Illusion: The art and writing of Samuel Van Hoogstraten, University of Chicago Press, Chicago

BURKE E.1990 A Philosophical Enquiry into the Origin of our Ideas of the Sublime and Beautiful, Oxford University Press, New York

CRARY J. 2001 Suspensions of Perception, Attention, Spectacle and Modern CultureMIT Press, London.

CROWTHER P. 1992 Les Immateriaux and the Post Modern Sublime, in Benjamin (ed) Judging Lyotard A. Routledge,London,

DAVIES C. 1998 Changing Space: Virtual reality as an Arena of Embodied Being in Beckman J (ed) The Virtual Dimension, Architecture, Representation and Crash Culture, Princeton Architectural Press, New York.

DAVIS R. - http://www.dafe.org/misc/peppers/peppers.htm, 2001

RASCHKE C. A. 1982 The Deconstruction of God in Deconstruction and Theology, Crossroad Publishing Company New York.

DYSON F. 1998 "Space," "Being," and other Fictions in the Domain of the Virtual in Beckman J. (ed) The Virtual Dimension, Architecture, Representation and Crash Culture Princeton Architectural Press, New York.

DIDI-HUBERMAN G. 1996 The Supposition of The Aura: The Now, The Then, and Modernity, Essay in Negotiating Rapture, in Richard Francis (ed) The Power of Art to Transform Lives, Museum of Contemporary Art Chicago.

EHRENZWEIG A (2000) The Hidden Order of art, A study in the Psychology of Artistic Perception, Phoenix Press London, 
TYKWER T. Run Lola Run, Film directed by Tykwer Film X Creative Pool.

FOUCAULT M. (1970) The order of Things, a translation of Les Mots et les choses New York Pantheon,.

FRIZOT M (1998).A New History of Photography Frizot M. (ed) Konemann, Italy.

FURNISS M. (1998) Art in Motion, Animation Aesthetics, John Libby and Company, Sydney.

GABLIK S (1985) Magritte, Thames and Hudson, Japan

GECZY A. AND GENOCCHIO B. (2001) What is Installation, an anthology of writings on Australian Installation Art, Power Publications, Sydney

GOMBRICH E.H. (2000) Art and Illusion, A Study in the Psychology of Pictorial Representation, Prinetown University Press Princetown and Oxford, Hong Kong,

HEIM M. (1993) The Metaphysics of Virtual Reality Oxford University Press,, New York

ILES C. (2001) Into the Light, The Projected Image in American Art 1964 - 1977 Whitney Museum of American Art, New York.

JAMESON F. (1992) The Signatures of the Visible, Routledge, New York and London.

KANT I. (1928) Kant's Critique of Judgement, trans, James Creed, Meredith Oxford, Clarendon Press

(2001) Critique of the Power of Judgement, Cambridge University Press. UK.

KEMP M. (1990) The Science of Art, Optical themes in western art from Brunelleschi to Seurat, Yale University Press, London.

KEOWN D. (1998) A Buddhist Perspective on Virtual Reality in Wood J. (ed) The Virtual Embodied, Routledge, London.

KLINGER C. (1997) The Concepts of the Sublime and the Beautiful in Kant and Lyotard in ScottR.M. (ed) Feminist Interpretations of Immanuel Kant The Pennsylvania State University Press, USA,

LEVY P (1998) Becoming Virtual, Reality in the Digital Age - Plenum Press New York.

LONGINUS (1953) On the Sublime in Aristotle's Poetics and Rhetoric: Demetrius on style. Longinus on the sublime; essays in classical criticism, revised ed, London

LYNN V. (2001).Space Odysseys: Sensation and Immersion, Essay in Deep Space Sensation and Immersion, Art Gallery of New South Wales, Sydney. 
LYOTARD J.F. (1989) The Sublime and the Avant-Guard, in Benjamin A. (ed) The Lyotard Reader, Blackwell, Oxford.

LYOTARD J.F (1993) The Postmodern Condition: A Report on Knowledge, University of Minnesota Press, Minneapolis,

LYOTARD J.F (1994) Lessons on the Analytic of the Sublime, Stanford University Press, USA.

NEITZSCHE F (1982) Quoted in RASCHKE C. A. De-construction and Theology, Crossroad, New York,.

PACHT O (1994) Van Eyck and the Founders of Early Netherlandish Painting, Harvey Miller Pub, London.

RASCHKE C. A. (1982) The Deconstruction of God Essay in De-construction and Theology, Crossraod, New York.

STAFFORD B. M. (2001) Devices of Wonder, From the World in a Box to Images on a Screen, Getty Research Institute, Los Angeles.

STEIGRAD http://www.mshepley.btinternet.co.uk/melies.htm Lawrence Steigrad Fine Arts Gallery 42, East 76th. Street, New York, 2003

TERPAK F. (2001) Devices of Wonder, From the World in a Box to Images on a Screen, Getty Research Institute, Los Angeles.

TERPAK F. and STAFFORD B.M. (2001) Devices of Wonder, From the World in a Box to Images on a Screen, Getty Research Institute, Los Angeles.

TOFTS D (1997) Memory Trade, A Prehistory of Cyberculture Interface, NSW.

VAN HOOGSTRATEN S. - Indeyling tot de Hooge Schoole der Schilderkonst, anders de Zichthaere Werelt. Verdelt in negen Leerwinkel, yder bestiert door eene der Zanggodinnen. Ten hoogsten noodzaklelijk, tot onderwijs, voor alle die deeze edele, vrye, en hooge Konst oeffenen, of met yver zoeken to leeren, of anders, een igzins beminnen. (Introduction to the Academy of Painting; or The Visible World. Divided into nine classrooms, each overseen by one of the Muses. Of the greatest utility for the instruction of all those who practice this noble, free, and esteemed art, or who dililgently seek to learn it or otherwise appreciate it) published by Francois Van Hoogstraten in a single edition, Rotterdam, 1968 
WERTHEIM M. (1999) The Pearly Gates of Cyberspace, A History of Space from Dante to the Internet, Doubleday, Sydney.

VELMANS M. (1998) Physical, psychological and Virtual Realities in Wood J. (ed) The Virtual Embodied, Presence, Practice, Technology, Routledge, London.. 


\section{APPENDICES}

Assorted Pages from Sketch books

Selection of pages from SLEEPWALKER (2001) comments book

Selection of pages from THE SUBLIME SLEEP (2003) comments book 
ASSORTED PAGES FROM SKETCH BOOKS 

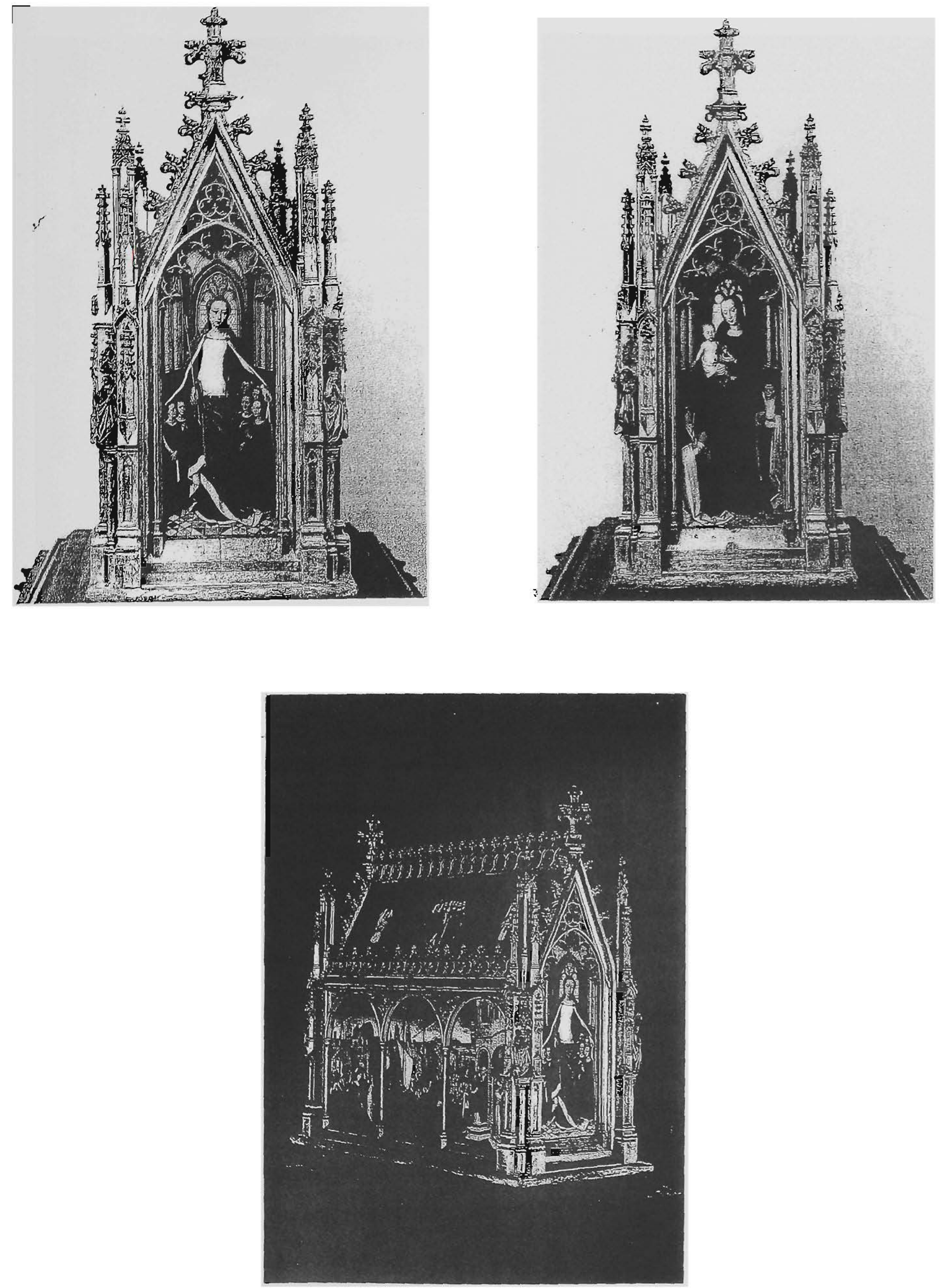

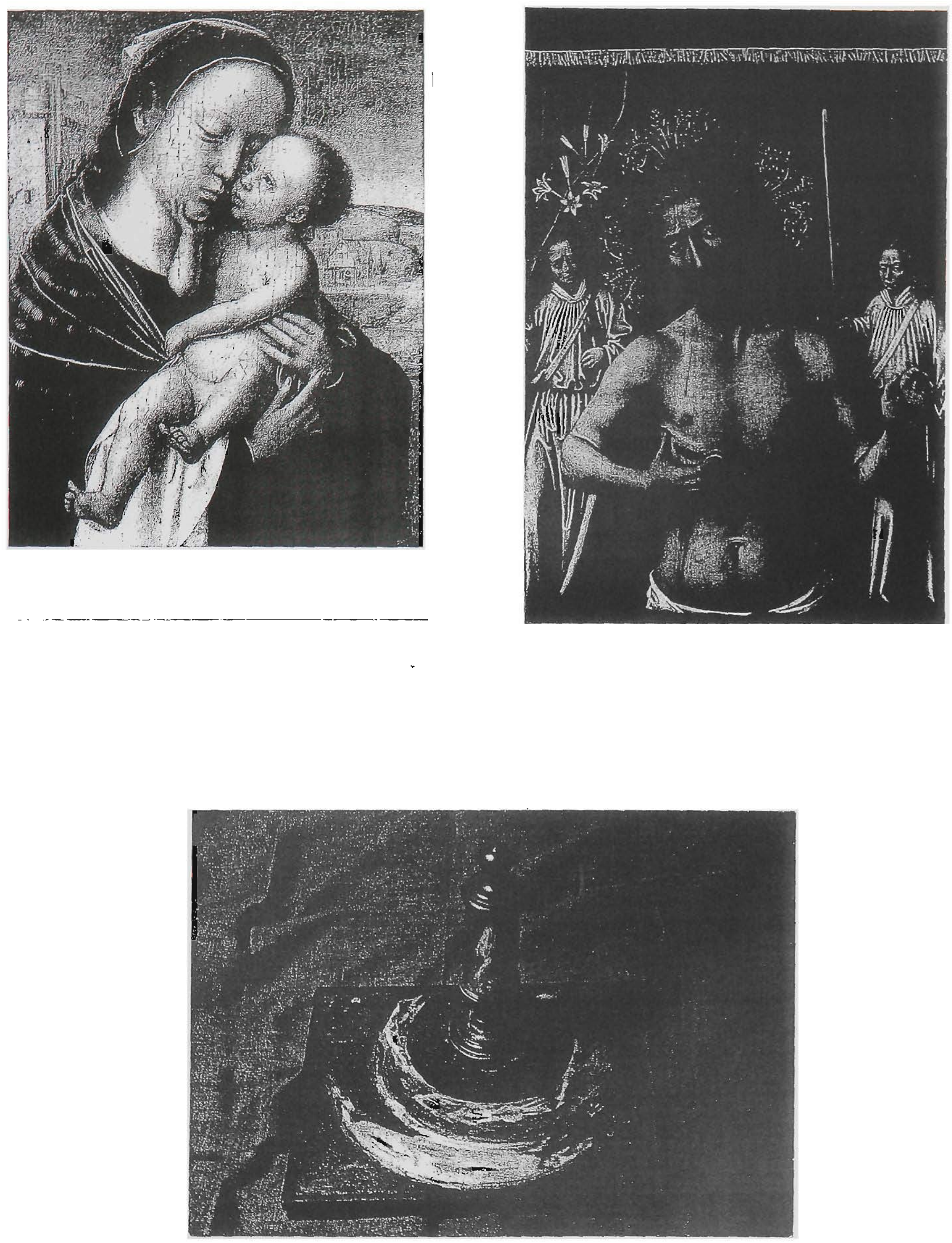


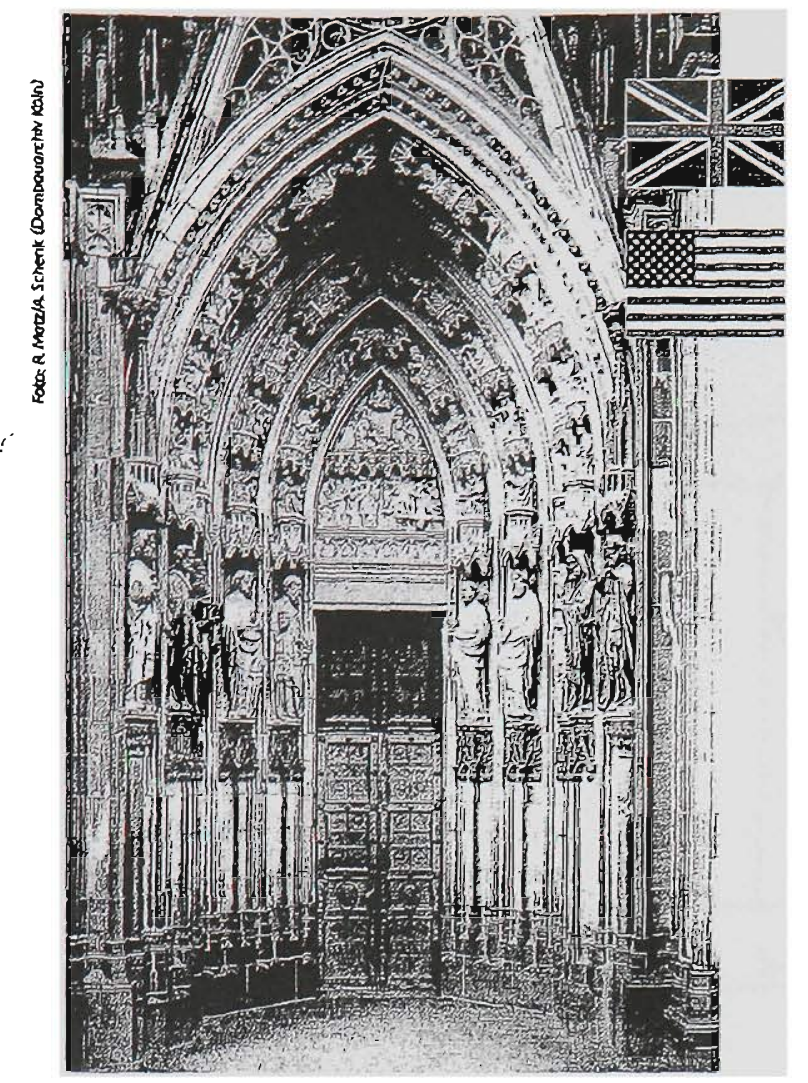

Welcome co Cologne Cathedral

\section{Dear Visitor,}

we are pleased that you have declded to wist the Cologne Cathedral. In this ittle brochure we would ilke to provide you with some information useful for a self-guided tour. it should help you appreciate the carthedral, its magnilicent architecture and nichness, as well as its expression of the Christian faith

After your tour, let us cordially invite you to the DOMFORUM, the Cathedral's new Visitor's Center. A varlety of information awaits you, including a multiviston on the castedral, (More information can be found on the back of this brochure)

\section{DORFORUM}

\section{Mariengebete}

deutsch - english - français - italiano

español - português - polska - japanese

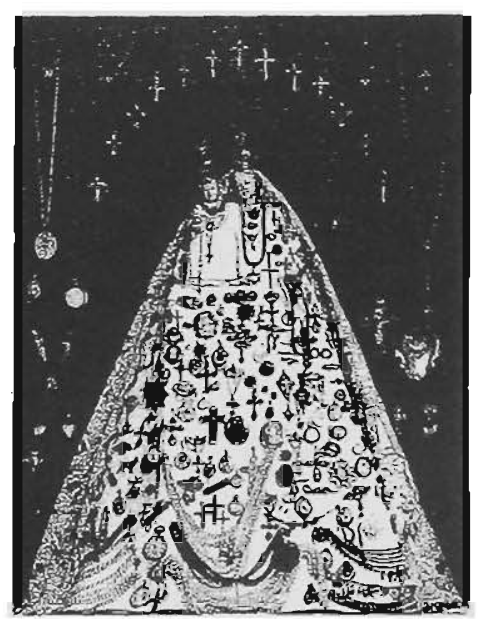

Die Schmuckmadonna

Schon seit ältester Zeit wird im Kölner Dom die Mutter Gotfes besonders verehrt.

Eine herausragende Stelle der Marienverehrung ist die sogenannte Schmuckmadonna, die heute im ehemaligen Dreikönigsaliar im nördlichen Querschiff aufgestellt ist. Auf ihrem Kleid aus weỉem Moirée sind einige der zahlreichen Schmuck- und Votivgaben aurgenäht, die der Goitesmutter von den Gläubigen geschenkt wurden.

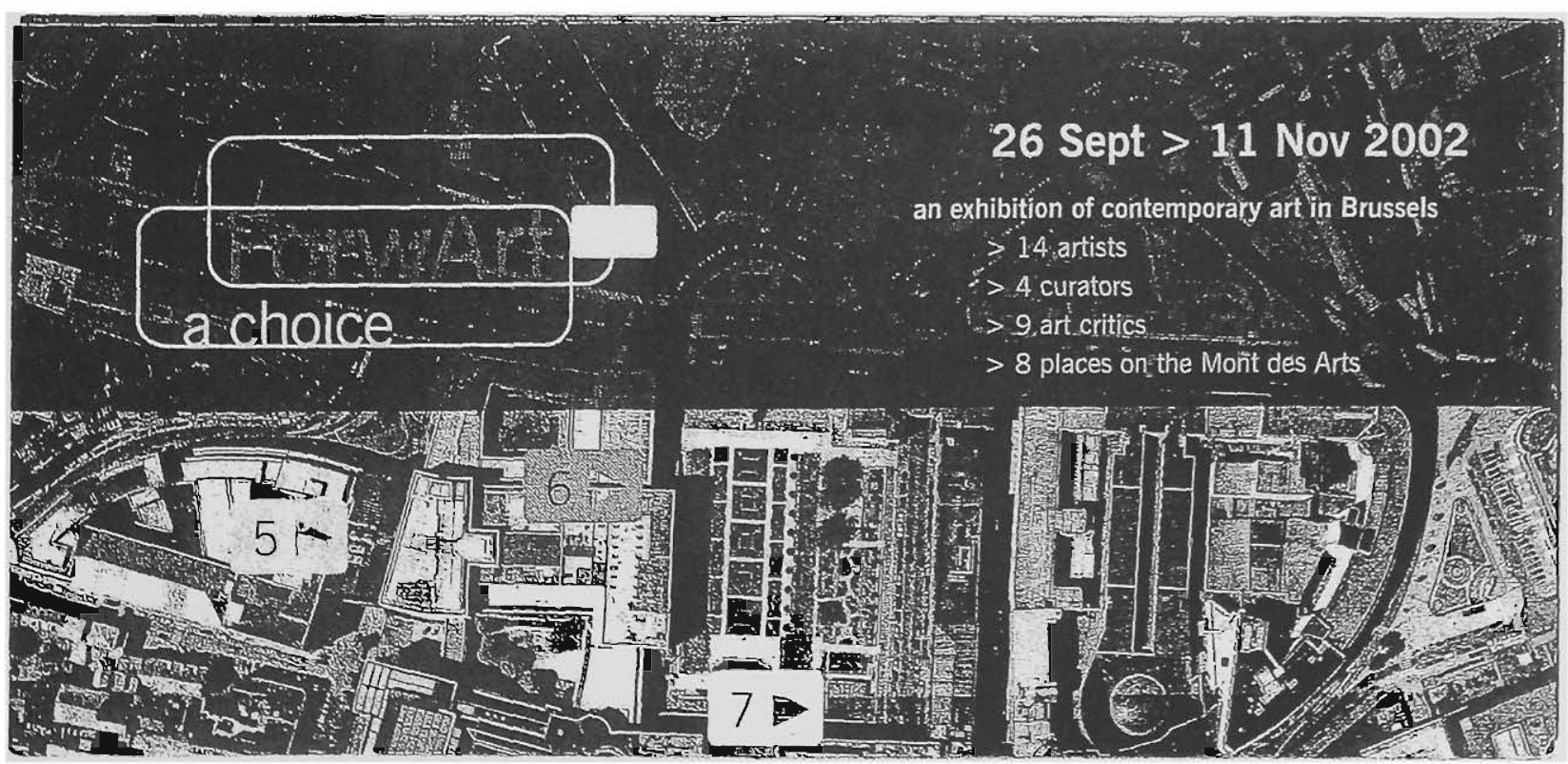


Babic Circuits

constant cunt sowe RL iL

8

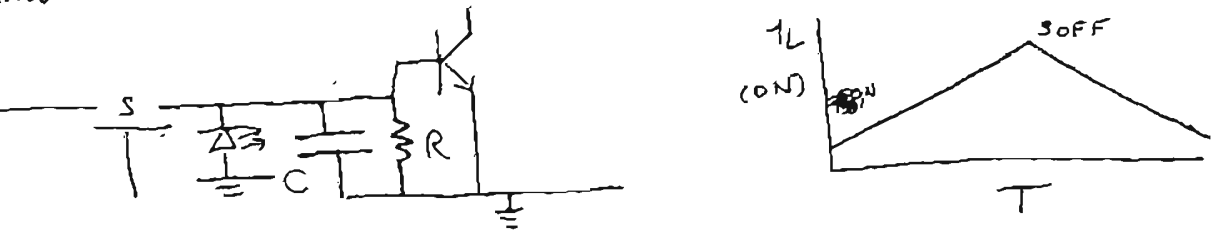

slow on slow off

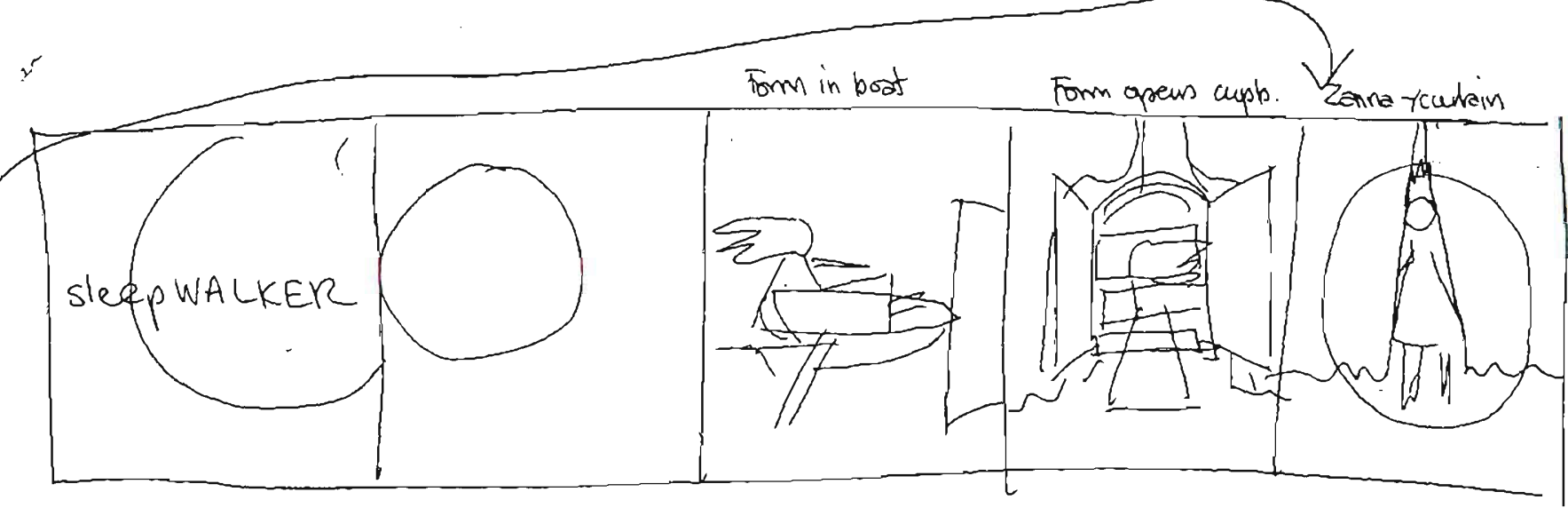

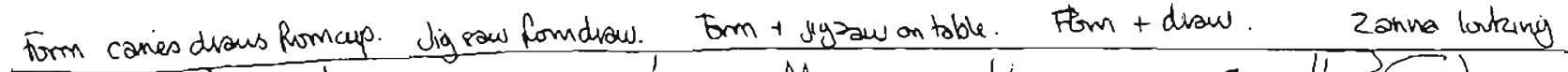
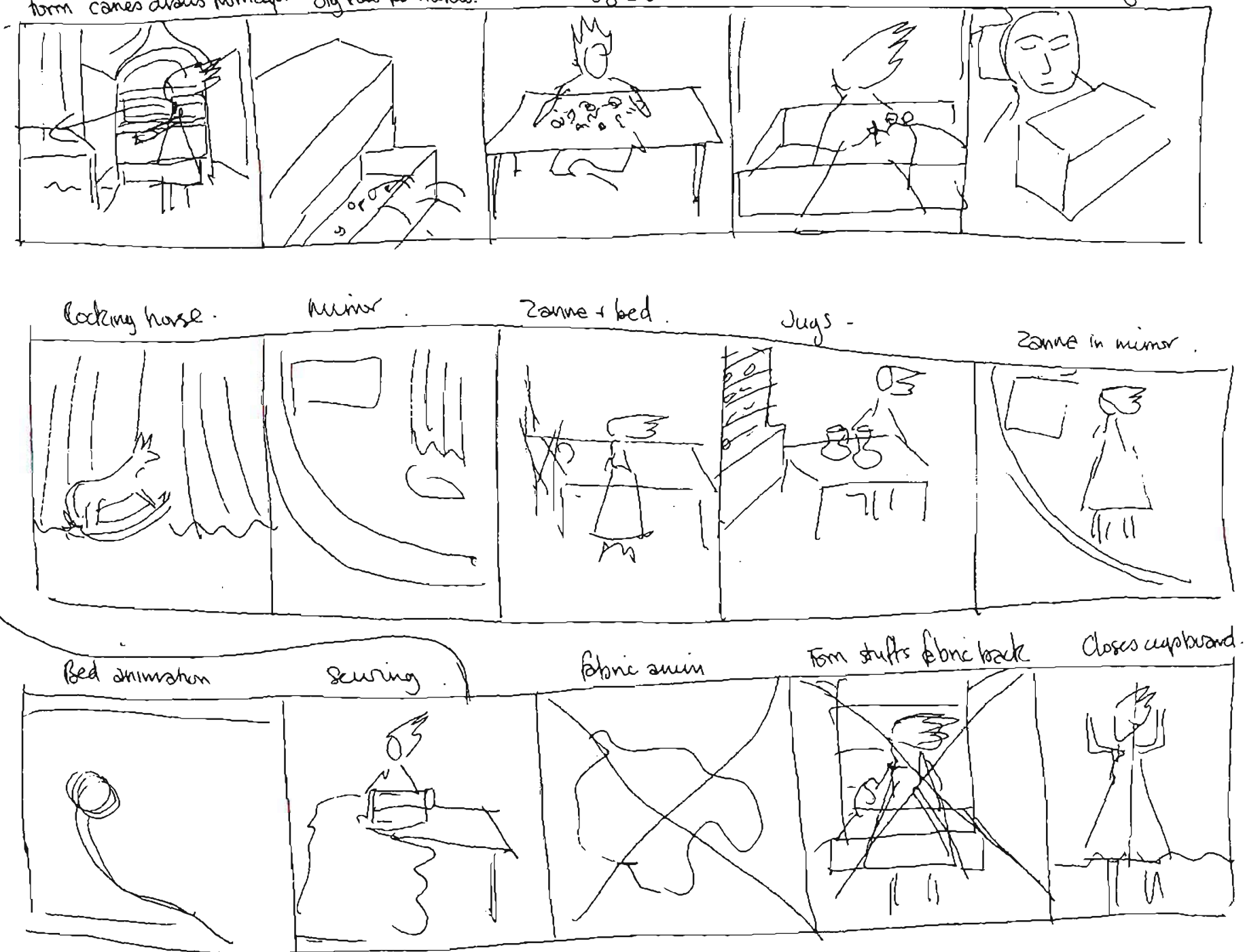

cello. 
zonna coming apboand.
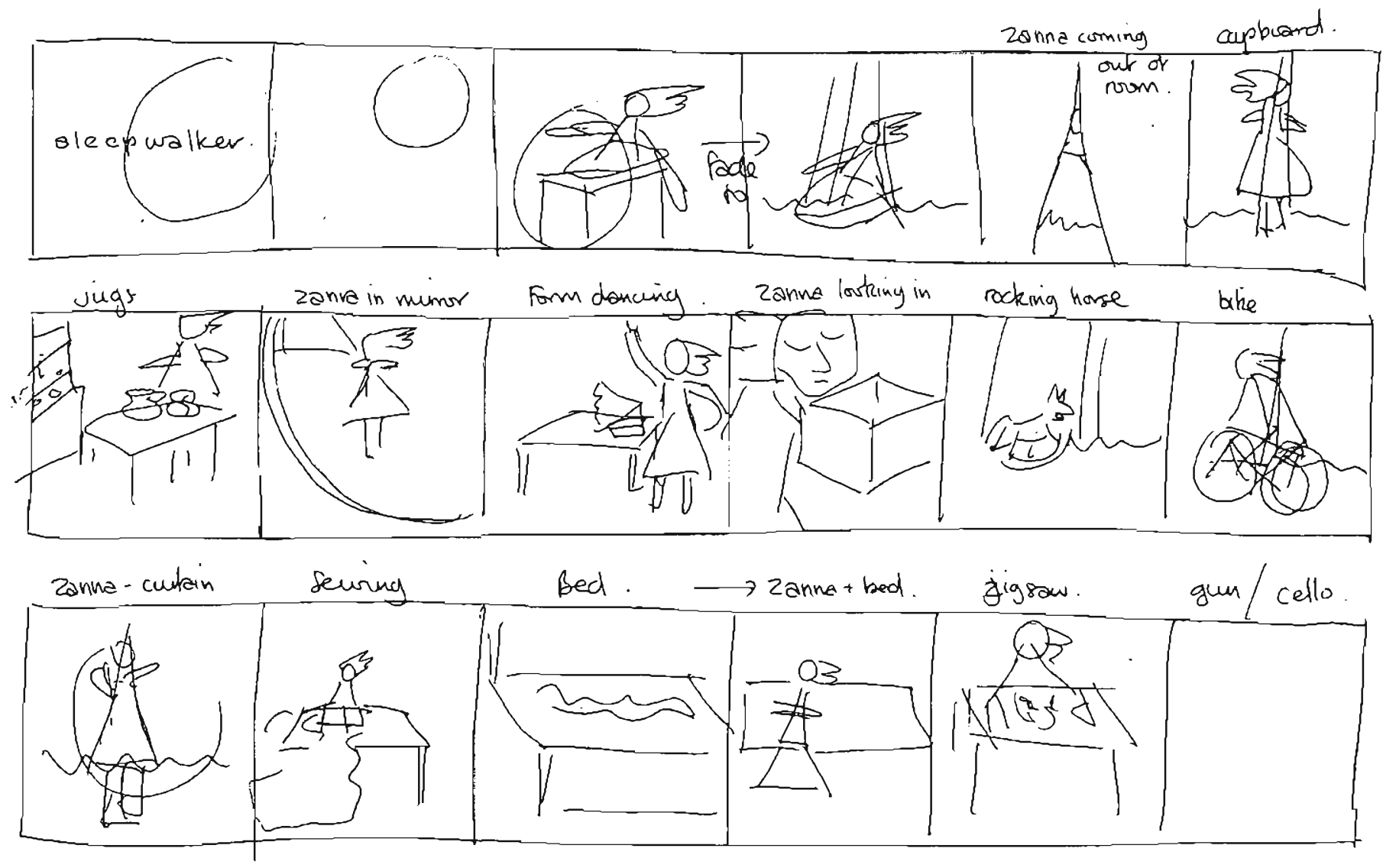

Sleepuatker foutage - vieuring ports. -

- Zanna in mimer tuming -

- Zanna in miñor walking across.

- Zonna in Tent -

- Zanna in currain stage.

- Bed anim

- Zanna and bed anim. ,

- Zanna looking in box.r
More anunation

Torm danaing.

- sereral camera angles.

Cupboand.

Form sgauist black going forword/bockew.

animation footage - playing cello

- jugs

- gun

- seuring

- gramsphone -

- cupboard $\checkmark$

- e

- jigraw

- boat/bine. 


\section{- Notes on contol 1 deas - 9.4.03. Hw.}

Condrol of events by a master cines, enabling sub times.

Events. to cardol.

Lights. - main liguts, 3 in ling rom $A B C$ now

1 "outside $D$.

- sub main lights. $-Z$ in tining room $E, F, E=F$ red zow

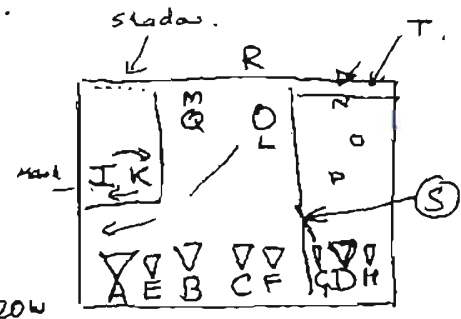

1 antsicle $G=$ blue/madala.

$\sigma^{\prime \prime \prime} \forall$

-H gobo-nescent moon H. $\theta>10 \mathrm{~W}$

- area lights $J$ in lefs room - above "daylight" $10 \mathrm{w}$.
$K$..

0

- effects lights $L$ in main room - lampshade "night variable" $2 \mathrm{~W}$.

$m$ in " "cupboard - "vaviable" $2 w$

$N, O, P_{1 .}$ - behind trees to cast shadows. $-2 w$. NN, $00, P P$. -

Actions. Cupboord door opens + closes sporadically, reveals contents

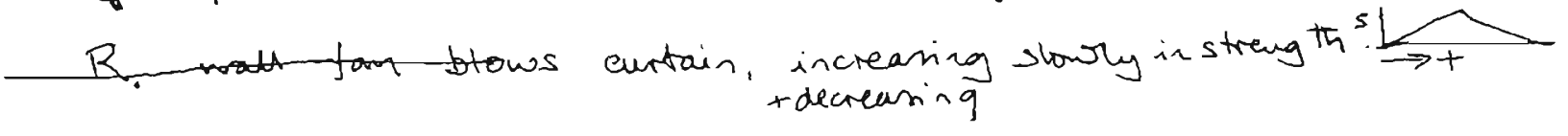

$S$ - ontside door opens + clodes - but when?

$T=$ sunnise /set .

Timer ontputs. $1=$ on $0=0$ H. -6 bit syotem for example.

年

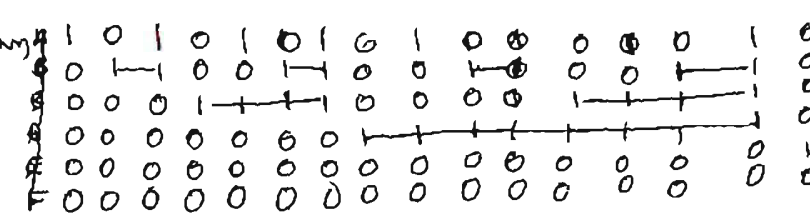

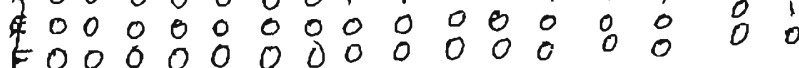

Derind $123445678910111213141516 \rightarrow$ ete we see for Eh if levelA = $1 \mathrm{sec}$, channel $A$ is on loff 8 tives in 16 seconds, ch $\theta$ is on 10 ff 4 times (each 2 dec)

$$
\begin{aligned}
& \text { c n m } 2 \text { ". (" } 4 \text { " } \\
& \text { D." n } 1 \text { " (" } 8 \text { " ) . }
\end{aligned}
$$

Msing for 29 a 16 bit system witha base frequency of $1 \mathrm{sec}$ gives an 8 bit $t$ ine of $2562 e c=4 \mathrm{~m} / \mathrm{bs}$ So a $16 \mathrm{BIT}$ comiter with $A_{0}=1 \mathrm{sec}$ gives a period of
$9 "$

$10 " 1$

$18 \mathrm{H} 12 \mathrm{~m} 16 \mathrm{~s}$ which is a complete veunig day.$$
11 \text { " }
$$

A

कo

B

14

15 "

ie $A G$ happens, then $B$ (once). 16n n

$512 "=8 \mathrm{~m} 32$

$1024 \cdots=17 \mathrm{mO4}$

$=34 \mathrm{~m} 08 \mathrm{sec}$

$=1 \mathrm{H} 8 \mathrm{~m} 16 \mathrm{sec}$

$=2 \mathrm{H} 16 \mathrm{~m} 32$

$=4 H 33 m 04$

$=9 \mathrm{H} 6 \mathrm{~m}$ O8s

$=18+12 \mathrm{~m} 16 \mathrm{~s}$$$
\text { (6) }
$$

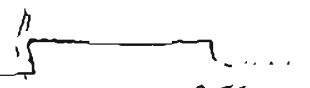

$192 \quad 256$

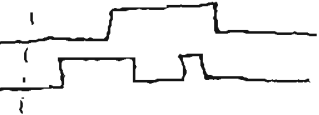

if $B_{2}=20 \mathrm{sec}$

is $B_{2}$ is on 20, of 20, on 4 , oft 84tete. 
u. ov $0.42 \mathrm{~A}$ equivalent reriskuce $\frac{u}{1}=\frac{11.2}{.92}=12.28 \Omega$

$$
\text { so } \frac{12 V}{.83 A}=14.45 \Omega .-12.28=2.17 \Omega
$$

power dissipated

$$
W=\left(v_{1}-v_{2}\right)^{\prime}=2.2 \times .83=1.82 \underline{\underline{w}}
$$

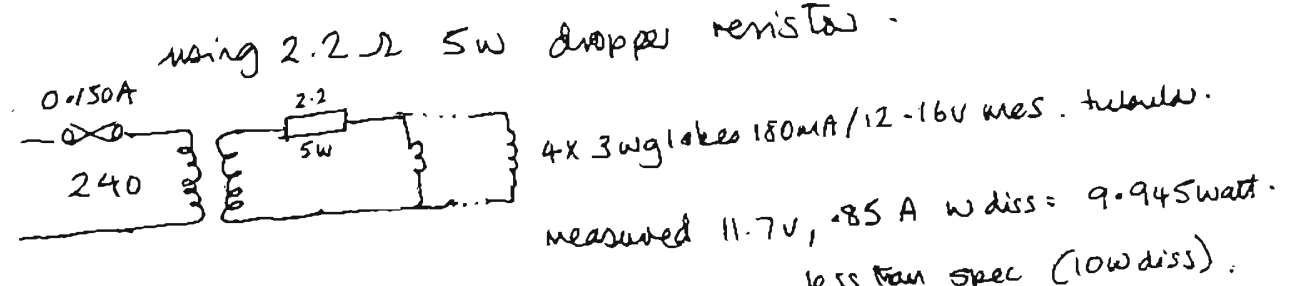
less tran spec (lowdiss). $P_{\text {diss in reristes }}=i^{2} R=1.59$ watts, $40 \%$ spec $/ \partial k$
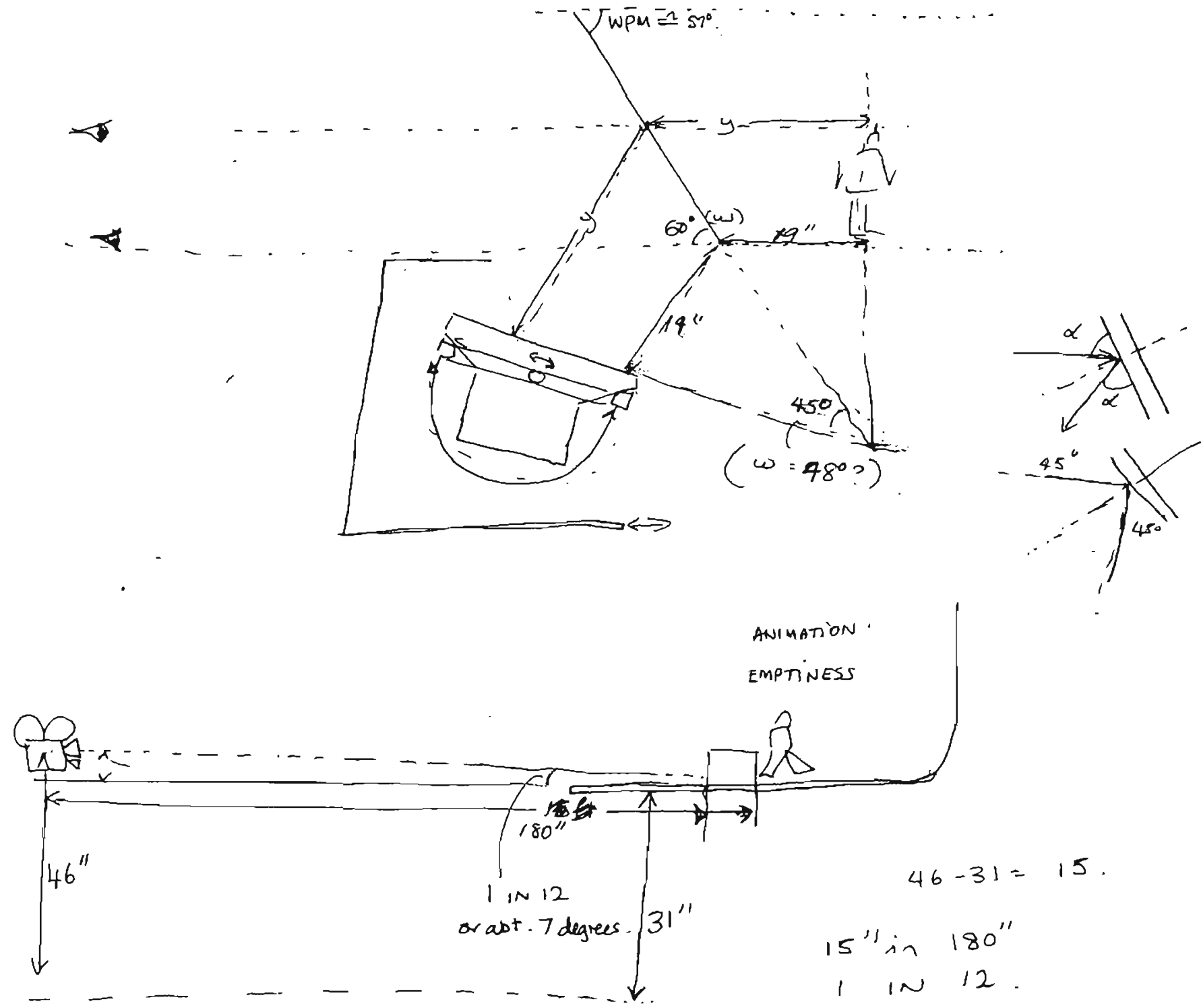

EMPTINESS 
SELECTION OF PAGES FROM SLEEPWALKER (2001) COMMENTS BOOK 
3: के

का รर

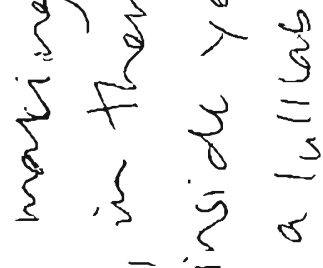

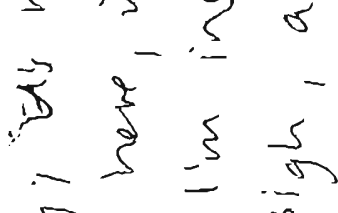

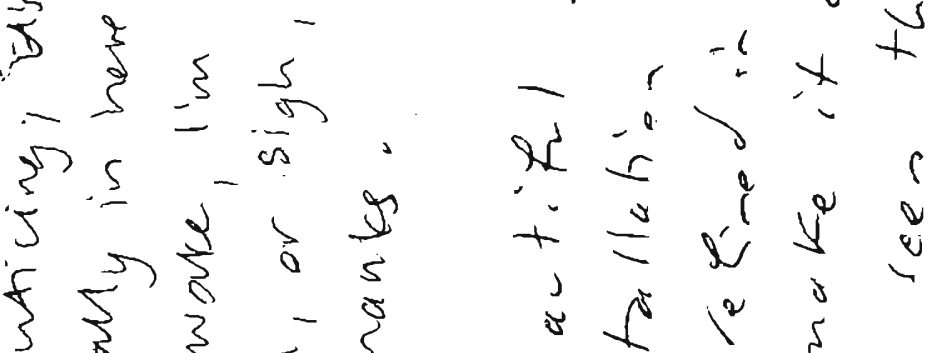

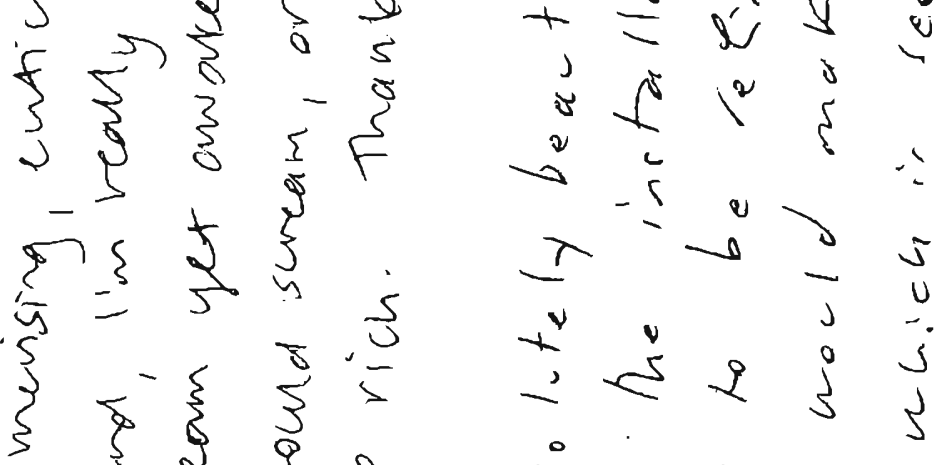

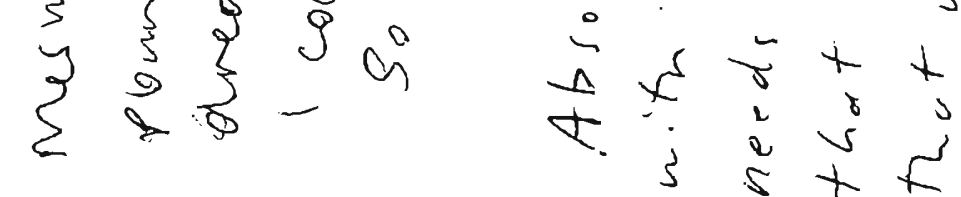

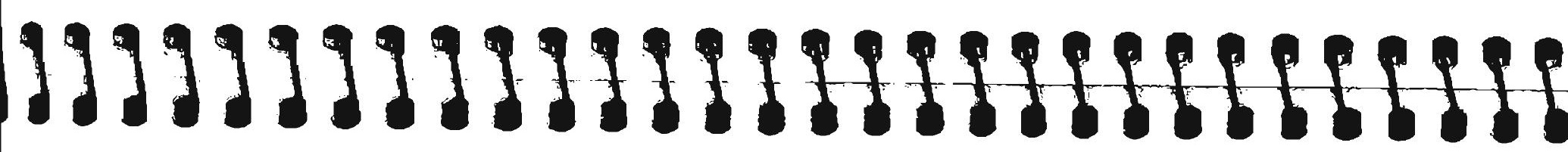

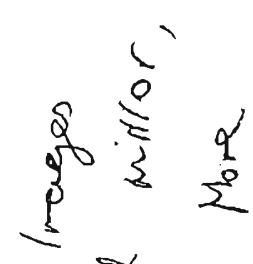

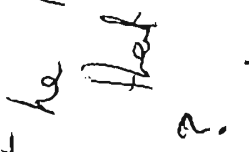

t. $\frac{a}{2}$

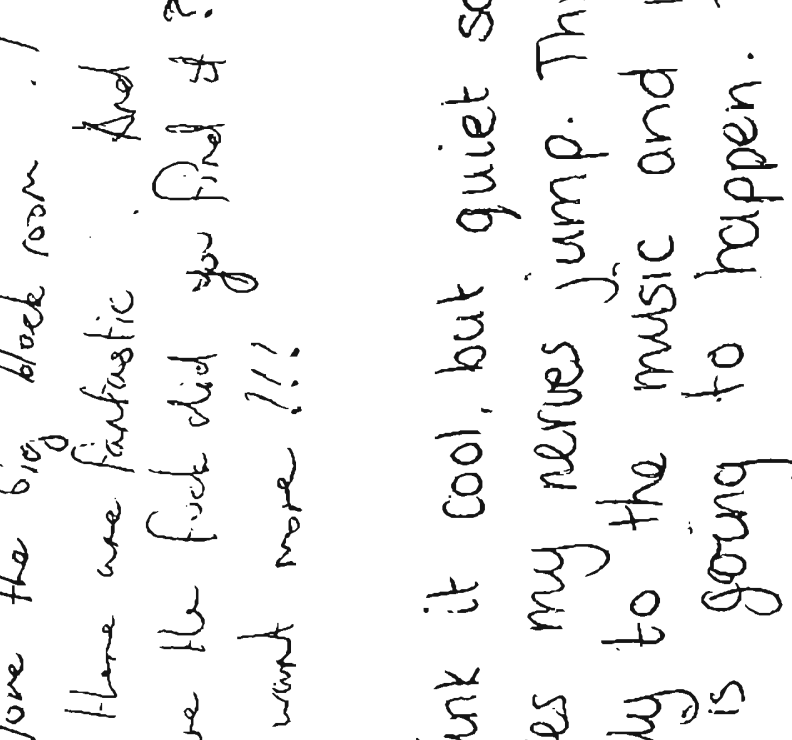

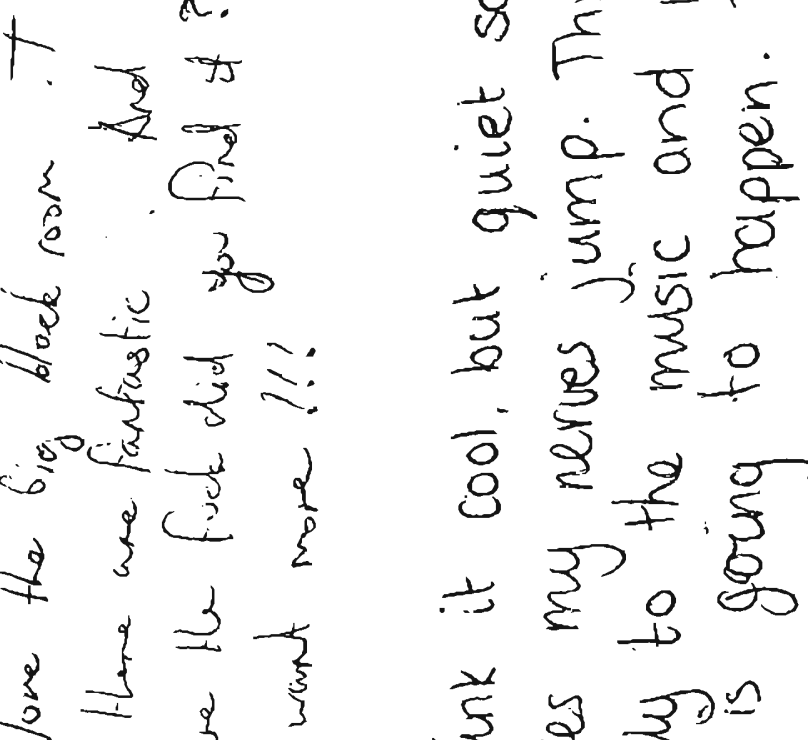

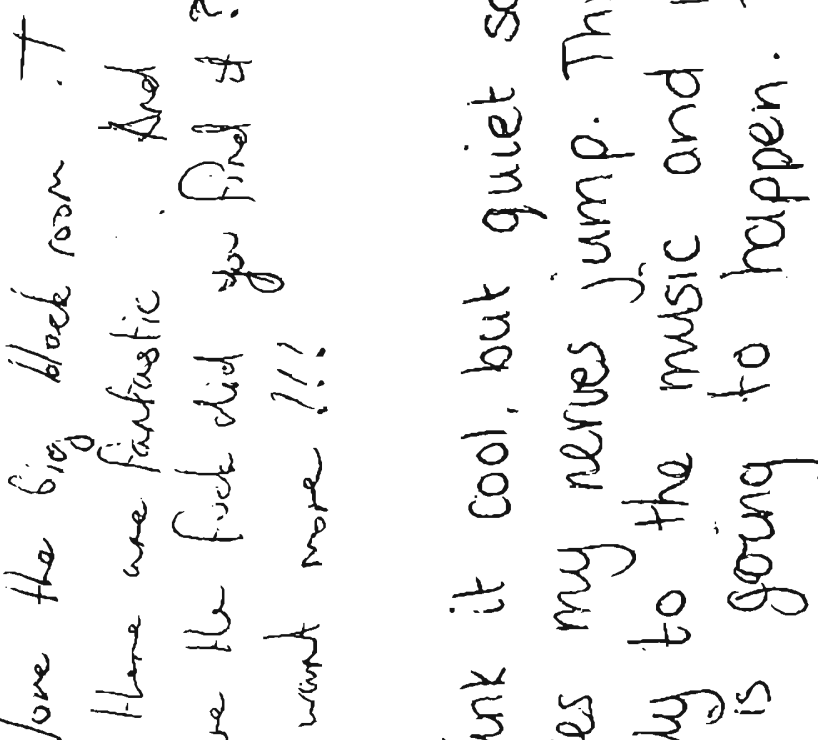

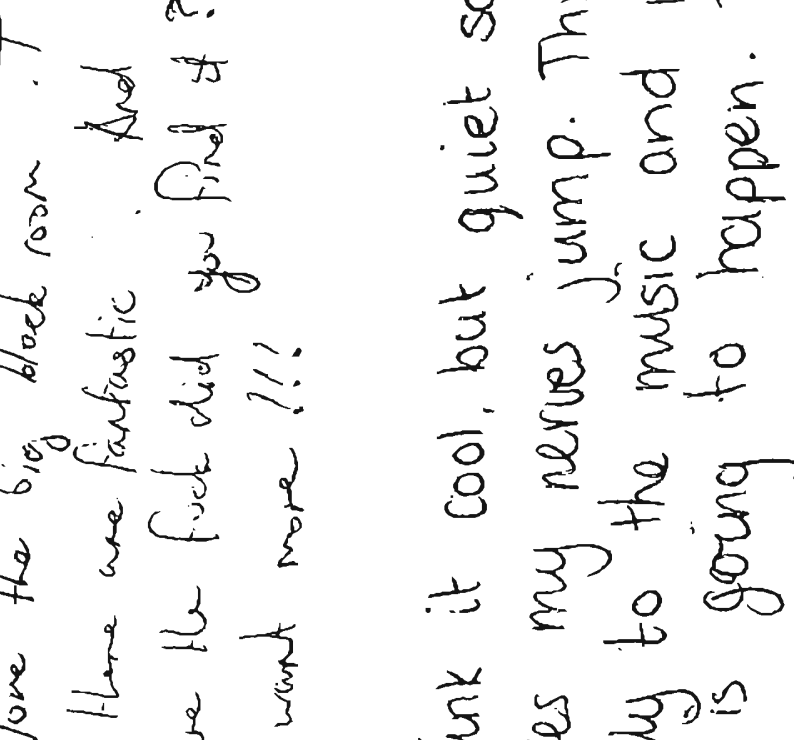

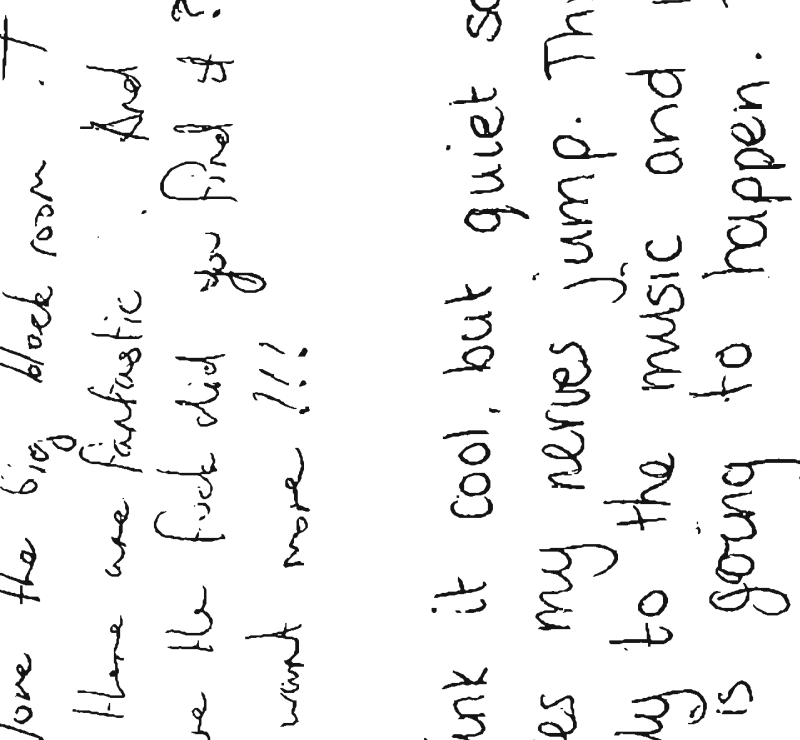

- $\frac{1}{2} \frac{3}{3}-$
.2

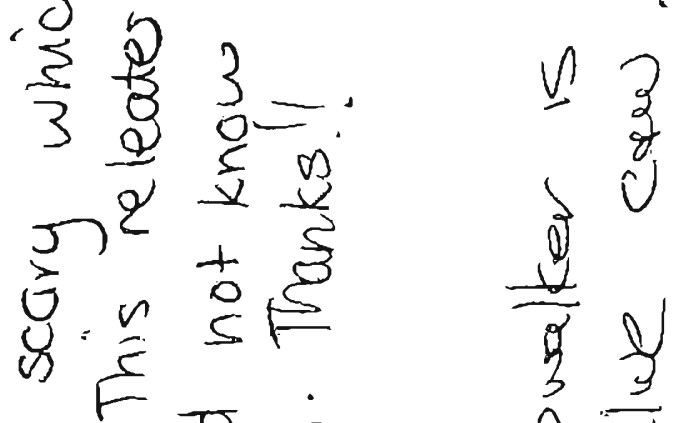

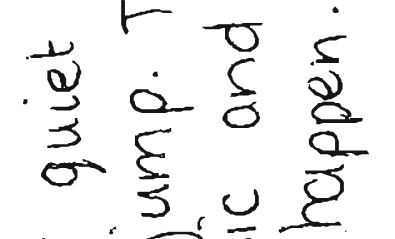

急偠

\&

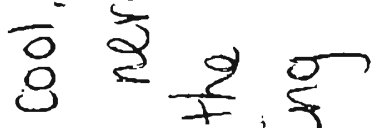

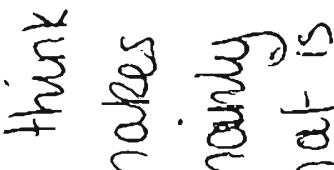

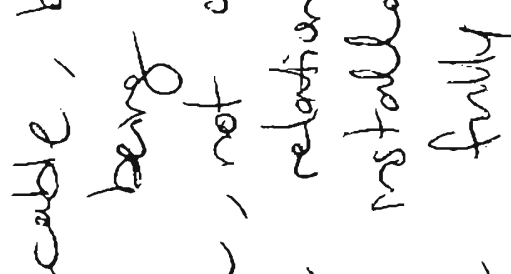

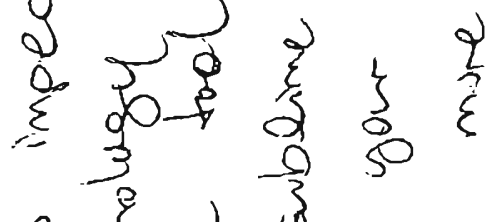

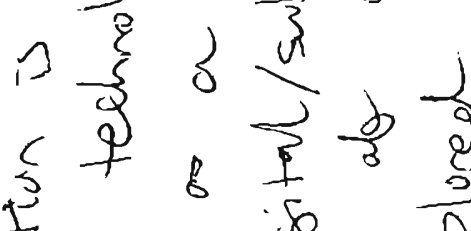

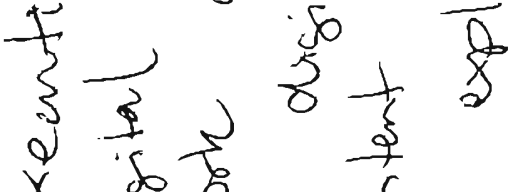

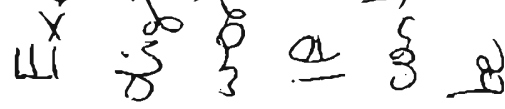


क्षक

है

$\frac{1}{0}\{$

1 को

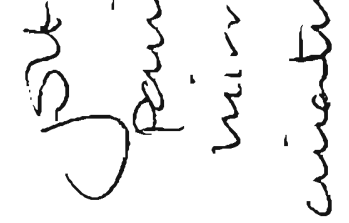

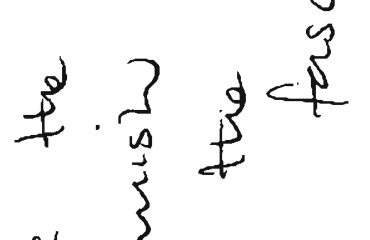

亲茾 600

- 00 多

\section{$x$}




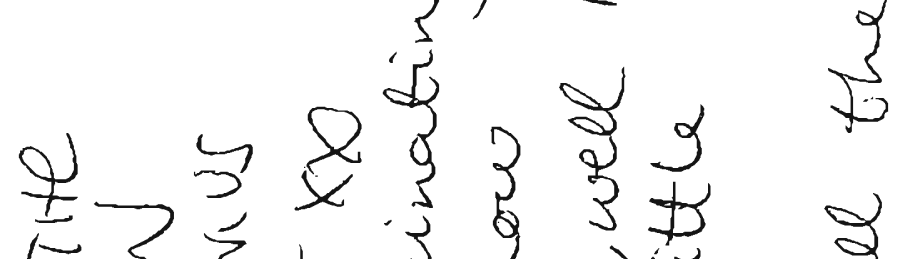

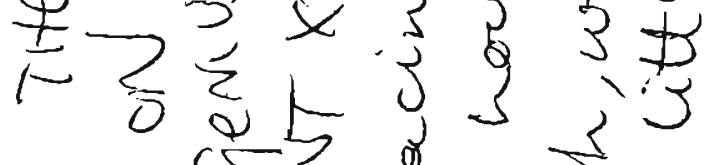

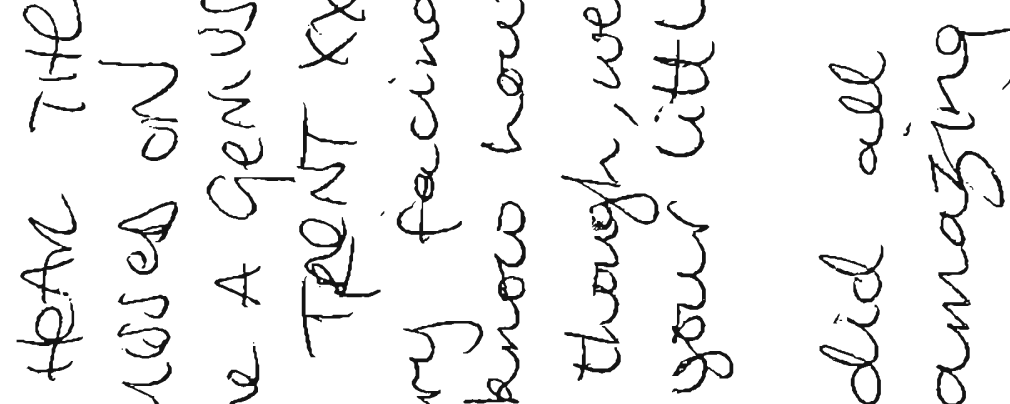

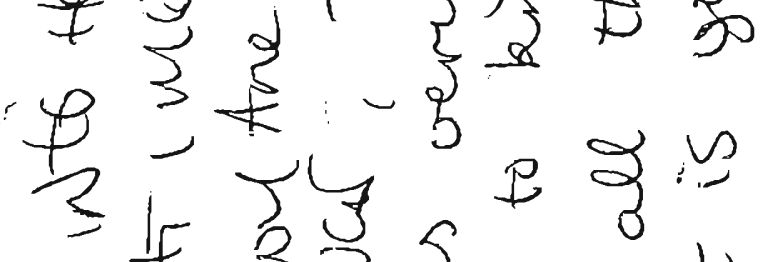

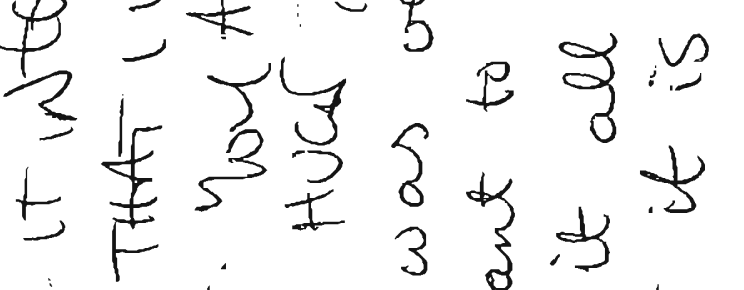

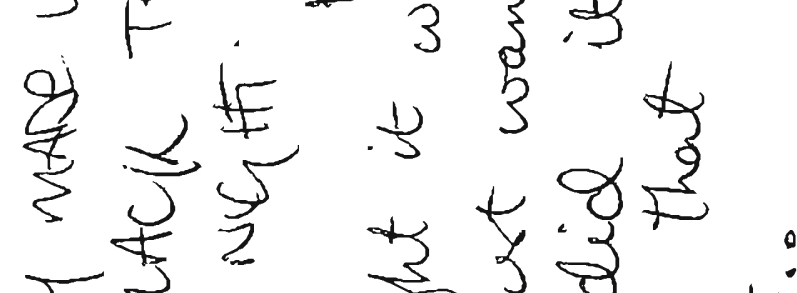

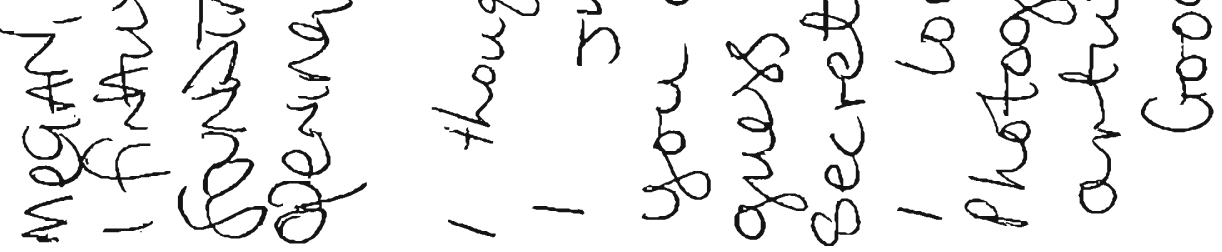

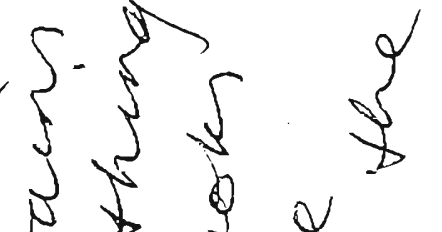

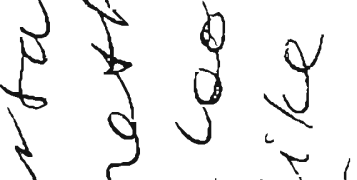

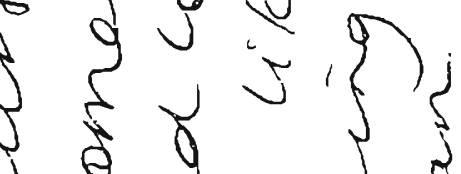

के व

0 g 20 के

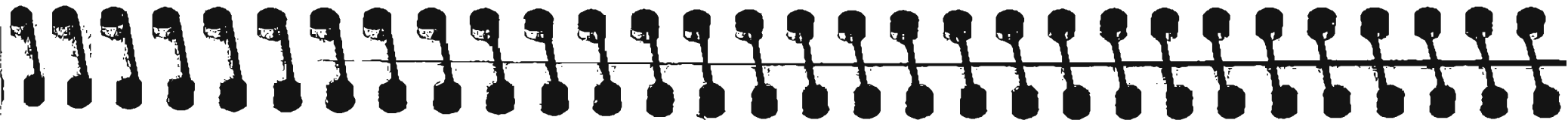

$a^{2}$

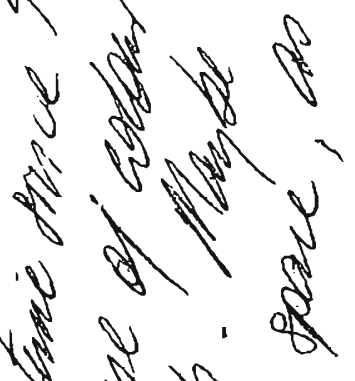

$\geqslant \geqslant$

$8 \sqrt{2}$

$\psi<p$ is

s y

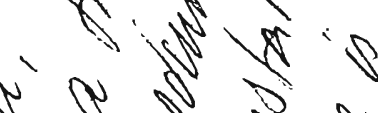

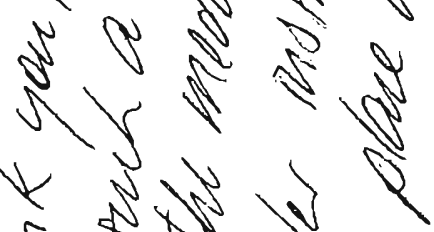

2 कर \& $\{0\}\{\}$ 


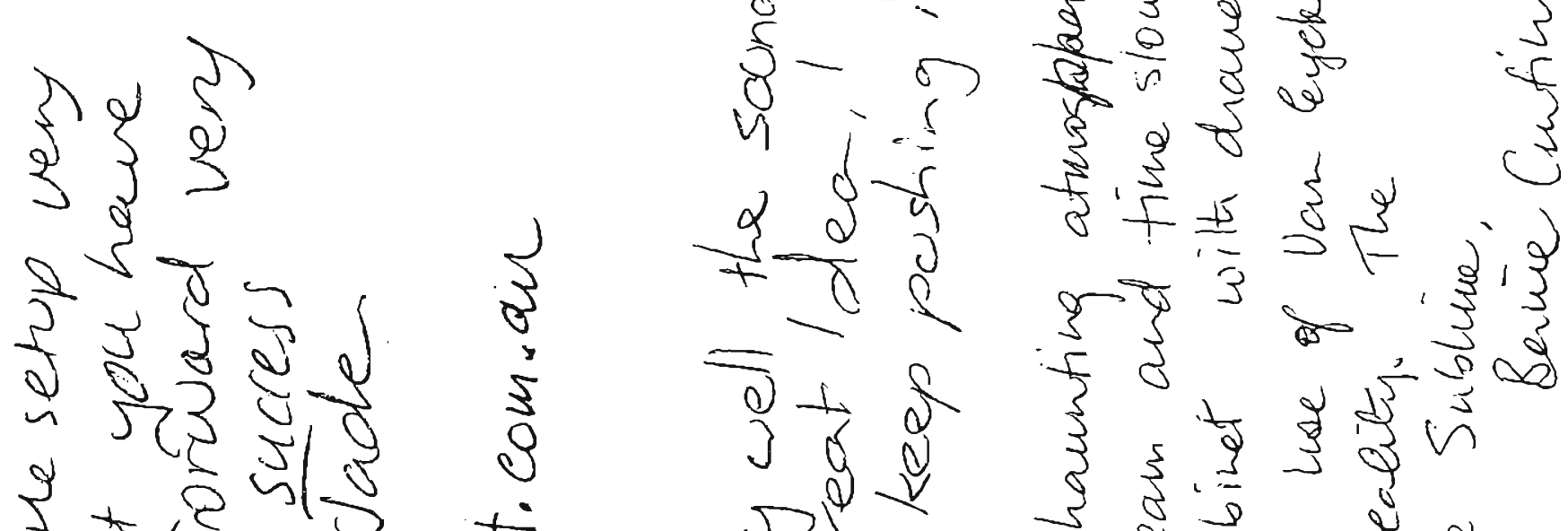

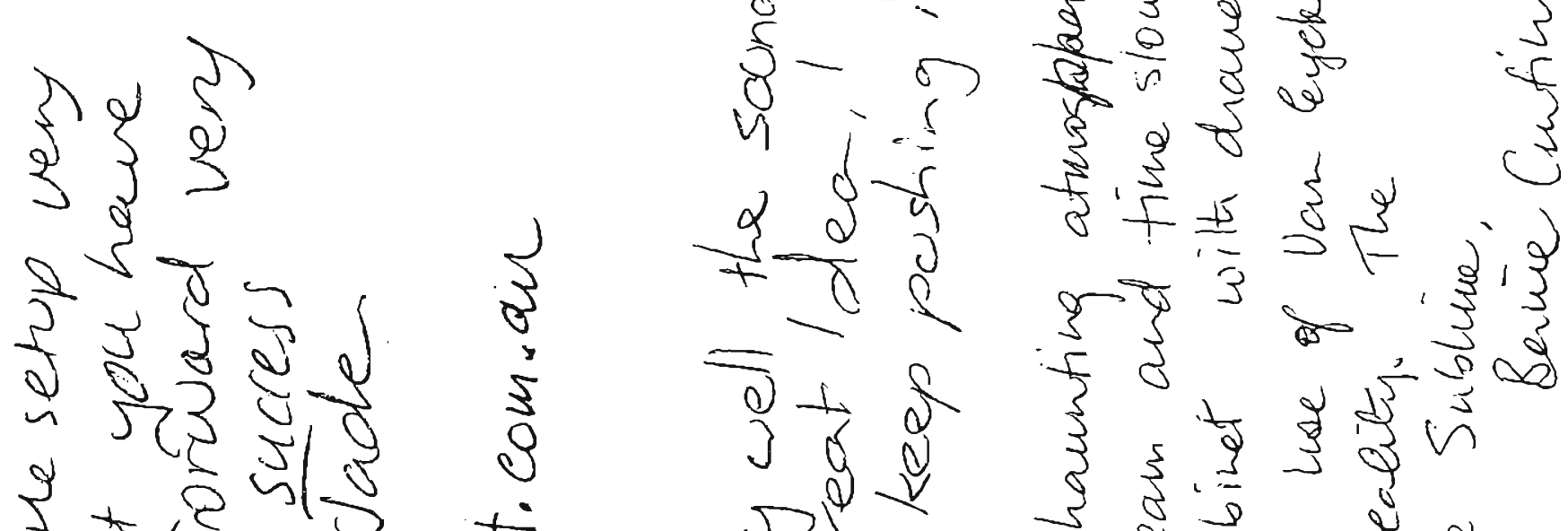

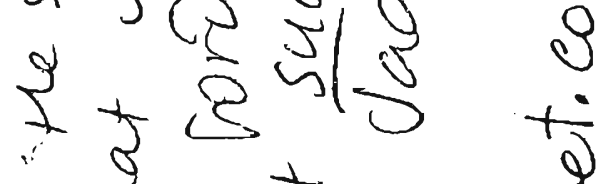

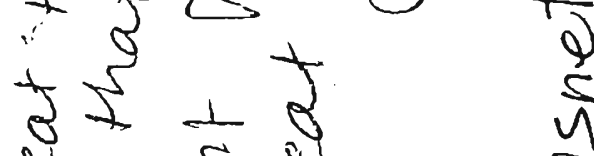

₹ 5

ous

$\simeq$

+ के

de

ई

克

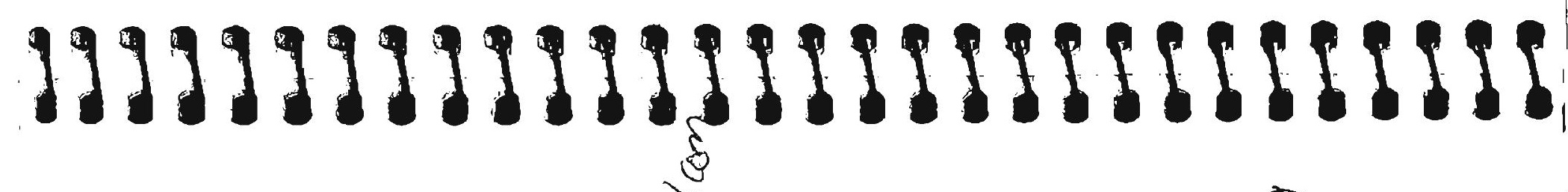

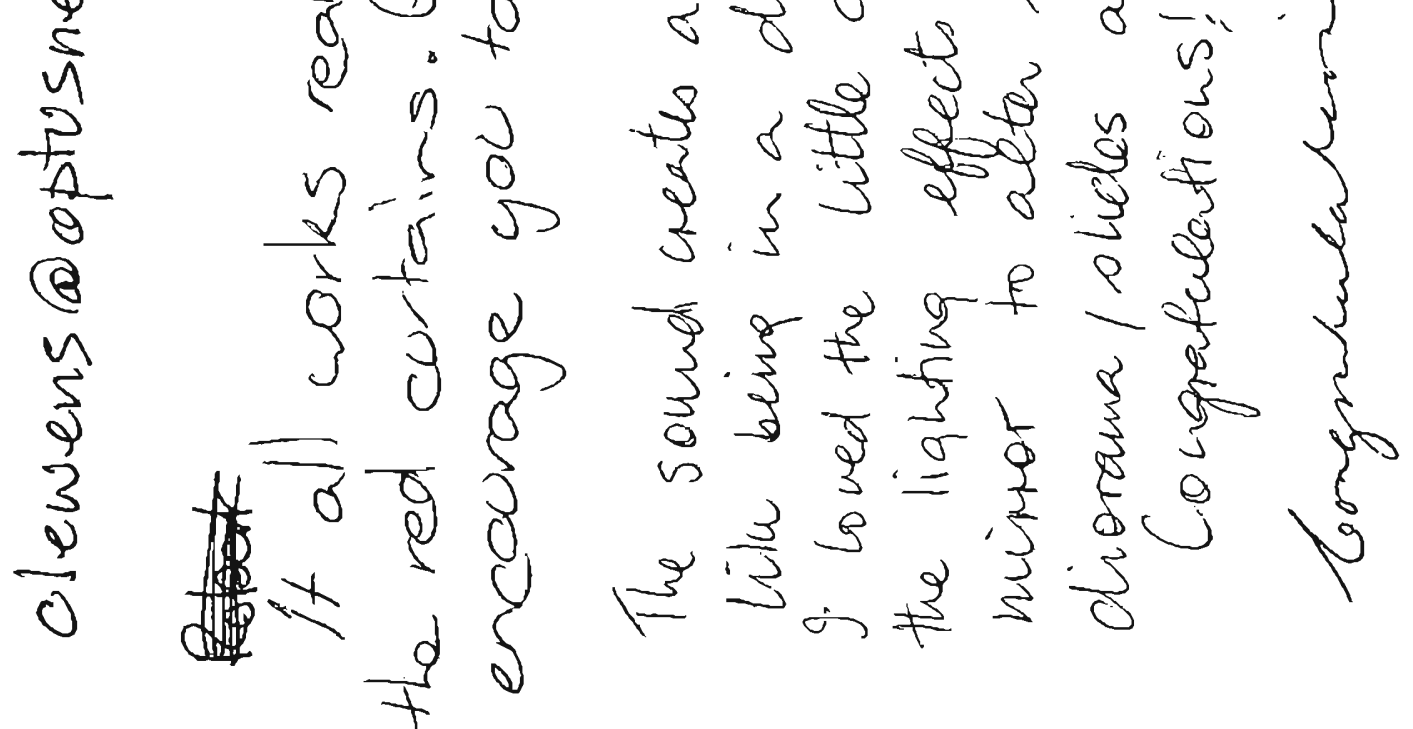

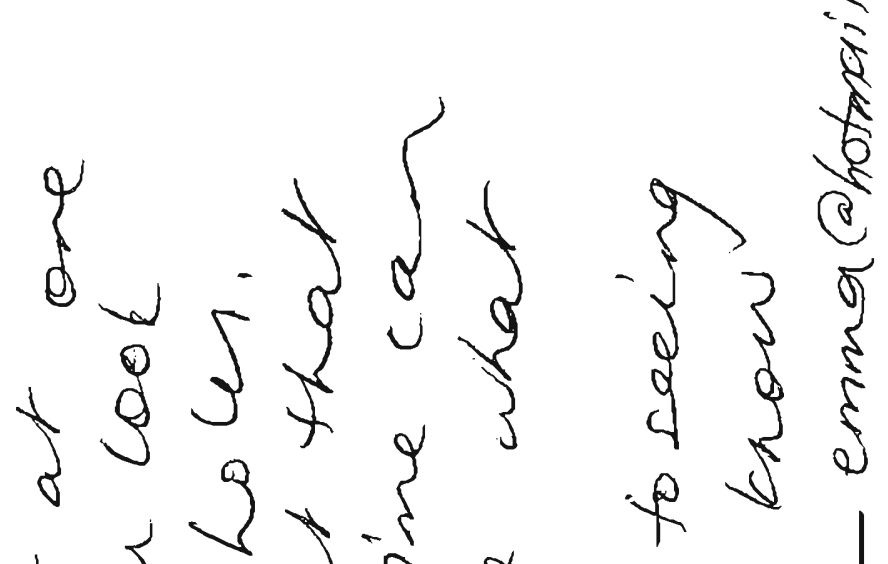

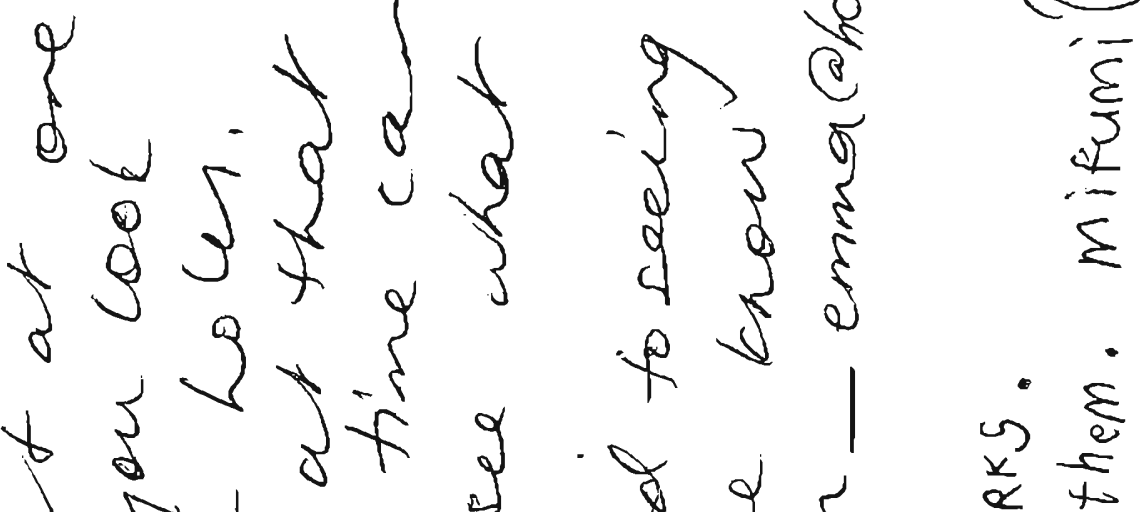

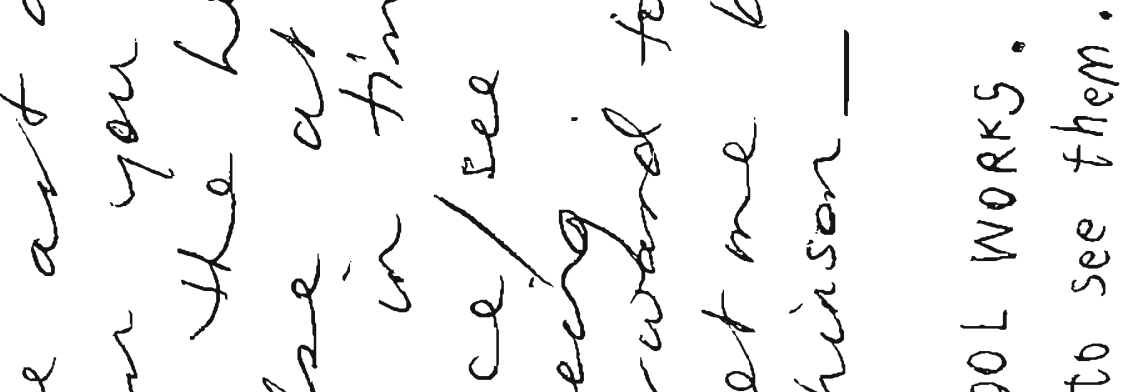

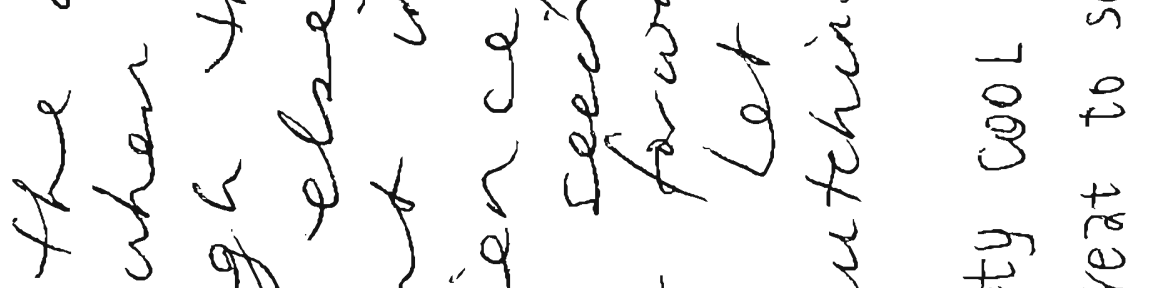

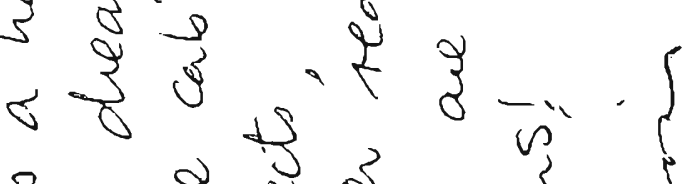

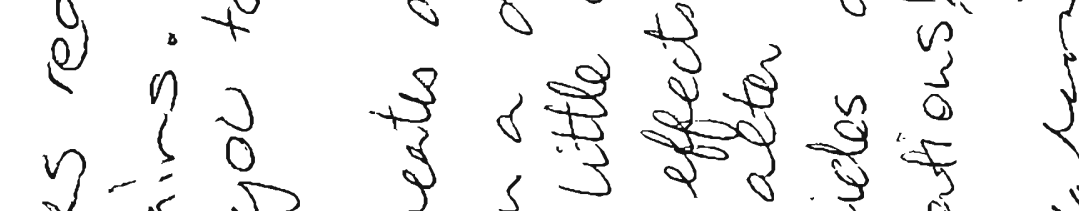




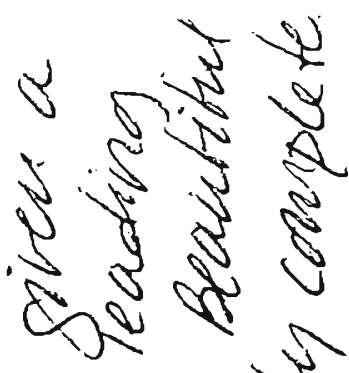

I 2

s. 35

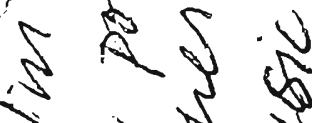

$<8$ है

ald 3

2. $\leqslant \leqslant$

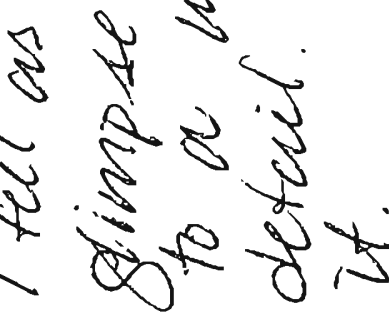

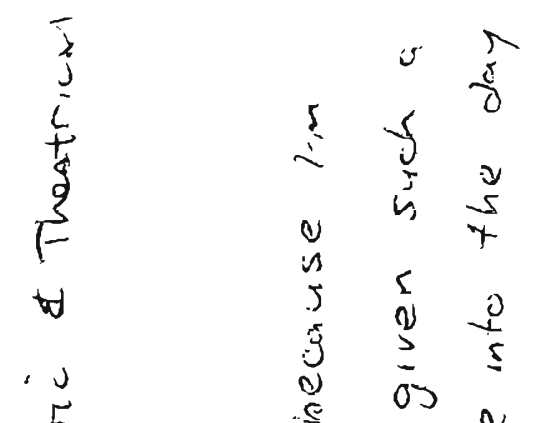

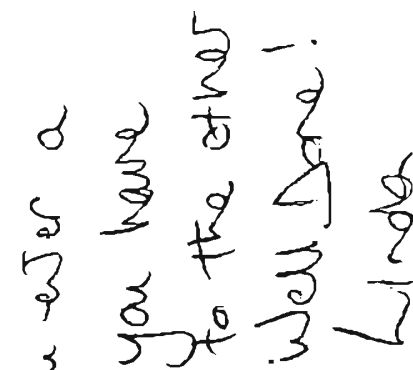

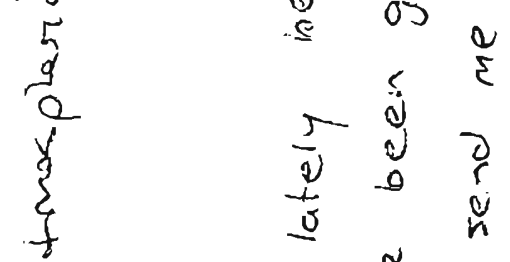

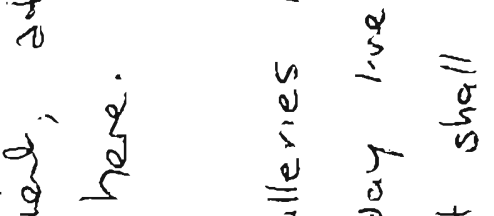

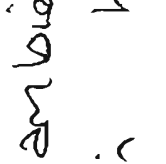

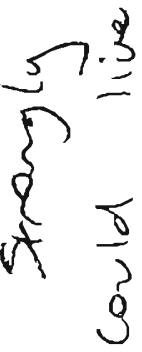

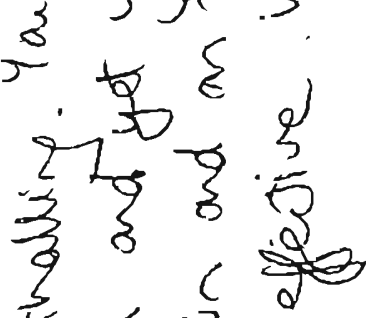

管蚛

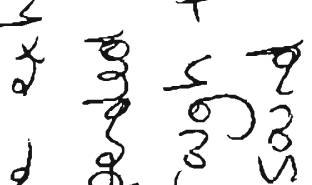

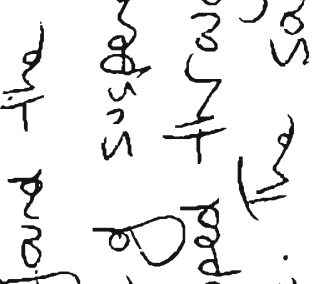

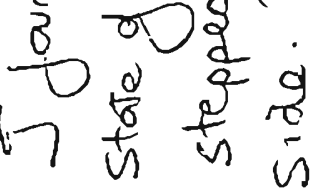

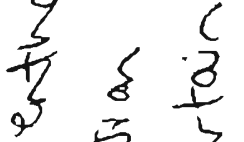

言要军心

\section{6}

ई $\frac{1}{5} \frac{3}{5} \sum^{3}$

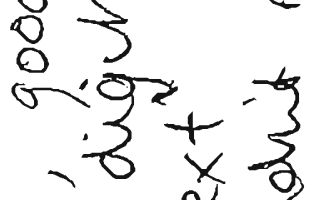

ज小类各

\{ \{\}

₹ $3 \frac{1}{3} 9$

ई $\alpha$

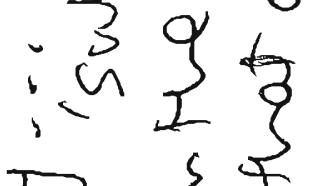

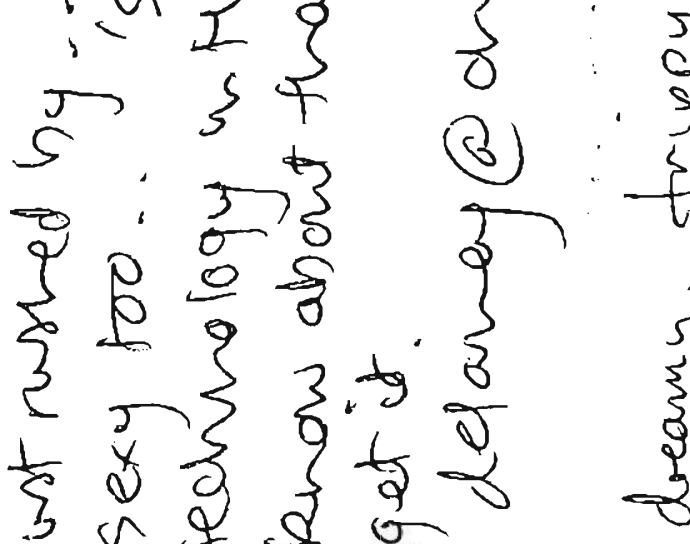

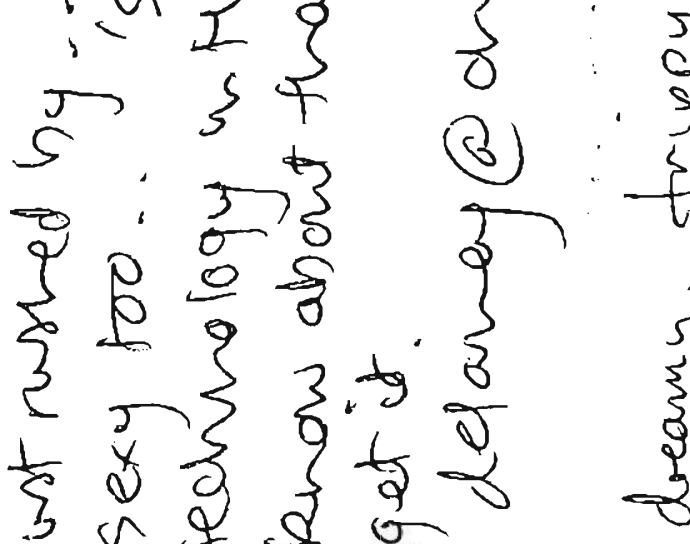

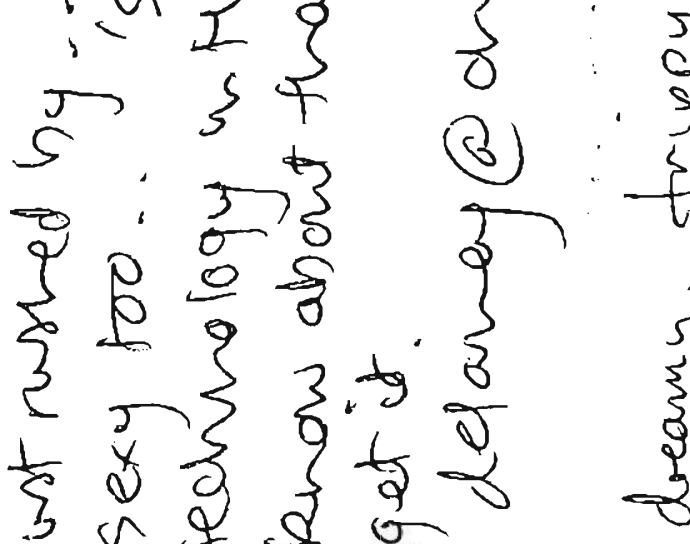

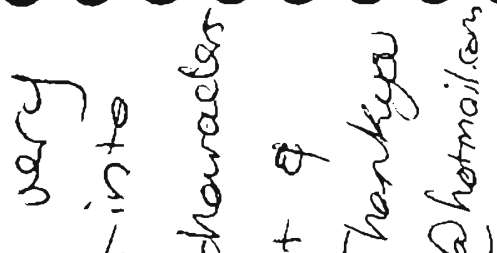

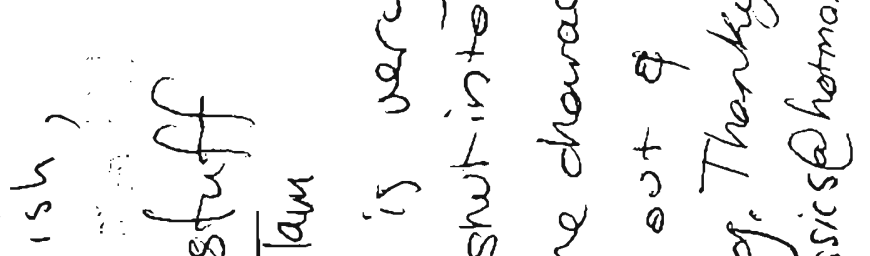

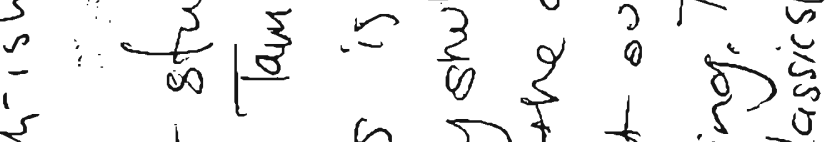

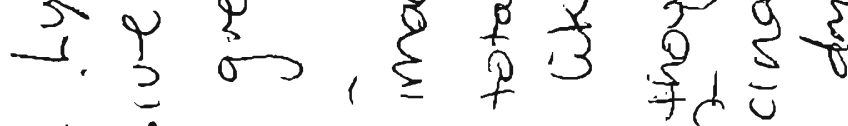

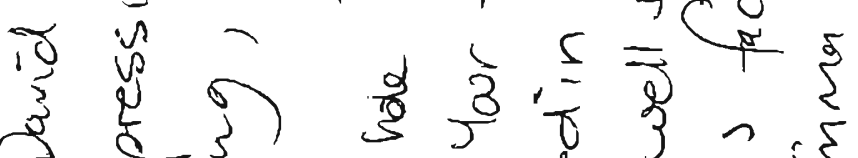

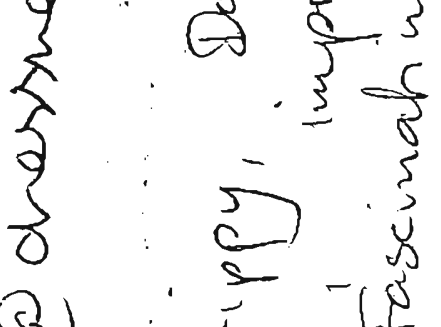

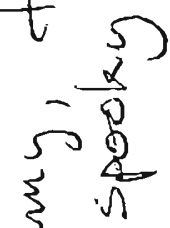

2
2
0

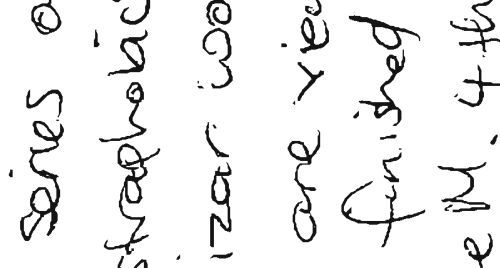

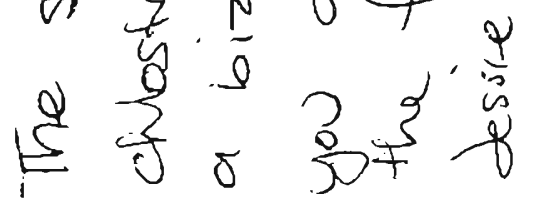

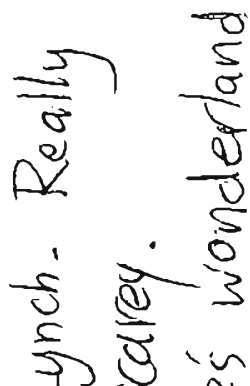

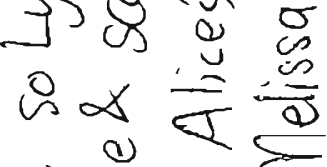

证

$\frac{2}{2} \frac{2}{2} \frac{5}{2}-\frac{5}{2}$

$\pi \cdot \frac{\pi}{a} \cdot \frac{0}{0}$

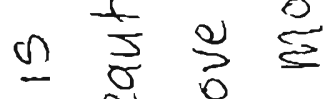

n $\cong \sigma$

$\frac{2}{2} \frac{\sqrt{2}}{2}$

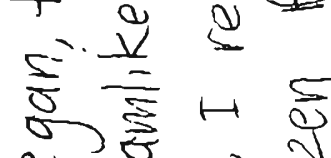

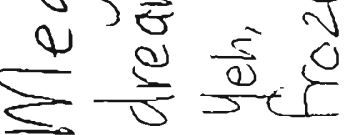


ईरा का के का

की

ईद

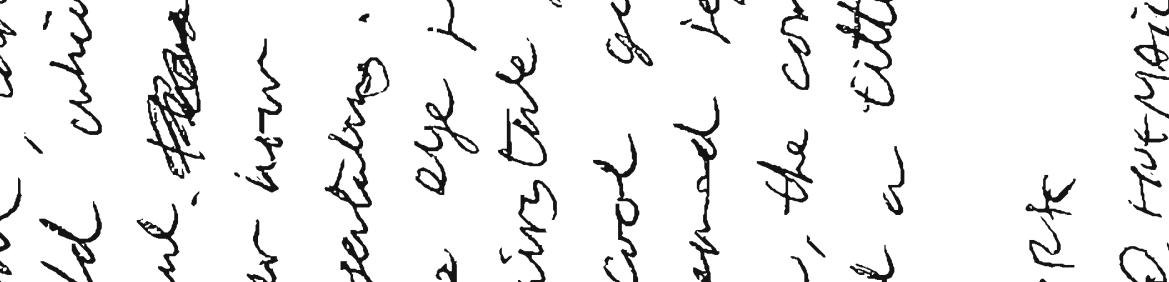

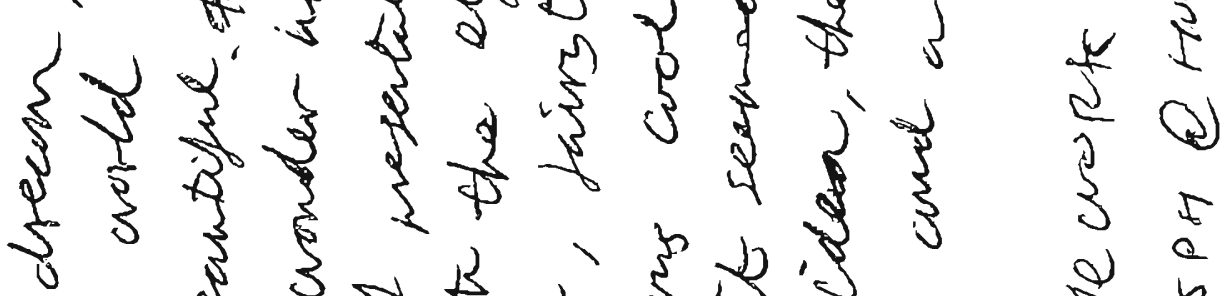

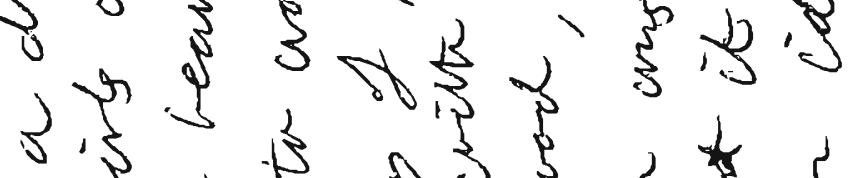

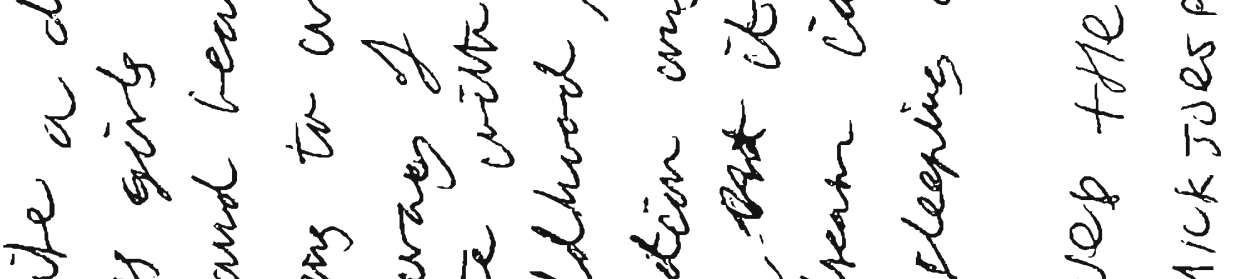

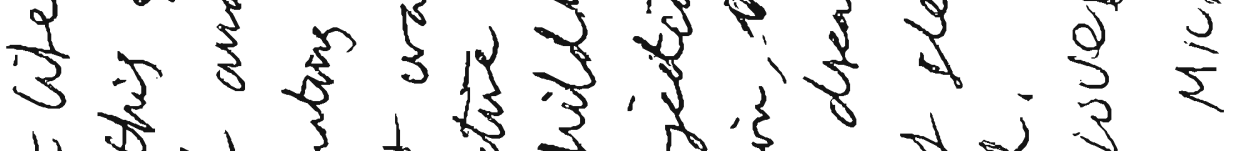

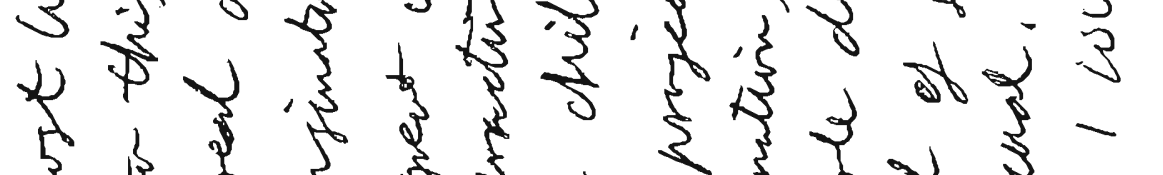

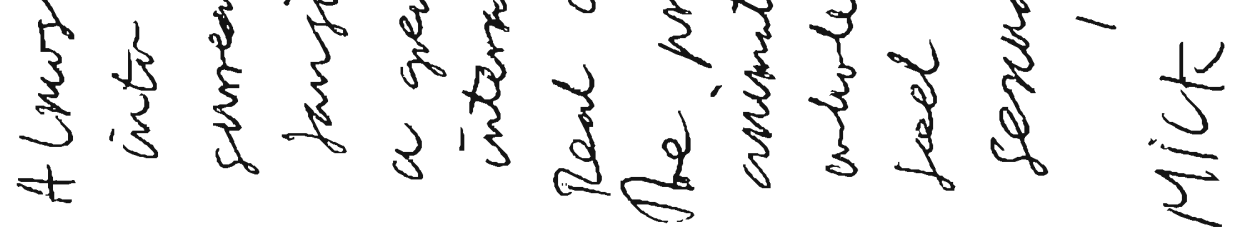

$\leftarrow$

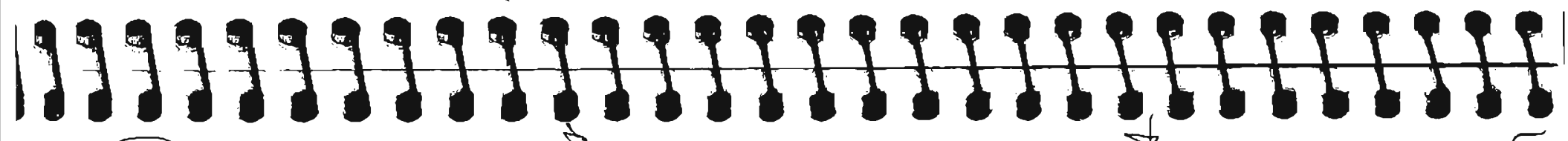

3
3
3
3

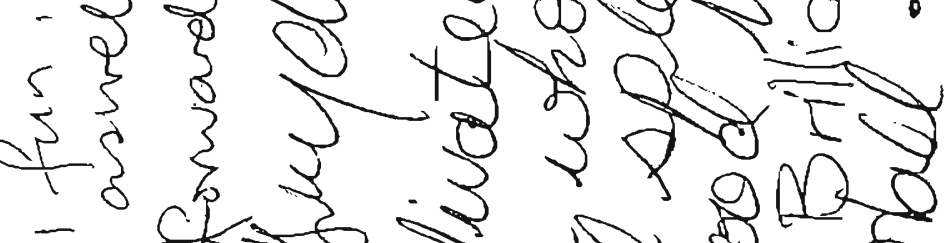

दे को

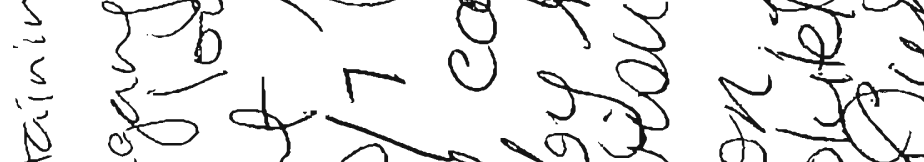

है

के इ1 अभु० मै०

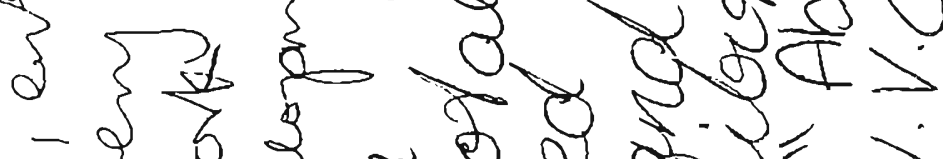

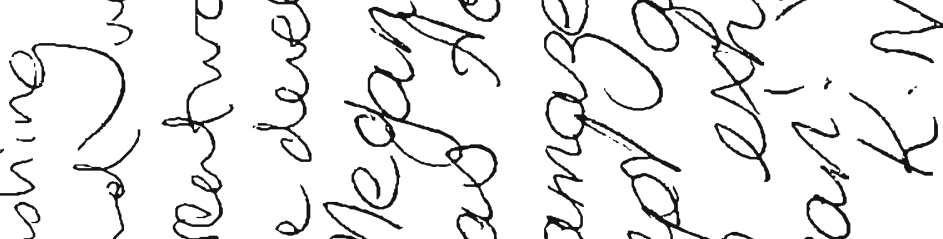

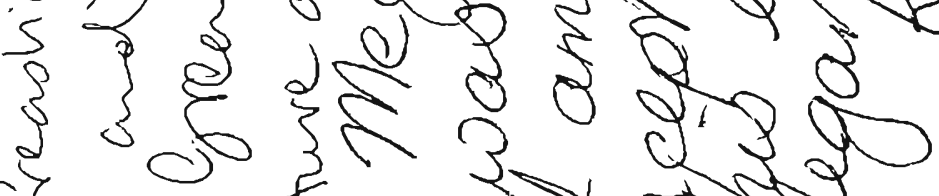

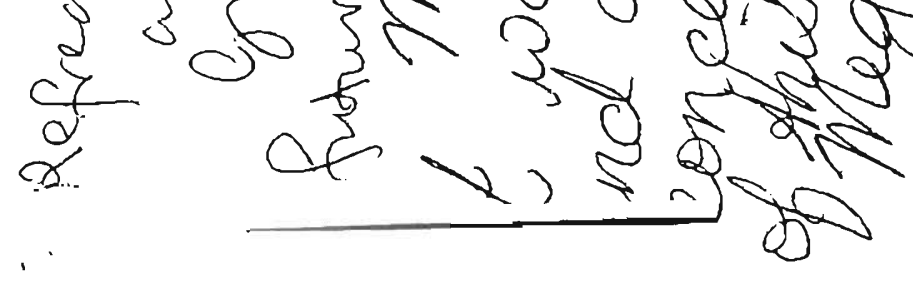

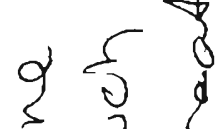

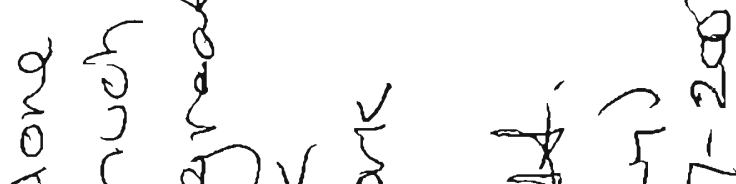

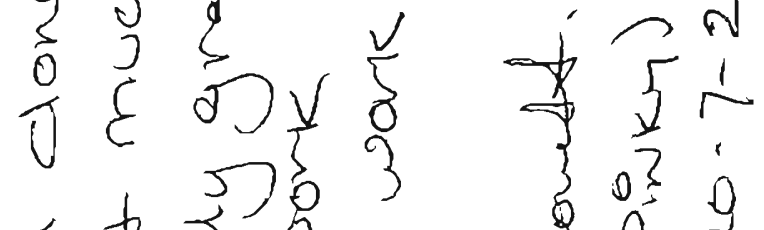

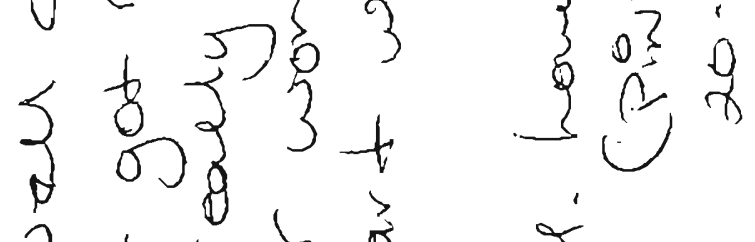

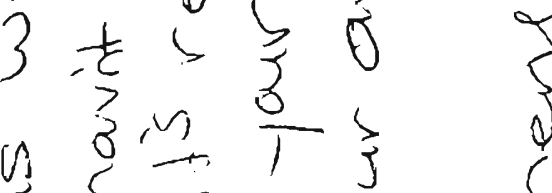

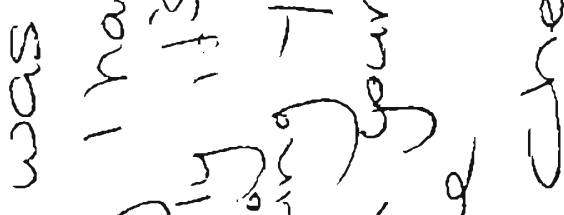

D

$\frac{1}{b} 50078$

$\left\{\begin{array}{lll}3 & 0 & 5\end{array}\right.$

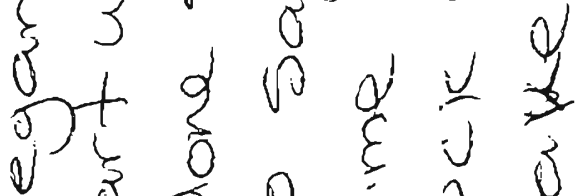

ह

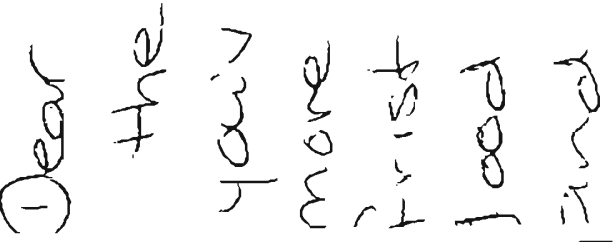




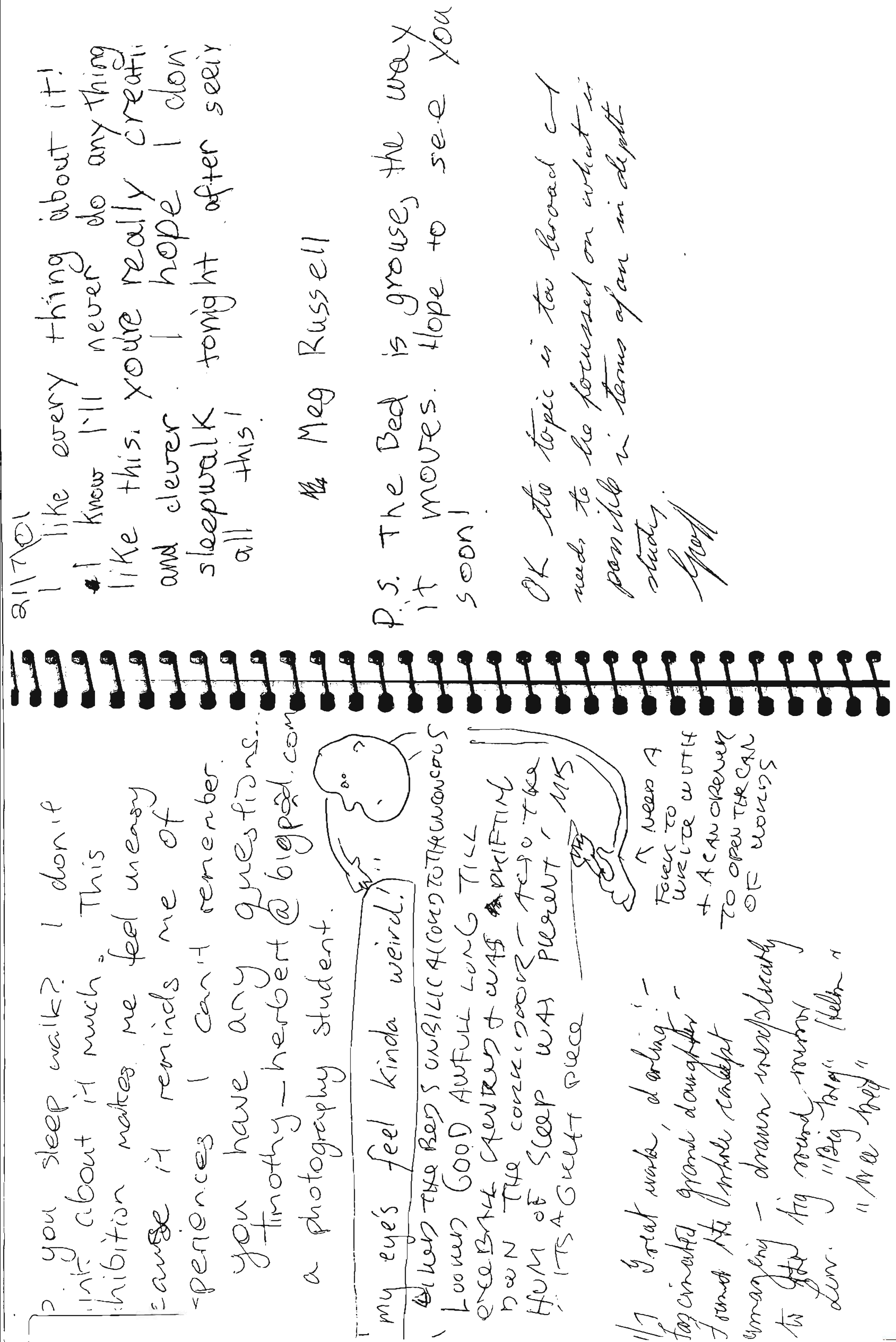


SELECTION OF PAGES FROM

\section{THE SUBLIME SLEEP (2003)}

COMMENTS BOOK 


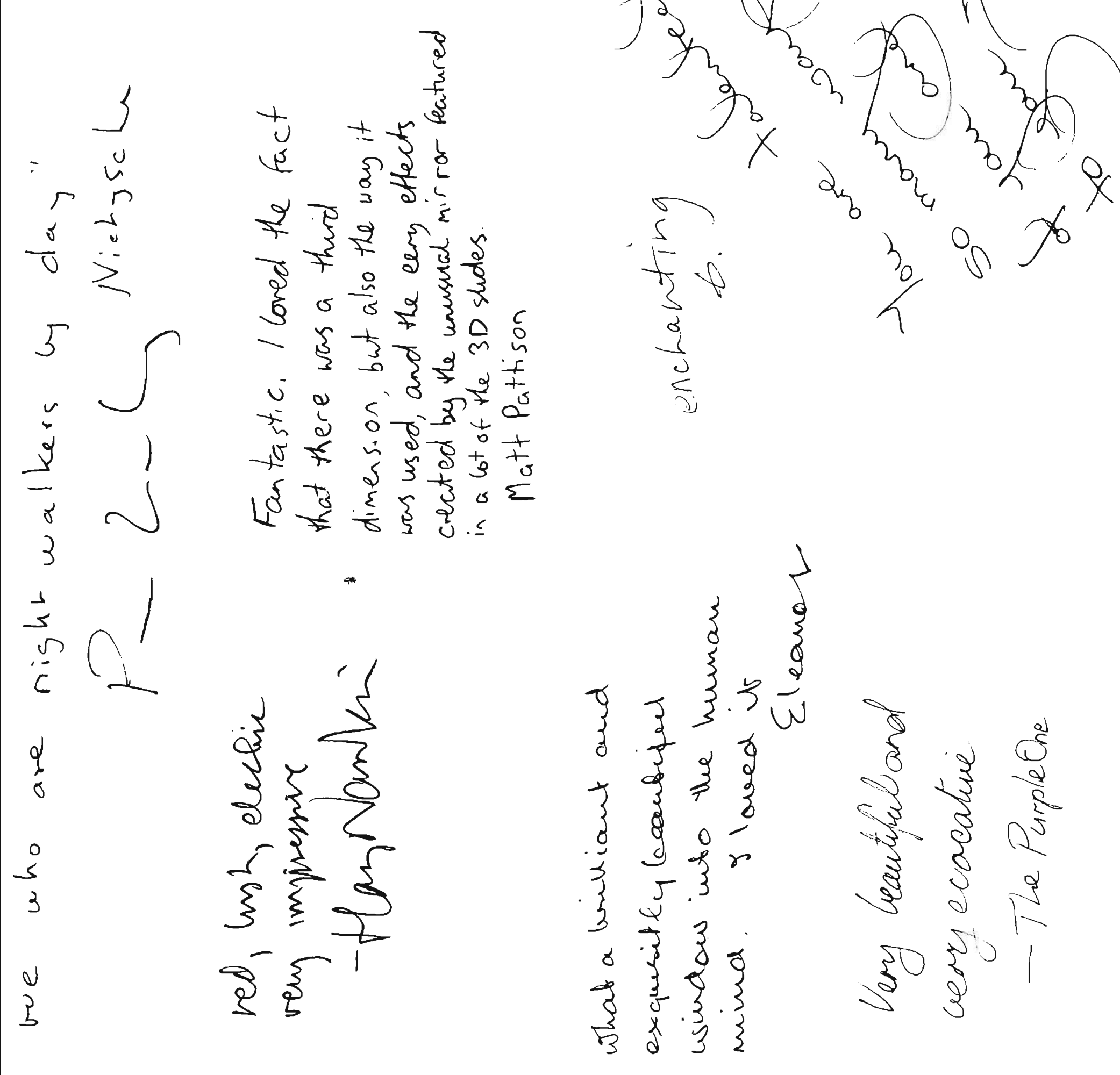




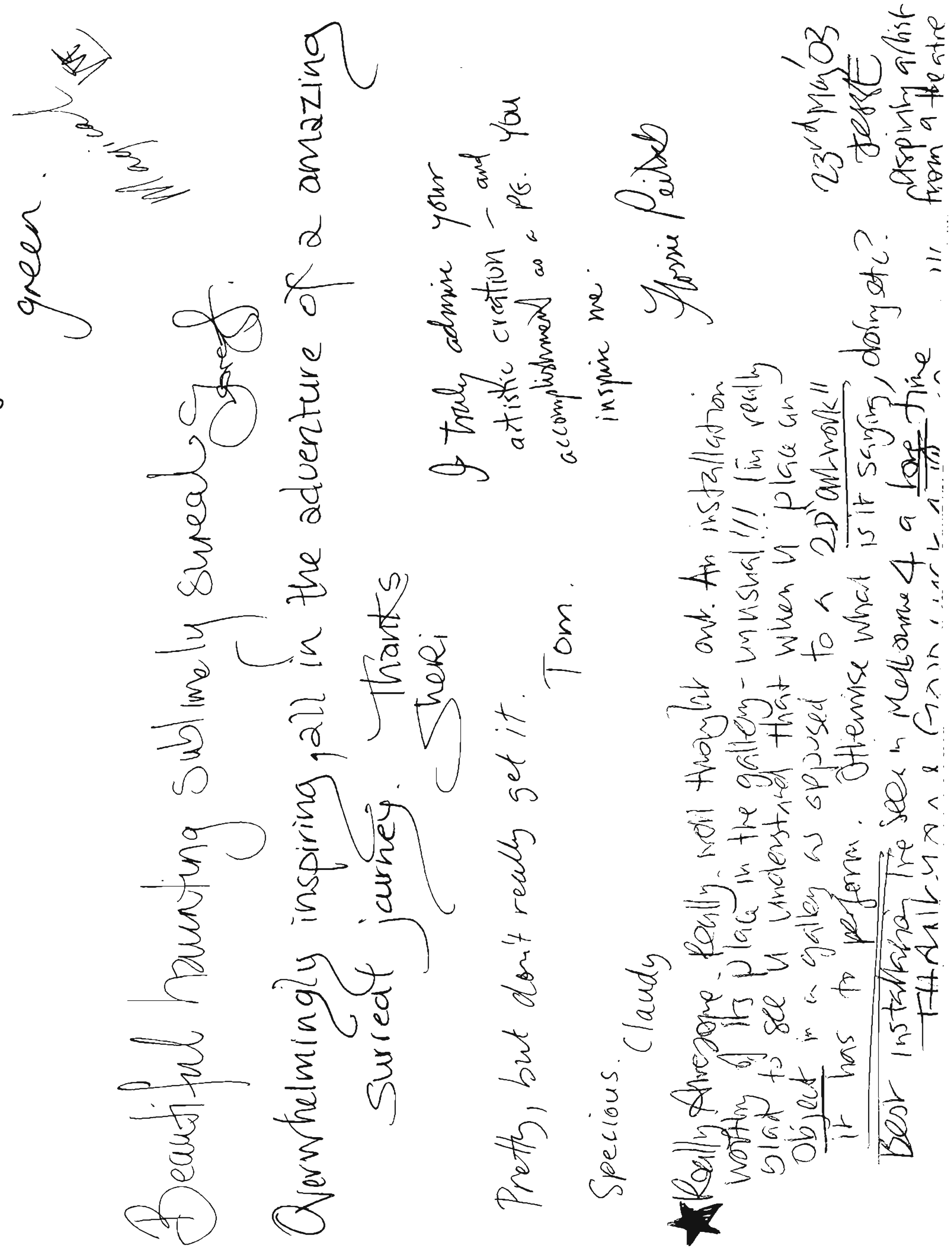



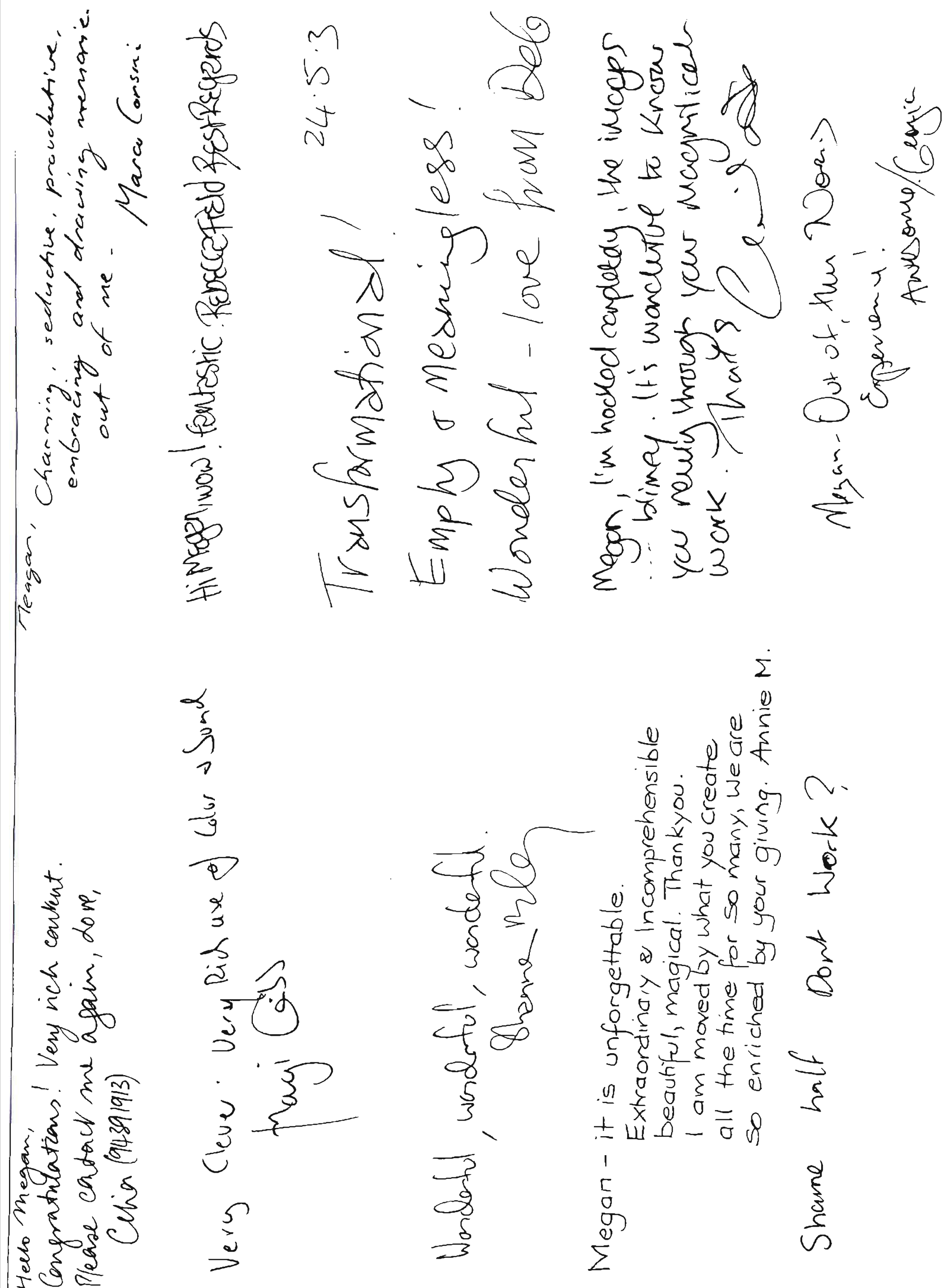

3
3
3
$\frac{3}{3}$

$$
\begin{aligned}
& \Sigma
\end{aligned}
$$

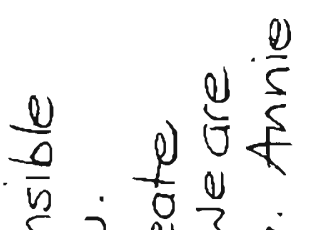$$
\text { \& }
$$

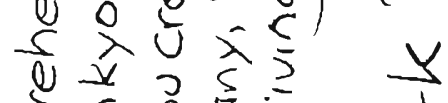$$
\text { e }
$$$$
3
$$

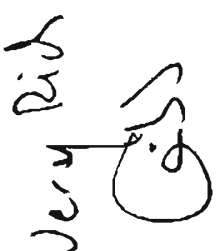$$
35
$$
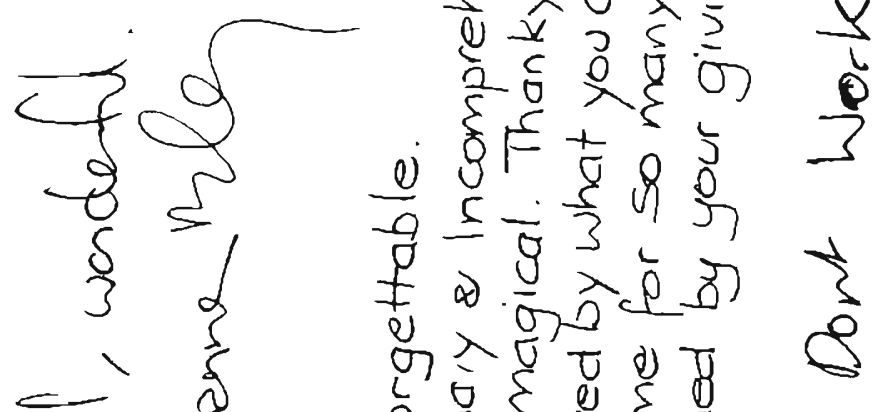

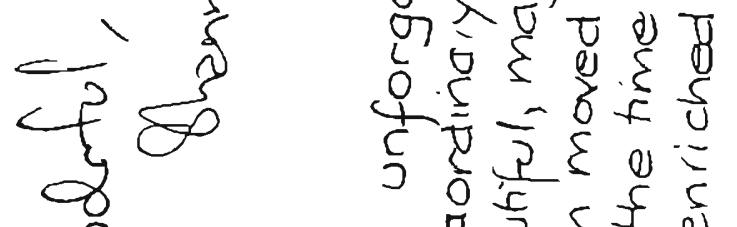$$
\text { 0) } 8 F+850
$$$$
\text { \& } 5 \quad \frac{0}{0}=\frac{8}{3} 90
$$

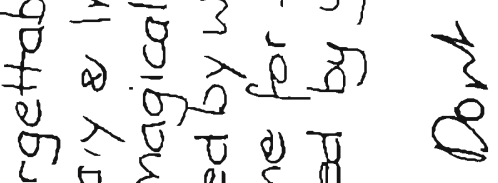
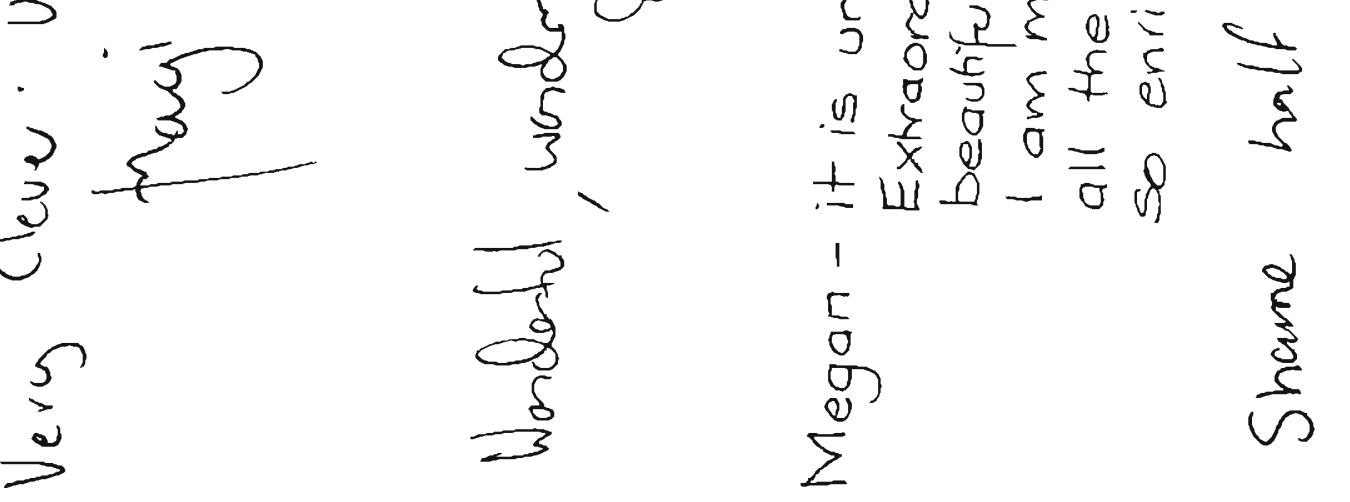


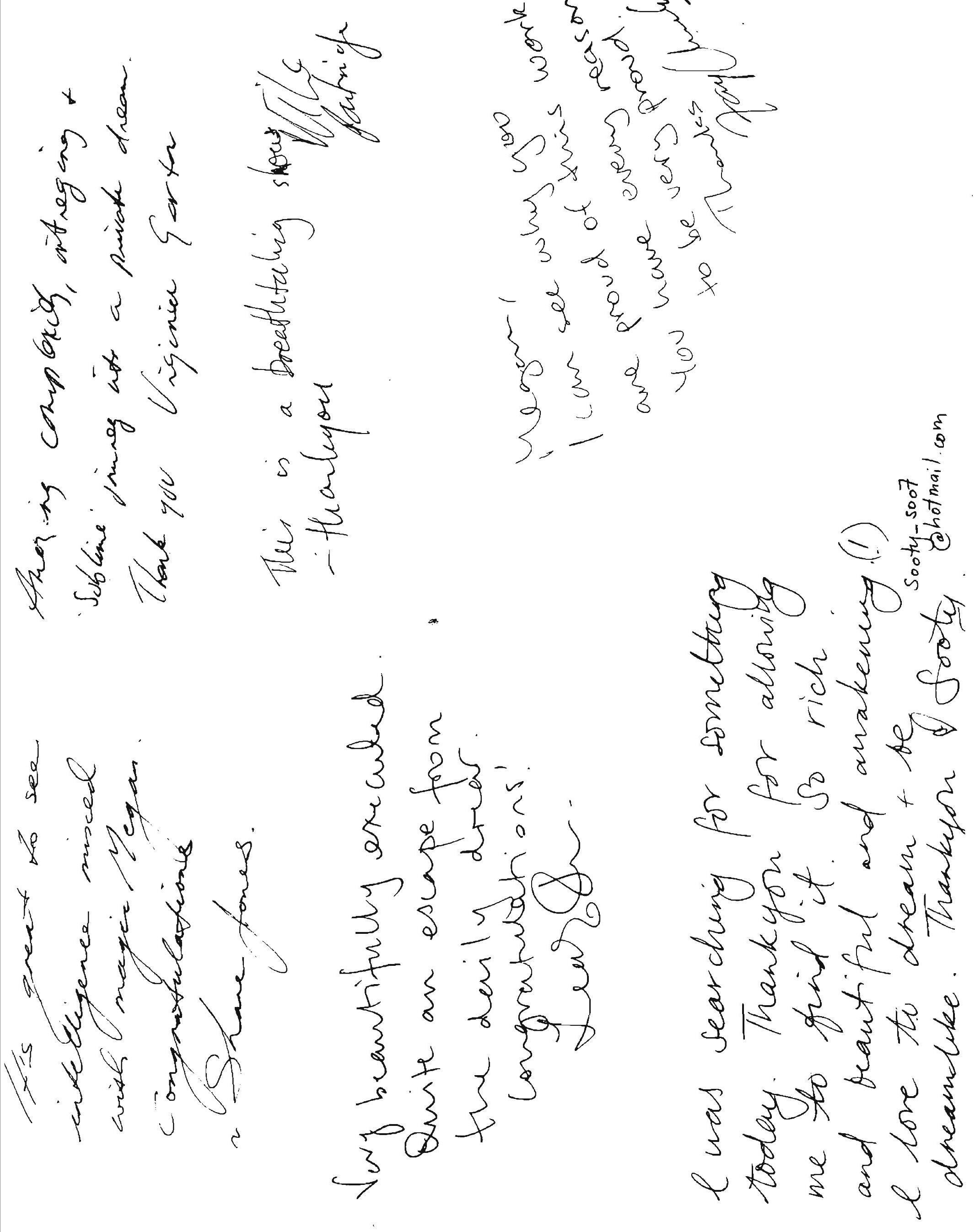




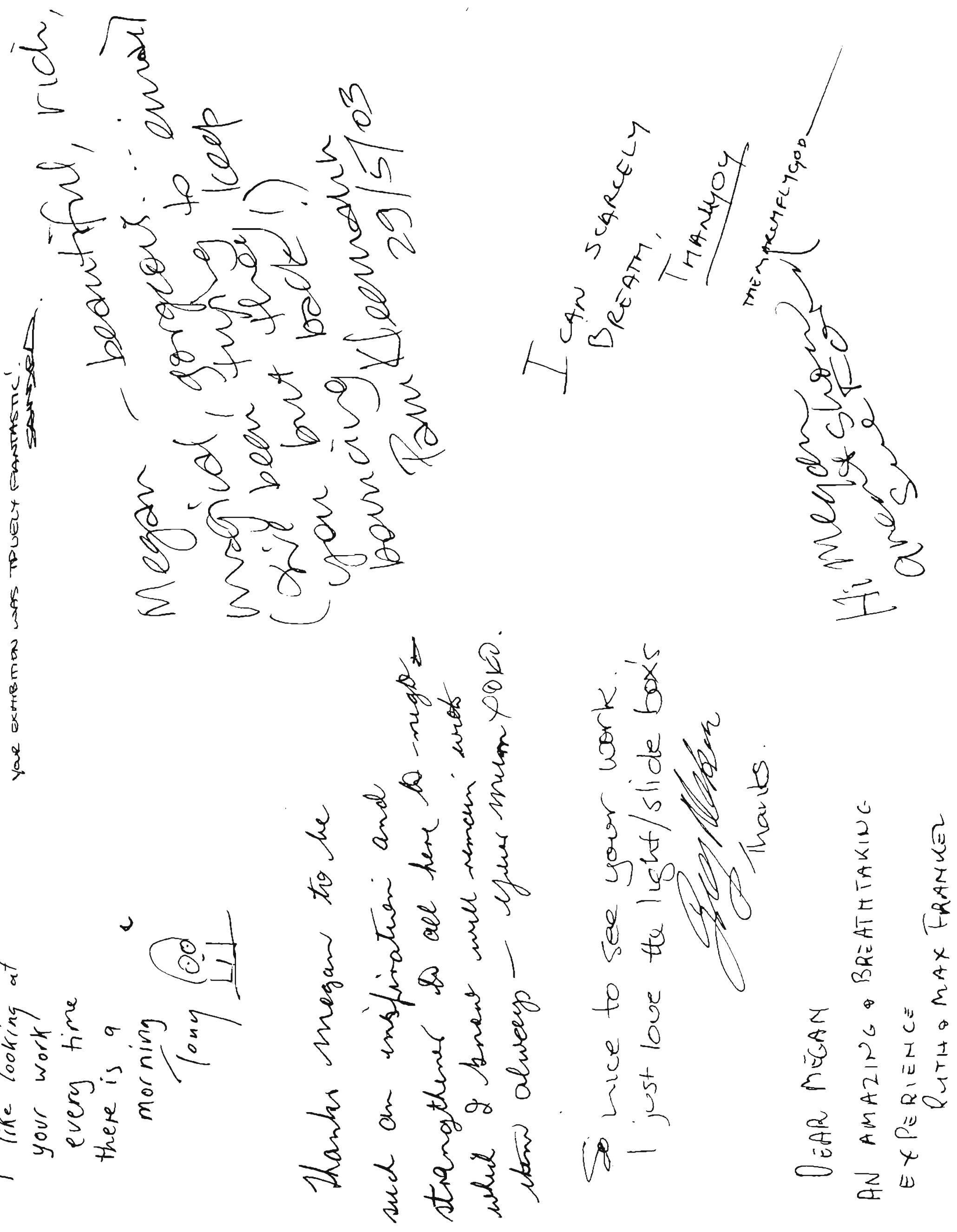




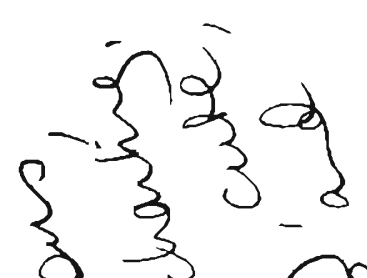
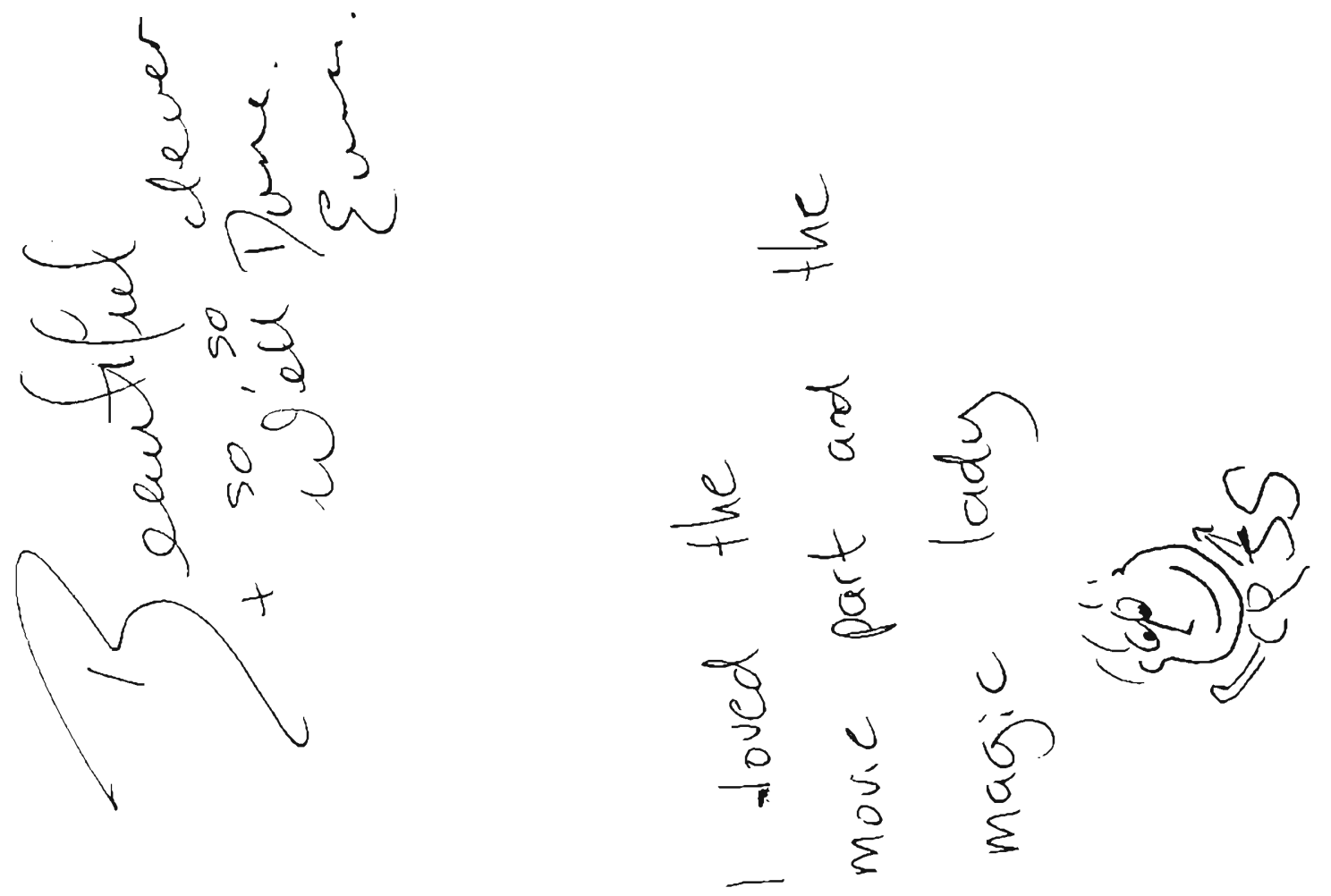

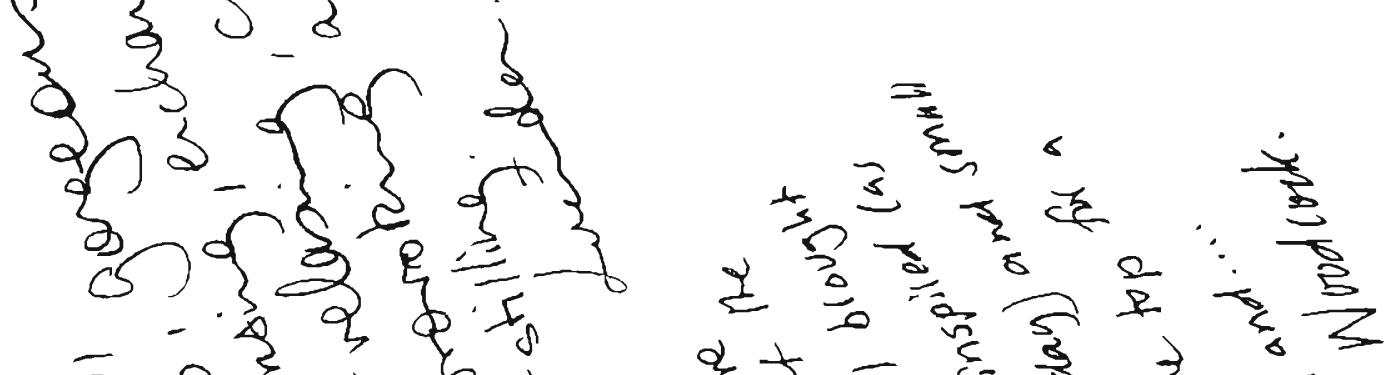

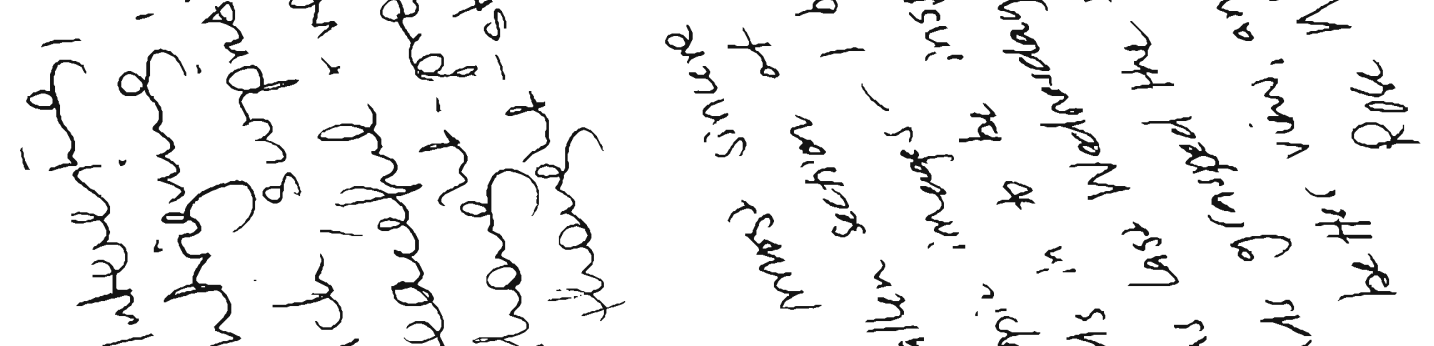

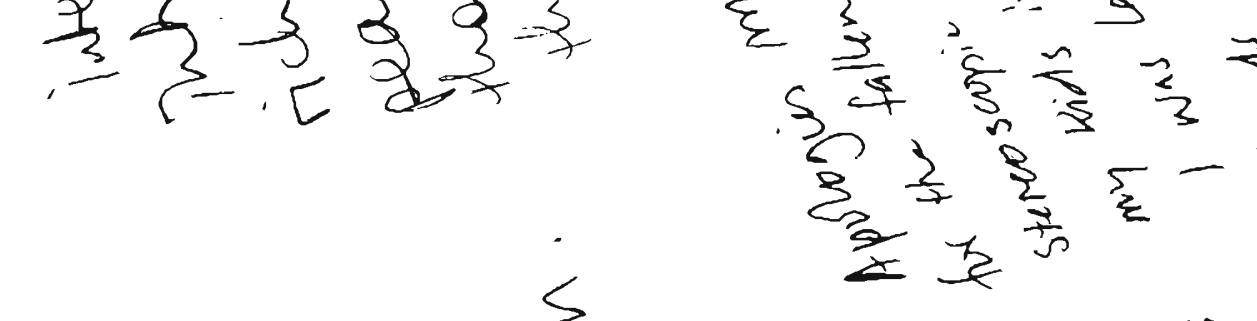

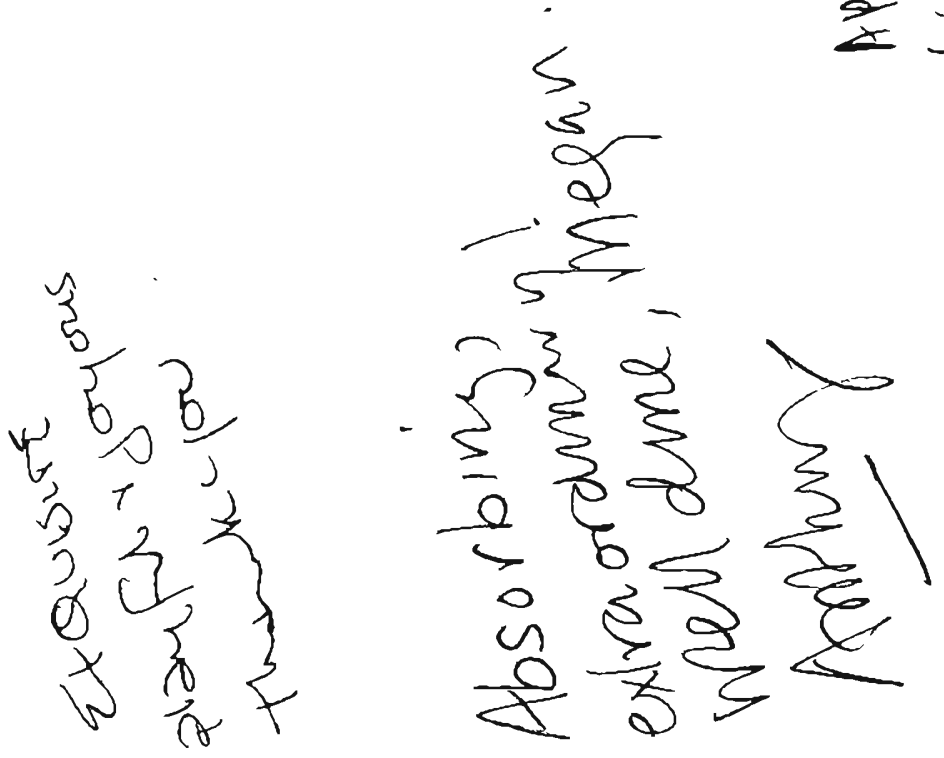

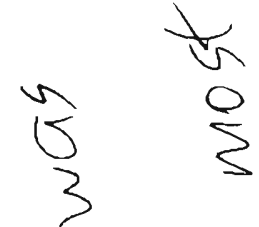
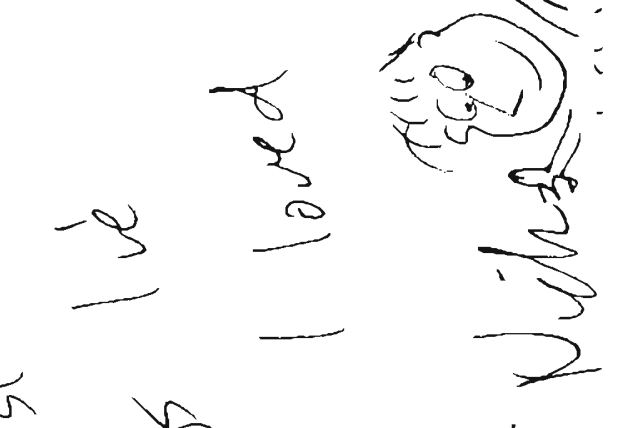

sis

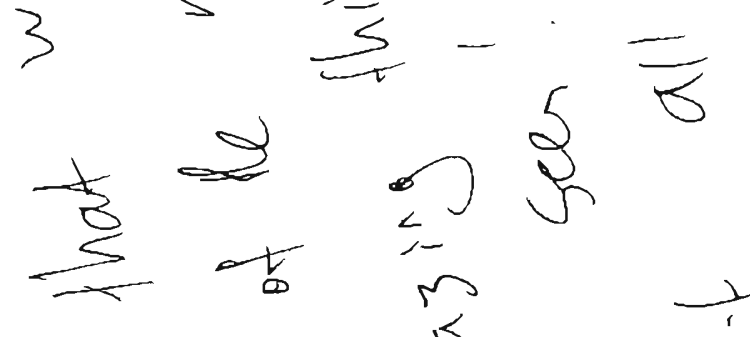

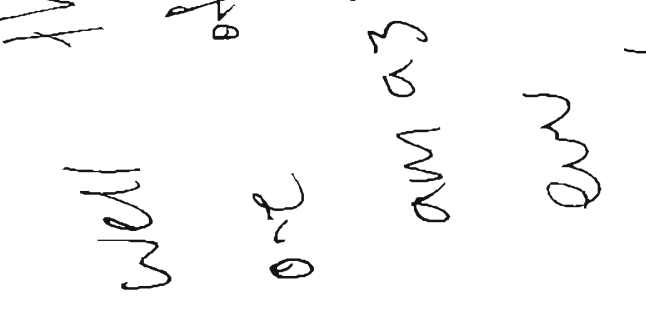




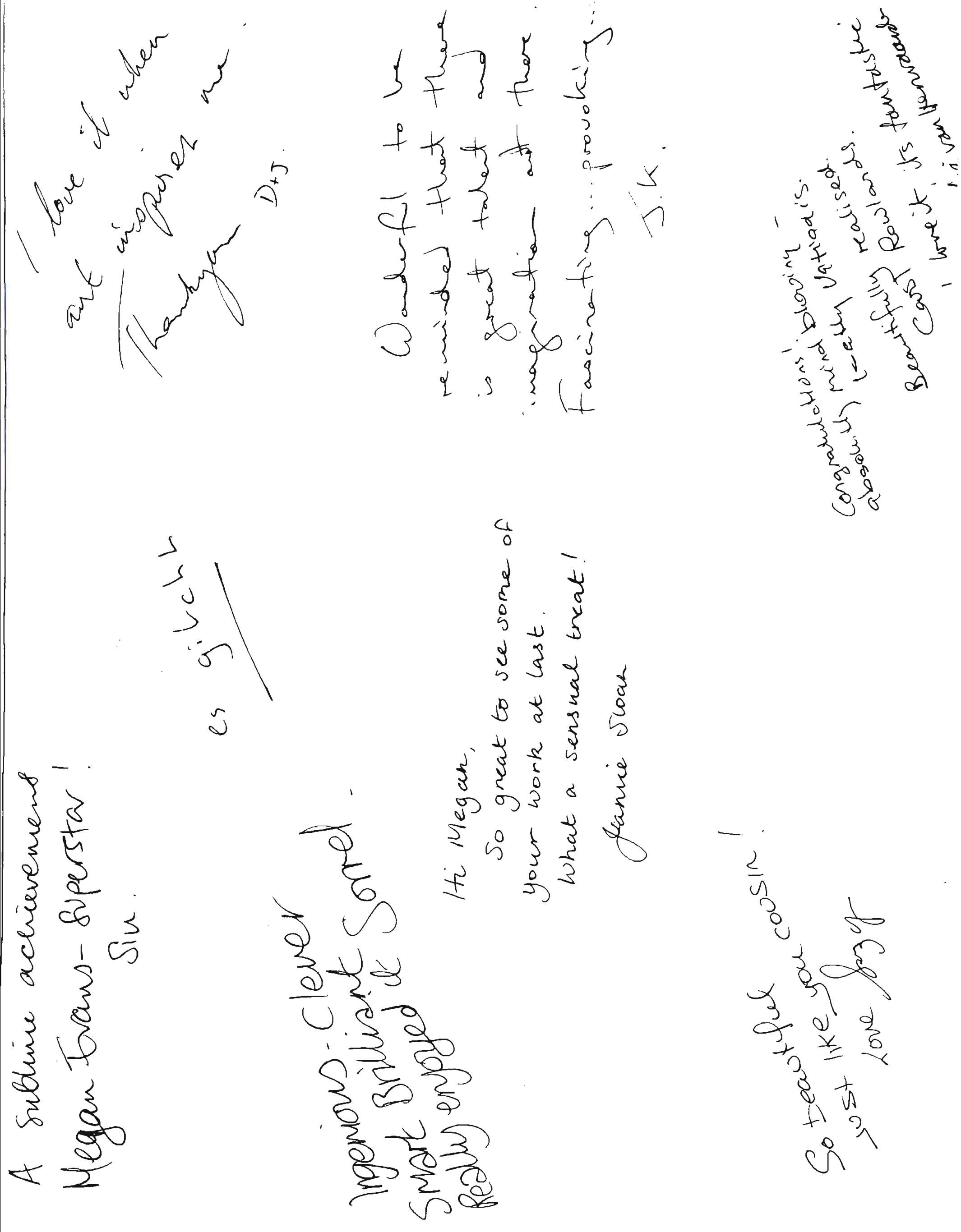




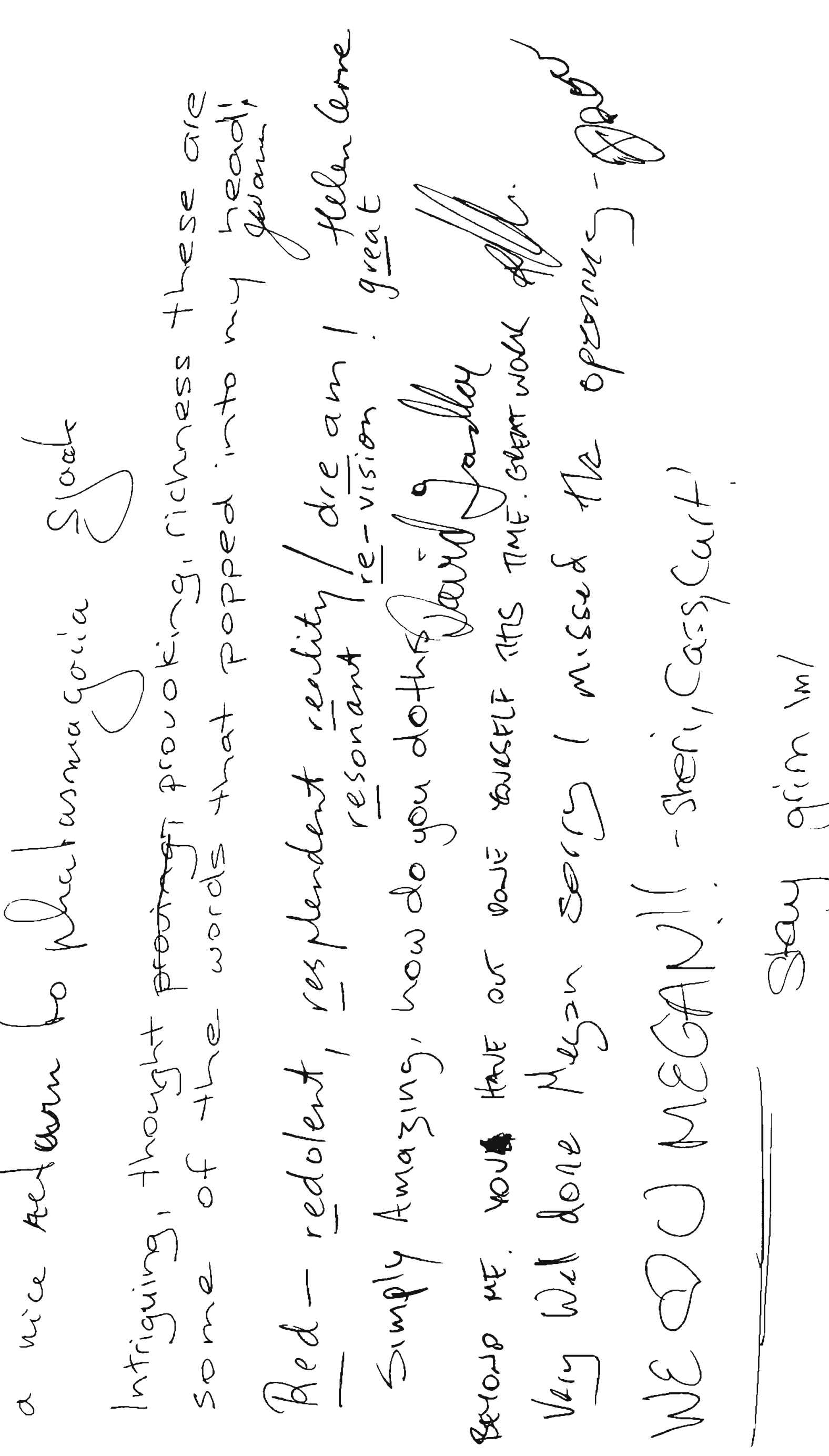




